TENDENCIAS Y PERSPECTIVAS

DE LA CULTURA CIENTÍFICA

EN CHILE Y AMÉRICA LATINA

Siglos XIX-XXI

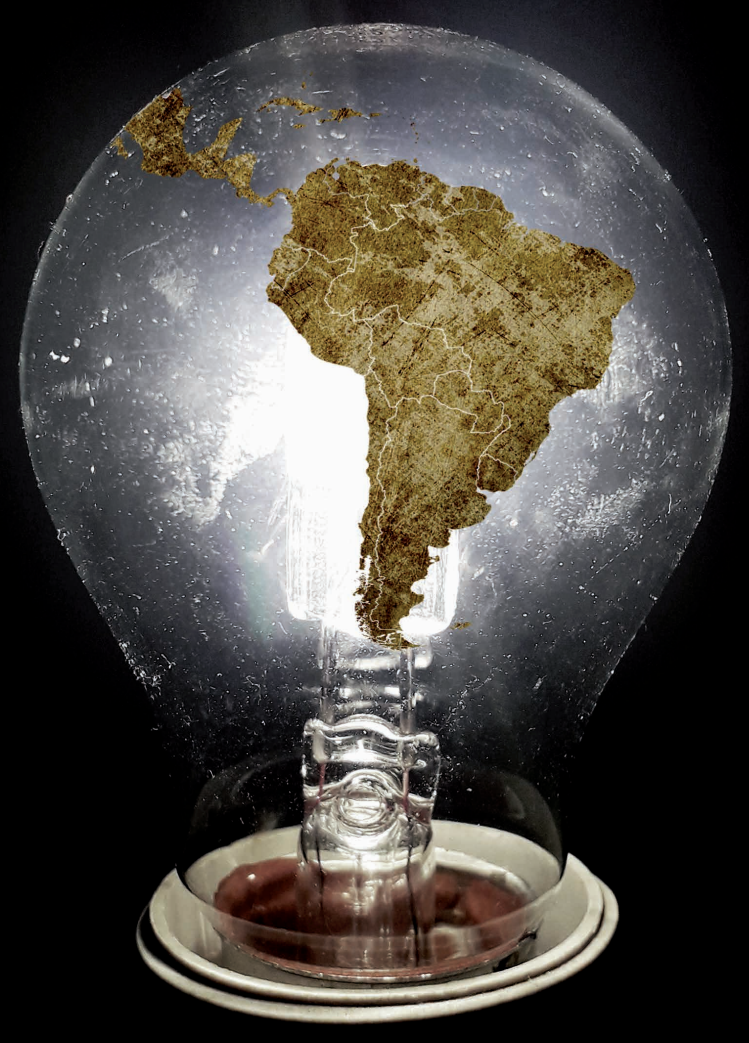

CAROLINA ANDREA

VALENZUELA MATUS

[EDITORA]

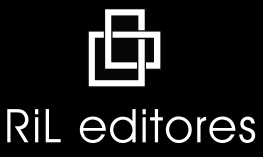




TENDENCIAS Y PERSPECTIVAS DE LA CULTURA CIENTÍFICA en Chile y América Latina Siglos XIX-XXI 

Carolina Andrea Valenzuela Matus (EDITORA)

\title{
Tendencias y PERSPECTIVAS DE LA CULTURA CIENTÍFICA EN Chile y América LATINA
}

\author{
Siglos XIX-XXI
}

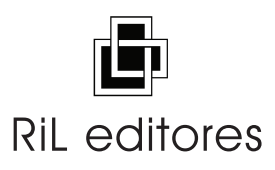




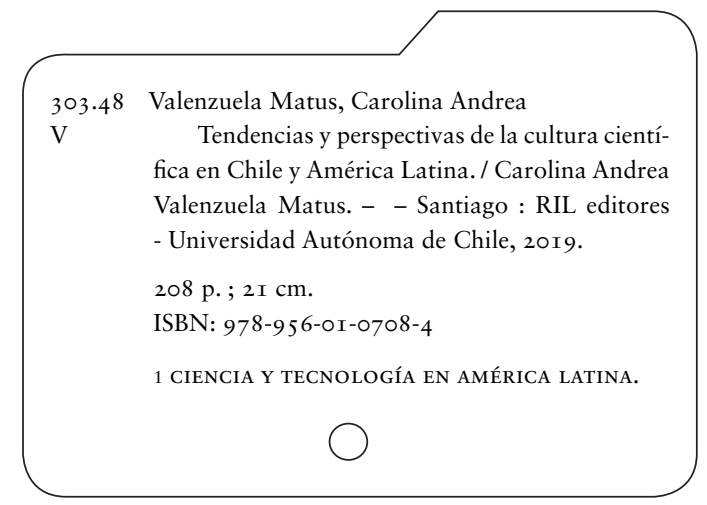

La publicación de esta obra fue sometida a referato externo, evaluada y revisada por un comité editorial de pares ciegos, evaluadores especialistas en la materia provenientes de diversas universidades chilenas y extranjeras.

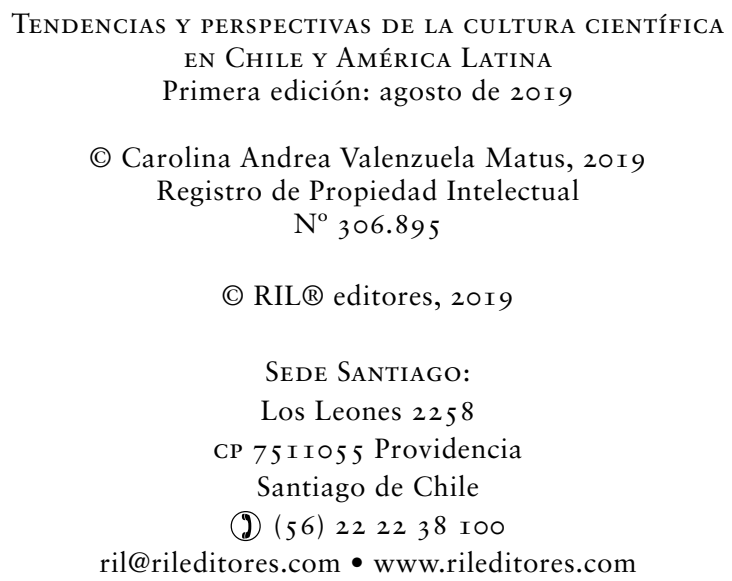

Sede Valparaíso:

Cochrane 639, of. 92

CP 236I 80 I Valparaíso

(j) (56) 322746203

valparaiso@rileditores.com

Sede España:

europa@rileditores.com・Barcelona

(C) Centro de Comunicación de las Ciencias, 2019

Universidad Autónoma de Chile

https://ciencias.uautonoma.cl I ciencias@uautonoma.cl

ISBN Universidad Autónoma 978-956-8454-39-5

Composición e impresión: RIL® editores

Diseño de portada: Matías González Pereira

Impreso en Chile $\bullet$ Printed in Chile

ISBN 978-956-OI-0708-4

Derechos reservados. 


\section{ÍNDICE}

INTRODUCCIÓN

Carolina Valenzuela Matus.

La ciencia de la independencia en Hispanoamérica:

el conocimiento al servicio de la nación, 1788-1830

Francisco Martínez Hoyos...

La configuración de un espacio para el saber natural en Chile.

El gabinete de historia natural de Santiago, 1830-1842

Daniela Serra Anguita

Los naturalistas en Chile y su aporte a los museos de historia natural del país

Carolina Valenzuela Matus.

Historia de vida de los instrumentos astronómicos en Chile.

Circulaciones, adaptaciones y apropiaciones (1855-1886)

Lorena B. Valderrama, Carlos Sanbueza Cerda

Ciencias y letras. Discursos de transición sobre la comprensión científica en torno a los mapuche (1900-1910)

Martín Lara Ortega.

Tecnologías de la energía solar en la industria de los nitratos (1872-2012).

Exploraciones en los archivos de una historia fragmentada Nelson Arellano-Escudero 
La cultura de la medición científica documentada en Chile.

La herencia de Kiev y Yale

Alejandro Vega Muñoz.......................................................... 173

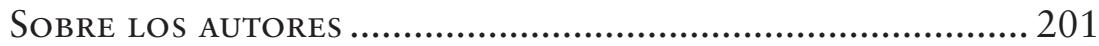

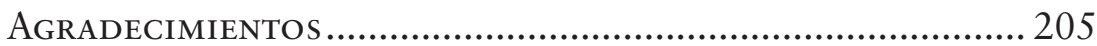


A mi madre, y a todas las madres y padres que, con amor y perseverancia, han alentado las inquietudes intelectuales de sus hijos e hijas. 



\section{INTRODUCCIÓN}

\section{Carolina Valenzuela Matus}

En las últimas décadas, la historia de la ciencia ha propiciado una significativa apertura al estudio de las conexiones entre los diversos participantes que construyen los saberes científicos. En este contexto, se valora cada vez más la contribución de América Latina como un agente activo en la construcción y difusión de este conocimiento. El presente libro quiere evidenciar este aporte reflexionando en torno al papel de Chile e Hispanoamérica en la cultura científica de los siglos XIX al XXI a partir de una amplia diversidad de temas que van desde las exploraciones científicas, las historias naturales, las colecciones de gabinetes y museos, las reflexiones positivistas acerca de los pueblos originarios, pasando por la historia de los instrumentos hasta las tecnologías de energía solar y la cienciometría.

La posibilidad que tenemos hoy de mirar a América Latina como un participante activo del conocimiento científico global ha sido factible gracias a los avances en la historia de la ciencia que, desde hace algunas décadas, propone enfoques más amplios, considerando temas tan variados como la cultura de la historia natural en torno a los objetos, las instituciones y las colecciones (Jardine, Secord, Spary, 1996), u otros temas vinculados a la curiosidad del mundo natural (Daston y Park, 1998), la objetividad (Daston y Galison, 2007), el rol de la burocracia en la construcción de las ciencias (Podgorny, 2019), el papel de la imaginación en la interpretación de las formas de los animales (Pimentel, 2010) o la relación entre ciencia y arte (Marcaida, 2014). En este contexto, también hay investigaciones que han puesto especial atención en la contribución científica de las regiones del mundo colonizadas, e invisibilizadas para la ciencia de 
Occidente, y sobre todo en lo que se refiere a la interacción científica entre extranjeros y locales como vínculo beneficioso para ambas comunidades (K. Raj, 2007), así como también en la circulación de objetos de interés científico entre Europa y América (Gänger, 2014 y Kohl, Podgorny y Gänger, 2014).

Desde Chile han surgido investigaciones que destacan la participación activa de América Latina en la generación y difusión de conocimiento científico. En Ciencia y espectáculo. Circulación de saberes científicos en América Latina, siglos XIX y XX (editado por Correa, Kottow y Vetö, 2016) se enfatizan los lugares de desarrollo y expresión de la experiencia científica en el continente, así como la circulación transnacional de saberes científicos a través de personas, objetos e instrumentos. Por otra parte, Paula Caffarena en su libro Viruela y vacuna. Difusión y circulación de una práctica médica. Chile en el contexto hispanoamericano (1780-1830) (2016) investiga sobre la práctica médica en la América española en el contexto de la difusión de la vacuna, proceso en el que los americanos, según la autora, no fueron entes pasivos que recibieron y aplicaron la vacuna de acuerdo a disposiciones europeas, sino que fueron parte activa en el proceso de inmunización. Este protagonismo de los actores locales en la ciencia global se ha abordado también en el libro colectivo La movilidad del saber científico en América Latina (editado por Carlos Sanhueza, 2018), donde se analizan las formas de producción del conocimiento científico como una práctica donde convergen los actores, las instituciones, los objetos y las ideas.

Además de los últimos libros sobre historia de la ciencia escritos desde Chile, tenemos que destacar otras importantes iniciativas para el desarrollo del área que se están gestando en nuestro país como el Laboratorio de Historia de la Ciencia, Tecnología y Sociedad ${ }^{1}$, espacio abierto que permite contribuir, desde el diálogo entre los investigadores, a una consolidación de la disciplina en Chile, proporcionando instancias para la reflexión y el intercambio fructífero de ideas. En este mismo espíritu, la Universidad Autónoma de Chile ha

1 Laboratorio de Historia de la Ciencia, Tecnología y Sociedad. https://labhcts. org/ 
sido un apoyo fundamental en la difusión de la historia de la ciencia y el conocimiento científico a través del Centro de Comunicación de las Ciencias, quienes apoyaron este libro desde el primer momento.

La idea de hacer esta obra surgió en el Seminario Tendencias y perspectivas de la Cultura Científica en Chile entre los siglos XIX y XXI ${ }^{2}$, celebrado en la Universidad Autónoma en agosto de 2018 y organizado por el proyecto Fondecyt Iniciación n ${ }^{\circ} 11170033$ : Antigüedades y naturaleza. Circulación interoceánica de objetos en los primeros gabinetes de historia natural como estrategia de posicionamiento de la ciencia en Chile. ${ }^{3}$

El objetivo de este evento era proponer una reflexión donde tuvieran cabida todos los actores involucrados en la cultura científica, considerando asimismo la relevancia del proceso de circulación interoceánica, que conlleva el intercambio de conocimiento y objetos a nivel global, entre los científicos locales y los de Europa y América, como una forma de comprender las nuevas tendencias y perspectivas de la cultura científica, que apuesta por una visión cada vez más amplia e interdisciplinar en la construcción de la historia de la ciencia en pleno siglo XXI.

Los investigadores respondieron de forma entusiasta a esta propuesta y nos mostraron los avances en sus respectivos ámbitos de estudio. A los académicos presentes en aquella ocasión, se sumaron otros investigadores que también han querido contribuir a los debates de la cultura científica y reflejar los avances de sus investigaciones en esta obra. Entre todos se ha construido este libro que espera aportar a las discusiones sobre la ciencia desde el cono sur de América. En este, se considera un extenso arco temporal para evidenciar de mejor manera las diversas perspectivas del trabajo científico en América Latina. Los cinco primeros capítulos se centran preferentemente en el siglo XIX y los últimos dos, lo hacen en los siglos XX y XXI.

En el primer capítulo - La Ciencia de la Independencia en Hispanoamérica: el conocimiento al servicio de la nación, 1788-1830-,

Sitio web: http://www.seminarioculturacientifica.cl/

Sitio web: http://www.gabinetesynaturaleza.cl/ 
Francisco Martínez Hoyos reivindica la tradición del saber basado en las raíces del movimiento ilustrado al servicio de la construcción de las naciones. A través de varios ejemplos, analiza qué grado de compromiso tuvieron la ciencia y los científicos en el proceso emancipador de la América Hispana, destacando la existencia de una ilustración criolla, que es posible si se considera que no hay un único modelo de desarrollo científico válido. Tras la Independencia, el poder se legitima a través de una ideología laica basada en la idea del progreso que tiene el saber como instrumento. En América Latina, la ciencia se habría visto reflejada en saberes técnicos de aplicación práctica dirigidos a la explotación de los recursos naturales de los nuevos países.

En el segundo capítulo - La configuración de un espacio para el saber natural en Chile. El Gabinete de Historia Natural de Santiago, 1830-1842-, Daniela Serra analiza cómo en el Chile independiente se organiza el primer espacio para el conocimiento en base a colecciones de objetos naturales a cargo de Claudio Gay. Pone énfasis en las dimensiones prácticas que posibilitaron la instalación de este espacio para el saber natural desde su origen y las problemáticas que acarreaban el almacenamiento, preparación y exhibición de las colecciones naturales. La autora presta atención a una de las facetas más descuidadas de Gay, que es su actividad como naturalista en la formación de colecciones de historia natural. En este sentido, este capítulo busca ampliar el entendimiento sobre la práctica naturalista que se desarrolló en el país. La empresa científico-natural que significó formar el gabinete involucró también a personas con intereses y conocimientos diversos que aportaron en la configuración de un lugar para el saber natural.

En el tercer capítulo - Los naturalistas en Chile y su aporte a los museos de historia natural del país-, Carolina Valenzuela sigue la misma temática destacando la labor de los naturalistas en el proceso de formación de los museos de historia natural en Santiago, Valparaíso y Concepción. Se analizan también los rasgos biográficos de algunos destacados naturalistas que trabajaron en Chile y su papel en la formación de las colecciones regionales, lo que evidencia la 
existencia de una red global de colaboración y circulación de conocimientos entre científicos que se manifiesta tanto entre las regiones con la capital como a nivel internacional.

En el cuarto capítulo - Historia de Vida de los instrumentos astronómicos en Chile. Circulaciones, adaptaciones y apropiaciones (1855-1886)—, Lorena Valderrama y Carlos Sanhueza analizan la historia de vida de los instrumentos del Observatorio Astronómico Nacional de Chile en sus dos primeros periodos. En el estudio se detallan diversas situaciones que afectan la vida de los instrumentos, considerando también el desplazamiento de los objetos como fenómeno, campo que se ha comenzado a estudiar en las últimas décadas, por lo que se interpretan las diversas propuestas en torno a la reflexión del desplazamiento y la apropiación de los objetos científicos.

Los autores estudian los instrumentos astronómicos arribados a Chile a mediados del siglo XIX como un producto particular de la circulación global del conocimiento. Asimismo, se construye una historia de los orígenes del Observatorio Nacional de Chile, señalando que la vida de los objetos del Observatorio dependió de una red global donde Estados Unidos y Alemania representaron los primeros lugares de procedencia de muchos instrumentos astronómicos del país, destacando también que la necesidad de ajuste de los instrumentos a su localización hemisférica implicaba la construcción de otros instrumentos a nivel local.

En el quinto capítulo - Ciencias y letras. Discursos de transición sobre la comprensión científica en torno a los mapuche (19001910)_, Martín Lara aborda la concepción que Tomás Guevara y Nicolás Palacios tienen sobre lo mapuche, planteando que se trataría de un discurso de transición entre los viejos textos coloniales y las investigaciones monográficas de las ciencias contemporáneas. El autor busca una aproximación desde la historia cultural de la ciencia a los discursos de transición que se dan en el 1900 sobre el conocimiento científico de lo mapuche, donde influyeron el evolucionismo darwinista, el historicismo hegeliano y el positivismo. Tanto Tomás Guevara como Nicolás Palacios podrían considerarse los precursores 
del indigenismo en el Chile de fines del siglo XIX, donde el mestizaje generó nuevas reflexiones desde las ciencias.

En el capítulo sexto - Tecnologías de la energía solar en la industria de los nitratos (1872-2012). Exploraciones en los archivos de una historia fragmentada-, Nelson Arellano señala las continuidades y cambios en el proceso industrial para la producción de la minería no metálica en Chile y la incorporación del uso de la energía solar térmica para procesos de desalación de agua y para la obtención de subproductos de salitre. En este análisis se combinan elementos de la historia económica y ambiental para analizar la gobernanza de la evolución de la tecnología en sus procesos de selección entre continuidad e innovación. El capítulo destaca la proyección de la ciencia y la tecnología desde la región del desierto de Atacama al mundo.

En el séptimo y último capítulo - La cultura de la medición científica documentada en Chile. La herencia de Kiev y Yale-, Alejandro Vega revisa los orígenes de la cultura de la medición de la ciencia, la cienciometría, en el contexto del movimiento ruso por la Nauka y la competencia académica de Kiev y Yale por definir mejores formas de medir los resultados científicos en el periodo entre y posguerras mundiales. En esta contribución se pretende dar tanto una visión sistémica como temática y disciplinar respecto a las investigaciones tratadas en esos documentos con el fin de comprender, en el contexto actual de Chile, los desafíos y las exigencias de la investigación impuestas hoy a las universidades chilenas. El especialista trabaja conceptos como bibliometría, cienciometría, big science y tecnociencia, entre otros, brindando interesantes reflexiones a partir de una diversidad de autores, sobre cómo la medición de la ciencia se posiciona como área de estudio.

Los estudios que aquí presentamos cuestionan el concepto de una historia de la ciencia periférica en pos de la construcción de una historia global que supone amplias interconexiones entre los distintos rincones del planeta y donde se pone de relieve el conocimiento científico generado por los actores locales, especialmente desde Latinoamérica. Estas investigaciones caracterizan la cultura científica de los siglos XIX al XXI destacando algunos de sus principales debates 
y los desafíos de la ciencia para el futuro. Los autores esperamos, a través de esta obra colectiva, seguir contribuyendo en la construcción de una historia de las ciencias desde América Latina.

Este proyecto agradece el apoyo de la Universidad Autónoma de Chile a través del Centro de Comunicación de las Ciencias y a CONICYT a través de su programa FONDECYT Iniciación, instituciones que hacen posible la continuidad de esta investigación y la publicación de este libro, así como también al comité editorial y los pares evaluadores quienes han contribuido con sus observaciones a elevar la calidad de nuestra propuesta.

\section{Bibliografía}

Caffarena, P. (2016). Viruela y vacuna. Difusión y circulación de una práctica médica. Chile en el contexto hispanoamericano 1780-1830. Santiago de Chile: Editorial Universitaria.

Correa, M. J., Kottow, A. y Vetö, S. (eds.). (2016) Ciencia y espectáculo. Circulación de saberes científicos en América Latina, siglos XIX y XX. Santiago de Chile: Ocho Libros.

Daston, L. y Gallison, P. (2007). Objectivity. New York: Zone Books.

Gänger, S. (2014). Relics of the past. The Collecting and Study of PreColumbian Antiquities in Peru and Chile, 1837-1911. Oxford: Oxford University Press.

Jardine, N., Secord, J. y Spary, E. (eds.) (1996). Cultures of Natural History. Cambridge: Cambridge University Press.

Kohl, P., Podgorny, I. y Ganger, S. (eds.) (2014). Nature and Antiquities. The making of archaeology in the Americas. Tucson: The University of Arizona Press.

Marcaida, J. R. (2014). Arte y ciencia en el Barroco Español. Madrid: Marcial Pons.

Pimentel, J. (2010). El Rinoceronte y el Megaterio. Un ensayo de morfología histórica. Madrid: Abada Editores.

Podgorny, I. (2019). Bureaucracy, Instructions and Paperwork- The Gathering of Data about the Three Kingdoms of Nature in the Americas, 1770-1815. Nuevo Mundo Mundos Nuevos [on line] Debates 25 de febrero de 2019. Recuperado de http://journals.openedition.org/ nuevomundo/75454

Raj, K. (2007). Relocating Modern Science. Circulation and the Construction of Knowledge in South Asia and Europe, 1650-1900. New York: Palgrave Macmillan. 
Sanhueza, C. (ed.) (2018). La movilidad del saber científico en América Latina. Objetos, prácticas e instituciones (siglos XVIII al XX). Santiago de Chile: Editorial Universitaria. 


\section{LA CIENCIA DE LA INDEPENDENCIA EN \\ HISPANOAMÉRICA: EL CONOCIMIENTO AL SERVICIO DE LA NACIÓN, I788-I830}

Francisco Martínez Hoyos

Doctor en Historia

Resumen. El tópico quiere que no exista conocimiento propio en los países «periféricos» de América Latina. Un examen cuidadoso, a la luz de los últimos planteamientos de la historia de la ciencia, nos muestra lo contrario. Desde el mismo momento de las independencias, existe una tradición del saber, con raíces en el movimiento ilustrado, que se pone al servicio de la construcción nacional. Las nuevas repúblicas quieren conocerse a sí mismas, explotar sus recursos con la mayor eficacia posible. Por eso, muchas protagonizarán una política de contratación de sabios extranjeros, con la vista puesta en el modelo de desarrollo de la vieja Europa. La inestabilidad posterior a la emancipación constituirá un obstáculo para estos planes.

Palabras clave: América, Chile, ciencia, Ilustración, independencia, México, Perú.

Aвstract. The topic suggests that there was no self-knowledge in the 'periphial' countries of Latin America. After careful examination, in light of the latest approaches to the history of science, it shows that the opposite is true. Since the beginning of Independence, there exists a tradition of knowledge, rooted with Enlightenment ideas, which serves as the building of a nation. The new republics wanted to know who they were and form a self awareness, using their resources in a more efficient way. For this reason, many will carry out a policy of contracting foreign scholars, with a desire to 
model the development based on Old Europe. The instability that came after emancipation became an obstacle for these plans.

KeYwords: America, Enlightenment, Independence, Science, Mexico, Peru, Chile.

La independencia de América fue, por decirlo con palabras del historiador peruano Jorge Basadre, una «inmensa promesa de vida próspera, sana, fuerte y feliz». La ciencia debía ocupar un puesto importante en el nuevo orden repúblico que aseguraría el bienestar de los ciudadanos. Con optimismo, Simón Bolívar pronosticaba en 1815: "Ciencia, artes, industrias, cultura, todo lo que en el día hace la gloria y excita la admiración de los hombres en el Continente europeo, volará a América». Al año siguiente, José Toribio Rodríguez de Mendoza, rector en Lima del Convictorio de San Carlos, manifestaba la misma esperanza. Gracias a las fabulosas riquezas que albergaban las entrañas del continente, prácticamente todas aún por descubrir, la Botánica, la Química o la Mineralogía conocerían progresos tan grandes que los americanos acabarían dando lecciones a los europeos (Burga, 2014).

Esta misma idea, que los americanos podrían igualar o superar a los científicos del viejo continente, que hasta entonces parecían haber detentado el monopolio del saber, se halla también presente en Francisco José de Caldas. En 1812, este sabio neogranadino hizo un llamamiento a sus compatriotas para que se sacudieran, junto a la dependencia política, una dependencia científica «que nos degrada y que nos mantiene en una infancia literaria más ignominiosa que la esclavitud misma». El camino a seguir, para Caldas, no ofrecía dudas. Los americanos debían cultivar las ciencias con «esfuerzos generosos» y arrebatar así la "gloria exclusiva al orgulloso europeo» (Renán, 2002, p. 518). Como muestra la documentación, en su caso existía un fuerte lazo entre su pasión por la ciencia y su mentalidad patriótica (Arboleda, 1994, pp. 139-145).

En el presente estudio, nuestro objetivo es acercarnos al protagonismo que tuvieron la ciencia y los científicos en el proceso emancipador, recudido a menudo a las gestas guerreras de algunos 
próceres. Interesa, por tanto, averiguar qué grado de compromiso con la Independencia tuvieron los sabios, y en qué medida las diversas áreas del conocimiento científico se integraron dentro del discurso nacionalista que legitimaba la fundación de nuevas repúblicas. La síntesis propuesta se centra, tal vez temerariamente, en el ámbito geográfico del conjunto de la América española, en un intento de presentar las investigaciones más recientes y formular hipótesis que puedan validarse o descartarse en futuras investigaciones. El apoyo documental parte, básicamente, de la bibliografía especializada, aunque en algún caso se ha tenido presente la prensa de la época y los papeles del Archivo de Indias, consultados por Internet a través del Portal de Archivos Españoles (PARES).

En un primer apartado, analizamos los avances científicos de las últimas décadas de la dominación hispana en América, desde la convicción de que sin los avances de esta época no se puede entender lo que vino más tarde. Concedemos un apartado específico a la relación entre ciencia y religión porque nos parece importante desmentir el tópico que contrapone fe y conocimiento. Los datos indican, por el contrario, la importancia de los hombres de Iglesia, entre ellos jesuitas, a la difusión del saber. Ponemos énfasis, asimismo, en la puesta en valor de la ciencia de los territorios denominados «periféricos", en contraposición a una historiografía que solo ha visto progreso en los estados de Europa occidental o en Estados Unidos.

Cuando llegamos a 1808, los científicos tienen que responder al dilema de seguir fieles al rey o posicionarse del lado de los patriotas. La prosopografía se convierte aquí en una ayuda inestimable, al permitirnos saber quién hizo qué y cuándo. Solo en el campo de la botánica, destacan dos figuras con apuestas políticas antagónicas. Mientras José Mejía Lequerica, defensor de la continuidad del Imperio español, se convirtió en uno de los grandes protagonistas liberales de las Cortes gaditanas, Francisco Antonio Zea pasó de dirigir el Jardín Botánico, en Madrid, a ser consejero de Simón Bolívar.

Veremos también como, una vez consumada la separación de la metrópoli, las nacientes repúblicas utilizarán la ciencia como una ideología legitimadora. Se busca convertir los territorios americanos 
en un espacio de progreso, con la vista puesta en la prosperidad alcanzada en el viejo continente. Abordaremos, por ello, la política de captación de cerebros dirigida a fomentar el desarrollo económico y científico.

\section{LOS FUNDAMENTOS VIRREINALES}

El conocimiento tenía que ayudar a los nuevos estados a controlar su territorio y explotar sus recursos. Las diversas iniciativas no surgieron de la nada porque, al contrario de lo que han pretendido las historiografías nacionales y nacionalistas, el mundo virreinal no era un páramo yermo en el ámbito científico. Durante las independencias y tras ellas, se repetiría que España, para garantizar su dominio, trató de mantener a los americanos en el subdesarrollo intelectual. Para el patriota chileno Camilo Henríquez, la ignorancia «estaba en el plan de la opresión» ${ }^{1}$.

Había, en este tipo de afirmaciones, una clara intencionalidad política. Los nuevos gobiernos, para legitimarse, procuraban establecer un contraste entre su propia actuación y un pasado pintado con los más negros colores. Por eso, en Colombia, a principios de la década de 1820, los políticos republicanos tratan de aparecer como benefactores de la ciencia para diferenciarse de la "pésima administración» de la etapa española (Soto, 1999, p. 91).

El escritor y político chileno José Victorino Lastarria (18171888), en una memoria histórica, expresó con particular radicalidad esta idea. Las pocas universidades del periodo colonial estaban lejos de acercar al hombre a la "verdadera ciencia». Servían, por el contrario, para sumirle en la «imbecilidad» (AA.VV., 1866, p. 32).

Los datos no avalan esta hipótesis, como muestra la existencia de una ilustración criolla. En la América colonial se conoció y valoró la obra de autores españoles, como el religioso Benito Jerónimo Feijoo, adalid de modernidad científica. Bajo el influjo del Siglo de las Luces, por otra parte, se fundaron instituciones como el Observatorio

1 Prospecto de Aurora de Chile, 1812. Véase la reimpresión paleográfica del periódico publicada en Santiago, 1903, p. 1. 
Astronómico de Bogotá (1803) o el Colegio de Cirugía y Medicina de Lima (1815). En México, a su vez, destaca la creación de la Cátedra de Botánica en México (1788) y del Real Seminario de Minería (1792), este último fue el tercer centro del mundo en su especialidad. Un profesor español, Andrés del Río Fernández (1765-1849), llegó para formar nuevas generaciones de mineros y se quedó en el México independiente (Uribe, 2010)

Este caso nos muestra la importancia del trabajo en territorio americano de figuras peninsulares. Algunas de gran magnitud, caso del químico Fausto de Elhuyar, descubridor del wolframio. Es la época, por otra parte, de las grandes expediciones científicas, como la protagonizada por Alejandro Malaspina o la encabezada por el botánico Celestino Mutis en el Reino de Nueva Granada. El magisterio de Mutis tuvo gran importancia en la formación de una generación de científicos criollos, entre los que destacaron algunos que después tendrían un gran protagonismo en la emancipación de España (como Francisco Antonio Zea, Francisco José de Caldas, entre otros). Es por eso que la historiografía colombiana ha señalado la obra de Mutis como precursora de la Independencia. Los autores más recientes, sin embargo, corrigen esta postura. La pasión por el conocimiento generó un "patriotismo científico» que permitió a los criollos generar sus propios saberes sin estar subordinados a los especialistas europeos. Sin embargo, la inquietud por promover los intereses locales no estaba reñida con la lealtad al Imperio en diferentes formas (Duque Muñoz, 2004). Mutis, además, no fue un precursor de la libertad, sino un agente del poder español (Nieto Olarte, 2000), leal a sus monarcas y contrario a cualquier veleidad independentista (Díaz Piedrahita, 2010).

Xavier Balmis, a partir de 1803, encabezó la expedición que llevó a tierras americanas la vacuna contra la viruela. La historia de este hallazgo no debe plantearse como un don de Europa a los territorios «bárbaros», sino como el fruto de una compleja red de interconexiones entre el «centro» y unas «periferias» en las que no se recibe pasivamente el conocimiento, sino que se participa en su elaboración y difusión de una manera activa. Para el caso de la 
América hispana y, más en concreto, de Chile, Paula Caffarena (2016) ha mostrado cómo las autoridades españolas elaboraron políticas de salud pública que tendrían continuidad en los primeros años del periodo republicano.

No todos los científicos que llegaron al Nuevo Mundo procedían de la metrópoli. Las autoridades hispanas dieron todas las facilidades posibles a un naturalista de talla internacional, Alejandro de Humboldt (Peset, 1987), para que desarrollara sus investigaciones. El científico alemán mostró su gratitud por el trato recibido y expresó su admiración por Mutis. También señaló que «desde fines del reinado de Carlos III, y durante el de Carlos IV, el estudio de las ciencias naturales ha hecho grandes progresos no solo en México, sino también en todas las colonias españolas» (Humboldt, 1989, pp. 32, 73).

Desde el punto de vista de la Corona, la inversión en conocimiento debía redundar en un aumento de poder político y económico, de forma que se pudieran solucionar carencias como la escasa información acerca del territorio o la deficiente productividad de la agricultura. La explotación de los metales preciosos constituía, obviamente, una prioridad. La Corona, como ya antes hemos anticipado, se preocupó de que se divulgaran los últimos conocimientos necesarios en este ámbito. Así, en 1790, el virrey del Perú recibió un cajón forrado con cien ejemplares de la obra Elementos de Mineralogía ${ }^{2}$. Debía tratarse, con toda probabilidad, de la obra de ese título de Richard Kirwan, publicada en Madrid un año antes, traducida por orden del rey a partir del original inglés de 1784 (Kirwan, 1789).

No deben olvidarse, asimismo, a los distintos autores que mostraron que la naturaleza americana, al contrario de lo que pretendían los prejuicios de los ilustrados europeos, era tan buena como cualquier otra, si es que no más. Es más, tampoco era cierto que los americanos estuvieran menos dispuestos al cultivo de la ciencia que los europeos. El educador chileno Manuel de Salas (1754-1841) se esforzó en deshacer este prejuicio y señaló que los habitantes del

2 Carta n 157 de Francisco Gil de Taboada y Lemos, virrey del Perú, a Antonio Valdés, Secretario de Estado de Indias, 5 de septiembre de 1790. Archivo General de Indias, 691, N.153. 
nuevo mundo poseían igual capacidad «para las ciencias que demandan meditación y perseverancia». Así lo demostraban ejemplos como del limeño Pedro Peralta, famoso astrónomo, o el de Juan Ignacio Molina, compatriota de Salas, autor renombrado en el campo de la Historia Natural. El problema, pues, no era la falta de talento sino la ausencia de doctrina (Gutiérrez, 2011).

En esos momentos, desde el punto de vista europeo, América representa la emoción de lo insólito. Esta atracción por lo nuevo está presente en la correspondencia en la que un infante de España, Luis de Borbón-Parma, pide al virrey de México, Manuel Azanza, el envío de animales disecados. No le importa que los ejemplares sean o no hermosos, sino que sean desconocidos en el viejo continente. Tanto es su interés que no reclama un solo envío sino una labor sostenida a lo largo del mandato de Azanza: "pues quiero mucho de esos pájaros disecados»(Archivo General de Indias, Diversos, 56, No 1 ) El virrey, por supuesto, no dejó de cumplir fielmente con el encargo en cuanto llegó al territorio que debía gobernar. El príncipe, como tantos otros poderosos de la época, deseaba aumentar las colecciones de su gabinete científico ${ }^{3}$.

Como acabamos de ver, el siglo XVIII asiste a un momento de efervescencia intelectual. La multiplicación de figuras relevantes desmiente un tópico clásico de la historiografía, que ha tendido a suponer que la ciencia hispanoamericana estaba por debajo de la anglosajona, como si existiera un único modelo de desarrollo científico, el que marca el Occidente europeo. Así, no es inusual que se afirme que, tanto en España como en sus antiguas posesiones ultramarinas, se produjo un «cortocircuito de la modernidad». A ambos lados del Atlántico, el mundo de habla hispana habría perdido el tren del progreso, hasta el punto de que hablar de «ciencia española» o "ciencia latinoamericana» sería caer en el oxímoron (Sotelo, 2007, pp. 59-76).

Se ha olvidado de esta manera la producción de conocimiento en la periferia, donde podemos encontrar valiosas aportaciones.

Azanza remite aves disecadas para Príncipe de Parma, 7 de noviembre de 1798. Archivo General de Indias. Estado, 27, N. 104. 
Como señala Carlos Sanhueza (2018), la movilidad del saber no es una vía de un solo sentido. La ciencia occidental, en contextos ajenos a los de su elaboración, se recontextualiza bajo parámetros propios. Los territorios periféricos no se limitan a recibir, de forma pasiva, un producto intelectual ajeno que vendría a incidir sobre un mundo premoderno. América Latina, por el contrario, contribuiría a «la emergencia de nuevos discursos y prácticas» (14).

¿Cómo se concretiza esta aportación? A través de investigaciones encaminadas primordialmente a su aplicación práctica, en función de necesidades locales. No obstante, esta idea merece alguna matización, puesto que se ha señalado que el poder imperial español amparó proyectos que se basaban, hasta cierto punto, en la ciencia pura (Cañizares-Esguerra, 2006).

La disciplina que alcanzó más relevancia, la botánica, constituye un ejemplo paradigmático de sentido utilitarista (López-Ocón, 1998), con su búsqueda de productos medicinales e industriales (Xia, 2010). En la realidad latinoamericana, un entorno natural muy distinto al europeo conduce a pensar la flora y la fauna en términos propios. En México, José Antonio Alzate cuestiona el sistema de nomenclatura propuesto por Linneo. Este caso muestra cómo, llegado el caso, los expertos criollos podían priorizar los datos recogidos en su entorno por encima de los conceptos elaborados en el viejo mundo (Brockmann, 2012).

Desde la perspectiva americana, la ciencia importa, fundamentalmente, por su función social. Manuel de Salas lo expresaría así en 1801: «Esparcid con dulzura vuestros conocimientos sobre el taller de laborioso artesano; facilitad sus operaciones al virtuoso labrador; mejorad los instrumentos de la industria; simplificad las labores del minero». Eso no significa, sin embargo, que Salas desdeñara la teoría en beneficio de lo puramente técnico. La sabiduría, a su juicio, se componía de dos elementos, el conocimiento y su aplicación. Ambos debían ir unidos (Amunátegui, 1872). 


\section{RELIGIÓN Y CIENCIA: ¿CONTRARIAS?}

La supuesta inferioridad de la ciencia latinoamericana sería fruto del predominio de la Iglesia católica en el mundo intelectual, lo que habría impedido un progreso en el mismo sentido que el de Inglaterra y Estados Unidos. Desde esta perspectiva, hay un sospechoso inequívoco de tanta calamidad: el Santo Oficio. Desde los tiempos de Felipe II, el cerrojazo al mundo exterior habría provocado un subdesarrollo cada vez más patente (Sotelo, 2007). Pero el problema, de hecho, afectaría al catolicismo en su conjunto, incapaz de armonizar sus doctrinas con los datos empíricos sobre la naturaleza. En un provocativo ensayo, el sociólogo Rodney Stark (2017) refuta esta idea tan asentada: puesto que Dios era perfecto y había creado al mundo, correspondía al científico, a través del uso de la razón, descubrir las leyes del mismo.

La realidad no se presta a simplificaciones fáciles. No se trata de negar la existencia de una represión de naturaleza confesional, pero, como ha señalado Joseph Pérez, si España no se incorporó a la locomotora del progreso no fue por la religión sino por su situación de decadencia en el momento en que la revolución científica tenía lugar. Esta revolución se basó en un cambio de paradigmas teóricos. Contaba la ciencia pura y eso fue lo decisivo para el futuro. Al sur de los Pirineos, lo mismo que en América, se privilegió, por el contrario, la ciencia práctica. Según Pérez (2003), la Inquisición tuvo en este proceso una responsabilidad limitada.

No hay ausencia de ciencia, por tanto, sino otra forma de concebirla. En el siglo XVIII, la que se practica en los dominios del Imperio español mezcla tradición y modernidad, de la mano de sacerdotes y religiosos (Xia, 2010).

El Siglo de las Luces había significado una revalorización de la ciencia como instrumento de conocimiento. Los seres humanos debían atreverse a utilizar su razón. Eso implicaba poner en cuestión toda forma de saber basada en el argumento de autoridad, desde la confianza en que la historia del ser humano estaba destinada a ser un progreso sin límites. No obstante, en España, lo mismo que en sus territorios ultramarinos, se tendió a adoptar una versión políticamente 
correcta de los nuevos principios. Estaba bien cuestionar los dogmas del conocimiento científico, pero el libre examen no se llevaría hasta el extremo de socavar las verdades de la religión relevada.

La modernidad científica y el tradicionalismo religioso fueron las apuestas de gente como el sacerdote argentino Luis José de Chorroarín (1757-1823), defensor de las verdades alcanzadas a través de los métodos empíricos, pero absolutamente contrario a que se arrojara la más mínima sombra de duda sobre los contenidos de la fe. Otro cura rioplatense, Juan Baltasar Maziel (1727-1788), se había mostrado partidario en un informe dirigido al gobernador en 1771, de que «todo sistema para la explicación de los efectos naturales» siguiera «sólo la luz de la experiencia». Eso implicaba, dentro de las instituciones educativas, introducir la libertad de cátedra para que fuera posible sustituir a Aristóteles por Descartes o Newton (Terán, 2008).

Entre las órdenes religiosas, los jesuitas brillaron por su dedicación al saber antes de que Carlos III decretara, en 1767, su expulsión. En sus centros de enseñanza se tenían en cuenta a autores modernos, como Newton y Leibniz, a la vez que se trataban cuestiones como las manchas solares o los nuevos cálculos acerca de la distancia de los planetas. La Compañía de Jesús hacía, pues, una ciencia más libre que la oficial. Favorecida, además, por una red científica de alcance mundial que tenía su centro en Roma (Millones, 2005).

Las famosas reducciones merecen una mención aparte, que fueron también espacios de ciencia. ¿Cómo podía ser de otra manera, si estaban en un entorno natural capaz de apasionar a cualquier naturalista? Este escenario fue, en cierta manera, un crisol de conocimientos, al agrupar tanto a religiosos sudamericanos como nacidos en España y otros países europeos (Asúa, 2014).

Nos situamos ante una historia olvidada la mayoría de las veces, pero con nombres propios que merecen un lugar en la posteridad. Entre los ignacianos dedicados al saber, sin duda brilla con luz propia el chileno Juan Ignacio Molina (1740-1829). Será en el exilio italiano donde dará a conocer una obra pionera en diversos campos de las ciencias naturales, como la botánica, la zoología o la geología. Sus 
estudios influirían en científicos tan importantes como el naturalista Jean B. Lamark, el paleontólogo Georges L. Cuvier o el botánico Adelbert von Chamisso. Filósofos como Kant y Lessing también se inspiraron en su trabajo.

Se ha debatido, por otra parte, si fue o no un precursor del evolucionismo darwiniano. Por la magnitud de sus contribuciones, uno de sus admiradores dijo de él que era «un cerebro de corte europeo", con lo que venía a expresar la superioridad del viejo continente sobre la producción intelectual de los países periféricos: «Aun prescindiendo de la cultura y del ambiente que lo modelaron, no puede comparársele ni juzgársele dentro de nuestro grado de desarrollo cerebral. Hay que referirlo a los sabios europeos de su época» (Briones, 1968, p. 13).

\section{LOS CAMINOS DE LA MODERNIDAD}

Pese a los intentos por introducir el pensamiento más vanguardista, las universidades y los colegios acostumbraban a ser reductos del tradicionalismo, por lo que fue necesario introducir las nuevas corrientes ideológicas por vías alternativas. Tanto de manera privada como a través de centros independientes de la autoridad eclesiástica, caso de la Real Escuela de Cirugía, creada en México en 1768. En Argentina, el Consulado de Buenos Aires, de la mano de su secretario, Manuel Belgrano futuro padre de la patria, se esforzó a su vez por dar un impulso a la ciencia aplicada como medio de favorecer la agricultura, la industria y el comercio. Con este fin, propuso, en 1796, la creación de escuelas gratuitas para niños. Debían destinarse a impartir materias como el dibujo, indispensable, entre otras cosas, para el diseño de máquinas eléctricas o para entender planisferios. Tres años después, en la misma línea de difusión del saber, abrió sus puertas una Escuela de Náutica que estaría en funcionamiento hasta 1806 (Asúa, 2010).

Se consiguieron así ciertos progresos, pero no siempre en proporción con las necesidades de la sociedad. Veamos un ejemplo. En la Nueva España, el virrey Revillagigedo se lamentaba, en 1794, 
de la escasa disponibilidad de ingenieros para construir caminos o levantar planos topográficos (Gortari, 2016). Pero, ¿qué significaba esta queja, en realidad? Tal vez no refleje un estado de postración. Tal vez se habían producido avances y, por eso mismo, las carencias resultaban más visibles que en épocas de estancamiento.

Las luces y las sombras aparecen mezcladas. En el futuro estado de México, la ciencia no era una carrera que ofreciera grandes expectativas de futuro profesional. Los que se dedicaban a ella, a fuerza de voluntarismo, sufrían una crónica falta de medios. No contaban con aparatos adecuados para los trabajos experimentales ni poseían bibliotecas actualizadas.

Con todo, encontramos figuras tan valiosas como la de José Antonio Alzate, un sacerdote conocido por obras sobre astronomía, química, meteorología y muchas otras disciplinas, el que llegó a ser socio correspondiente de la Academia de Ciencias de París (Saladino García, 2001). Ese mismo honor también lo alcanzó José Ignacio Bartolache, médico y matemático.

Se debe tener presente que Humboldt, tras su visita a Ciudad de México, afirmaría que ninguna otra capital del mundo poseía «establecimientos científicos tan grandes y sólidos». Existía, según el sabio alemán, un vínculo con las ideas más innovadoras. En México se habían impreso dos traducciones de los elementos de química de Lavoisier (Humboldt, 1989), mientras que las publicadas en Madrid brillaban por su ausencia (Gortari, 2016).

Precisamente en el país azteca, hallamos, entre 1803 y 1804, un intento de renovar la enseñanza universitaria. El mexicano José Mociño y el español Martín de Sessé propusieron un nuevo plan de estudios destinado a relanzar la docencia médica. Recibieron el apoyo de la Real Academia de Medicina de Madrid, institución que se manifestó a favor de sacar provecho del saber curativo de los indígenas, que estos habían obtenido por métodos empíricos. Por desgracia, la idea acabó por empantanarse en una maraña burocrática que impidió su materialización (Maldonado, 1999).

Esta inquietud reformista se percibe en diversos puntos del continente. Poco antes, en 1791, el colombiano Francisco Antonio 
Zea había concebido un proyecto con el objetivo de que en la universidad dejaran de impartirse conocimientos inútiles, a partir de una metodología que contribuía a la atrofia del espíritu, no a su desarrollo. Los estudios debían estar dirigidos hacia cuatro ámbitos fundamentales: las ciencias, las artes, la agricultura y el comercio (Soto Arango, 1999).

En Chile, a finales del siglo XVIII, parece haberse llegado también a una situación de relativo progreso, por más que la oferta educativa fuera todavía insuficiente. Fruto de la inquietud por el saber, nace, en 1797, la Academia de San Luis, primera institución del país en proporcionar una educación técnica. En sus clases se impartían matemáticas y dibujo, con el objeto de favorecer la agricultura, el comercio y la industria. Contó, por otra parte, con un laboratorio de física. Y fue el escenario de la primera tentativa por constituir un Museo de Historia Natural y Mineralogía. Su artífice y director, Manuel de Salas, consiguió que la Corona reconociera en 1798 la fundación del Centro. Por tanto, si el rey daba su bendición a esta iniciativa pedagógica, no parece que hubiera una voluntad por parte de España para mantener a los criollos «en la oscuridad». En 1801, el propio Salas elogiaba a los borbones por "propagar las verdades útiles hasta los confines del vasto imperio que para su felicidad les confió la providencia». El monarca, a su modo de ver, debía proteger la Ilustración para que la verdad se abriera paso dentro de la sociedad ${ }^{4}$.

Destaca, en Ecuador, la obra de Eugenio Espejo (1747-1795), crítico con la medicina tradicional y autor de unas Reflexiones acerca de las viruelas, donde queda patente que estaba al día de las novedades médicas (AA.VV., 1988).

Mientras tanto, en Perú, sobresale la figura de Hipólito Unanue (1755-1833), el personaje más significativo de la Ilustración en el país inca, desde unos planteamientos en los que no era fácil deslindar la ciencia de la política. Su defensa de la anatomía como principal

\footnotetext{
Revisar Gutiérrez, Claudio; Gutiérrez, Flavio. Forjadores de la ciencia en Chile. Santiago. RIL editores, 2008, p. 12. Aedo Richmond, Ruth. La educación privada en Chile: un estudio histórico-analítico desde el periodo colonial hasta 1990. Santiago. RIL editores, 2000, pp. 22-23. Serrano, Sol. Universidad y Nación. Chile en el siglo XIX. Santiago. Editorial Universitaria, 1994, pp. 26-28.
} 
elemento de la medicina se explica por su preocupación demográfica: una atención de mayor calidad a los pacientes redundaría en un incremento de la población, con las consiguientes repercusiones positivas en ámbitos como la industria y la defensa. Desde esta óptica, de lo que se trata es de defender la «salud pública» en las dos acepciones posibles de la expresión (Salaverry, 2016).

Unanue fue también un docente innovador, preocupado por impartir medicina y cirugía de forma conjunta, con atención no solo a la teoría, también a los datos empíricos proporcionados por los pacientes. No obstante, sus carencias como científico, más allá de los ditirambos de sus hagiógrafos, resultan también patentes. Su producción, escasa, respondió a planteamientos conservadores. No dejó de ser un seguidor de las vetustas teorías de Hipócrates, ya superadas por los descubrimientos de un Andrés Vesalio o un William Harvey. Uriel García Cáceres, un biógrafo abiertamente favorable, pero no un admirador acrítico, señala que Unanue no escribió artículos científicos de acuerdo con los parámetros de su época, ni tuvo en cuenta la bibliografía extranjera a su disposición (García Cáceres, 2010).

Por otra parte, no quiso ver la importancia de la quina, al contrario que su rival, el mulato José Manuel Dávalos (1758-1821), un hombre formado en Europa y de ideas renovadoras, merecedor de los elogios de Humboldt, pero que vio su carrera obstaculizada por los prejuicios que despertaba el color de su piel. Dávalos fue uno de los médicos mulatos y negros que abundaban en Lima, dedicándose, sobre todo, a la cirugía (Jouve Martin, 2014).

En Perú, Galeno permaneció en el plan de estudios hasta 1843. Este hecho da pistas de las enormes dificultades para adoptar las ideas más modernas en el campo de la medicina y en la ciencia general. Imperaba, como ha señalado Manuel Burga (2014), un discurso epistemológico atrasado, a mucha distancia del que se estilaba en Europa, donde, por ejemplo, ya se había pasado de la historia natural a la biología.

Por el contrario, en la Universidad de Guatemala, pese a ser este un territorio mucho menos importante en la organización imperial 
española, las ideas de la nueva ciencia se introdujeron con más facilidad. Aunque el currículum oficial de la universidad continuaba dentro de los márgenes de un escolasticismo trasnochado, lo cierto es que en la enseñanza superior ya se divulgaban las contribuciones de Newton. El método experimental se divulgaba, pues, más de lo que se acostumbra a suponer. Mientras tanto, libros prohibidos de sabios franceses, como Montesquieu o Condillac, llegaban al público a través de los canales del comercio clandestino (Brockmann, 2012).

\section{ENTRE LA CIENCIA Y LA PATRIA}

Durante los procesos de Independencia, ¿cómo afectó el huracán político y militar a la actividad científica? Una respuesta posible enfatizaría las consecuencias negativas de la inestabilidad. Elías Trabulse, refiriéndose al caso mexicano, afirma que la emancipación, en este ámbito, supuso una auténtica hecatombe. Cortó en seco los progresos del siglo XVIII y abrió la brecha con los países europeos, por entonces inmersos en un desarrollo acelerado. Se habría originado así un desfase condenado a perpetuarse durante los siglos XIX y XX (Trabulse, 2014).

Como vamos a ver enseguida, las cosas no fueron tan sencillas. La ciencia se dirigió, en buena parte, a sostener el esfuerzo bélico de la causa patriota. Hacía falta un saber utilitario que permitiera, por ejemplo, la fabricación de pólvora y armas. En México, los primeros treinta y seis cañones del bando patriota se fundieron en la ferrería de Coalcomán (Ruiz, 2010).

Los militares, además, necesitaban para su cometido estar formados en materias como el álgebra, la trigonometría o la aritmética. Para garantizar su enseñanza se fundó una Academia de Matemáticas en Buenos Aires, en noviembre de 1810. Algún tiempo más tarde, un exiliado español, el liberal Felipe Senillosa, ejercería la docencia en un centro análogo con la misma finalidad (Asúa, 2010).

Los científicos también se involucraron en la lucha política, a favor o contra el dominio español. A un botánico ilustre, el ecuatoriano José Mejía Lequerica, primero de su país que aplicó métodos 
modernos a su disciplina, responsable también de la creación de la cátedra de botánica, en la Universidad de Quito, lo hallamos como destacadísimo diputado liberal en las Cortes de Cádiz. Fue allí donde realizó muchas aportaciones relevantes, como la defensa de la autonomía para los territorios americanos y la igualdad de la representación para criollos y españoles. No fue escuchado, por desgracia. Los liberales peninsulares temían quedar en minoría frente a los americanos si establecía un sistema proporcional a la demografía de cada territorio (Chust, 1999).

En Colombia, tenemos los casos de otros dos botánicos importantes que militarían en la trinchera opuesta. El primero, Juan Eloy Valenzuela, era un adicto a la monarquía de Fernando VII. Se decantó por la emancipación ante la seguridad de que España, invadida por Bonaparte, solo podía salvarse gracias a un milagro. En esa circunstancia, temía que Napoleón, encarnación de los principios de la Revolución francesa, acabara gobernando España y América. Para evitar el dominio de unas gentes que juzga fieras y ateas, propugna la constitución de un estado de menores dimensiones que el virreinato y, por lo tanto, más fácil de gobernar. Esto no le parece una medida revolucionaria, ni una deslealtad hacia el rey, sino el proceder lógico del «hijo obediente a quién faltan sus padres» (Soto Arango, 2014). El nuevo país tendría entre sus prioridades la industria, la agricultura y las minas.

No menos fascinante fue la evolución de Francisco Antonio Zea, miembro de la expedición botánica de Celestino Mutis -fue su discípulo predilecto-, marchó a París objeto de instruirse en los últimos avances de las ciencias naturales, al tiempo que recogía libros e instrumentos. En la capital francesa se formó en química, al entender que era un campo muy necesario en Colombia. De nuevo en España, utilizó hábilmente sus contactos en el círculo del favorito real, Manuel Godoy, con lo que en 1804 pasó a ser director del Jardín Botánico de Madrid, con lo que se impuso a otro aspirante al cargo que también provenía de América, el mexicano José Mociño.

Más tarde sería diputado en las cortes afrancesada de Bayona. De vuelta en América, destacó como redactor de la Constitución 
de Angostura y consejero de Simón Bolívar. Ocupó diversos cargos políticos y consiguió que diversos estados europeos reconocieran a la naciente Colombia. Imbuido de los principios liberales, no vio ningún peligro para la libertad en la llegada de capitales extranjeros ni en reconocer a Gran Bretaña una posición preponderante en el comercio exterior.

No fue el único que pasó de la metrópoli a ocupar altos puestos en una nueva república. El naturalista mexicano Pablo de La Llave (1773-1833) ostentó el cargo de director segundo del Real Gabinete de Historia Natural, en Madrid, pero el cambio político, es decir, el regreso de Fernando VII, debió perjudicarle. En 1815 su situación ya era crítica. Al solicitar el pasaporte para regresar a su patria, dejó constancia de una situación desoladora. Su salud era muy delicada y no tenía medios económicos para subsistir, a excepción de la generosidad de sus amigos. Había fracasado en su intento de obtener una prebenda y debía regresar a casa sin una "colocación», algo que, según sus propias palabras, suponía la mayor fatalidad para un criollo.

Más tarde, durante el Trienio Liberal, sería diputado por Veracruz en las Cortes. Consumada la Independencia mexicana, ocuparía el Ministerio de Exteriores, y con posterioridad los de Justicia y Hacienda, en los primeros años de la república azteca ${ }^{5}$.

En Perú, diversos médicos asistían a la tertulia de Mariana Belzunce (1742-1791), una viuda rica e influyente. Entre los presentes, citar los nombres de tres profesores de la Universidad de San Marcos: José Valdez, Félix Devotti y José Pezet. Pero, sin duda, el galeno más célebre fue Unanue. ¿Se proponían, como se ha dicho, alentar la revolución? Parece improbable que se dieran actividades clandestinas en el marco donde se reunían miembros de lo más granado de la sociedad limeña, aristócratas como el conde de Monteblanco o el de Vistaflorida.

En aquellos momentos, individuos como Devotti estaban del lado del orden establecido. Aunque eso no obstaría para que, llegado

Su expediente puede encontrarse en Archivo General de Indias, Ultramar, 329, N. 107. 
el caso, sostuvieran la causa de los patriotas (García Cáceres, 2010). Los médicos, en general, tendían más hacia el autonomismo reformista que hacia el secesionismo. Gente como Unanue tenía buenas relaciones con las autoridades, dispuestas a financiar determinados periódicos mientras no se radicalizaran demasiado. Sin embargo, eso no significaba que, si se presentaba el momento, no estuvieran dispuestos a jugar a dos barajas.

Finalmente, en 1821, el Acta de la Independencia del Perú estará firmada por varios médicos: Hipólito Unanue, Miguel Tafur, José Pezet, José Manuel Dávalos, José Vergara y José Eugenio Eizaguirre (Pamo Reyna, 2009).

La prensa desempeñó una importante tarea en la difusión de los conocimientos científicos, en continuidad con la inmensa labor realizada en la centuria precedente. El siglo XVIII había sido una época dorada para la divulgación del conocimiento científico, que alcanzó un nivel sin precedentes a través de «la publicación de semanarios, gacetas, diarios y en general revistas y periódicos de vulgarización científica y técnica» (Trabulse, 2014, p. 83).

Encontramos, por ejemplo, numerosas publicaciones del Río de la Plata, hecho que muestra la existencia de interés entre el público. Entre 1810 y 1811 apareció El Correo de Comercio, que se propuso tratar en sus páginas «todo ramo de las Ciencias y las Artes conocidas». Como señala Miguel de Asúa (2010), aquella era una época en la que era habitual abordar de manera pública cuestiones que en la actualidad estarían restringidas, por su carácter técnico, a los medios especializados. Entre el aficionado y el profesional, no existía en aquellos momentos una frontera tan nítida como podríamos imaginar.

En la Nueva Granada, los periódicos abordaban cuestiones relacionadas con diversas disciplinas. La agricultura, la minería, la astronomía o la zoología aparecen entre los centros de interés del Semanario del Nuevo Reino de Granada (Nieto Olarte, 2007). Francisco José de Caldas inició su publicación en 1808. Contó entre sus colaboradores con una figura tan ilustre como Jorge Tadeo Lozano, autor, entre otros trabajos, de investigaciones sobre la fauna. Procuró, 
en principio, ganarse las simpatías de los comerciantes ilustrados de Bogotá, pero no fue capaz de reunir suficientes suscriptores para garantizar la viabilidad económica de la publicación (López-Ocón, 1998).

Tanto Caldas como Lozano pagaron un alto precio por su compromiso político. Ambos fueron fusilados cuando el general Morillo reconquistó la actual Colombia para España. Al igual que su compatriota, el químico José María Cabal. En otras zonas de América también se dieron casos de hombres de ciencia que se convirtieron en mártires de la Independencia. En México, a varios alumnos del Colegio de Minería, como Casimiro Chowell o Mariano Jiménez, también les esperó la pena de muerte. El primero fue coronel, nombrado por el prócer Manuel Hidalgo. El segundo fue capitán de artillería de los rebeldes (Afanador Llach, 2007).

En Chile, un político ilustre, Juan Egaña, redactor de la Constitución de 1823, abogó por la promoción de la ciencia como medio para alcanzar el bienestar de la ciudadanía. El ser humano requería saberes destinados a mejorar su existencia. «El hombre es un ente real y necesita de sólidos y prácticos conocimientos para vivir bien», afirmaba un discurso que se suele atribuir a Egaña, en el que se citaban, como ejemplos de saberes útiles, la física, la historia natural, la geometría o la mecánica. Aunque, en realidad, esas palabras pertenecen al italiano Antonio Genovesi.

\section{CONOCERnOS A NOSOTROS Mismos}

Consumada la emancipación, diversos hombres doctos, entre ellos médicos, naturalistas e ingenieros, ocuparon cargos importantes. El caso de Unanue parece responder a una adaptación más o menos oportunista a las circunstancias, vista la forma en que pasó de hombre de confianza de los virreyes a defensor de la constitución liberal de Cádiz. Diputado por Arequipa en las Cortes de Cádiz, llegó a España cuando se había restaurado el absolutismo. Tras la separación de la metrópoli, sería ministro de San Martín y de Simón Bolívar. En 1824 funda el semanario Nuevo Día del Perú, que se 
publicó entre julio y septiembre de ese año, consagrado básicamente a la política, pero sin olvidar las ciencias y las artes.

¿De qué manera estas y otras figuras contribuyeron a que el saber ocupara un espacio público? Para responder a esta pregunta necesitamos una historia social que nos muestre cómo, en palabras de Juan José Saldaña, la ciencia «es consustancial a la concepción y formación de los estados nacionales en América Latina» (Saldaña, 1996, p. 288). Eso es así ya en una fecha tan temprana como 1811, cuando la Constitución promulgada en Cundinamarca, Colombia, establece la obligación de constituir una Sociedad Patriótica que tendrá entre sus obligaciones el impulso de las ciencias ${ }^{6}$. Otro ejemplo, entre tantos, lo tenemos en la Bolivia de 1827, año en el que Sucre, el vencedor de Ayacucho, decreta la creación del Instituto Nacional de Artes y Ciencias, orientado al trabajo en pro de la modernización, como se decía entonces, de la difusión de «los conocimientos útiles y agradables» ${ }^{7}$.

Dicho de otra manera: el poder se legitima a través de una ideología laica basada en la idea de un progreso que tiene el saber como un instrumento. Naturalistas, ingenieros y otros especialistas se ocupan de investigar el territorio y los recursos de los nuevos estados, de forma que las autoridades políticas tengan datos fiables tanto de su geografía como de las riquezas disponibles.

Un ejemplo de esta política lo tenemos en proyecto que se propusieron acometer dos sabios, el peruano Manuel Rivero y el francés Jean-Baptiste Boussingault: la descripción geognóstica del territorio de la República de Colombia. Entre sus tareas, se ocuparían de cuestiones como los yacimientos metálicos. Humboldt, en carta a Bolívar, no dejó de señalar que todos estos temas científicos estaban relacionados con «los intereses de la industria y del comercio del país» (Humboldt, 1989, pp.171-72).

6 El texto de la constitución cundinamarquesa en Http://www.cervantesvirtual. com/obra-visor/constitucion-de-cundinamarca-30-de-marzo-de-1811-ypromulgada-el-4-de-abril-de-1811--0/html/008e4dae-82b2-11df-acc7002185ce6064_2.html\#I_19_

7 Véase la Ley de Educación de Bolivia, del 9 de enero de 1827, en Https://www. lexivox.org/norms/BO-L-18270109.html 
Juan Dauxion Lavaysse, en Chile, fue comisionado por el gobierno para realizar el viaje científico, a lo largo de todo el país, en el que se deberían reunir todo tipo de datos sobre geología, mineralogía y demás aspectos de la Historia Natural. El gobierno necesitaba información de primera mano con vistas a materializar políticas que promovieran «la prosperidad nacional» (Sagredo, 2014, p.117).

Como señaló un periódico argentino, La Gaceta Mercantil, a propósito de la fundación de Museo de Historia Natural en Buenos Aires, unos recursos inmensos resultaban por completo inútiles si nadie era consciente de su existencia: «nada importaría que nuestro fértil suelo encerrase tesoros inapreciables en los tres reinos de la naturaleza, si privados del auxilio de las ciencias naturales ignoramos lo que poseemos» (Asúa, 2010, p. 64). Este museo, en la actualidad, lleva el nombre de su promotor, el prócer Bernardino Rivadavia.

La creación de este tipo de instituciones estatales, a lo largo de toda la América hispana, obedecía tanto a fines académicos como identitarios, puesto que se trataba, también, de hacer que la nación apareciera como una realidad tangible ante los ojos del pueblo.

\section{TRANSFERENCIA DE CONOCIMIENTOS}

Había que asumir la reforma de las universidades y promover la formación de cuadros técnicos. Tras la Independencia, muchos sabios habían desaparecido, exiliados o muertos. ¿Cómo sustituirlos? ¿De dónde sacar los funcionarios que necesitaba el Estado para garantizar su funcionamiento eficaz? Frank Safford (1976) dedicó un magnífico estudio a los intentos de Colombia por establecer una elite científica. En teoría, se trataba de encarrilar a los jóvenes de clase alta hacia las carreras tecnológicas, de forma que contribuyeran a crear la economía fuerte que el Estado necesitaba. En la práctica, los buenos deseos chocaban con la debilidad de los gobiernos y la ausencia de suficientes recursos económicos. La inquietud por la ciencia de los ministros de interior no bastaba para traducir las intenciones en hechos. 
Para dar respuesta a las necesidades nacionales de ciencia, en diferentes puntos del continente se planteó una política: dar facilidades a la entrada de población foránea, en la seguridad de que aportarían los conocimientos propios de países más avanzados. No se trataba, por supuesto, de una estrategia nueva en la historia. ¿Acaso el zar Pedro el Grande no buscó en Europa los cerebros que debían sacar a Rusia de su atraso? España, a partir de Felipe V, también había buscado la colaboración de los especialistas de otras naciones (Clément, 1993).

En un sugestivo estudio reciente, Peter Burke (2018) ha arrojado luz sobre las migraciones de académicos y la forma en que ponen en contacto distintas tradiciones culturales. En muchos casos, estos expertos de diferentes disciplinas acaban convirtiéndose en especialistas en sus países de acogida y renuevan el conocimiento del mismo al aportar una mirada desde fuera, desprovista de los asentados prejuicios que los naturales suelen dar por datos incuestionables.

Unos países siguieron esta línea de captación de inteligencias con una actuación sistemática. Otros se limitaron a ofrecer facilidades puntuales. Los historiadores han debatido si la presencia extranjera se debió a un imperialismo cultural europeo o si, por el contrario, la iniciativa partió del lado americano. En una síntesis equilibrada de la polémica, López-Ocón (2010) señala que ambas posturas poseen su parte de razón. Se dieron tanto factores exógenos como condiciones endógenas.

Para atraer a eminencias foráneas, una condición indispensable era la tolerancia religiosa. Así lo planteó, en Venezuela, un tal William Burke en un controvertido artículo periodístico. Posiblemente, bajo la máscara de Burke se escondía el mismísimo Francisco de Miranda. En cualquier caso, el texto defendía la necesidad de que llegaran inmigrantes que llevaran consigo las artes y las «ciencias útiles» que no se podían adquirir sino a través de un contacto fructífero con el exterior (Grases, 1988).

En Argentina, Rivadavia también creyó en la necesidad de que los extranjeros contribuyeran al desarrollo nacional. Por eso se esforzó en promover la llegada de profesores originarios de otras latitudes. 
En los diversos cargos políticos que ocupó, incluida la presidencia de la República, la preocupación por la enseñanza de la ciencia aparece como una constante. Mientras fue secretario del Primer Triunvirato, buscó la contratación en Europa de dos profesores de matemáticas, uno de física experimental, uno de química, uno de mineralogía, uno de economía política, un arquitecto y un dibujante. Sus instrucciones establecían que los españoles, por una cuestión idiomática, debían ser preferidos a igualdad de méritos. A continuación, debía tenerse en cuenta a los italianos y los franceses. Y, solo como última opción, vendrían los alemanes y británicos (Ramos, 2012).

Más tarde, durante su etapa como diplomático en el viejo continente, Rivadavia prosiguió con su labor de captación de científicos, a los que debía ofrecer una tarea docente en Buenos Aires. A cambio, los elegidos disfrutarían de «sueldos proporcionados para su decorosa existencia». Su mayor éxito fue conseguir la llegada del prestigioso naturalista Aimé Bonpland, recomendado por Humboldt. Bonpland era un decidido partidario de la independencia latinoamericana, amigo de patriotas como Manuel Belgrano (Ortuño Martínez, 1999). Para él, viajar a América abría la posibilidad de hacer fortuna y alcanzar así una independencia económica que le permitiera dedicarse a proyectos de su agrado. Debía ocuparse, en principio, de organizar el Museo de Historia Natural, pero, cuando llegó a Argentina, no encontró el apoyo del gobierno que esperaba.

Más suerte tuvo el físico piamontés Carlos José Ferraris, que se dedicaría al Museo durante las siguientes dos décadas. Ferraris era un prófugo de la revolución liberal piamontesa de 1821, lo mismo que otros dos sabios italianos que también acabarían en Argentina: Pedro Carta Molino y Carlos Enrique Pellegrini (Candido, 1996).

Ninguno de ellos fue un caso aislado. Formaban parte de lo que Stephen Bell (2010), biógrafo del primero, definió como un intento de llevar Europa a América del Sur: «a project that was intent of bringing Europe to South America» (23). También llegaron al Río de la Plata el astrónomo italiano Octavio Fabricio Mossotti. Rivadavia también contactó con un matemático francés, Ramón Chauvet, al 
que algún tiempo más tarde encontramos en la Universidad de Buenos Aires como introductor del cálculo infinitesimal (Ramos, 2012).

En Chile, mientras tanto, el gobierno siguió una política similar de reclutamiento de sabios extranjeros, también con el objeto de formar una nueva generación de cuadros técnicos y de alentar el desarrollo a través de las contribuciones de los científicos. Entre los que llegaron al país destacó el francés Claudio Gay (1800-1873), destinado a constituir el gabinete que se transformaría en el Museo Nacional de Historia Natural. Su aporte, valioso para el desarrollo económico y el ejercicio de la soberanía chilena, iba a ser inapreciable en el proceso de configuración de la nación (Sagredo, 2017).

Pero, sin duda, la más célebre de las eminencias llegadas al país fue Andrés Bello, el célebre escritor venezolano. Se le conoce como eminente gramático y poeta, pero una de las facetas de su amplia obra fue la de divulgador científico. Tocó disciplinas tan diversas como la astronomía, la botánica, la física o la meteorología. Por otra parte, su labor literaria también estuvo conectada con la ciencia. Ahí está su oda a la vacuna o la composición que dedicó a la «agricultura de la zona tórrida» (Latorre, 2018).

De 1842 a 1865, Bello dirigió la universidad chilena, en una época que se acogieron científicos europeos como el mineralogista lituano-polaco Ignacio Domeyko. Esta política, según López-Ocón (2010), resultó esencial para convertir un antiguo territorio marginal del imperio español en la potencia emergente del Pacífico, a finales del siglo XIX.

Lo habitual es que los historiadores elogien el trabajo de Bello. Se cita, por ejemplo, su énfasis en que los chilenos desarrollaran una ciencia propia, adaptada a las circunstancias locales, sin repetir como papagayos lo que dijeran los sabios europeos (AA.VV., 1982). Pero, ¿hasta qué punto dejó un legado fructífero? En cierto sentido es posible que su labor fuera contraproducente. Claudio Gutiérrez (2011) habla de «contrarrevolución bellista» porque el venezolano partía del supuesto de que el conocimiento debe estar subordinado a la moral católica y al orden establecido. El fundamento de la prosperidad no radicaría en las ciencias sino en las letras. El derecho debía 
tener prioridad porque, sin un reconocimiento de la propiedad, todo lo demás no servía de mucho.

Tengamos en cuenta, por último, que también se produjo el movimiento inverso, el de latinoamericanos que se marcharon a Europa para imbuirse de los últimos adelantos científicos y técnicos. Colombia, por ejemplo, envió al viejo continente a Joaquín Acosta (1800-1852), ingeniero militar, geólogo e historiador. En París, desarrolló un intensivo programa de estudios en las instituciones más prestigiosas, como la Sorbona, la Academia de Ciencias o el Instituto de Francia. Adquirió así conocimientos de las más diversas disciplinas: mineralogía, química, física, geodesia, topografía. Mientras tanto, entró en contacto con los sabios e intelectuales más destacados. Entre ellos, Humboldt, Laplace y Gay-Lussac.

El influjo cultural no se produjo solo en un sentido. Acosta también influyó sobre personalidades europeas, a las que facilitó una visión más exacta de lo que sucedía en el Nuevo Mundo, lejos del complejo de superioridad que habían mostrado determinadas figuras de la Ilustración. Al constitucionalista Benjamin Constant, sin ir más lejos, le proporcionó informaciones con destino a un texto en el que refutaba las críticas a los americanos del abate Pradt.

Se produce, como acabamos de ver, un fenómeno de hibridación cultural que no acaba aquí. Porque, tras varios años de aprendizaje, Acosta regresa a Colombia, donde su preparación lo catapulta a diversas responsabilidades, como la cátedra de Química que ocupó en 1833 (Figueroa, 2011).

\section{Conclusiones}

La ciencia hispanoamericana del periodo de la emancipación no fue un producto exclusivo de las diversas repúblicas: existe una relación de continuidad con el periodo del virreinato. Tampoco puede hablarse de una asunción pasiva de todo lo que venía desde Europa. En todo caso, la relación con el mundo exterior presenta una naturaleza bidireccional, llena de influencias recíprocas. 
Las independencias prometieron desarrollo científico. Pero, en todo el continente, la inestabilidad política y los problemas financieros iban a limitar con frecuencia el alcance de los programas educativos y tecnológicos, desatendidos en vistas que no prometían una rentabilidad instantánea a gobiernos obsesionados con lo inmediato, aunque eso no significa que la ciencia no fuera una inquietud importante en la agenda política tras la emancipación. López-Ocón (2010), para el caso de los países andinos, señala que los nuevos gobernantes republicanos se comprometieron con programas de renovación educativa en los que se concedía gran importancia al desarrollo científico y tecnológico. De todas formas, hay que valorar estas iniciativas con cuidado. Porque en todo el continente, como señala Frank Safford (1976), aparece una fuerte tendencia al "proyectismo", es decir, a plasmar sobre el papel grandes ideas que después no cuentan con el adecuado soporte financiero.

Por otra parte, la separación de España implicó, en un primer momento, el aislamiento respecto a las redes académicas internacionales (Carreras, 2014). Para vencer ese obstáculo, las diversas repúblicas se embarcaron, con más o menos entusiasmo y con más o menos éxito, en un programa de captación de cerebros.

Atribuir el fracaso de los proyectos científicos republicanos a «la herencia sociocultural de la colonia», como hace Juan José Saldaña, es desviar la cuestión. Como hemos visto, el periodo virreinal fue un momento de desarrollo científico. Saldaña (1996), en cambio, da en el clavo cuando apunta, también, a los «formidables desafíos tanto internos como externos que debieron enfrentar las nuevas naciones» (11).

La inestabilidad política interfirió de forma desastrosa en los intentos de establecer instituciones docentes, de cara a facilitar la formación de cuadros técnicos. Tomemos el caso mexicano. En 1825 se crea en Guadalajara un Instituto Literario donde se imparten física experimental y matemáticas, entre otras disciplinas. Apenas nueve años después, este centro desaparece. Por otra parte, el doctor Mora, con el apoyo del presidente Gómez Farías, proyecta una escuela de matemáticas y otra de medicina. Solo pudo desarrollarse la segunda, 
aunque lo hizo «en medio de penurias económicas y convulsiones sociales». No obstante, eso no implica que la ciencia médica estuviera desprovista de contribuciones significativas por parte de figuras que estaban en contacto con los avances extranjeros. En 1845, por citar un solo ejemplo, Matías Béistegui y Francisco Vértiz realizaron la primera transfusión de sangre de la historia mexicana (Trabulse, 2014).

América Latina no obtuvo los resultados espectaculares que algunos habían imaginado a principios del XIX, pero eso no implica, ni mucho menos, que el continente viviera la centuria decimonónica de espaldas al conocimiento. Lo que sucede es que las prioridades se centran, no en la ciencia pura, sino en la que tiene aplicación práctica. Más que comparar a las distintas repúblicas con Estados Unidos o Gran Bretaña, hay que analizar su grado de desarrollo científico en función de su situación política, social y económica. Eso significa, en el contexto del surgimiento y consolidación de nuevos estados nacionales, que los saberes técnicos ejercen una influencia como legitimadores del poder. ¿Al servicio de una visión eurocéntrica de la realidad? Sí, claro. ¿Cómo podría ser de otra puesto que el mundo de los criollos no es sino el Extremo Occidente? Para las poblaciones indígenas, las independencias no serán sino un nuevo episodio en su historia secular de marginación.

\section{BibLIOGRAFÍA}

Afanador Llach, María José. «La obra de Jorge Tadeo Lozano: apuntes sobre la Ciencia Ilustrada y los inicios del proceso de Independencia». Historia Crítica.Julio- diciembre 2007: 8-31.

Amunátegui, Miguel Luis. (1872). Los precursores de la Independencia en Chile, vol. 3. Santiago.

Arboleda, Luis Cardoso; Díaz-Piedrahita, Santiago (Eds.). (1994). Francisco Joseph de Caldas y Thenorio, 1768-1816. Bogotá: Molinos Velásquez editores.

Asúa, Miguel de. (2010). La ciencia de mayo. La cultura cientifica en el Río de la Plata, 1800-1820. Buenos Aires: Fondo de Cultura Económica.

Asúa, Miguel de. (2014). Science in The Vanished Arcadia. Knowledge of Nature in the Jesuit Missions of Paraguay and Río de la Plata. Holanda: Brill. 
AA.VV. (1866). Historia jeneral (sic) de la República de Chile desde su independencia hasta nuestros días. Santiago de Chile: Imprenta Nacional. AA.VV. (1982). Homenaje a Andrés Bello en el bicentenario de su nacimiento (1781-1981). Diálogos Hispánicos de Amsterdam, no 3.

AA.VV. (1988). Visión actual de Eugenio Espejo. Quito: Fundación Friedrich Naumann.

Bell, Stephen. (2010). A Life in Shadow. Aimé Bonpland in Southern South America, 1817-1858. Stanford: Stanford University Press.

Brockmann, Sophie. (2012). Retórica patriótica y redes de información científica en Centroamérica, c 1790-1810. Cuadernos De Historia Moderna, (XI). 165-184.

Burga, Manuel. (2014). De la patria a la nación/del mundo natural al mundo cultural: la ciencia en el Perú, 1790-1930. En Carreras, Sandra; Carrillo Zeiter, Katja (Eds.). La ciencia en la formación de las naciones americanas. Madrid: Iberoamericana.

Caffarena Barcenilla, Paula (2016). Viruela y vacuna. Difusión y circulación de una práctica médica. Chile en el contexto hispanoamericano 1780-1830. Santiago de Chile: Universitaria.

Candido, Salvatore. (1996). Entre guerras y revoluciones en Europa. El aporte al progreso de América Hispánica de hombres de ciencia italianos (1815-1850). En Gil Novales, Alberto (ed.). Ciencia e independencia política. Madrid: Ediciones del Orto, 55-75.

Cañizares-Esguerra, Jorge. (2006). Nature, Empire and Nation. Stanford: Stanford University Press.

Carreras, Sandra; Carrillo Zeiter, Katja. (Eds.). (2014). La ciencia en la formación de las naciones americanas. Madrid: Iberoamericana.

Chust, Manuel. (julio-diciembre de 1999). «José María Lequerica, un revolucionario en las Cortes hispanas». Procesos. Revista Ecuatoriana de Historia, (14), 53-68.

Clément, Jean Pierre. (1993). Las instituciones científicas y la difusión de la ciencia durante la Ilustración. Madrid: Akal.

Díaz Piedrahita, Santiago. (Ed.). (2010). Hombres de ciencia e independencia. Bogotá: Academia Colombiana de Ciencias Exactas, Físicas y Naturales..

Duque Muñoz, Lucía. (2004). «Patriotismo, Geografía y Astronomía en la coyuntura independentista de la Nueva Granada». Cahiers $d u$ monde hispanique et luso-brésilien. (83), 149-177.

Elías Ortiz, Sergio. (1966). «Francisco Antonio Zea y sus actividades científicas». Boletín Cultural y Bibliográfico, (Vol. 9, 5), 839-848.

Figueroa Cancino, Juan David. (julio-diciembre de 2011). La formación intelectual de Joaquín de Acosta y el Compendio histórico del descubrimiento y colonización de la Nueva Granada (1848). Anuario Colombiano de Historia Social y de la Cultura, (Vol. 38, 2),190-192. 
García Cáceres, Uriel. (2010). La magia de Unanue. Lima: Fondo Editorial del Congreso del Perú.

Genovesi, Antonio. (1785). Lecciones de comercio o bien de economía civil. Tomo 2. Madrid.

Gortari, Eli de. (2016). La ciencia en la historia de México. Ciudad de México: Fondo de Cultura Económica.

Grases, Pedro (ed.). (1988). Pensamiento político de la emancipación venezolana. Caracas: Biblioteca Ayacucho.

Gutiérrez, Claudio. (2011). Educación, ciencias y artes en Chile, 1797-1843. Santiago. RIL editores.

Huerta Jaramillo, Ana María. (1999). «Pablo de La Llave, un ilustrado entre dos siglos y dos mundos». LLULL, (22), 421-430.

Humboldt, Alejandro de. (1989). Cartas americanas. Caracas: Biblioteca Ayacucho.

Jouve Martin, José R. (2014). The Black Doctors of Colonial Lima: Science, Race and Writing in Colonial and Early Republican Era. Montreal: McGill-Queen's University Press.

Kirwan, Richard. (1789). Elementos de mineralogía. Madrid.

Latorre, Guillermo; Medel, Rodrigo. (2018). Andrés Bello científico. Escritos publicados (1823-1843). Santiago de Chile: Universitaria.

López-Ocón Cabrera, Leoncio. (1998). «La formación de un espacio público para la ciencia en la América Latina durante el siglo XIX». Asclepio, (Vol. L, 2), 205-226.

López-Ocón, Leoncio. (2010). «Los primeros pasos de una ciencia republicana emancipatoria en la América andina». Historia de la Educación, (29), 57-75.

Maldonado Polo, José Luis. (1999). «El naturalista novohispano José Mariano Mociño en Europa», En Soto Arango, Diana; Puig-Samper, Miguel Ángel; González-Ripoll, $\mathrm{M}^{\mathrm{a}}$ Dolores (Editores). Científicos Criollos e Ilustración. Madrid: Doce Calles, 55-72.

Maldonado Polo, J. Luis. (2003). «Científicos americanos en las Cortes Constituyentes. La cuestión ultramarina». Revista de Indias, (Vol. LXIII, 227), 275-302.

Millones, L.; Ledezma, D. (eds.) (2005). El saber de los jesuitas, historias naturales y el Nuevo Mundo. Madrid: Iberoamericana.

Nieto Olarte, Mauricio. (2000). Remedios para el Imperio. Historia natural y la apropiación del Nuevo Mundo Bogotá: Instituto Colombiano de Antropología e Historia.

Nieto Olarte, Mauricio. (2007). Orden natural y orden social. Ciencia y política en el Semanario del Nuevo Reyno de Granada. Madrid: CSIC.

Ortuño Martínez, Manuel. (1999). «Hispanoamericanos en Londres a comienzos del siglo XIX». Espacio, Tiempo y Forma, (Serie V, $\mathrm{H}^{\mathrm{a}}$ Contemporánea, T. 12.), 45-72. 
Pamo Reyna, Oscar G. (enero-marzo de 2009). «Los médicos próceres de la independencia del Perú». Acta Médica Peruana, (vol. 26, 1), 45-72.

Pérez, Joseph. (2003). Breve Historia de la Inquisición en España. Madrid. Crítica.

Peset, José Luis. (1987). Ciencia y Libertad. El papel del científico ante la independencia americana. Madrid: CSIC.

Ramos, Víctor A. (2012). «Bernardino Rivadavia y las Ciencias Naturales». Revista del Museo Argentino de Ciencias Naturales, (vol. 14, 2). Web. < http://www.scielo.org.ar>

Ruiz, Rosaura; Argueta, Arturo; Zamudio, Gabriela (coords.). (2010). Otras armas para la Independencia y la Revolución. Ciencias y bumanidades en México. México D.F.: Fondo de Cultura Económica.

Safford, Frank. (1976). The Ideal of the Practical. Colombia's Struggle to Form a Technical Elite. Austin: University of Texas Press.

Sagredo Baeza, Rafael. (2014). Historia minima de Chile. Madrid: Turner.

Sagredo Baeza, R. (2017). "Ciencia, estado, territorio y soberanía en el siglo XIX». En I. Jaksic \& F. Rengifo (Eds.), Historia política de Chile, 1810-2010. Tomo II. Estado y Sociedad. Santiago: Fondo de Cultura Económica, 139-172.

Saladino García, Alberto. (2001). El sabio José Antonio Alzate y Ramírez de Santillana. Toluca: Universidad Autónoma del Estado de México.

Salaverry García, Oswaldo. (2016). Las «observaciones sobre el clima de Lima» (1806) de Hipólito Unanue como topografía ilustrada. Tesis doctoral. Universidad de Salamanca.

Saldaña, Juan José (Coord.). (1996). Historia social de las ciencias en América Latina. México D.F.: Miguel Ángel Porrúa.

Sanhueza Cerda, Carlos. (editor). (2018). La movilidad del saber científico en América Latina. Objetos prácticas e instituciones (siglos XVIII al XX). Santiago de Chile: Universitaria.

Silva, Renán. (2002). Los ilustrados de Nueva Granada, 1760-1808. Genealogía de una comunidad de interpretación. Medellín: Fondo Editorial Universidad EAFIT.

Sotelo, Ignacio. (2007). El cortocircuito del mundo hispánico en ciencia y tecnología. En Rehrmann, Norbert; Ramírez Sáinz, Laura (eds.). Dos culturas en diálogo. Historia cultural de la naturaleza, la técnica y las ciencias naturales en España y América Latina. Madrid: Iberoamericana/Vervuert, 59-76.

Soto Arango, Diana E. (1999). «Francisco Antonio Zea: un criollo ilustrado en Europa». En Soto Arango, Diana; Puig-Samper, Miguel; GonzálezRipoll, $\mathrm{M}^{a}$ Dolores (Editores). Científicos Criollos e Ilustración. Madrid. Doce Calles, 73-94. 
Soto Arango, Diana Elvira. (julio-diciembre de 2014). «Valenzuela y Zea: Científicos Criollos en la Independencia Americana». Revista Historia de la Educación Latinoamericana, (Vol. 16, 23), 15-40.

Stark, Rodney. (2017). Falso testimonio. Denuncia de siglos de historia anticatólica. Sal Terrae: Maliaño.

Terán, Oscar. (2008). Historia de las ideas en Argentina. Diez lecciones iniciales, 1810-1980 ( $5^{\circ}$ edición). Buenos Aires: Siglo veintiuno.

Trabulse, Elías. (2014). Historia de la ciencia en México (versión abreviada). México D.F.: Fondo de Cultura Económica.

Uribe Salas, José Alfredo. (2010). «Ciencia e independencia. Las aportaciones de Andrés del Río a la construcción del nuevo Estado-nación». En Ruiz, Rosaura; Argueta, Arturo; Zamudio, Gabriela (coords.). Otras armas para la Independencia y la Revolución. Ciencias y humanidades en México. México D.F: Fondo de Cultura Económica, 43-58.

Xia, Song. (2010). "The Role of Science in Latin American Independence Revolution» <ilas.cass.cn/webpic/web/ilas/manager/.../2010102618328164.pdf> 



\title{
LA CONFIGURACIÓN DE UN ESPACIO PARA EL SABER NATURAL EN CHILE. EL GABINETE DE HISTORIA NATURAL DE SANTIAGO, I 830-I $84^{\mathrm{I}}$
}

\author{
Daniela Serra Anguita \\ Pontificia Universidad Católica de Chile
}

Resumen. A partir de 1830 comenzó a organizarse en Santiago el primer espacio para el conocimiento en base a colecciones de objetos naturales en el Chile independiente, como parte de la empresa científica que el gobierno encargó al joven naturalista francés Claudio Gay. Mientras el científico recorría diferentes rincones del país investigando y reuniendo ejemplares de historia natural, una comisión científica nombrada por las autoridades para examinar los trabajos de Gay se encargó de almacenar y cuidar las colecciones que iban arribando a la capital, al mismo tiempo que gestionó un espacio e infraestructura para la preparación y exhibición de los ejemplares naturales. Esta investigación tiene como objetivo ahondar en el proceso que condujo a la formación del Gabinete de Historia Natural de Santiago entre 1830 y 1842, cuya instalación fue posible gracias a un esfuerzo colectivo propio del quehacer naturalista en el Chile de la primera mitad del siglo XIX. Junto con mostrar la diversidad

\footnotetext{
Esta investigación fue financiada por CONICYT a través de la Beca Doctorado Nacional, convocatoria 2014 y por el Premio Excelencia Doctorados UC, de la Pontificia Universidad Católica de Chile. Al mismo tiempo, este trabajo formó parte del proyecto Ecos-Conicyt, «Fragmentos de mundo en tránsito. Objetos y artefactos americanos en Europa, siglos XVII-XX» (ECOS-C16H04), Instituto de Historia de la Pontificia Universidad Católica de Chile y Centre AlexandreKoyré. Histoire des Sciences et des Techniques, de la École des Hautes Études en Sciences Sociales, París.
} 
de actores involucrados en esta empresa científica, se pondrá énfasis en las dimensiones prácticas que posibilitaron la instalación de este espacio para el saber natural, con el fin de reflexionar sobre la incidencia que tuvieron los elementos cotidianos en la actividad naturalista nacional.

Palabras clave: Chile, ciencia, colecciones, Gabinete de Historia Natural.

AвSTRACT. In 1830 the first place to promote natural knowledge based on collections in independent Chile began to organize in Santiago, as part of the scientific work commissioned by the Chilean government to the French naturalist Claudio Gay. While the scientific travelled to different localities in the country, researching and gathering specimens of natural history, a scientific commission named by the authorities to examine Gay's work managed the storage and protection of the collections that arrived to the capital city. At the same time, it arranged an infrastructure to prepare and exhibit the natural specimens. This investigation aims to deepen in the process that led to the formation of the Cabinet of Natural History of Santiago between 1830 and 1842 as a result of a collective work characteristic of the naturalist practice in Chile during the first half of the nineteenth century. The article shows the diversity of individuals involved in this scientific enterprise and emphasizes the practical dimensions that allowed the installation of a place for natural knowledge. The purpose of these investigation is to reflect about the impact of everyday elements in the national naturalist activity.

KeYwords. Cabinet of Natural History, collections, science, Chile.

El 13 de julio de 1836 las autoridades del Gobierno de Chile recibieron un informe que detallaba parte de los resultados obtenidos hasta ese momento por el naturalista francés Claudio Gay (ANC, Min. del Interior), contratado en 1830 por el Estado para realizar un viaje científico por el país. El documento había sido redactado por una comisión científica creada en agosto de 1830 para examinar 
los trabajos científicos de Gay, la cual estaba integrada por Alejo Bezanilla, presbítero que se desempeñaba como profesor de física experimental del Instituto Nacional; Vicente Bustillos, botánico aficionado, químico autodidacta y dueño de la Botica Bustillos; y Francisco García Huidobro, director de la Biblioteca Nacional de Chile y hombre muy instruido. En el informe sobre los avances del naturalista los integrantes de dicha comisión indicaban la necesidad de:

La organización del Gabinete de Historia Natural en que se deben ir colocando todos los objetos. Sin esto, en vano será que se vayan acopiando materiales que por falta de un local a propósito para su colocación, no se sacaría más de ellos que su destrucción y el consumo de los recursos que gasta el Gobierno para colectarlos (Gay, 1836).

Dedicado a recorrer diferentes rincones de Chile desde diciembre de 1830, estudiando y recolectando objetos de historia natural, el naturalista envió periódicamente el resultado de sus colectas de especímenes naturales a Santiago para formar el gabinete que debía instalarse en aquella ciudad. Sin embargo, una vez que los objetos arribaban a la capital, estos comenzaron a acumularse en la bodega de una casa particular a la espera de que se destinase un espacio especialmente acondicionado para el almacenamiento, preparación y exhibición de las colecciones naturales. La comisión científica, preocupada por el estado de conservación de los ejemplares que venían acumulándose hacía seis años, llamó la atención a las autoridades sobre la urgencia de gestionar un lugar para la organización definitiva del gabinete.

La formación de un espacio para el saber natural en base a la reunión de colecciones de historia natural era una antigua aspiración de las autoridades del país, la cual se remontaba a 1803 con la creación del Gabinete de Historia Natural en la Real Academia de San Luis. Posteriormente, los revolucionarios independentistas intentaron fundar un gabinete en el nuevo establecimiento educacional que debía fundarse en Santiago hacia 1813, proyecto que se vio interrumpido por la reinstauración de la administración española hacia 1814. En 1820, el director supremo Bernardo O’Higgins 
encargaría la fundación de un museo de historia natural al francés Juan José Dauxión Lavaysse, proyecto que también fracasó. De esta manera, cuando en julio de 1830 Claudio Gay ofreció al gobierno sus servicios como naturalista para estudiar la historia natural del país y formar un gabinete de historia natural con «la mayor parte de las producciones de la República, con sus nombres vulgares y científicos» ( ANC, Min. del Interior, vol. 51, fs. 35v), el gobierno vio la oportunidad de concretar este anhelo.

Debido a que Gay se encontraba viajando por Chile la mayor parte del tiempo, fue labor de los miembros de la Comisión científica velar por el cuidado de las colecciones naturales que arribaron a Santiago y gestionar un espacio para su disposición definitiva. En este sentido, y contrariamente a lo que se ha señalado hasta ahora (Sanhueza, 2013: 201; 2016: 147-148; Schell, 2001: 46; Urizar, 2012: 216), la instalación y organización del Gabinete de Historia Natural que debía fundarse en el centro de la ciudad no fue una obra exclusiva del francés, sino el resultado de un trabajo colectivo característico del quehacer científico-natural en el Chile del 1830.

Considerado por la historiografía como pionero de las ciencias naturales modernas en el país y responsable de fundar el primer museo nacional, Claudio Gay ha sido ampliamente reconocido por los relevantes y amplios aportes que realizó en diversas ramas del conocimiento sobre Chile, especialmente en el estudio de la historia y naturaleza del país (Barros Arana, 1876; Stuardo Ortiz, 1973b; Vicuña Mackenna, 1873. Otros textos relevantes: Mizón, 2001, 2008; Sagredo, 2003, 2010; Sagredo \& Donoso, 2012). Lo anterior, en sintonía con una historia de la ciencia centrada en la figura del genio cuyos descubrimientos superaban las doctrinas contemporáneas del contexto en el que se desenvolvieron; $y$, al mismo tiempo, comulgando con una historia sobre museos y sus colecciones vinculada directamente con la biografía de sus fundadores y la empresa de formación y grandeza nacional (Podgorny \& Lopes, 2013). Así, atraídos por la figura de Gay y la monumentalidad de su obra escrita, titulada Historia física y política de Chile y que fue publicada en treinta volúmenes a partir del año 1842, los historiadores han 
prestado poca atención, en cambio, a una de las principales dimensiones de su actividad como naturalista: la formación de colecciones de historia natural.

Tomando distancia de esta historiografía y de la historia de la ciencia que privilegia las ideas o conceptos sobre las prácticas y los espacios de conocimiento(Biagioli, 1993; Livingstone, 2003; Shapin \& Schaffer, 1985), el siguiente trabajo tiene como objetivo dar cuenta del proceso de formación del Gabinete de Historia Natural de Santiago a partir de los actores involucrados en su gestión, de las negociaciones en torno a su instalación y de la infraestructura dispuesta para su funcionamiento, en sintonía con aquellos enfoques que privilegian las prácticas, lugares y las relaciones entre ciencia y sociedad. En este sentido, además del importante rol desempeñado por Claudio Gay, se ahondará en la labor encabezada en el acondicionamiento del gabinete por los integrantes de la comisión científica, Vicente Bustillos, Alejo Bezanilla y Francisco García Huidobro, así como también en el papel que cumplieron otros actores en la configuración de este espacio para el saber natural, como por ejemplo jornaleros, agentes de aduana o taxidermistas. Con esto se busca ampliar el entendimiento sobre la práctica naturalista que se desarrolló en el país, la cual tuvo una dimensión colectiva poco relevada por la historiografía de la ciencia sobre Chile.

\section{UN ESPACIO PARA EL SABER NATURAL EN CHILE}

«Deseo muy de veras que la reunión de todos estos objetos clasificados puesto en orden estimule algún día a la juventud chilena al estudio de la ciencia no menos útil por sus numerosas aplicaciones a todos los ramos de la sociedad que por los dulces y felices momentos que proporciona a todos los que se consagran a ella» (Gay, 1831 a s/n).

Con estas palabras Claudio Gay manifestó, al iniciar la década de 1830, sus aspiraciones respecto del gabinete de historia natural que organizaría en Santiago, concebido como un espacio destinado al almacenamiento, exhibición y estudio de ejemplares para el conocimiento natural del país. Acorde al concepto francés Cabinet 
d'histoire naturelle, utilizado para designar un espacio de exhibición de producciones naturales para el estudio o curiosidad (Dictionnaire de l'Académie Française. 1835), al momento de ofrecer sus servicios como naturalista al gobierno de Chile, Gay propuso establecer un gabinete que albergara «la mayor parte de las producciones de la República», el cual serviría tanto para la exhibición de dichos objetos como para el conocimiento de la naturaleza nacional (ANC, Min. del Interior, vol. 51, fs. 35v.). La inspiración de Gay procedía del Muséum d'Histoire naturelle de París, lugar donde recibió su formación como naturalista y del cual era naturalista corresponsal. Descrito a comienzos del siglo XIX como un depósito donde se acumulan las muestras de aquello que se encuentra en abundancia disperso por el mundo, el gabinete parisino reunía y desplegaba le Livre du Monde, a la razón del viejo proyecto enciclopedista (Cramer, Mercier, \& Pinkerton, n.d.). De igual manera que el establecimiento parisino, los objetos de la colección del Gabinete de Historia Natural a formarse en Santiago debían ser dispuestos y clasificados con sus nombres científicos y vulgares, indicándose además su lugar de procedencia (Gay, 1831b). Para Gay, el Gabinete de Historia Natural no debía ser un mero objeto de curiosidad, sino un espacio que ofreciera «esa utilidad y ese interés que hacen apreciar más la ciencia» (Stuardo Ortiz, 1973b, p. 114). Concebido entonces como un lugar consagrado al adelantamiento del conocimiento científico natural en base a colecciones de objetos de los tres reinos de la naturaleza (vegetal, animal y mineral), el gabinete debía también ser «útil a los progresos de una alta e ilustre civilización» como la chilena (Gay, 1831b, $\mathrm{s} / \mathrm{n})$. Para esto, el francés recomendaba situar el establecimiento en el centro de la ciudad, de manera que fuera accesible a «toda clase de personas para que puedan ir, sin muchas fatigas, a estudiar las plantas, los minerales, etc., que quieran conocer» (Gay, 1831b, s/n).

$\mathrm{Al}$ iniciarse el proyecto científico encabezado por Gay no existía un espacio asignado por las autoridades para instalar el proyectado gabinete. En consecuencia, se determinó utilizar la casa de uno de los integrantes de la comisión, Francisco García Huidobro, para guardar «los objetos que aquel individuo [Gay] le haya 
de remitir mientras dure su expedición» (Stuardo Ortiz, 1973, p. 251), así como los libros y colecciones personales del naturalista (ANC, Min. del Interior). Debieron pasar varios años para que las colecciones naturales abandonaran la casa de García Huidobro y pasaran a ser dispuestas en un lugar diseñado especialmente para su resguardo y exhibición. Los procedimientos que realizaba Claudio Gay a los ejemplares naturales durante el trabajo de campo eran provisorios, teniendo como objetivo hacerlos estables frenando su deterioro para que permanecieran en el mismo estado en que habían sido encontrados o cazados.

Una vez que los objetos naturales arribaban a la capital, estos debían ser sometidos a procesos de conservación, entendidos como un conjunto de operaciones técnicas y materiales que tenían como objetivo cuidar la permanencia y estabilizar la integridad de los especímenes naturales de potenciales daños, en orden de asegurar su supervivencia indefinida (Alberti, 2009). Por lo mismo, el cuidado y preparación de las colecciones preocupó a los miembros de la comisión científica, quienes no contaban con los conocimientos necesarios para montar adecuadamente los ejemplares ni aplicar medidas de conservación a los objetos naturales que iban llegando a la capital. Frente a esta situación, la comisión elevó un informe a las autoridades de gobierno manifestando que «se necesitan libros, instrumentos exactos, ojos para los animales y los pájaros, y sobre todo, una persona ejercitada en la taxidermia que ya estuviese montándolos» (ANC, Min. del Interior, vol. 315, fs. 444v.). Producto de la falta de implementos y de ayuda para la preparación de los especímenes en Santiago, en parte debido al rudimentario desarrollo de las ciencias en Chile, el gobierno respondió favorablemente a esta petición y en julio de 1831 autorizó la contratación de Pedro Martín, experto en taxidermia, para que colaborara con la preparación de las colecciones.

La poca información que existe sobre el trabajo desarrollado por Martín en la conservación de los especímenes zoológicos, así como en general de la labor llevada adelante por técnicos y trabajadores de museos y gabinetes, ha sido un problema recurrente en la historia 
de la ciencia que busca reconstruir el funcionamiento cotidiano de estas instituciones (Shapin, 1989; Alberti, 2008; Patchett, 2008; Robert McCracken, 2003). En el caso de Martín, su contratación además fue breve, interrumpiéndose en julio de 1832 con motivo del viaje que Gay emprendió a París en marzo de ese año (Stuardo Ortiz, 1973$)^{2}$. A pesar de la falta de registros que permitan reconstruir esta práctica durante las primeras décadas del siglo XIX, la contratación del taxidermista evidencia que existía en Chile un saber y quehacer relativos a la preservación de ejemplares animales. La necesidad de conservación de los especímenes recolectados y los requerimientos materiales y de infraestructura que surgieron -como por ejemplo la importación de instrumentos y artículos para ejecutar la taxidermia-, movilizaron objetos, conocimientos y prácticas al servicio del gabinete y sus colecciones naturales. Un ejemplo de esto fue el viaje que hizo Gay a París entre 1832 y 1834 para, entre otras cosas, adquirir diversos utensilios para el montaje de las colecciones del gabinete en Santiago (Sesiones de los cuerpos legislativos. Tomo $X I X, 1898)^{3}$. En virtud de esto, la colaboración de Martín muestra que la empresa científico-natural involucró a personas con intereses y conocimientos diversos que aportaron a la configuración de un lugar para el saber natural en el país.

\section{Un lugar Para El Saber natural en Chile}

Con el paso de los años, y en la medida que las colecciones naturales comenzaron a acumularse en la casa de García Huidobro, se hizo indispensable gestionar un lugar especialmente acondicionado para albergar y exhibir los objetos de historia natural. Nuevamente, la principal preocupación de la comisión tenía que ver con el deterioro que podrían sufrir los objetos naturales si se mantenían en cajas ya que, por ejemplo, podrían destruirlos las polillas (ANC, Min. del Interior). Al advertir la urgencia de comenzar a construir estantes donde disponer los ejemplares, los integrantes de la comisión

ANC, Min. de Justicia, vol. 29, fs. 42.

ANC, Min. del Interior, vol. 315, fs. 446-447v 
instaron a las autoridades a agilizar los trámites para la asignación de un espacio donde emplazar definitivamente el gabinete, jugando un rol clave en el destino de este establecimiento (ANC, Min. del Interior).

En Chile, así como en otros países del continente, la capacidad de negociación de los hombres de ciencias para obtener financiamiento y respaldo estatal fue un elemento clave en el quehacer científico nacional y que perduró en el tiempo, evidenciando la importancia de las redes de colaboración y el carácter colectivo de la práctica científico-natural (Podgorny \& Lopes, 2008; Lopes, 2013). A pesar del entusiasmo manifestado por las autoridades sobre la organización de un espacio dedicado al estudio y fomento de las ciencias naturales en base a la reunión de colecciones de historia natural en el país, las múltiples negociaciones y gestiones que encabezaron los miembros de la comisión científica para que se destinase un lugar donde albergar los objetos muestran hasta qué punto el fomento de la ciencia era prioridad frente al aún frágil estado de la política y economía chilena (Collier \& Sater, 1999). Esto no quiere decir que la ciencia no fue igualmente útil para la construcción del Estado y para el fortalecimiento de la soberanía nacional. Por el contrario, gran parte del impulso público al desarrollo científico estuvo orientado precisamente como medio e instrumento para integrar regiones, definir las fronteras nacionales y conocer especies y recursos naturales que aportaran al progreso del país (Sagredo, 2017). En este panorama, las negociaciones en torno a la instalación del gabinete muestran las complejidades del proceso de valorización del saber natural en Chile durante la década de 1830 entre las autoridades y la élite local.

Así, luego de seis años de formalizada la contratación de Claudio Gay por parte del Gobierno de Chile, recién a mediados de 1836 se dieron los primeros pasos para el establecimiento de un lugar físico donde emplazar el gabinete. Para esto, el gobierno consideró que podía destinar un espacio para su construcción al costado este del Instituto Nacional, «ocupados ahora por paredes ruinosas», que servía como cuartel de serenos del establecimiento educacional (Sesiones de los cuerpos legislativos. Tomo XXV, 1903, p.167). El 
futuro edificio estaría ubicado en la esquina sur poniente de las calles Bandera con Catedral y albergaría también a la Biblioteca Nacional y a los Tribunales de Justicia, los cuales funcionarían en aquel inmueble hasta su traslado en el año 1845 a una nueva ubicación. De esta manera, el proyectado gabinete quedaría emplazado en el centro de la capital, a solo dos cuadras de la plaza de Armas, tal y como había recomendado Claudio Gay en un comienzo para procurar el fácil acceso de los futuros visitantes al establecimiento (Gay, 1831b). Además de los elementos prácticos esgrimidos por el francés, en términos simbólicos la centralidad de la ubicación del establecimiento y su cercanía con algunas de las principales instituciones públicas de la época, muestran el valor asignado a este espacio científico al momento de su construcción y el posicionamiento de la ciencia en el epicentro de la vida urbana.

En julio del mismo año, se solicitó verbalmente un presupuesto para la construcción del inmueble a un señor llamado Francisco Reclus, proyecto que fue sometido a evaluación del Sargento Mayor de Ingenieros, José Antonio Guilisasti. En su informe del 19 de julio de 1836, Guilisasti hizo algunas recomendaciones respecto de los materiales para la construcción y de las terminaciones que debían realizarse para finalizar la obra, concluyendo que era poco probable que el edificio estuviera terminado en marzo de 1837, fecha estimada por el constructor (Stuardo Ortiz, 1973) ${ }^{4}$. A finales del mes de agosto de 1836, el Congreso Nacional aprobó el presupuesto para la ejecución de las obras (Sesiones de los cuerpos legislativos. Tomo $X X I V, 1902)$, las cuales se iniciaron recién en octubre de 1837 bajo la dirección de Andrés Antonio Gorbea, ingeniero español y profesor del Instituto Nacional (Stuardo Ortiz, 1973).

A pesar de la atenta preocupación y de la gestión realizada por los integrantes de la comisión, la construcción del edificio demoró más de lo estimado, terminándose parcialmente hacia finales del año 1838. Entonces se trasladó al nuevo inmueble la Biblioteca Nacional, abriendo al público en enero de 1839, tal como informó su director Francisco García Huidobro, también miembro de la

4 ANC, Min. del Interior, vol. 164, s/n. 
comisión científica (ANC, Min. de Justicia). Respecto del gabinete, aún faltaba para que el acondicionamiento del espacio estuviera finalizado (Stuardo Ortiz, 1973).

\section{El acondicionamiento Del Gabinete}

La sala donde debía organizarse el gabinete, ubicada en el segundo piso del inmueble, era más bien austera, sobre todo en comparación con la arquitectura monumental desarrollada en Europa asociada a la construcción de los museos de historia natural durante el siglo XIX (Sheets-Pyenson, 1987; Yanni, 1999). En este sentido, la infraestructura para la instalación del gabinete fue reflejo de los recursos disponibles en la época, debiendo compartir espacio con otras divisiones de la administración pública. Sin embargo, considerando que las circunstancias físicas, junto con las sociales y culturales, determinaron la forma, sentido y dominios de producción del conocimiento natural, el espacio físico asignado para la instalación del gabinete y la infraestructura para la disposición de las colecciones también revelan la estimación de la ciencia en el Chile de la primera mitad del siglo XIX (Ophir \& Shapin, 1991).

A mediados de 1839, el lugar donde debía ubicarse el Gabinete de Historia Natural estaba dotado con algunos estantes para acondicionar los objetos naturales, los cuales eran insuficientes para disponer el total de las colecciones reunidas hasta ese momento (ANC, Min. de Justicia). Ante esto, nuevamente fue tarea de la comisión buscar soluciones con el gobierno. Al respecto, el 17 de abril sus miembros enviaron una nota a las autoridades manifestando que, habiendo concluido la construcción del edificio, se necesitaban nuevos recursos para terminar de dotar de infraestructura a la habitación donde debían ubicarse los especímenes recolectados por Claudio Gay. El informe continuaba: «se necesita por ahora mandar se construyan por lo menos algunos estantes, que se calcula el número de quince y con este objeto se acompaña el presupuesto del artista que se ha encontrado los hace más baratos» (ANC, Min. de Justicia, vol. 29, s/n). 
El gobierno respondió a esta solicitud a la brevedad, aprobando los fondos para la construcción de los nuevos estantes. Para su ejecución se contrató al carpintero José del Tránsito Cárdenas, quien fabricó el mobiliario de la siguiente manera: los costados y fondos de las repisas las hizo con madera de alerce, las divisiones y armazones con laurel, mientras que las puertas y las cornisas las ejecutó en cedro (ANC, Min. de Justicia). Junto al material de los muebles, la comisión se preocupó también que su diseño armonizara con la infraestructura ya dispuesta en la sala, solicitando a Cárdenas que los estantes guardaran «una extrema exactitud en imitar los que ya existen en dicho gabinete» (ANC, Min. de Justicia, vol. 29, s/n).

Siguiendo con los arreglos en el mobiliario, en junio del mismo año Gay pidió al gobierno nuevos recursos, esta vez para la confección de cajones entomológicos para el arreglo de las colecciones de insectos. Para esto, recomendó al gobierno la adquisición de "palos de balsa de Guayaquil de los que suelen usar los pescadores de Valparaíso» (ANC, Min. de Justicia, vol. 29, s/n), ya que la naturaleza blanda de este tipo de madera permitiría que los insectos fuesen fijados sin dificultad con alfileres en el fondo de los cajones.

Además de lo anterior, el gabinete recibió la donación de parte de particulares de algunos materiales para la disposición y preparación de las colecciones, como por ejemplo fardos de papel para la realización de herbarios y un barril de alcohol para la conservación de ejemplares naturales (ANC, Min. de Educación). Este último fue donado por Carlos Segeth, doctor alemán y colector para el Museum für Naturkunde de Berlín, quien a su arribo a Chile en 1838 decidió renunciar a las incomodidades propias de la vida del recolector de especímenes para dedicarse a ejercer como médico (Anrique, 1901; Cubillos, 2002; Schell, 2013). La donación de utensilios al gabinete por Segeth debió de corresponder al material que utilizaba en su actividad como colector, quehacer que no abandonó por completo y que lo mantuvo estrechamente vinculado a la incipiente comunidad de la historia natural en Chile, ya fuese mediante la donación de colecciones o recomendando personas para asistir a las futuras actividades del establecimiento (Schell, 2013). No obstante, la escasa 
información que existe sobre estos actores, la donación de implementos para el funcionamiento del gabinete muestra, nuevamente, la participación de particulares en la empresa naturalista en el país, quienes, junto a las autoridades, miembros de la comisión científica, funcionarios públicos, maestros y carpinteros, colaboraron en la instauración de este espacio para el conocimiento natural en Santiago.

A pesar de estos avances, el acondicionamiento de la habitación donde se emplazaría el gabinete fue más lento de lo planificado. La recepción de los estantes, programada para el mes de mayo de 1839, se hizo finalmente en octubre (ANC, Min. de Justicia). Por su parte, los materiales donados, como el papel para la elaboración de herbarios y barril de alcohol para la conservación de los ejemplares naturales, fueron entregados en mayo de 1840 (ANC, Min. de Justicia). Frente a esta demora era poco lo que Claudio Gay podía hacer para acelerar la instalación de las colecciones (Barros Arana, 1876; Philippi, 1908; Stuardo Ortiz, 1973 ). Imposibilitado de trabajar en el arreglo del gabinete hasta la finalización de la construcción de los estantes, el primero de julio de 1839 abandonó nuevamente la capital esta vez con destino a Perú. Gay permaneció más de un año en el país vecino producto de este viaje, motivado por el encargo que le hizo Mariano Egaña, ministro de Justicia, Culto e Instrucción Pública, para escribir una historia política de Chile (Stuardo Ortiz, 1973). A pesar de la prolongada ausencia del naturalista en Santiago, las autoridades veían con buenos ojos el progreso del gabinete. Y así lo destacó el ministro Egaña en la memoria que presentó en agosto de 1839 ante el Congreso Nacional. Junto con anunciar la finalización del edificio, mandado a construir en 1836, agregó que «están ya trasladados en parte el Museo y Gabinete de Historia Natural» (Sesiones de los cuerpos legislativos. Tomo XXVI, 1905, 402). Tal y como constató el ministro, la formación del gabinete avanzaba, aunque su instalación y arreglo definitivos quedaron pendientes hasta el regreso de Claudio Gay a Chile.

Durante la estadía de Gay en el extranjero, los miembros de la comisión científica quedaron nuevamente a cargo del adelantamiento del establecimiento. Así, por ejemplo, junto con tramitar el envío de 
materiales y colecciones naturales desde Valparaíso hacia Santiago, se preocuparon también de ultimar los detalles para que la sala quedara completamente dispuesta para que, cuando Gay retornara a Chile, él terminase de ordenar las colecciones de historia natural. Y así quedó expresado en una carta remitida por Vicente Bustillos, a nombre de la Comisión, al ministro Egaña en mayo de 1840:

Con la llegada del Señor Gay se debe comenzar a trabajar en el establecimiento y se deben hacer varios gastos de suma necesidad; como son la compra de unas esteras, la construcción de unos cajoncitos para colocar los insectos, la preparación de unas tablitas para los objetos de conquiliología, pagar un escribiente para escribir las tarjetas, asear las piezas, etc., etc.

En julio de 1840, el gobierno aprobó nuevos fondos para «la formación y amueblamiento del Museo y Gabinete de Historia Natural» (ANC, Min. de Justicia, vol. 29, $\mathrm{n}^{\circ}$ 62), coincidiendo con el regreso de Claudio Gay al país. El 17 de agosto el ministro Mariano Egaña reportó sobre las actividades del naturalista en la capital, señalando que «concluido el viaje científico de la República, se halla el ilustrado viajero ocupado en concluir la organización y colocación del Museo y Gabinete de Historia Natural, con cuya tarea debe dar fin a su comisión» (Sesiones de los cuerpos legislativos. Tomo XXVII, 1903, p. 173). Como queda de manifiesto en la cita anterior, con el arreglo definitivo de las colecciones naturales en el gabinete se pondría término a la tarea científica encomendada a Gay por el gobierno de Chile a finales de 1830. De esta manera, entre agosto de 1840 y septiembre de 1841 el naturalista se abocó casi por completo a dar orden a las colecciones en la sala especialmente acondicionada para el funcionamiento de este nuevo establecimiento científico.

Hacia mediados del año 1841 los avances en la puesta en marcha del gabinete eran considerables, como anunció al Congreso Nacional Manuel Montt, nuevo ministro de Justicia, Culto e Instrucción Pública:

Me es grato decir a la Cámara que el benemérito naturalista, a quien encomendó el gobierno once años ha, el viaje científico de la República, ha coronado sus interesantes 
tareas con la formación de un Museo Nacional, en donde se encuentra ya reunida una rica colección de objetos indígenas y extranjeros. (Sesiones de los cuerpos legislativos. Tomo XXVII, 1903, pp. 333-334).

No obstante estas declaraciones, la preparación de las colecciones del gabinete no estuvo exenta de dificultades. Durante el arreglo de los objetos de historia natural quedó en evidencia la falta de experiencia y conocimientos del francés en el manejo de algunos especímenes naturales, particularmente aquellos pertenecientes al reino animal. Para subsanar lo anterior, a comienzos de 1841 el naturalista había solicitado a las autoridades la contratación de manos auxiliares que lo asistieran en el montaje de los objetos de historia natural. Reconociendo que la iniciativa científica encabezada por Gay sobrepasaba las aptitudes y conocimientos de un individuo, el gobierno contrató a Bernardino Cortés, quien trabajó disecando y preparando «doscientos pájaros y cuadrúpedos para el gabinete de Historia Natural» (ANC, Min. de Educación, vol. 4, fs. 62). La ayuda de Cortés en la empresa naturalista no era nueva, ya que al parecer habría acompañado a Claudio Gay como colaborador en algunas de sus expediciones por el país. Junto con asistirle en diversas tareas propias del trabajo de campo, y dado que «entendía algo del modo de sacar los cueros de las aves», ayudó también en la disección de los ejemplares animales recolectados en terreno. Con el paso del tiempo, Bernardino sería contratado como disector y asistente del Gabinete de Historia Natural, pasando a formar parte del personal del establecimiento hasta su muerte a comienzos de la década de 1860 (Philippi, 1908).

Los arreglos finales de las colecciones naturales para la puesta en marcha del gabinete, junto a otras preocupaciones y requerimientos del gobierno, hicieron que Gay permaneciera en la capital hasta noviembre de 1841 (Stuardo Ortiz, 1973). En una carta enviada en agosto de ese año a Ignacio Domeyko, científico polaco avecindado en la ciudad de Coquimbo, el francés le señaló que, a pesar de su gran deseo de volver a Francia, se había visto detenido por otros trabajos y muy particularmente por el Gabinete de Historia 
Natural (Feliú Cruz \& Stuardo Ortiz, 1962). Finalmente, en una nueva misiva fechada el 11 de septiembre Claudio Gay le comunicaba a Domeyko que sus «trabajos en el Museo están totalmente terminados (...) de manera que nada pueda detenerme en Chile» (Feliú Cruz \& Stuardo Ortiz, 1962, p. 32), informando sobre el término de su estadía en Chile.

\section{El retorno de Claudio Gay a Francia}

Concluidos los arreglos del gabinete, en noviembre de 1841, Claudio Gay emprendió un último viaje por el país con el objetivo de recorrer el extremo norte del territorio (Stuardo Ortiz, 1973). De regreso en la capital en enero de 1842, su partida a Francia se hizo inminente. La comisión científica encomendada por el gobierno al naturalista había llegado a su término, por lo menos en lo relativo a la exploración y estudio in situ del territorio y naturaleza nacional, y a la recolección y organización de una colección de especímenes naturales representativos de Chile.

Antes de partir, Gay hizo devolución de todos aquellos elementos que facilitaron sus trabajos en Chile y que eran propiedad del Estado. De esta manera, dejó depositados en el gabinete los instrumentos científicos que utilizó para realizar sus investigaciones en el país, así como implementos para la preparación de las colecciones naturales, los cuales servirían al futuro quehacer científico del establecimiento (ANC, Min. de Justicia, ANC, Min. de Educación). Entre los materiales para el montaje y conservación de los especímenes, se encontraban:

- Varios frasquitos de diversos tamaños con reactivos de cuyo estado no me he podido asegurar aún.

- Varios rollos de alambre de yeso delgado de diversos grosores para armar pájaros (...).

- Un paquete de arsénico

- Más de 150 piececitos de madera para montar pájaros. 
- Otros varios útiles de poca monta de que daré razón si fuese necesario(ANC, Min. de Justicia)

Al haber entregado instrumentos científicos, libros e implementos para las colecciones del gabinete, el naturalista partió rumbo a Valparaíso, desde donde se embarcó con destino a Europa. Días antes de abandonar el puerto, Gay expresó el gran sentimiento que le producía alejarse de un país que desde hace mucho tiempo había considerado como una segunda patria en una carta remitida al ministro Montt. Junto a esto, el naturalista agregó:

Por ahora me bastará encomendarle encarecidamente el Museo de Santiago que considero como el objeto más notable de mi feliz tránsito por esta República. Aunque sea muy nuevo y el gobierno no cuente más que el costo de los estantes, sin embargo, puedo asegurarle que no sería despreciado en muchas grandes ciudades de Europa y que no se encontraría uno igual en ninguna de las repúblicas españolas (Feliú Cruz \& Stuardo Ortiz, 1962).

El francés consideraba que el establecimiento recién creado para el saber científico natural hacía honor al país. Por lo mismo, junto con hacer notar al gobierno respecto de la atención y cuidado que requería el gabinete, se comprometió a continuar enriqueciendo las colecciones de la institución con nuevos envíos de objetos naturales y utensilios desde Francia. De esta manera, en adelante, el naturalista continuó colaborando con la organización del gabinete, sirviendo como agente en Francia del Gobierno de Chile para la adquisición de utensilios y objetos naturales para este establecimiento (ANC, Min. de Justicia).

A finales del mes de junio de 1842, Gay se embarcó definitivamente con destino al viejo continente, finalizando las investigaciones científicas de campo que durante once años desempeñó para el gobierno sobre Chile. De regreso en París, Claudio Gay se abocó íntegramente a investigar sobre la historia, producciones y fenómenos naturales chilenos, reemplazando los viajes y las observaciones directas de la naturaleza por el estudio de gabinete, al igual que muchos de los naturalistas viajeros europeos de la primera mitad del siglo 
XIX que en su juventud se aventuraron a recorrer territorios poco explorados. Gay retornaría una vez más a Chile en marzo de 1863, oportunidad en la cual el naturalista visitó diferentes establecimientos públicos y educacionales de la capital, además de participar en ceremonias y premiaciones. Junto a esto, Gay emprendió algunos viajes por el Chile central, especialmente las regiones de Aconcagua, Concepción y la Araucanía (Stuardo Ortiz, 1973).

\section{De gabinete a Museo Nacional}

El establecimiento del Gabinete de Historia Natural de Santiago durante la década de 1830 quedó como huella material del paso de Gay por Chile. Su fundación fue resultado del quehacer colectivo encabezado por el naturalista, los integrantes de la comisión científica y colaboradores de este proyecto, que aportaría al proceso de institucionalización de la historia natural en Chile. En este sentido, y al igual que varios países de la región que inauguraron museos durante la primera mitad del siglo XIX, el gabinete no solo puso a prueba la cultura científica del país, sino que terminaría convirtiéndose en un símbolo de la identidad nacional (Lopes \& Podgorny, 2000).

Una vez que el naturalista abandonó Chile con destino a Europa, la dirección y administración del establecimiento quedó en manos de Francisco García Huidobro, quien venía colaborando activamente en la configuración de este espacio destinado al saber natural, como miembro de la comisión científica. Junto con esto, tras la partida del francés se producirían otras modificaciones. Concebido el gabinete en un comienzo como un espacio que serviría tanto para el desarrollo del conocimiento científico natural en Chile y para el adelantamiento del país mediante el fomento de sus industrias, durante su instalación y acondicionamiento se produjeron transformaciones que redefinieron el proyecto inicial formulado por Gay, siendo adaptado y resignificado por los actores locales involucrados en su organización. Un ejemplo de lo anterior se manifestó en la ampliación del tipo de colecciones que albergó dicha entidad. Así, en un inventario elaborado por el nuevo director del gabinete en 
enero de 1843, García Huidobro detalló algunos de implementos y objetos de la institución, entre los cuales señaló:

- Cuarenta y dos búcaros de greda de diversas formas, fabricadas por los indios y traídos del Perú.

- Una escopeta de dos cañones.

- Tres tarros de fósforos.

- Una espada que se supone fue de los conquistadores.

- Una coraza de cuero de los indios.

- Una lanza de los indios.

- Cinco flechas de los mismos.

- Ocho peces disecados.

- Un cajón de objetos de historia natural duplicadas.

- Una moneda de plata, de la República de Génova, de valor de un peso fuerte.

- Una medalla de plata, de las concedidas a los vencedores en Maipú.

Como queda de manifiesto, el documento hace referencia a una serie de artículos que poco tenían que ver con una colección de historia natural, como por ejemplo documentos, armas, medallas, monedas y artefactos indígenas ${ }^{5}$. La presencia en el gabinete de artefactos evidencia profundas transformaciones en la naturaleza de las colecciones de la institución, no necesariamente por el tipo de objetos, ya que desde el siglo XVIII fue común que artefactos e instrumentos de diversa índole y procedencias fueran exhibidos junto a ejemplares naturales (Kohl, Podgorny, \& Gänger, 2014), sino porque en las fuentes disponibles respecto del proyecto científico encabezado por Claudio Gay hasta ese momento, no habían referencias a la recopilación o adquisición de artefactos. En adelante, el gabinete serviría no solo para el resguardo y exhibición de especímenes naturales, sino como lugar de depósito y conservación

5 Se entiende por artefacto aquellos objetos que son creados o producidos intencionalmente por el hombre para un fin determinado. Además, en general, se contrasta con los objetos naturales que no son creados por los seres humanos (Rudder Baker, 2004). 
de una amplia variedad de objetos cuyo valor radicaba en la antigüedad, singularidad o importancia histórica o cultural. Así, quien visitara este establecimiento en 1842 encontraría el primer herbario de especies chilenas creado por el botánico italiano Carlos Bertero, un catálogo de maderas reunidas por las autoridades provinciales en el sur del país, minerales remitidos por Ignacio Domeyko, pero también una momia humana de Perú, artefactos indígenas donados por privados, e inclusive el arma con que se había dado muerte a Diego Portales, exministro de Chile.

La diversidad de las colecciones del museo al momento de su apertura fue reflejo de las transformaciones que operaron en la resignificación de este espacio, inicialmente destinado para el saber natural, pero que hacia 1842 perseguía nuevos objetivos y encarnaba renovados significados. Por lo mismo, si bien a primera vista esta transformación en el carácter de las colecciones podría interpretarse como resultado de una necesidad práctica o administrativa, la de almacenar colecciones que no pertenecían al universo natural y que no tenían una institución a cargo de su resguardo, en realidad refleja un cambio más profundo relativo a la definición epistemológica del establecimiento.

A la par del cambio en la naturaleza de las colecciones que albergó esta institución, se produjo también una transformación relativa a la denominación asignada a este espacio. Ya en el año 1836, con motivo de la aprobación del presupuesto en el Congreso Nacional para la construcción del edificio donde se instalaría el gabinete, aparece por primera vez la palabra museo para designar al establecimiento que debía ubicarse en dicho inmueble (respecto del concepto de museo ver: Findlen, 1996, pp. 73-74) ${ }^{6}$. En adelante, y cada vez con mayor frecuencia, esta denominación apareció indistintamente junto a la de gabinete en la mayoría de los registros relativos a la organización del establecimiento que Claudio Gay, ayudado por los miembros de

$6 \quad$ En la glosa correspondiente de la ley de presupuesto del Departamento del Interior y Relaciones Exteriores para el año 1837, discutida en el congreso a mediados de 1836, se menciona que dicha edificación alojaría «la biblioteca y museo». (Sesiones de los cuerpos legislativos. Tomo XXIV, 1902, p. 311) 
la comisión científica, debía formar en la capital' ${ }^{7}$ El cambio en la denominación del establecimiento respondió, en parte, a un contexto más general, relativo al paulatino desuso del concepto de gabinete y la proliferación de museos de historia natural en las principales ciudades del mundo occidental a partir del 1800 (Hooper Greenhill, 2003; Lawrence, 2000. Sobre el cambio de gabinetes a museos, ver: Daston \& Park, 2012; Preziosi \& Farago, 2004). En sintonía con este escenario, hacia 1842 dejaría de utilizarse la denominación de gabinete en Chile, siendo reemplazado, en cambio, por diferentes apelativos para nombrar la iniciativa dirigida por Gay, incluyendo al ya mencionado Museo de Santiago, los de Museo de Historia Natural, Museo de Chile y Museo Nacional, siendo este último el más recurrente (ANC, Min. de Justicia).

De alguna manera la noción de gabinete, gestado gracias al ejercicio de coleccionismo de historia natural ideado y encabezado por Gay desde 1830, dejó de ser útil para representar lo que la comunidad de chilenos a cargo de su administración concibió sobre este espacio al inicio de la década de 1840. Transcurridos doce años desde la propuesta formulada por Gay relativa a la organización de una colección de historia natural, la realidad de Chile hacia 1842 era diferente. En este sentido, la modificación del nombre del establecimiento no es un hecho trivial. El reemplazo de la palabra gabinete por el concepto de museo evidencia un proceso más profundo de redefinición del sentido y orientación de este espacio erigido inicialmente para la producción de conocimiento natural sobre el país, que en adelante se concibió como un espacio de mayor envergadura, dedicado a albergar las huellas materiales de la nación en su conjunto, incluyendo la naturaleza, cultura e historia del país.

\footnotetext{
El concepto de gabinete se había utilizado en Chile a comienzos del siglo XIX con motivo de la formación del gabinete de Historia Natural de la Academia de San Luis. El término museo, en cambio, surgió primeramente con motivo de la creación del Instituto Nacional en 1813 y posteriormente con la comisión encargada a Dauxión Lavaysse de fundar un museo en 1822.
} 


\section{Conclusiones}

El estudio de la puesta en marcha del Gabinete de Historia Natural de Santiago permite ampliar el entendimiento de la práctica naturalista que tuvo lugar en el país en la primera mitad del siglo XIX, mostrando la centralidad que tuvo la formación de colecciones de historia natural en la empresa científica encabezada por Claudio Gay. Asimismo, el análisis de los procesos y actores que posibilitaron la formación del gabinete aporta a un mejor entendimiento de lo que posibilitó la institucionalización de la ciencia en el país. Al respecto, si bien este proceso fue impulsado desde el Estado, en la medida que aportó con financiamiento, instituciones y empleados públicos para la recolección de objetos y establecimiento del gabinete, este no se entiende sin la participación del heterogéneo grupo de actores que, como se vio a lo largo de este trabajo, colaboró de maneras diversas.

$\mathrm{Al}$ indagar en el proceso de acondicionamiento del inmueble para la disposición de los objetos reunidos por Gay, queda de manifiesto la ayuda aportada por diferentes personas que asistieron en la recolección, traslado y preparación de los ejemplares naturales, y que donaron utensilios para el establecimiento y sus colecciones, evidenciando, en último término, el carácter colectivo de la empresa naturalista del Chile del 1830. En este sentido fue clave el rol jugado por los integrantes de la comisión científica, quienes sirvieron como mediadores entre el gobierno y el científico francés y su amplia red de colaboradores. De igual manera, la existencia de sujetos con experiencia y conocimientos en taxidermia posibilitó la preparación, conservación y montaje de los ejemplares naturales dispuestos en el gabinete.

La ampliación del tipo de colecciones y el cambio de denominación de gabinete a museo evidencia la adaptación y resignificación que experimentó este espacio por parte de los actores locales, que se manifestó de manera más evidente tras el regreso de Claudio Gay a Francia. El estudio de la conformación del gabinete y sus transformaciones cristaliza la dimensión colectiva de esta iniciativa científica, al mismo tiempo que permite un mejor entendimiento del proceso de institucionalización de la ciencia en el país durante la primera mitad del siglo XIX y los alcances del conocimiento natural sobre Chile. 
Fuentes primarias manuscritas

ANC, Min. de Educación, vol. 4, fs. 45.

ANC, Min. de Educación, vol. 4, fs. 62.

ANC, Min. de Educación, vol. 4, fs. 65v.

ANC, Min. del Interior, vol. 51, fs. 35v.

ANC, Min. del Interior, vol. 51, fs. 36v.

ANC, Min. del Interior, vol. 51, fs. 39v.

ANC, Min. del Interior, vol. 164, s/n.

ANC, Min. del Interior, vol. 315, fs. 444v-445.

ANC, Min. del Interior, vol. 315, fs. 446-447v

ANC, Min. de Justicia, vol. 29, s/n.

ANC, Min. de Justicia, vol. 29, s/n.

ANC, Min. de Justicia, vol. 29, s/n.

ANC, Min. de Justicia, vol. 29, s/n.

ANC, Min. de Justicia, vol. 29, s/n.

ANC, Min. de Justicia, vol. 29, s/n.

ANC, Min. de Justicia, vol. 29, s/n.

ANC, Min. de Justicia, vol. 29, s/n.

ANC, Min. de Justicia, vol. 29, s/n.

ANC, Min. de Justicia, vol. 29, s/n.

ANC, Min. de Justicia, vol. 29, s/n.

ANC, Min. de Justicia, vol. 29, fs. 42.

ANC, Min. de Justicia, vol. 29, no 57.

ANC, Min. de Justicia, vol. 29, $\mathrm{n}^{\circ} 61$.

ANC, Min. de Justicia, vol. 29, $\mathrm{n}^{\circ} 62$.

ANC, Min. de Justicia, vol. 59, s/n.

ANC, Min. de Justicia, vol. 59, $\mathrm{n}^{\circ} 38$.

\section{BibLIOGRAFÍA}

Alberti, S. J. M. M. (2009). Nature and culture. Objects, disciplines and the Manchester Museum. (P. Kohl, I. Podgorny, \& S. Gänger, Eds.). Nueva York: Manchester University Press.

Anrique, N. (1901). «La Goleta de Guerra Ancud». Anales de La Universidad de Chile, 108, 931-985. 
Barros Arana, D. (1876). Don Claudio Gay, su vida i sus obras: Estudio biográfico i crítico. Santiago: Imprenta Cervantes.

Biagioli, M. (1993). Galileo Courtier: The Practice of Science in the Culture of Absolutism. Chicago: University of Chicago Press.

Collier, S., \& Sater, W. (1999). Historia de Chile. 1808-1994. Madrid: Cambridge University Press.

Cramer, K. F., Mercier, L.-S., \& Pinkerton, J. (n.d.). Ansichten der Hauptstadt des französischen Kaiserreichs vom Jahre 1806 an. Vol. II. Amsterdam: Kunst- und Industrie-Comptoir.

Cubillos, L. (2002). «Epistolario de Alexander Von Humboldt con personajes vinculados a Chile». Revista Universum, 17.

Daston, L., \& Park, K. (2012). Wonders and the Order of Nature: 11501750. Nueva York: Zone Books.

Dictionnaire de l'Académie Française. Gème édition. (1835). París: Imprimerie et Librairie de Firmin Didot Frères.

Feliú Cruz, G., \& Stuardo Ortiz, C. (1962). Correspondencia de Claudio Gay. Santiago: Ediciones de la Biblioteca Nacional.

Findlen, P. (1996). Possessing Nature. Museums, Collecting, and Scientific Culture in Early Modern Italy. Berkeley: University of California Press.

Gay, C. (1831a). «Viaje científico. Segundo informe sobre sus exploraciones en la provincia de Colchagua». El Araucano, s/n. May 14.

Gay, C. (1831b). «Sobre la utilidad de un curso especial de química aplicado a la industria y a la agricultura». El Araucano, s/n. Jul 30.

Gay, C. (1836). No Title. El Araucano, s/n.Jul 8.

Hooper Greenhill, E. (2003). Museums and the Shaping of Knowledge. Nueva York: Routledge.

Kohl, P. L., Podgorny, I., \& Gänger, S. (Eds.). (2014). Nature and Antiquities. The Making of Archaeology in the Americas. Tucson: The University of Arizona Press.

Lacour, P.-Y. (2013). «El gran depósito de la naturaleza. El Muséum Nacional de historia Natural de París hacia 1800». In M. Achim \& I. Podgorny (Eds.), Museos al detalle. Colecciones, antigüedades e historia natural, 1790-1870 (pp. 27-49). Rosario: Prohistoria ediciones.27-49.

Lawrence, P. (2000). Finding Order in Nature. The Naturalist Tradition from Linnaeus to E. O. Wilson. Baltimore: The Johns Hopkins University Press.

Livingstone, D. N. (2003). Putting Science in its Place. Geographies of Scientific Knowledge. Chicago: University of Chicago Press.

Lopes, M. M., \& Podgorny, I. (2000). «The Shaping of Latin American Museums of Natural History: 1850-1990». Osiris, 15, 108-118. 
Ophir, A., \& Shapin, S. (1991). «The Place of Knowledge: A Methodological Survey». Science in Context, 4(1), 3-22.

Philippi, R. A. (1908). Historia del Museo Nacional. Boletín Del Museo Nacional de Chile, 1(1), 4-30.

Podgorny, I., \& Lopes, M. M. (2008). El desierto en una vitrina, Museos e historia natural en la Argentina del Siglo XIX. Dc. México: Limusa.

Podgorny, I., \& Lopes, M. M. (2013). «Trayectorias y desafíos de la historiografía de los museos de historia natural en América Del Sur». Anais Do Museu Paulista: História e Cultura ..., 21(1), 15-25.

Preziosi, D., \& Farago, C. (Eds.). (2004). Grasping the World: The Idea of the Museum. Burlingtone: Ashgate.

Rudder Baker, L. (2004). "The ontology of artifacts». Philosophical Explorations, 7(2), 99-112.

Sagredo, R. (2017). "Ciencia, estado, territorio y soberanía en el siglo XIX». In I. Jaksic \& F. Rengifo (Eds.), Historia política de Chile, 1810-2010. Tomo II. Estado y Sociedad. Santiago: Fondo de Cultura Económica, 139-172.

Sanhueza, C. (2013). «El gabinete de Historia Natural de Santiago de Chile (1823-1853)». En Museos al detalle. Colecciones, antigüedades e historia natural, 1790-1870. Rosario: Prohistoria ediciones, 201-218. Sanhueza, C. (2016). "Objetos en movimiento. Acerca de la formación de las colecciones del Museo Nacional de Chile (1853-1897)». Revista de Humanidades, 34, 143-169.

Schell, P. (2001). Capturing Chile: Santiago's Museo Nacional during the Nineteenth Century. Journal of Latin American Cultural Studies, 10(1). Web. <https://doi.org/10.1080/13569320020030042>

Schell, P. (2013). The Sociable Sciences. Darwin and His Contemporaries in Chile. Nueva York: Palgrave Macmillan.

Sesiones de los cuerpos legislativos. Tomo XIX. (1898). Santiago: Imprenta Cervantes.

Sesiones de los cuerpos legislativos. Tomo XXIV. (1902). Santiago: Imprenta Cervantes.

Sesiones de los cuerpos legislativos. Tomo XXV. Santiago: Imprenta Cervantes.

Sesiones de los cuerpos legislativos. Tomo XXVI. (1905). Santiago: Imprenta Cervantes.

Sesiones de los cuerpos legislativos. Tomo XXVII. (1903). Santiago: Imprenta Cervantes.

Shapin, S. (1989). «The Invisible Technician». American Scientist, 77(6), $554-563$.

Shapin, S., \& Schaffer, S. (1985). Leviathan and the Air-Pump: Hobbes, Boyle and the Experimental Life. Princeton: Princeton University Press. 
Sheets-Pyenson, S. (1987). "Cathedrals of Science: The Development of Colonial Natural History Museums During the Late Nineteenth Century». History of Science, 25(3), 279-300.

Stuardo Ortiz, C. (1973a). Vida de Claudio Gay, 1808-1873. Tomo I. Santiago: Fondo Histórico y Bibliográfico José Toribio Medina y Editorial Nacimiento.

Stuardo Ortiz, C. (1973b). Vida de Claudio Gay, 1808-1873. Tomo I y II. Santiago: Fondo Histórico y Bibliográfico José Toribio Medina y Editorial Nacimiento.

Urizar, G. (2012). «Estado y museos nacionales en Chile durante el siglo XIX. Representación de una nación en construcción». Boletín Americanista, 2(65), 211-229.

Vicuña Mackenna, B. (1873). «Biografía de don Claudio Gay». El Mercurio. 


\section{LOS NATURALISTAS EN CHILE Y SU APORTE A LOS MUSEOS DE HISTORIA NATURAL DEL PAÍS ${ }^{I}$}

\section{Carolina Valenzuela Matus}

Universidad Autónoma de Chile

Resumen. La labor de los naturalistas es esencial para comprender la formación de los museos de historia natural en Chile, no tan solo en Santiago sino también en regiones. En este capítulo, nos referiremos, en primer lugar, al origen de las primeras historias naturales $\mathrm{y}$ de quienes se dedicaron a esta disciplina. Asimismo, analizaremos los rasgos biográficos de aquellos naturalistas más destacados que trabajaron en Chile durante el siglo XIX y principios del siglo XX, con especial énfasis en su contribución a la consolidación de redes de intercambio científico y su papel en el proceso de formación de colecciones de historia natural en el país, considerando especialmente los casos de Santiago, Valparaíso y Concepción.

Palabras clave: Colecciones, intercambio científico, museos de historia natural, naturalistas.

ABSTRACT. The work of naturalists is essential to understand the formation of the museums of natural history in Chile not only in Santiago but in other regions. In this chapter, we will refer to the origin of the first natural histories and those who were dedicated to the discipline. In addition, we will analyze the biographical features

\footnotetext{
Este trabajo es producto del proyecto CONICYT/FONDECYT INICIACIÓN n 11170033 Antigüedades y naturaleza. Circulación interoceánica de objetos en los primeros gabinetes de Historia Natural como estrategia de posicionamiento de la ciencia en Chile. Esta investigación se desarrolla en la Universidad Autónoma de Chile.
} 
of the most distinguished naturalists who worked in Chile during 19 th century and the beginning of 20th century. We will highlight their contribution in the consolidation of scientific knowledge exchange and their role in the process of forming Natural history collections in the country, considering the cases of Santiago, Valparaíso and Concepción.

KeYwOrds: Naturalists, collections, Museums of Natural History, Scientific exchange.

La observación de la naturaleza ha sido una actividad desarrollada por los seres humanos a lo largo de toda la historia. Las primeras civilizaciones de Mesopotamia ya observaban el cielo y las estrellas vinculando muchos fenómenos observados con la acción de las primeras deidades. Posteriormente, un griego como Anaximandro de Mileto $^{2}$, buscaba explicaciones racionales sobre diversos fenómenos de la naturaleza. También mencionar a otros filósofos de la Grecia Clásica como Aristóteles y Teofrasto, que escribieron importantes tratados sobre el medio natural ${ }^{3}$, mientras que Heródoto describía el mundo hasta entonces conocido en sus Historias, y a los seres maravillosos que, según las creencias de la época, habitaban los límites de la tierra.

Como continuadores de la herencia griega, los antiguos romanos siguieron escribiendo sobre el tema como Lucrecio, quien en su poema De rerum natura ${ }^{4}$, indagaba sobre los misterios de la

2 Anaximandro (siglo VI, Asia Menor) fue uno de los primeros en buscar explicaciones a los fenómenos de la naturaleza independiente de la voluntad de los dioses. De acuerdo a Rovelli (2018) «en todos los textos anteriores a Anaximandro de que disponemos, griegos y no griegos, los fenómenos naturales como la lluvia, los truenos, los terremotos y los vientos siempre se explican en términos exclusivamente místicos y religiosos, como otras tantas manifestaciones de fuerzas incomprensibles, atribuidas a seres divinos» (p. 62).

3 Entre los tratados de Aristóteles encontramos Acerca del cielo, Acerca de los animales o Los meteorológicos. Teofrasto escribió Sistema naturae, realizando una de las primeras clasificaciones sistemáticas de las plantas.

4 «La materia de que se compone el universo, proponía Lucrecio, es un número infinito de átomos que se mueven al azar por el espacio, como motas de polvo en un rayo de sol, chocando, enganchándose unas con otras, formando estructuras complejas, y separándose de nuevo, en un proceso incesante de creación y destrucción (...) Estamos viendo el mismo mundo material del que formamos 
naturaleza. Mientras que la herencia enciclopédica de los griegos se vio reflejada en las obras de los romanos Varrón y Plinio el Viejo, quienes establecieron un modelo para la elaboración de las historias naturales, sirviendo de referente para varias generaciones futuras de naturalistas hasta bien avanzado el siglo XIX. En especial, la Naturalis Historia de Plinio el Viejo se adaptaba, por su amor al detalle, la maravilla y lo particular, mucho mejor al modelo vigente hasta la Revolución Científica, de ahí que su obra no perdiera actualidad (Morgado, 2018).

De acuerdo a María José Correa Gómez (2018), naturalista es un apelativo "que aludía a una comunidad de hombres formados en la tradición de la filosofía natural, la que, transformada en el curso del tiempo, había depurado la metafísica aristotélica y el ocultismo en las explicaciones e inaugurado nuevos estándares de evidencia y experimentación, comenzando a adquirir una forma moderna y a transformarse en ciencia» (p. 57).

Los naturalistas de la época moderna se habían formado gracias a una labor sistemática para completar el trabajo de los autores clásicos y también para refutarlos en aquellos aspectos en los que aparecían equivocados ${ }^{5}$. Desde el descubrimiento y conquista de América, los cronistas de Indias hicieron descripciones del medio natural que se les presentaba ante sus ojos y el mismo Cristóbal Colón manifestó un amplio interés de tipo naturalista ${ }^{6}$ (Mason, 1998). Sin embargo,

parte y de cuyos elementos estamos hechos. No existe ningún plan magistral, ningún arquitecto divino, ningún designio inteligente» (Greenblatt, 2012, pp. 12-13).

5 De acuerdo a Paula Findlen, los naturalistas, que habían comenzado sus carreras con la tarea de corregir los errores de Plinio o completar el trabajo de Aristóteles, pronto se encontraron a sí mismos en posesión del mundo. Paula Findlen, Courting Nature, en Jardine, Nicholas; Secord, James; Spary, Emma (eds.) (1996), Cultures of Natural History, Cambridge University Press, pp. 57-74.

6 Peter Mason (1998) plantea que, desde el mismo momento del descubrimiento de América, Colón conecta a un mismo nivel los objetos naturales con la población autóctona. "Describing his initial impressions of native Americans, Columbus concluded: 'To please Our Lord, I will bring six of them from here when I leave to your Highness to learn to talk'. He immediately followed this statement with a comment on the lack of animals: 'I saw no animal of any kind, except parrots on this island'. These two sentences were logically connected in 
consideramos que, para el caso americano los jesuitas fueron uno de los primeros en asumir este rol. Desde fines del siglo XVI hasta la expulsión de la Orden en el siglo XVIII, destacados miembros de la compañía describieron la naturaleza americana a través de sus crónicas y cartas $^{7}$, especialmente por una política concreta de la compañía que solicitaba noticias del clima y la naturaleza de todas aquellas regiones donde los padres se encontraran desarrollando su labor misional (Valenzuela, 2018).

No obstante, llegó un momento donde el problema de la naturaleza dejó se ser expresado solo en palabras y los objetos comenzaron a revestir una especial importancia (Justo, 2015). Por tanto, junto a las crónicas, los eruditos valoraron también los objetos materiales provenientes de alejados rincones del globo, que se convirtieron en el fruto de un intercambio interoceánico. Algunos de estos objetos pasaron a formar parte de los gabinetes de historia natural formados en Europa durante el siglo XVIII, espacios que permitían a los privilegiados espectadores europeos observar piezas procedentes de alejados rincones del mundo ${ }^{8}$. La circulación de objetos provenientes del mundo natural se vio favorecida por importantes expediciones que recolectaron información sobre la naturaleza del territorio americano, esto implicaba también para los europeos la recolección de materiales provenientes de sus colonias, gracias a viajes como la expedición geodésica franco-española dirigida por Jorge Juan y Antonio de Ulloa (1735-1744), la expedición al virreinato del Perú de los botánicos Hipólito Ruiz y José Pavón (1778-1788), la

Columbus's mind: the native Americans formed a part of the natural history of the New World, on a par with its fauna» (p. 17).

7 Un desarrollo completo de esta temática se encuentra en Valenzuela, C. Clásicos y naturalistas jesuitas. Los antiguos en la interpretación de la naturaleza americana. Siglos XVII-XVIII, Editorial Rubeo, Barcelona, 2018.

8 Un caso interesante lo constituye el caso de Pedro Franco Dávila quien «logró tener uno de los gabinetes privados más importantes de París, lo que sin duda le situó en una posición privilegiada a los ojos del rey de España cuando le planteó comprar su museo» (Puig-Samper, 2012, p. 12). Este dio origen al Real Gabinete de Historia Natural, inaugurado por el rey de España Carlos III en 1771, quien nombró a Pedro Franco Dávila como director del establecimiento científico. El continuador del Real Gabinete ha sido el Museo Nacional de Ciencias Naturales de Madrid. 
expedición de Alejandro Malaspina y José Bustamante (1789-1794) $y$, tras la independencia de las colonias, la comisión científica del Pacífico (1862).

Es justamente la formación de un Estado propio, lo que amerita el conocimiento de las nuevas fronteras y de los recursos naturales de un país, situación que experimentaron las nacientes repúblicas de Hispanoamérica a comienzos del siglo XIX y, entre ellas, el Estado chileno. Con el fin de conocer mejor el territorio y los recursos disponibles, el Gobierno de Chile encomendó a científicos extranjeros las primeras expediciones para el reconocimiento del país. La llegada de estos primeros naturalistas formó parte de una estrategia para posicionar a la ciencia y la entrada de científicos al país vio favorecida la circulación de saberes entre Chile, Europa y el norte de América, en un contexto más integrado y global, que puede ser observado más allá del tradicional paradigma centro periferia, pues las nuevas repúblicas hispanoamericanas buscaron participar activamente del intercambio científico unido al ideal de progreso para las naciones, proveniente en parte del influjo de las ideas positivistas de Augusto Comte (1798-1857) ${ }^{9}$.

Los gabinetes que dieron origen a los primeros museos de historia natural fueron una expresión de la labor de acopio de estos naturalistas, del esfuerzo de los ciudadanos que contribuyeron con la donación de piezas, así como de los colectores locales y colaboradores del extranjero. Estos gabinetes se convirtieron en los depositarios de los objetos de naturaleza que representaban el conocimiento científico, pero que también contribuyeron al intercambio de saberes entre Chile y otros rincones del orbe, como una estrategia de posicionamiento de la ciencia al interior de la nueva república.

Por lo tanto, los naturalistas tuvieron un rol esencial en la formación de estos gabinetes y posteriormente en los Museos de Historia Natural en Chile. En Santiago, Claudio Gay fue el primer encargado en formar un gabinete de historia natural, el cual se alojó en una sala de la Biblioteca Nacional. Luego tras dejar el país, Rodulfo Philippi

$9 \quad$ En Chile, el filósofo Juan Enrique Lagarrigue (1852-1927), junto a sus hermanos Jorge (1854-1894) médico de profesión, y Luis (1864-1949), ingeniero, formó el grupo más destacado en la divulgación del positivismo de Augusto Comte. 
fue el responsable de la reorganización del gabinete y de convertir a este en el Museo Nacional. Desde regiones, Edwyn Reed y Carlos Porter realizaron una contribución fundamental para la conformación de los museos de historia natural en Valparaíso y Concepción. El naturalista inglés Edwyn Reed se convirtió en el primer director oficial del Museo de Historia Natural de Valparaíso, a lo largo de su vida fundó también un Museo en el Seminario San Rafael, otro en los baños de Cauquenes, convirtiéndose en el primer director del Museo de Historia Natural de Concepción. Por otra parte, Carlos Porter fue el creador de la Revista Chilena de Historia Natural y director del Museo de Historia Natural de Valparaíso por trece años.

En este capítulo, analizaremos, mediante el análisis de fuentes documentales, algunos de los rasgos biográficos de estos naturalistas, con especial énfasis en su contribución a la consolidación de redes de intercambio científico y su papel en el proceso de formación de las colecciones de historia natural en Chile. Este último punto es importante si consideramos que el coleccionismo no comenzó en el museo, sino que fue el final de un complejo viaje que empieza con la posesión del objeto en manos humanas y termina con un lugar en un museo para su exhibición (Justo, 2015). Los naturalistas fueron los grandes facilitadores de este proceso.

\section{i. Claudio Gay (i 800-i 873)}

Desde su juventud, este naturalista francés demostró su inclinación por el estudio de las Ciencias Naturales y hacia 1820 arribó desde Draguignan, en La Provenza, a París para seguir estudios superiores de Medicina y Farmacia, también concurría a los cursos públicos de Ciencias Naturales del Museo de Historia Natural y de la Sorbona.

Entre 1821 y 1828 «se adentró como autodidacta en el estudio de la Física y de la Química, para más tarde seguir cursos de Geología y de Anatomía comparada» (Sagredo, 2010, p. 167). En diciembre de 1828, Claudio Gay llegó a Chile para desempeñarse como profesor del Colegio de Santiago. En 1830, el estado comisiona al naturalista para realizar exploraciones del territorio en el 
contexto de la organización del nuevo Estado nación. De acuerdo a Rafael Sagredo, "Gay vio en su viaje a Chile, más que el inicio de una carrera destinada a la docencia, la posibilidad cierta de dedicarse a la investigación en un país casi total y absolutamente desconocido por los hombres de ciencia europeos»(Sagredo, 2010, p. 170).

Los primeros viajes los realizó a Atacama y Colchagua. Los años siguientes viajó al archipiélago de Juan Fernández, isla de Chiloé y zona central, y con los materiales recopilados en estos viajes Gay escribió su monumental obra, Historia Física y Política de Chile, durante 1844 y 1871 en 28 tomos.

Por otra parte, el gobierno lo comisionó para formar un gabinete de historia natural en Santiago ${ }^{10}$. La idea ya fue dada por el mismo Claudio Gay cuando ofrece sus servicios al Estado:

Me comprometo a formar un Gabinete de Historia Natural que contenga la mayor parte de las producciones de la República, con sus nombres vulgares y científicos; me contraeré muy particularmente a un herbario, y sobre todo a una colección tan completa, como sea posible, de todas las piedras y minas que pueda encontrar o cuyos conocimientos pueda adquirir, dándoles, además, nombres de números que correspondan a un catálogo en que se detallen los usos y las localidades que tengo intento de multiplicar según la importancia y la rareza del objeto. Este trabajo hecho con cuidado indicará a las personas que quieran aprovecharse de las riquezas aún desconocidas de este país, los materiales que puedan emplear, y los lugares donde puedan encontrarlos ${ }^{11}$.

La propuesta fue aceptada y en el texto del contrato se especifica el objetivo que persigue la formación de un Gabinete de Historia Natural:

10 Mayores detalles sobre la conformación de este gabinete de Historia Natural y de la trayectoria de Claudio Gay pueden encontrar en este libro en el capítulo de Daniela Serra, La configuración de un espacio para el saber natural en Chile. El Gabinete de Historia Natural de Santiago, 1830-1842.

11 Claudio Gay ofrece sus servicios al gobierno de Chile. 31 de Julio de 1830, en: Stuardo, C. (1975), Escritos de Claudio Gay, Tomo II Fondo Histórico y Bibliográfico José Toribio Medina, Editorial Nascimiento, Santiago de Chile, pp. 88-90. 
$5^{\text {a }}$. Se obliga a formar un Gabinete de Historia Natural que contenga las principales producciones vegetales y minerales del territorio, $\mathrm{y}$ un catálogo en que se denominen por sus nombres vulgares y científicos, y en que se demuestren los usos y utilidades de dichos objetos y los lugares donde se encuentran ${ }^{12}$.

Los gabinetes habían comenzado a proliferar en los centros intelectuales más importantes de Europa y América desde el siglo $\mathrm{XVIII}^{13}$. En estos primeros gabinetes convivían los objetos de la naturaleza (naturalia), manufacturas (artificialia) y las antigüedades (piezas arqueológicas prehispánicas y europeas) dispuestas de manera ordenada y clasificada, constituyendo así un espacio para la reflexión intelectual de las ciencias de la naturaleza además de ser el origen de los primeros museos de Historia Natural. De acuerdo a Daniela Serra (2017), el gabinete organizado por Claudio Gay no había sido el primero en Chile, pues hubo algunos que funcionaron con anterioridad; en 1812 la academia de San Luis contaba con un gabinete de Minerales y al año siguiente se creaba un museo de Ciencias en el Instituto Nacional en 1813 (Serra, 2017). En 1822, Bernardo O’Higgins, director Supremo de la República, también concibió la idea de reunir en un museo muestras de las producciones naturales de Chile y encargó esta misión a Juan José Dauxion Lavaysse sin ningún éxito ${ }^{14}$.

12 Texto del Contrato II. 14 de septiembre de 1830, en: Stuardo, C. (1975). Escritos de Claudio Gay, Tomo II Fondo Histórico y Bibliográfico José Toribio Medina, Editorial Nascimiento, Santiago de Chile, pp. 90-91.

13 Durante el siglo XVIII se dio paso de los gabinetes a colecciones mayormente especializadas. "His move away from the concept of the cabinet of curiosity which its rich if chaotic blend of antiquities constitutes an important shift in nineteenth-century collecting practices that were becoming increasing more focused and specialized (Sellen, 2014, p. 106). De acuerdo a Diderot en la definición de Cabinet d'Hisoire Naturelle de la Encyclopèdie «Un verdadero gabinete de historia natural- sostenía- no debía reproducir el orden de la naturaleza, puesto que en ella todo era «sublime desorden»; sentencia amplificada después por Lammarck cuando escindió con claridad entre gabinetes de curiosidades y gabinetes de historia natural, los primeros entregados al entretenimiento de diletantes y virtuosos, los segundos consagrados al progreso de las ciencias» (Pimentel, 2003, p.177).

14 «El 26 de junio de 1823 este mismo francés recibió además la comisión de explorar el territorio chileno para informar al Gobierno del director don Ramón 
Hasta 1838, el naturalista francés estuvo casi exclusivamente centrado en la recolección de objetos naturales, los que además de ser un material importante para la confección de su monumental Historia física y política de Chile, constituyó una forma de ampliar piezas para el gabinete de Historia Natural. En este sentido, éstas no solo provenían de sus propias recolecciones, sino que también las adquiría de los improvisados excursionistas locales a los que ofrecía alguna suma si el objeto que portaban resultaba de interés, y así lo evidencia esta carta de Diego Portales a Antonio Garfias:

En el tiempo que está aquí, ha gastado más de \$150 en pagar a peso cada objeto nuevo que le han presentado. Con esto, ha puesto en alarma a todos los muchachos que trasnochan buscando pescaditos, conchas, pájaros, cucarachas, mariposas y demonios, o salen a expedicionar hasta San Antonio, por el sur, y hasta Quintero, por el norte. El dueño de la posada donde reside, ya está loco, porque todo el día hay en ella un cardumen de muchachos y hombres que andan en busca de Mr. Gay: siempre que sale a la calle, los muchachos le andan gritando mostrándole alguna cosa: Señor, esto es nuevo, nunca visto; Ud. No lo conoce; y anda más contento con algunas adquisiciones que ha hecho, que lo que Ud. podría estar con $\$ 10.000$, y platónicamente querido de todas las señoritas de Santiago ${ }^{15}$.

Esto también ejemplifica la red colaborativa de los naturalistas que considera el papel de los actores locales como excursionistas, mineros o pescadores, que podían adquirir especies de gran interés para el Gabinete. Claudio Gay también participó en activas redes de

Freire acerca de los medios más convenientes para fomentar la colonización y facilitar la comunicación por mar y tierra entre los distintos puntos de la República. Este hombre era un aventurero que había vivido en Haití, en Venezuela y en Brasil, y que tenía conocimientos, pero muy superficiales de varios ramos, lo que le había dado crédito inmerecido. Murió en 1830 sin haber cumplido en lo más mínimo las tareas que le habían sido encomendadas. Philippi, Federico. Historia del Museo Nacional de Chile por el Dr. R. A. Philippi, en Boletín del Museo Nacional, tomo I, Santiago de Chile, Imprenta, Litografía y Encuadernación Barcelona, 1908, p. 4.

15 Carta de Diego Portales a Antonio Garfias, 19 de enero de 1832, en: Feliú Cruz, G. (1975). Perfil de un sabio: Claudio Gay a través de su correspondencia, pp. 16-17. 
intercambio interoceánico como corresponsal del Museo de Historia Natural de París enviando a Francia "prolijos herbarios, muestras de rocas, datos sobre la meteorología, es decir, los resultados de sus empresas científicas, de las que siempre les participó» ${ }^{16}$.

Entre 1842 y 1844 comenzó la divulgación de los resultados de sus indagaciones en Francia y empezó a publicar su Historia física y política de Chile ${ }^{17}$. Con su ausencia del país comienza un periodo de deterioro del gabinete y pérdida de casi la totalidad de las colecciones. Posteriormente, la tarea de elevar el gabinete y convertirlo en Museo Nacional le correspondió a Rodulfo Philippi ${ }^{18}$.

\section{Rodulfo Philippi (i 808-I904)}

Rodulfo Philippi nació en Prusia en 1808 y parte de su infancia y juventud la pasó en Suiza en un instituto de Yverdon donde realizó frecuentes excursiones a las montañas con sus compañeros y profesores. Se formó como doctor en Medicina y Cirugía en su país natal, pero sus intereses estuvieron enfocados en profundizar el estudio de la botánica y la zoología. Debió salir de Berlín por sus ideales liberales tras el fracaso de la revolución de 1848 cuando fue invitado por su hermano Bernardo a venir a Chile junto a otros colonos alemanes, arribando al país en 1851.

En Chile, el gobierno le encomendó en primer lugar la Dirección del Liceo de Valdivia y luego, la recuperación del Gabinete de

16 Feliú Cruz, G. (1975). Perfil de un sabio: Claudio Gay a través de su correspondencia, p. 23.

17 De acuerdo a Feliú Cruz: «La Historia de la cual fue autor, influyó considerablemente en la historiografía nacional. El método que empleó fue determinante en esa influencia. Superó a la antigua crónica, aplicó un criterio crítico para valorizar las fuentes, realizó el proceso de investigación y escribió la historia simplemente como un expositor de los hechos, narrándolos». Feliú Cruz, G. (1975). Perfil de un sabio: Claudio Gay a través de su correspondencia, p. 23.

18 El naturalista alemán Rodulfo Philippi (1808-1904) habíase referido, en un sentido crítico, a los caracteres, tanto generales como especiales de la obra de Gay en la parte de la zoología y la botánica. Según Diego Barros Arana, las críticas no se debían a ninguna rivalidad: "Philippi ha declarado en varias ocasiones el alto aprecio que aquella obra le ha merecido y la necesidad de señalar sus vacíos para llenarlos sea en un suplemento, sea en una nueva edición». Feliú Cruz, G. (1975). Perfil de un sabio: Claudio Gay a través de su correspondencia, p. 58. 
Historia Natural en Santiago. Más tarde asumió las cátedras de botánica y de zoología en la Universidad de Chile y la de historia natural en el Instituto Nacional ${ }^{19}$.

Philippi se empeñó especialmente en la recuperación del Gabinete de Historia Natural elevándolo a la categoría de Museo Nacional, asumiendo como director del mismo en 1853. De acuerdo a Carlos Sanhueza (2018), «la llegada de Philippi supuso un reordenamiento y una profesionalización del museo, crea una cultura monográfica, transforma un conjunto de objetos en una entidad al servicio de la investigación científica en Chile» (p. 173).

La conformación de un museo de carácter nacional conllevaba un compromiso en la configuración de las colecciones, que llevó a Philippi a dedicar la mayor parte de su tiempo a dibujar, medir, y clasificar los objetos que llegaban a su despacho (Sanhueza, 2016), donde las piezas de antigüedades prehispánicas y de otras regiones del mundo ocuparon también un lugar relevante (fig. 1). Además de la labor realizada al interior del museo, hay un trabajo emprendido por Philippi y sus colaboradores que se relaciona con la búsqueda de especies por el territorio nacional. Esta se realiza por medio de viajes exploratorios en los que influyen factores circunstanciales como los intereses del director y su equipo en determinados territorios, las facilidades de transporte para el viaje y las vías de acceso. El proceso de colectar objetos se organiza en gran medida «de acuerdo a las posibilidades de obtener víveres, las relaciones con los lugareños, los arrieros por casualidad encontrados, la posibilidad de comprar animales de carga, etc.» (Sanhueza, 2016, p. 151). Este trabajo requiere también el apoyo de las autoridades locales y de los migrantes alemanes, especialmente de la zona de Valdivia.

Por otra parte, Philippi buscaba difundir el museo más allá de los límites nacionales. Esto se evidencia en el establecimiento de redes de colaboración con otras instituciones. De esta manera, Philippi gestionó el canje, la compra e intercambio de especies con el extranjero, ofreciendo especímenes a instituciones como el Museo de Historia

19 Rodulfo Amando Philippi, en: http://www.memoriachilena.cl/602/w3-article-795.html 
Natural de París o el Museo Británico, con el fin de enriquecer las propias colecciones del Museo Nacional con piezas provenientes de canjes con el extranjero. Estas acciones se vieron favorecidas por el hecho que Philippi pertenecía a diferentes sociedades científicas y también por la difusión de los resultados de sus investigaciones, que hicieron cobrar importancia a las especies del Museo Nacional (Sanhueza, 2016).

En los últimos años de su vida, Philippi se hizo cargo del traslado del Museo Nacional a la Quinta Normal en 1876 y de la formación allí de un jardín botánico, así como también se dedicó a incrementar las especies para los gabinetes de historia natural en los liceos del país ${ }^{20}$, preocupación compartida también por el naturalista inglés Edwyn Reed.

La larga trayectoria de Rodulfo Philippi le fue reconocida en vida por sus pares y las autoridades del país. Fue Federico Philippi (1838-1910), su hijo, quien entre 1897 y 1910, consolidaría el Museo Nacional como director de la institución.

\section{EDWyn ReED (I84I-I9IO)}

Edwyn Reed nació en Bristol en 1841 y desde su juventud manifestó vocación por el naturalismo, especialmente por la entomología. Algunos datos biográficos de Reed fueron presentados por Carlos Porter, quien escribió sobre el naturalista inglés en la sección Galería de Naturalistas de Chile de la Revista Chilena de Historia Natural. Porter señalaba que Reed ocupó algunos cargos destacados en su ciudad natal como secretario ad-honorem de la Sociedad Entomológica de Bristol, de la Sociedad Microscópica y ayudante ad-honorem de la Dirección del Museo de dicha ciudad. En 1859 viajó a Londres a estudiar Ingeniería civil, pero «habiendo, en Londres, llegado a formar parte de varias sociedades científicas i hecho

20 Información sobre los materiales enviados a los gabinetes de los liceos puede encontrarse en: Libro de comunicaciones relativas a la Instrucción Pública. Oficios enviados, 1843 mayo- 1846 marzo. Ministerio de Instrucción Pública, 1843-1900. Archivo Ministerio de Educación. 
amistad con naturalistas eminentes como Darwin, Wallace, Bates, Hamlet, Clark i otros, determinó abandonar la carrera titulada que lo llevara a la capital i entregarse de lleno a la hermosa ciencia de la historia natural» (Porter, 1903, p. 138).

Hacia 1863, viajó a Brasil a estudiar la fauna entomológica, permaneciendo en ese país por cinco años. En 1868 regresó a Inglaterra aquejado por la fiebre amarilla. Allí, los médicos tratantes le aconsejaron establecerse en un clima seco. Carlos Porter (1903) señala que:

Por este tiempo algunos de los más distinguidos naturalistas ingleses le indicaron que la fauna de Chile no era bastante conocida en Europa i que haría un buen acuerdo si se decidiera buscar en Chile un nuevo campo para sus estudios al mismo tiempo que para la recuperación de su quebrantada salud. (p. 139)

En marzo de 1869 llegó a Valparaíso y en junio de ese año aceptó el puesto de entomólogo del Museo Nacional donde estuvo por siete años, en los que se dedicó al estudio y exploración de la fauna y flora de Chile bajo la dirección de Rodulfo Philippi. Reed complementó la clasificación entomológica chilena realizada por Claudio Gay en su obra, identificando nuevas especies gracias a las diversas expediciones que realizó por el territorio nacional. Sobre todas estas actividades, informa el director del museo al ministro de Instrucción Pública.

El señor Reed ha seguido clasificando los insectos extranjeros, que había recibido en varias ocasiones, y habían quedado, hasta ahora en los mismos cajones que habían venido. Ahora está preparando un envío para California en canje de los insectos de esa interesante provincia que nos han sido prometidos y que podemos esperar de un día a otro ${ }^{21}$.

En 1873, Philippi envió a Reed a una misión científica a la isla Mocha, ya que llegaron noticias que allí se había descubierto el sándalo,

21 Carta de R.A. Philippi al Ministerio de Instrucción Pública. Santiago 3 de agosto de 1870. Archivo Ministerio de Educación. vol. 138. Documento 35, foja 3. 
hecho curioso al tratarse de una especie de palo proveniente de la zona tórrida. Reed fue a comprobarlo y a conocer más sobre la naturaleza del territorio y sus producciones, descubriendo que no se trataba del sándalo sino de un arbustito con flores, también llamado Siete camisas (escalornia macrantha). De acuerdo a Philippi, Reed halló entre los insectos de la isla «varios muy interesantes y aún nuevos para la ciencia ${ }^{22}$, lo que indica la labor de continuidad en el descubrimiento y clasificación de especies, iniciada por Claudio Gay en el país.

Por otra parte, Reed actuó, al igual que el naturalista francés, como agente en la adquisición de colecciones para el Museo Nacional en París y Londres. En 1873, se le encargó cotejar un número de insectos y otros animales chilenos con los tipos que existían en las grandes colecciones de dichas ciudades europeas. Asimismo, se dedicó a estudiar la organización de los principales museos de Europa: adquirió así unos conocimientos que le servirían para su trabajo posterior de organización de museos de historia natural en regiones. Este bagaje se complementaba con un trabajo aprendido también al alero de la organización del Museo Nacional, experiencia que adquirió con Philippi en sus años de trabajo en Santiago.

En 1875, solicitó permiso para formar un pequeño museo en los Baños de Cauquenes, que fue presentado a la Exposición de 1876, en la que obtuvo una medalla de oro (Porter, 1903). Al año siguiente se retiró del Museo Nacional para comenzar el arreglo del Museo de Valparaíso junto a su fundador, el político, literato y diplomático Eduardo de la Barra. El museo fue fundado en 1879 y Reed se transformó en su primer director oficial (1878-1879), dejando luego el puesto para desempeñar las clases de Historia Natural y Geografía en la Escuela Naval. Durante este tiempo formó el Museo de Historia Natural del Seminario San Rafael en Valparaíso. Luego de estos siete años se trasladó a los Andes «dedicándose allí al estudio de la fauna i flora andinas. Por este tiempo escribió varias monografías de grupos de insectos chilenos» (Porter, 1903, p. 140).

Cuando asumió la dirección del Museo de Concepción en 1902 ya era un científico de importante trayectoria. Los años dedicados a

22 Carta de R.A. Philippi al Ministro de Instrucción Pública. Santiago 13 de mayo de 1872, Archivo Ministerio de Educación. Volumen 138. Documento 42. Foja 1. 
la formación de Museos de Historia Natural le dieron experiencia y consolidaron sus redes de intercambio de conocimientos y objetos con museos e instituciones alrededor del globo. Estas redes eran esenciales para la formación de colecciones, nutridas por la compra de objetos, pero también por el canje y las donaciones ${ }^{23}$.

Desde su juventud, Reed manifestó interés en potenciar la enseñanza de las ciencias naturales mediante la preparación de gabinetes para los liceos del país. El naturalista inglés adhería a un pensamiento, muy extendido en el siglo XIX, que consideraba que las prácticas coleccionistas y el estudio de la historia natural era beneficioso para forjar el carácter del individuo, cultivando la simplicidad y el autocontrol (Schell, 2018). De esta manera, la práctica de la historia natural se vinculaba a la formación en valores de los estudiantes. En Concepción, Edwyn Reed continuó impulsando la creación de gabinetes para la enseñanza de las ciencias naturales, sobre todo valorando las especies nacionales. En 1903 escribe:

«Mi deseo es formar y suministrar a todas las escuelas del Sur, colecciones escolares en el ramo de Historia Natural que harán posible una enseñanza práctica y rudimentaria de la Zoología y de la Botánica; pero tropiezo con varias dificultades (...) En primer lugar el museo de Concepción se halla escaso de recurso y con un muy reducido personal. Como naturalista y antiguo profesor de las ciencias naturales, se ve que la enseñanza ... es imposible sin muestras a la vista de los alumnos. Los liceos en general no tienen los gabinetes escolares necesarios para la correcta enseñanza y en cuanto á las escuelas superiores carecen de mucho. Cuando tienen algunos objetos extranjeros y de muy poca utilidad» ${ }^{24}$.

23 Edwyn Reed, como otros naturalistas, también asume el rol de donador. Antes de venir a Chile, donó cincuenta y cinco coleópteros para la Institución de Bristol para el avance de la ciencia, la literatura y las artes (Reed, Walter. (2013). Edwyn C. Reed y el Archivador Rojo. Madrid, p. 79). En 1886, cedió al Museo de Bristol parte de las colecciones que formó en las selvas de Brasil (Reed, Carlos (1911). Apuntes para la Historia del Museo de Concepción. Buenos Aires. Establecimiento Gráfico Olivetti Hermanos, p. 12). En 1895, el Instituto Smithsonian, de Washington, ofreció canje mientras Reed estuvo en Cauquenes. Reed, Walter. (2013) Edwyn C. Reed y el Archivador Rojo. p. 81.

24 Edwin Reed al señor Juan Miranda en Concepción 8 de noviembre 1903. Reed, C. Apuntes para la Historia del Museo de Concepción, p. 41. 
Toda su práctica naturalista la empleó también en incrementar las colecciones del Museo de Concepción. Como director, Edwyn Reed promovió la donación, el canje y la recolección de objetos para la formación de las colecciones que serían parte de la nueva institución. En 1902, encargó ejemplares de tuninas a los pescadores de la bahía de Concepción, en Talcahuano, Penco y San Vicente ${ }^{25}$, así como también solicitó diversos peces, a los pescadores de Tomé, Lota y Talcahuano, en un esfuerzo por reunir especies regionales.

Reed, junto a la infatigable tarea de organizar las colecciones, se daba algo de tiempo para la investigación científica. A finales de 1902, informaba en la Revista Chilena de Historia Natural, acerca de nuevos insectos chilenos que había observado: "Aunque los múltiples trabajos de la instalación no me han dejado mucho tiempo para la recolección de insectos (...) en el cerro Caracol, de Concepción, he encontrado una especie nueva de mariposa diurna del jénero Neosatyrus en abundancia, una especie nueva de grillo tal vez» (Reed, 1902, p. 20).

Estas labores de observación, las complementaba con el empeño en aumentar la colección (fig. 2). Sobre estos esfuerzos daba cuenta el naturalista y director del Museo de Historia Natural de Valparaíso, Carlos Porter, quien visitó a Reed en el Museo de Concepción, haciendo notar los rápidos progresos que había hecho este en el establecimiento que dirigía ${ }^{26}$. A la muerte de Reed, en 1910, el joven Carlos Oliver Schneider se hizo cargo de las colecciones del museo custodiadas en el Liceo de Hombres de Concepción.

25 Reed, Edwyn, «Sobre una tunina chilena». Revista Chilena de Historia Natural. Junio. Año VIII, (1904). p. 139.

26 Revista Chilena de Historia Natural. Periódico mensual fundado por Carlos Porter (director) el 1 de octubre de 1897. Año VII.1903. Biblioteca Científica John Juger, Museo de Historia Natural de Valparaíso. 


\section{Carlos Porter (I867-I942)}

Carlos Porter nació el 20 de agosto de 1867. Su padre, un marino de ascendencia norteamericana, brindó al joven Carlos un ambiente propicio para el aprendizaje de la historia natural. Gracias a ello, Porter se formó como naturalista autodidacta dedicado al estudio de la biología, la botánica, anatomía, histología y geografía. En su juventud, estuvo encargado de enviar especímenes a diversos liceos cumpliendo una comisión asignada por el gobierno (Saldivia, 2017), actividad que lo prepararía para las tareas que desarrollaría posteriormente en su vida profesional en la gestión de colecciones de objetos provenientes de la naturaleza.

Junto al interés que cultiva por las ciencias naturales, Porter se caracterizó por ser un prolífico escritor, habilidad que desarrolló ampliamente en la Revista Chilena de Historia Natural, fundada en 1897 por él mismo. En esta publicación daba cuenta de los avances del Museo de Historia Natural, así como también divulgaba los avances de sus colegas gracias a las redes de intercambio que estableció con científicos e instituciones de todo el mundo.

Durante su etapa como director del Museo de Historia Natural de Valparaíso entre 1897 y 1910, las colecciones se incrementaron de forma considerable, en parte gracias al empeño de su director en solicitar activamente a la comunidad la donación de objetos del mundo natural. Esto se complementaba con un intenso trabajo de recolección de especímenes mediante excursiones realizadas por el mismo Porter y su equipo del Museo a Viña del Mar, el valle de Copiapó o diversas zonas cordilleranas (Fig. 3 y Fig. 4). Sabemos de algunas piezas en exhibición por la Guía del Museo de Historia Natural de Valparaíso (1898), confeccionada por Porter. Este, gracias a un orden metódico, también contabilizó y registró todos los ingresos publicados en el boletín de la Revista Chilena de Historia Natural.

Por aquella misma época ejerció como profesor de microscopía en el Instituto Técnico Comercial de Valparaíso, donde fue el fundador de la asignatura. También impartió clases como catedrático de historia natural, fisiología e higiene en la Escuela Naval Militar y de Ingenieros de Valparaíso. El terremoto y posterior incendio del 
Museo de Valparaíso en 1906 resultaron eventos desafortunados al que Porter le tocó hacer frente. Este siniestro marcó un antes y un después en la historia del museo, ya que se perdieron casi la totalidad de las colecciones y la institución debió comenzar prácticamente de cero, pues solo lograron salvarse algunos libros de la biblioteca y una antigua colección de herbarios ${ }^{27}$. Por ello es que, tras la reconstrucción del museo, las piezas más antiguas que se encuentran actualmente en inventario son, en su mayoría, posteriores a 1915.

El 19 de octubre de 1906, Carlos Porter escribió una circular para todo el país:

El Museo de Valparaíso, como todos los de su jénero, habrá de formarse en gran parte por medio de los obsequios.

Confiamos que Ud., con su reconocido patriotismo, querrá ayudarnos a hacer renazca de las cenizas el Museo, enviándonos de cuando en cuando, todo objeto de historia natural y obra científica que usted considere de utilidad para el incremento de nuestras colecciones.

Las pocas piezas rescatadas del fuego fueron trasladadas temporalmente por su director al Liceo Miguel Luis Amunátegui, en Santiago, donde acondicionó una sala museo, que funcionó hasta 1910, fecha en que Porter es enviado en comisión de servicio a distintos Museos de Argentina y Europa (Saldivia, 2017). Pese a los intentos por reabrir el Museo de Valparaíso para las fiestas del Centenario de la Independencia, en 1910, este solo reanudó su actividad cuatro años más tarde bajo la dirección de John Juger (Jaksic et al. 2012).

Porter se acoge a jubilación en 1928 aunque luego del retiro de la vida pública continúa en comunicación con científicos de todo el mundo y al tanto de los avances de la ciencia hasta su muerte, ocurrida en diciembre de 1942. Para Saldivia (2017), su figura constituye un eslabón entre la ciencia finisecular decimonónica y la ciencia de comienzos del siglo veinte. Su trayectoria y legado pasa a ser parte de la larga lista de naturalistas chilenos y extranjeros que

27 Se revisaron fichas desde 1890, en área biología, MHNV. 
contribuyeron significativamente al desarrollo de las ciencias naturales y a la formación de colecciones de historia natural en el país.

\section{REFLEXIONES FINALES}

Desde los antiguos griegos encontramos documentación relevante que nos habla acerca de las preocupaciones del ser humano por dar respuesta a las interrogantes del mundo natural. Un antiguo naturalista como Plinio el Viejo a través de su Naturalis Historia estableció una forma de describir la naturaleza que se mantuvo como referente hasta bien entrado el siglo XVIII. Con el descubrimiento de América se abren nuevas posibilidades de examinar el mundo natural, por ello los conquistadores y evangelizadores europeos se dedicaron a la descripción de la naturaleza del Nuevo Mundo. En este contexto, los miembros de la Compañía de Jesús contribuyeron significativamente a este ámbito al asumir un rol naturalista evidenciado en las detalladas descripciones de los territorios donde misionaban y la creación de una red global que los conectaba con otros miembros de la Orden a lo largo del globo con quienes intercambiaban conocimientos.

Desde el siglo XVIII, los objetos tomaron especial relevancia para el conocimiento del mundo natural y en Europa se comenzaron a formar gabinetes de naturaleza más especializados, dejando atrás las antiguas cámaras de maravillas o gabinetes de curiosidades donde se disponían objetos de distinta naturaleza sin un orden establecido. Algunos de estos gabinetes se nutrieron de objetos provenientes de las excursiones científicas financiadas por la Corona española y francesa.

Durante el siglo XIX, la historia natural alcanzó un mayor grado de especialización. Los naturalistas serían personas eruditas y viajeras que, gracias a sus observaciones y reflexiones en torno a la naturaleza, contribuyeron a la formación de colecciones que nutrieron a gabinetes y museos. En este estudio, consideramos especialmente el papel de Claudio Gay, Rodulfo Philippi, Edwyn Reed y Carlos Porter, sobre todo porque a lo largo del siglo XIX y principios del siglo XX, jugaron un rol importante en el conocimiento de la naturaleza y del 
territorio chileno en el contexto de la formación del nuevo Estado nación y con sus conocimientos y redes, formaron los museos de historia natural más importantes del país, además de contribuir a la educación de las ciencias naturales.

Según Paula Findlen (1996), el coleccionar permitió a los naturalistas expandir su rango de conocimientos entrando en contacto virtualmente con cada sección de la sociedad, desde el pescador de más abajo que les vendía rarezas en el mercado, a los príncipes quienes pagaban generosamente para ver tales cosas. Estas relaciones las veremos reproducidas en parte en los naturalistas que trabajaron en Chile, pues fueron los protagonistas en el proceso de la formación de las colecciones en los museos gestionando donaciones, canjes e intercambios con el extranjero, donde se consideraban tanto objetos de naturaleza como objetos provenientes del mundo natural. Estos naturalistas establecieron una red colaborativa a nivel local, que les permitió acceder a piezas conseguidas por los lugareños, de allí que el papel de arrieros, pescadores y excursionistas locales no esté completamente agotado (Sanhueza, 2018) en su relación con la contribución de estos actores al conocimiento de la historia natural.

Los naturalistas también asumieron el papel de donadores, pues ellos mismos donaban los objetos que recolectaban de sus excursiones a lo largo del país, piezas que formarían parte de colecciones alojadas en los museos y liceos o materiales para canjes con otras instituciones. Las redes internacionales también son un elemento relevante en la formación de las colecciones. Naturalistas como Gay, Philippi, Reed y Porter cultivaron relaciones con diversas sociedades científicas y mantuvieron contacto y correspondencia con los grandes museos de Historia Natural en París o Londres. Hubo también una estrecha colaboración con colegas de distintas partes del globo, que compartieron y difundieron conocimientos de los últimos avances en la disciplina, lo que confirma una red global de trabajo cultivada por estos especialistas a lo largo del siglo XIX, en una relación de doble dirección entre los centros de conocimiento de Europa, América del Norte y el conocimiento generado en América del Sur, lo que también nos indica la posibilidad de mirar más allá 
de la perspectiva tradicional del centro y la periferia en cuanto a la transmisión del conocimiento sobre el mundo natural.

\section{GRÁFICOS E IMÁGENES}

Fig. I Algunas piezas de antigüedades donadas al Museo Nacional

\begin{tabular}{|l|l|}
\hline \multicolumn{1}{|c|}{ Pieza } & \multicolumn{1}{c|}{ Información/ Procedencia } \\
\hline Mosaico romano & Europa \\
\hline Jarro de China & Siglo XVIII \\
\hline Cántaro flechas & $\begin{array}{l}\text { Donación del coronel Maturana/ } \\
\text { Pompeya }\end{array}$ \\
\hline $\begin{array}{l}\text { Cetros, bastones, mazas de armas, } \\
\text { arcos y flechas }\end{array}$ & $\begin{array}{l}\text { Donación de José Tomás Urmeneta/ } \\
\text { Polinesia }\end{array}$ \\
\hline Lanzas de los patagones & Donación de Jorge Schythe \\
\hline Hombres y mujeres araucanos & Guillermo Manns \\
\hline $\begin{array}{l}\text { Hamaca venezolana decorada con } \\
\text { plumas }\end{array}$ & Julio Besnard \\
\hline $\begin{array}{l}\text { Modelo de buque de Tahití incrustado } \\
\text { en conchas de perla }\end{array}$ & José Tomás Urmeneta \\
\hline Vaso de cáscara de árbol & Jorge Schyte/ Tierra del Fuego \\
\hline Pequeños ídolos de piedra & Egipto \\
\hline $\begin{array}{l}\text { Pequeño ídolo de mármol blanco que } \\
\text { representa a dios como ídolo griego }\end{array}$ & Huacas de Vichuquén/ Chile \\
\hline
\end{tabular}

Fuente: Guía del Museo Nacional de Chile destinado a los visitantes. Septiembre de 1878. Imprenta de los Avisos, Santiago de Chile. 
Fig. 2 Concepción: Colecciones bajo la dirección de Edwyn Reed PARTE De los objetos Colocados EN ESTANTES EN EXHIbición EN EL museo, en las dependencias del Liceo de Hombres de Concepción (I903)

\begin{tabular}{|l|l|}
\hline \multicolumn{1}{|c|}{ Tipo } & \multicolumn{1}{c|}{ Cantidad } \\
\hline Mamíferos & 51 \\
\hline Aves extranjeras & 200 \\
\hline Aves chilenas & 400 \\
\hline Reptiles & 20 \\
\hline Peces & 120 \\
\hline Evertebrados & 5000 \\
\hline Minerales y objetos etnológicos & 300 \\
\hline
\end{tabular}

Fuente: El País, agosto de 1903. Reed, C. Apuntes para la Historia del Museo de Concepción, p. 17. 
Fig. 3 Adquisición de colecciones en el Museo de Historia NatuRAL DE VALPARAíSO EN EL PERIOdo I899-I904

\begin{tabular}{|c|c|c|c|c|}
\hline \multicolumn{5}{|c|}{ Adquisición de piezas mediante excursiones } \\
\hline Colector & Procedencia & Año & Objetos & Otros datos \\
\hline Carlos Porter & Chañarcillo & 1899 & $\begin{array}{l}\text { Coleópteros y } \\
\text { arácnidos }\end{array}$ & $\begin{array}{l}\text { Excursiones a } \\
\text { los valles de } \\
\text { Copiapó }\end{array}$ \\
\hline Carlos Porter & Viña del Mar & 1904 & $\begin{array}{l}1 \text { ortóptero } \\
1 \text { coleóptero } \\
1 \text { crustáceo }\end{array}$ & Viña del Mar \\
\hline $\begin{array}{l}\text { Bracey Wilson } \\
\text { (Armada de } \\
\text { Chile) }\end{array}$ & Aysén & 1900 & $\begin{array}{l}\text { Ortópteros } \\
\text { Arácnidos } \\
\text { Vermes } \\
\text { Dípteros } \\
\text { Crustáceos } \\
\text { Coleópteros } \\
\text { Himenópteros }\end{array}$ & $\begin{array}{l}\text { Armada de } \\
\text { Chile }\end{array}$ \\
\hline F. T Delfín & Talcahuano & 1902 & Crustáceos, peces & $\begin{array}{l}\text { Armada de } \\
\text { Chile }\end{array}$ \\
\hline $\begin{array}{l}\text { Porter y equipo } \\
\text { del Museo }\end{array}$ & Cordillera & 1903 & $\begin{array}{l}\text { Coleópteros } \\
\text { Neurópteros } \\
\text { Arácnidos } \\
\text { Himenópteros } \\
\text { Anélidos }\end{array}$ & $\begin{array}{l}\text { Excursión del } \\
\text { Museo a la } \\
\text { Cordillera }\end{array}$ \\
\hline F. T. Delfín & Juan Fernández & 1904 & $\begin{array}{l}27 \text { arácnidos, } \\
26 \text { peces, } 2 \\
\text { equinodermos }\end{array}$ & $\begin{array}{l}\text { Excursión } \\
\text { del Dr. F.T. } \\
\text { Delfín a Juan } \\
\text { Fernández. }\end{array}$ \\
\hline Agustín Prat & $\begin{array}{l}\text { Seno de Última } \\
\text { Esperanza }\end{array}$ & 1904 & $\begin{array}{l}\text { Aves } \\
\text { Peces } \\
\text { Equinodermos } \\
\text { Moluscos }\end{array}$ & $\begin{array}{l}\text { Marina de } \\
\text { Chile }\end{array}$ \\
\hline
\end{tabular}

Fuentes: Memoria presentada al Sr. ministro de Instrucción Pública por Carlos E. Porter, Santiago 12 de abril de 1899, 12 de octubre de 1899, Memorias al Ministerio de Instrucción Pública en Revista Chilena de Historia Natural, Años 1899- 1905. 
FIG. 4 INCREMENTO DE LA SECCión ZOOLÓGICA

ENTRE I 898 Y I905 EN VALPARAÍSO

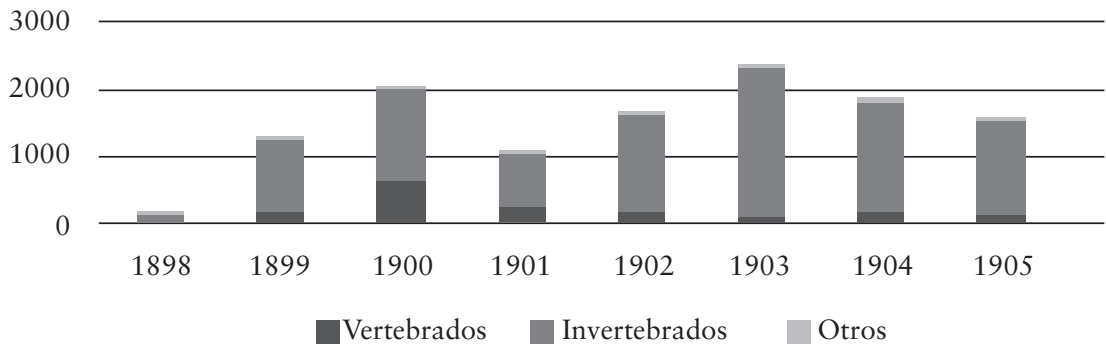

Fuente: resumen del movimiento que hubo en el Museo de Historia Natural de Valparaíso desde el 1 de enero de 1898 hasta el 31 de diciembre de 1902, en Memoria del Museo, Revista Chilena de Historia Natural, 1903, Año VII, p. 89 y resumen estadístico: el Museo de Historia Natural de Valparaíso durante el año 1906. Memoria presentada al ministro de Instrucción Pública, 25 de febrero de 1907, Revista Chilena de Historia Natural, pp. 39-42. Información del Boletín del Museo de Valparaíso, periodo 1900-1906, en Revista Chilena de Historia Natural. Consultado en Biblioteca especializada del Museo de Historia Natural de Valparaíso. 


\section{BiBLIOGRAFÍA}

Carta de Edwyn Reed s/f en Carta de R. A. Philippi al ministro de Instrucción Pública, Santiago, diciembre 5 de 1876, Archivo Ministerio de Educación. Volumen 138. Documento 77. foja 1.

Carta de R.A. Philippi al Ministerio de Instrucción Pública. Santiago 3 de agosto de 1870. Archivo Ministerio de Educación. vol. 138. Documento 35 , foja 3 .

Correa, M.J. (2018). "A kind of little Wiesbader, or rather Leukerbad, in the bosom of the Andes» Experiencia científica y cultura termal en los Andes, siglo XIX, en: Sanhueza, Carlos (ed.) La movilidad del saber científico en América Latina. Objetos, prácticas e instituciones (siglos XVIII al XX). Santiago de Chile: Editorial Universitaria, 55-74.

Eyzaguirre Philippi, M. T. (2008). «Homenaje Rodulfo Amando Philippi (1808-1904). Explorador de nuestra Biodiversidad»Gayana Botánica. Web <https://scielo.conicyt.cl/scielo.php?script=sci_ arttext\&pid=S0717-66432008000200001\&lng=pt\&nrm=i\&tlng $=$ es $>$ Consultado el 5 de noviembre de 2018.

Findlen, P. (1996). «Courting Nature», en Jardine, Nicholas; Secord, James; Spary, Emma (eds.), Cultures of Natural History. Cambridge University Press, 57-74.

García Cañizares, F. (1908). Propuesta del profesor Carlos E. Porter como académico de mérito, 13 de marzo de 1908. Extracto de los «Anales de la Academia de Ciencias Médicas, Físicas y Naturales de la Habana", Archivo Interno del Museo de Historia Natural de Valparaíso.

Gay, Claudio. (1830). «Claudio Gay ofrece sus servicios al gobierno de Chile». En Stuardo, C. 1975, Escritos de Claudio Gay, Tomo II Fondo Histórico y Bibliográfico José Toribio Medina. Santiago de Chile: Editorial Nascimiento, 88-90.

Greenblatt, S. (2012). El giro. De cómo un manuscrito olvidado contribuyó a crear el mundo moderno. Barcelona: Crítica.

Hoja de servicio y actuación científica del prof. Dr. Carlos E. Porter, Revista Chilena de Historia Natural, Santiago de Chile, 1 de enero 1927.

Jaksic, F. Camus, P. y Castro, S. (2012). Ecología y Ciencias Naturales. Historia del Conocimiento del Patrimonio Biológico de Chile. Santiago de Chile: Centro de Investigaciones Barros Arana.

Kohl, P.; Podgorny, I. y Ganger, S. (2014). (eds.). Nature and Antiquities. The making of archaeology in the Americas. Tucson: The University of Arizona Press.

Mahan, S. (1942). «Porter, el sabio chileno ha muerto». En En Viaje, s/f. Archivo Interno Museo de Historia Natural de Valparaíso. 
Mason, P. (1998). «Infelicities». Representations of the exotic. Baltimore: The John Hopkins University Press.

Morgado, A. (2018). «La imagen de la ballena en la España Moderna». En Carretero, M., y Marchena, J. Representaciones culturales de la naturaleza alter-humana. Aproximaciones desde la ecocrítica y los estudios filosóficos y sociales. Cádiz: Editorial UCA, 97-113.

Philippi, F. (1908). Historia del Museo Nacional de Chile por el Dr. R. A. Philippi. En Boletín del Museo Nacional, tomo I. Santiago de Chile: Imprenta, Litografía y Encuadernación Barcelona, : 4.

Pimentel, J. (2003). Testigos del mundo. Ciencia, literatura y viajes en la Ilustración. Madrid: Marcial Pons Historia.

Porter, C. (1898). Guía del Museo de Historia Natural de Valparaíso. Valparaíso: Taller de San Vicente de Paul.

Porter, C. (1903). Galería de naturalistas de Chile. Don Edwyn C. Reed, 30 de junio, año VII, núm. 3, 138-140.

Reed, C. (1911). Apuntes para la Historia del Museo de Concepción. Buenos Aires: Establecimiento Gráfico Olivetti Hermanos.

Revista Chilena de Historia Natural. (1903). Periódico mensual fundado por Carlos Porter (director) el 1 de octubre de 1897. Año VII. Biblioteca Científica John Juger, Museo de Historia Natural de Valparaíso.

Rovelli, C. (2018). El nacimiento del pensamiento científico. Anaximandro de Mileto. Barcelona: Herder.

Sagredo, R. (2010). "Ciencia, historia y arte como política. El Estado y la Historia física y política de Chile de Claudio Gay». En Sagredo, Rafael (editor), Ciencia-Mundo. Orden republicano, arte y nación en América. Santiago de Chile: Centro de Investigaciones Diego Barros Arana, Editorial Universitaria, 165-234.

Saldivia, Z. (2017). Carlos Porter: un científico de dos mundos. Web. Obtenido de $<$ http://critica.cl/historia-de-la-ciencia/carlos-porter-uncientifico-de-dos-mundos> Consultada el 4 de noviembre de 2018.

Sánchez-Almazán, J. (coord.) (2012). Pedro Franco Dávila (1711-1786). De Guayaquil a la Royal Society. La época y la obra de un ilustrado criollo. Consejo Superior de Investigaciones Científicas, Madrid.

Sanhueza, C. (2016). "Objetos naturales en movimiento. Acerca de la formación de las Colecciones del Museo Nacional de Chile (18531897)». Revista de Humanidades, no 34. Julio-diciembre, : 143-169. Sanhueza, C. (ed.) (2018). La movilidad del saber científico en América Latina. Objetos, prácticas e instituciones (siglos XVIII al XX). Santiago de Chile: Editorial Universitaria.

Sanhueza, C. (2018). «Coleccionismo en el Museo Nacional de Chile (18531897)». Sanhueza, Carlos (ed.). La movilidad del saber científico en América Latina. Objetos, prácticas e instituciones (siglos XVIII al XX). Santiago de Chile: Editorial Universitaria,169-196. 
Serra, D. (2017). Plantas, rocas y animales. Colecciones de la naturaleza chilena en París y Santiago en la década de 1830. Conferencia 8 de noviembre Objetos-Actores-Saberes, Pontificia Universidad Católica de Chile.

Schell, P. (2018). Natural history values and meanings in nineteenth-century Chile. Notes and Records, Royal Society Publishing, 1-25.

Sellen, Adam T. (2014). «Fraternal Curiosity. The Camacho Museum, Campeche, Mexico». En Kohl, Philip; Podgorny, Irina; Ganger, Stefanie (eds.). Nature and Antiquities. The making of archaeology in the Americas. Tucson: The University of Arizona Press, 91-109.

Stuardo, C. (1973). Vida de Claudio Gay 1800-1873. Seguida de los escritos del naturalista e historiador, de otros concernientes a su labor y de diversos documentos relativos a su persona. Obra póstuma Escritos y Documentos con un estudio sobre Gay a través de su correspondencia, de Guillermo Feliú Cruz, tomo II, Fondo Histórico y Bibliográfico José Toribio Medina. Santiago de Chile: Editorial Nascimento.

Valenzuela, C. (2018). "Aristóteles en el Nuevo Mundo. La zona tórrida en las Historias naturales jesuitas (siglos XVI-XVII)». En Alvarado, T. Grigariadou, T., García, F. (eds.). Ecos y resplandores helenos en la literatura hispana. Siglos XVI-XXI. Madrid: Sociedad Bolivariana de Estudios Clásicos, 557. 



\title{
Historia DE VIDA DE LOS INSTRUMENTOS ASTRONÓMICOS EN CHILE. Circulaciones, ADAPTACiOnes Y APROPIACIONES (I $855^{-I}$ I866) ${ }^{\mathrm{I}}$
}

\author{
Lorena B. Valderrama \\ Universidad Alberto Hurtado
}

Carlos Sanhueza Cerda

Universidad de Chile

\begin{abstract}
Resumen. El presente trabajo analiza la historia de vida de los instrumentos del Observatorio Astronómico Nacional de Chile en sus dos primeros periodos administrativos: bajo la dirección de Karl Moesta (1855-1867) y la de José Ignacio Vergara (1867-1889). Al respecto se analizan diversas situaciones que afectan la vida de los instrumentos: su adaptabilidad al uso en un hemisferio distinto al original, dificultades del transporte, la necesidad de tecnologías asociadas, factores climáticos, utilizaciones distintas a las planificadas inicialmente y la mantención y reparación de estos. Además, estas circulaciones, adaptaciones y apropiaciones de los instrumentos generan experticias en torno a estos y se vuelven objetos de disputa entre diversos profesionales y técnicos.

Palabras Clave: instrumentos, Astronomía, Observatorio Astronómico Nacional de Chile.
\end{abstract}

Este trabajo es parte del proyecto FONDECYT-Regular N. ${ }^{\circ} 1170625$. Se agradece al citado programa el apoyo. 
Aвstract. This chapter analyzes the history of life of the instruments of the Chilean National Astronomical Observatory in its first two administrations: under the directions of Karl Moesta (1855-1867) and José Ignacio Vergara (1867-1889). In this regard, several situations that affect the life of instruments are analyzed: their adaptability to the use in a hemisphere other than the original one, transport difficulties, the need for associated technologies, climatic factors, uses different from those initially planned and the maintenance and repair of these. Furthermore, these circulations, adaptations and appropriations of instruments generate expertise around these ones and become objects of dispute between several professionals and technicians.

KeYwords: Instruments, Astronomy, Chilean National Astronomical Observatory.

\section{INTRODUCCIÓN}

Diversos son los trabajos sobre instrumentos astronómicos que se han abordado desde la historia de la ciencia durante la segunda mitad del siglo XX, principalmente centrados en la fabricación y masificación de los telescopios durante los siglos XIX y XX. Tal es el caso del trabajo de King (1955), que abarca la historia del telescopio desde el 1400 A. C. hasta el siglo XX, profundizando en estudios históricos sobre la tecnología del vidrio, la óptica, la construcción de instrumentos, la ingeniería y la astronomía práctica. Otros trabajos se han focalizado en la historia del telescopio refracto durante el siglo XIX e inicios del XX (Williams, 1997) o en el uso de tecnologías específicas como la fotografía, el fotómetro electrónico, el bolómetro, el polarímetro, el cronógrafo, el espectroheliógrafo, el espectrógrafo, los objetivos prismáticos, el interferómetro para mediciones de diámetros estelares, el telescopio zenit o el astrolabio, entre otros (Fehrenbach, 1984). Se ha abordado la historia centrada en fabricantes relevantes (Chinnici, 2017) o desde una mirada panorámica (Dunn, 2009), sin embargo, el desplazamiento de estos como 
fenómeno en sí se ha comenzado a estudiar en las últimas décadas, desde el giro praxiológico de los estudios sociales de la ciencia.

Al respecto, hay autores que proponen que los instrumentos solo adquieren su significado si pueden ser desplazados, construidos y negociados (como el experimento, solo si puede ser replicado). En este desplazamiento, el instrumento se separa primero de los contextos iniciales de su producción o usos anteriores y es reapropiado en un nuevo entorno, pero logra retener una proporción de su identidad inicial suficiente para permitir la comparación de sus datos en ambas situaciones bajo un estándar común (la original y la apropiada). En el nuevo lugar los instrumentos son calibrados, pero requieren de prácticas disciplinarias como los manuales instructivos, normas de uso y registro. En el fondo, este proceso de desplazamiento-apropiación permite analizar la construcción de una experiencia (observacional) compartida, un conocimiento común, la intersubjetividad, la confianza y el consenso, para poder proporcionar datos que tengan sentido dentro de un conocimiento global (Bourguet, Licoppe y Sibum, 2003).

Otras propuestas se centran en cuestionar la supuesta neutralidad de la tecnología. El trabajo de Pacey (2000), por ejemplo, ilustra esta problematización con varios ejemplos. Uno de los más significativos es el caso del trineo de nieve motorizado. Esta máquina fue diseñada para fines deportivos en Norteamérica, pensando en un tipo de usuario. Sin embargo, su uso se ha expandido a comunidades diversas, usándose también para fines de subsistencia y trabajo. Los esquimales, por ejemplo, han podido reemplazar sus tradicionales trineos tirados por perros por estas máquinas. Ahora bien, como toda tecnología, requiere de otras para su correcto funcionamiento: en el caso del trineo de nieve deportivo, este fue diseñado pensando en utilizarse para deportes de invierno en los centros de recreación. Está asociado a máquinas dispensadoras de combustible, instrumentos de reparación, zonas de resguardo, mecánicos capacitados, tecnologías de comunicación en caso de emergencias, etc. Los cazadores y pescadores del Ártico no cuentan con estas tecnologías asociadas, por lo que el uso del trineo durante su trabajo requiere de elementos 
adicionales, dado que ellos no tienen máquinas dispensadoras de combustible repartidas por su territorio ni tecnologías de comunicación en caso de que la máquina falle en medio de la nieve. Por esta razón, el trineo de nieve motorizado en comunidades esquimales es usado junto al trineo tradicional: la motonieve permite desplazar el trineo tradicional con perros, el cual transporta los instrumentos de reparación, gasolina e incluso los mismos perros, en caso de que la máquina falle. De esta manera, una misma tecnología puede ser usada en distintos contextos, pero no de la misma forma y, en algunos casos (como el de los esquimales), su uso requerirá del doble de trabajo que en el uso original.

Otros autores plantean que al analizar los instrumentos se puede observar la ideología tras las máquinas, pues estas son mediadores entre comunidades diferentes (la industria y la ciencia, por ejemplo) y, al mismo tiempo, son mediadores metodológicos porque permiten producir y justificar teorías, como el telégrafo, que permitió justificar la teoría electromagnética. En este marco, las personas dialogan de modo diferente con las máquinas y les designan usos que envuelven diversas ideas que tenemos sobre ellas, en un proceso de «adaptación» que es mutuo, activo y deliberado (Wise, 1988).

En este sentido cabe entonces preguntarse, ¿pueden los instrumentos tener un uso universal? ¿Son las tecnologías neutrales? ¿Qué desafíos se presentan en el tránsito y movilidad de instrumentos? El presente artículo se propone indagar los desafíos que presentaron los instrumentos del observatorio astronómico nacional durante las primeras décadas de su funcionamiento. El traslado desde el hemisferio norte y los centros de construcción, su adaptación para la observación en el hemisferio sur, su reparación y mantenimiento en el contexto local, implicaron muchas veces trabajo adicional, subutilización o desgaste de los instrumentos y disputas en torno a las experticias, aspectos que se analizarán en los apartados siguientes. 


\section{INSTRUMENTOS PARA EL HEMISFERIO SUR}

Los instrumentos astronómicos arribados a Chile a mediados del siglo XIX fueron producto particular de la circulación global del conocimiento, entendida no solo como un movimiento de ideas, sino por sobre todo de instrumentos adoptados, adaptados y reproducidos que llegaron a ser la base para que estas ideas pudieran llevarse a cabo (Hollenback y Schiffer, 2010).

En 1847, Christian Ludwig Gerling (1788-1864), de la Universidad de Marburg en Alemania, sugirió que la paralaje solar podía determinarse midiendo la posición de Venus cerca de su conjunción inferior, especialmente en puntos estacionarios, desde observatorios cercanos en su meridiano, pero distanciados latitudinalmente (Keenan, Pinto y Álvarez, 1985; Schrimpf, 2014). James M. Gilliss (1811-1865), astrónomo en el Observatorio Naval de Estados Unidos, adoptó esta idea y, a pesar de que no pudo comenzar la tarea en 1847, propuso a Gerling una expedición a Chile para el año 1849 a fin de efectuar un conjunto de observaciones que se compararían con las que realizarían sus compatriotas en los Estados Unidos. Gilliss emprendió las observaciones astronómicas desde Chile, instalando sus equipos (telescopio ecuatorial, telescopio portátil y cronómetros, entre otros), así como casetas circulares en el cerro de Santa Lucía ubicado en Santiago (Keenan, Pinto y Álvarez, 1985; Schrimpf, 2014). Desde entonces se advirtió un plan global, dado que el éxito de la empresa dependía de que se hicieran observaciones similares en el otro hemisferio y se pudiesen realizar los cálculos necesarios para establecer las distancias. Para esto se requería de una elección de instrumentos que permitieran tal empresa comparativa.

En 1852, tras la partida de Chile de Gilliss, el Estado de Chile compró los instrumentos de la expedición norteamericana y fundó el Observatorio Nacional de Chile (OAN), nombrando a Karl Moesta (1825-1884) -astrónomo alemán y discípulo de Gerling- como su director. En esta etapa fundacional se puede identificar una primera red que vinculó a Alemania, Estados Unidos y Chile: Moesta tomaba los datos en Chile y los hacía circular a los Estados Unidos y a Alemania a través de la publicación de sus resultados en el Astronomical 
Journal (EE.UU.) y en el Astronomische Nachrichten (Alemania), así como también participaba en congresos internacionales (como en la primera reunión de la Deutsche Astronomische Gesellschaft y el Congreso Astronómico Internacional del Leipzig, ambos en 1865). Desde un comienzo, la vida de los instrumentos astronómicos en Chile dependió de esta red global, destacándose la relación entre estos tres países y Alemania como el lugar de procedencia de muchos instrumentos astronómicos en el país.

¿Qué sucedió con los instrumentos tras la partida de la expedición norteamericana del país? En el primer inventario de los instrumentos realizado en 1853 se mencionan aquellos adquiridos a la expedición de Gilliss, destacándose el meridiano de Pistor y Martins fabricados en Berlín, el Ecuatorial grande (de 8 1/2 pies de largo), el Ecuatorial de Fraunhofer (de 5 pies de largo) y el Círculo de reflexión de Ortel $^{2}$.

Transcurrido un año tras la fundación del OAN, el director Karl Moesta informó sobre la labor de manutención de estos instrumentos por Luis Grosch, mecánico encargado. En esta memoria se indicaba "la compostura de un heliostato efectuada los primeros meses de 1854» (Archivo Nacional Histórico de Chile, Fondo Ministerio de Justicia e Instrucción Pública, vol. 40, 13 de agosto de 1853, sin número de identificación). En esta compostura, según Moesta, «no tuvo otra cosa que hacer el mecánico que cambiar la dirección del movimiento del espejo, adaptándolo a nuestro hemisferio» ${ }^{3}$.

2 El listado era el siguiente:

- Instrumento de meridiano (dos círculos graduados) de Pistor y Martins fabricados en Berlín.

- Ecuatorial grande (de 8 1/2 pies de largo).

- Ecuatorial de Fraunhofer (de 5 pies de largo).

- Círculo de reflexión de Ortel.

- Dos termómetros (un vertical, el otro horizontal).

- Un reloj astronómico que da el tiempo sideral.

- Un cronómetro (de tiempo sideral).

- Un cronómetro (de tiempo medio).

- Dos termómetros de comparación. Ver: Archivo Nacional Histórico de Chile, Fondo Ministerio de Justicia e Instrucción Pública, vol. 40, 13 de agosto de 1853, sin número de identificación.

3 Este instrumento pertenecía al Instituto nacional y por ello no está en el inventario de 1852. 
De esta forma los instrumentos debían ajustarse a su localización hemisférica, lo que muchas veces no solo implicaba la adaptación, sino que también la construcción de otros instrumentos a nivel local:

Es verdad que en el arriba citado inciso del decreto no se habla de la construcción de los instrumentos nuevos sino de las composturas; pero debo poner en conocimiento a U.S. que en lugar de emplear a Don Luis Grosch en las composturas que no me parecían urgentes, varias veces conveníamos con este señor que hiciese para el gabinete de física uno que otro aparato sencillo de los que nos faltaba en el Instituto (Archivo Nacional Histórico de Chile, p. 74).

Este es el caso también del Busca Cometas del OAN en 1886, bajo la administración de José Ignacio Vergara, quien reemplazó a Moesta tras su partida a Alemania. La búsqueda de cometas en la época requería de un examen detenido del cielo al menos dos veces al mes y, por lo mismo, no era posible realizarla con los grandes instrumentos, cuyo campo de visión era muy estrecho. Sin embargo, el instrumento del OAN dedicado a esta tarea había sido construido para observar los astros en el hemisferio norte y no se podía usar en Chile sin los debidos ajustes que permitieran adecuarse a la latitud:

Fue, pues, necesario agregar un apéndice para dar al eje del círculo horario la debida inclinación; esta pieza se fundió el año próximo pasado i llevada al observatorio. En este año, al armar por mí el Busca Cometas, pude notar que era indispensable agregar otra pieza mas para afianzar el eje del círculo horario en su movimiento jiratorio. Ella fue mandada construir, segun mis indicaciones, en el establecimiento de los señores Klein: (Archivo Nacional Histórico de Chile, 1886).

De esta forma, se puede apreciar cómo en el transcurso de veintiséis años los instrumentos se habían renovado y se habían adquirido nuevos para su uso en el hemisferio sur. Además se habían creado otros observatorios en el hemisferio sur que adquirían sus instrumentos en las potencias europeas, como por ejemplo el Observatorio Astronómico de Córdoba (creado en 1871) y el Observatorio Astronómico de La Plata (creado en 1883); pese a ello, los 
instrumentos astronómicos que se podían adquirir para participar de observaciones astronómicas globales que permitieran la comparación de datos con otros puntos de observación, seguían estando diseñados para el hemisferio norte.

\section{LAS AGENCIAS EXTERNAS SOBRE LOS INSTRUMENTOS}

La utilización de los instrumentos para el funcionamiento ordinario del Observatorio Astronómico Nacional de Chile no solo dependió de la relación con los astrónomos a su cargo, sino también de su vinculación con otros agentes, como el clima, los transportes y los requerimientos públicos que le hacían a la institución. Por ejemplo, en el primer informe anual sobre la marcha del OAN redactado por el director en 1857, podemos ver cómo los factores meteorológicos actuaban sobre los instrumentos determinando su utilización. Un temporal ocurrido en 1856 obligó a desmontar el Segundo Ecuatorial y, al desarmarlo, «se hizo pedazos el precioso anteojo quedando inutilizado del todo el referido instrumento»(Archivo Nacional Histórico de Chile, 1857).

También es interesante advertir cómo los instrumentos, transcurridos cinco años desde la fundación del observatorio chileno, fueron utilizados para otras observaciones que la expedición de Gilliss no siempre había considerado. En este sentido, el director Moesta informaba al Ministerio chileno sobre la adquisición en la fábrica de Pistor \& Martins de Berlín de un círculo de reflexión. Este, según Moesta, se «distingue de los círculos de reflexión usados anteriormente por tener un prisma en lugar de un espejo fijo» (Archivo Nacional Histórico de Chile, 1857). La adaptación del objeto era crucial para los nuevos usos que las instituciones chilenas le estaban dando, como es el caso del reconocimiento del territorio: «Por este arreglo dicho instrumento se hace útil en este país, sobre todo para para determinaciones geográficas de puntos en el Norte de la República durante los meses de verano, pudiéndose medir con él las alturas hasta 90 grados con la mayor exactitud» (Archivo Nacional Histórico de Chile, 1857). 
Los movimientos de instrumentos entre su lugar de fabricación y Chile no estaban exentos de dificultades de transporte. Al respecto, el informe de Moesta afirmaba:

Llegó a principio del mes pasado para este Observatorio el instrumento universal, encargado hace como dos años a los célebres [...] Repsold Hermanos en Hamburgo. Por el particular esmero con que ha sido construido este instrumento hubiera sido utilísimo a este Observatorio y a propósito para poder emprender con él una clase nueva de observaciones, si por una desgracia nada común y difícil de explicar no hubiese sufrido en el viaje descomposturas de varias piezas. No habiendo al presente en la capital un artista a quien encomendar estas composturas se ha remitido con este objeto al referido instrumento a los mismos artistas en Hamburgo ${ }^{4}$.

También los instrumentos, de poderse reparar en sus nuevos destinos, debían en ocasiones volver a sus lugares de origen, para sortear las dificultades del transporte. Tal fue el caso de la Segunda Ecuatorial que quedó inutilizable tras el temporal del 15 de junio de 1856, pues se rompió cuando la estación que la resguardaba hecha de madera colapsó encima de ella rompiéndole el anteojo. Tras esta descomposición se intentó enviar de vuelta a la fábrica de origen en Hamburgo (Repsold Hermanos) para su reparación:

[...] fue encajonado luego después i mandado junto con otro pequeño instrumento de pasos i otro aparato á Valparaíso con el objeto de embarcarlos allí i de remitirlos el todo a la fábrica de Repsold Hermanos en Hamburgo para su pronta reparación. Desgraciadamente dichos cajones están en la Comisaria de Marina de Valparaíso hasta hace poco por la falta de un buque para Hamburgo (Archivo Nacional Histórico de Chile, 1857).

Sin embargo, al no conseguir un buque que viajara a esa ciudad hubo que esperar hasta junio de 1857 para que esto sucediera y hasta 1859 para contar con el instrumento reparado, el cual finalmente fue

4 Archivo Nacional Histórico de Chile, Fondo Ministerio de Justicia e Instrucción Pública, vol. 84, Memoria del OAN 1857, mayo 20 de 1857. 
refaccionado por la Casa Steinheil en Munich, proveyéndolo de un fotómetro para mediciones de mayor exactitud (Archivo Nacional Histórico de Chile, 1857). De este modo, la comunicación entre el OAN y los fabricantes en Europa resultaba crucial para la vida y el uso de tales objetos, en la medida en que en Chile no pudieran repararse, ya fuese porque no existían las piezas necesarias, o porque acá no se realizaban ese tipo de reparaciones.

\section{LAS TECNOLOGÍAS ASOCIADAS}

Además de los problemas que enfrentaban los instrumentos y que repercutían en la calidad de la información que estos podían obtener, también requerían de tecnologías asociadas que limitaban su uso y correcto funcionamiento. Por ejemplo, en 1885 el Círculo Meridiano de la institución tenía un problema de disminución de la inclinación, debido a que las pilastras sobre las cuales estaba montado el círculo meridiano se dilataban por el viento suroeste ${ }^{5}$. También se había gastado un tornillo de corrección, y la limpieza de los pivotes había producido que estos perdieran su forma cilíndrica. La solución local fue reemplazar el tornillo y envolver estas pilastras, para que la inclinación se mantuviera constante. Pese a ello, la inclinación no se lograba mantener estable y, por lo tanto, no permitía lograr con exactitud las observaciones. Por esta razón, el segundo astrónomo intentó enviar el círculo meridiano a los fabricantes en Europa para su reparación, solicitud que fue rechazada por el director del observatorio, con la excusa de que «en otros Observatorios las cosas tampoco se hacen con tanta prolijidad» (Archivo Nacional Histórico de Chile, 1885 ). En 1886 los astrónomos intentaron nuevamente solucionar el problema, sin mayores resultados.

En otros casos, los instrumentos precisaban otras tecnologías que no existían necesariamente en los contextos locales, como lugares de almacenamiento adecuados que permitieran usar el instrumento y luego dejarlo bien resguardado como torres, portalones y casuchas, entre otros. Tal fue el caso de los ecuatoriales del OAN en la

5 Entre 2", 3', según la misma carta. 
década de 1880, cuya torre de resguardo presentaba deficiencias que produjeron deterioros en los instrumentos e imposibilitaron tareas científicas:

En el interior de la torre se había amontonado escalas y tablas. Las escalas estaban amarradas al tubo del telescopio con gruesos cordeles ¿acaso para que no se cayeran las escalas o el telescopio (...) La construcción de la torre fue errada desde el principio, pues no se puede hacer girar la cúpula ${ }^{6}$ (Archivo Nacional Histórico de Chile, 1885).

Otra situación similar fueron los problemas ocasionados por la apertura de los portalones de la torre que albergaba al Gran Ecuatorial y el mecanismo giratorio de la brújula de la torre. Los portalones de la torre no se conseguían cerrar del todo, ocasionando que aves y la lluvia entraran, ensuciando el instrumento y produciendo moho en sus partes. De igual manera, la torre no giraba de manera expedita requiriendo de dos peones y media hora de trabajo físico, para lograr girar solo 90 grados. De esta forma, el instrumento no pudo ser usado para la observación de una estrella rojiza en Orión y el cometa de Fabry, teniendo el astrónomo del OAN que usar «para ello el viejo Ecuatorial de seis i media pulgada de abertura, instrumento deficiente en cuanto a la parte óptica i micrométrica ${ }^{7}$ (Archivo Nacional Histórico de Chile). Para solucionar este problema el OAN recurrió a una fundición local de inmigrantes alemanes

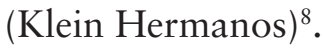

La estación de resguardo del Buscacometas del observatorio, también fue construida inicialmente por la misma Fundición con

6 Carta de Wickmann a Marcuse, 25 de diciembre de 1885. Respecto al ecuatorial de 6 pulgadas Wickmann afirmó: «Inutilmente me he esforzado por obtener observaciones servibles con el micrómetro anular. Fue imposible. Arranqué el anillo y lo boté. El micrómetro filar está también en el mismo mal estado. El círculo de posición está torcido, además no se pudo ver con ese instrumento ninguno de los cometas del último año».

7 Informe de Marcuse a petición de Vergara,16 de agosto de 1886.

8 Archivo Nacional Histórico de Chile, Fondo Ministerio de Justicia e Instrucción Pública, vol. 554, Documento N. ${ }^{\circ}$ 2, Contrainforme de Wilhem Wickmann, 18 de agosto de 1886. 
una «base de fierro necesaria para la altura polar» ${ }^{9}$. Sin embargo, tiempo después el arquitecto Eloy Cortínez Fuentes (1841-1905) le construyó un edificio siguiendo las indicaciones del primer astrónomo, las cuales no habrían sido las adecuadas a juicio del arquitecto, dado que el astrónomo la habría pedido en ladrillo y este material absorbía mucha humedad y la expandía por el instrumento, por lo que habría sido «más adecuado utilizar piedra» ${ }^{10}$.

El gran pedestal del Buscacometas se construyó de albañilería de cal y ladrillo y cimiento Portland. Mi opinión fue que debería ejecutarse de piedra con mezcla de cimiento Portland, por ser este material más resistente, barato [...] para las construcciones bajo tierra ${ }^{11}$.

\section{LAS EXPERTICIAS SOBRE EL INSTRUMENTO}

Las circulaciones, adaptaciones y apropiaciones de los instrumentos generan experticias que son disputas entre diversos profesionales y técnicos. La acción reparativa, por ejemplo, permite a algunos actores catalogados en niveles más técnicos posicionarse ante los que ostentan cargos científicos, cuestionando los usos dados a dichos instrumentos o los diseños originales (Edgerton, 2008; Henke, 1999). ¿Quién es la persona indicada para discernir la utilidad y calidad de un instrumento científico? ¿Es quien realiza las observaciones, o quien se encarga de reparar los instrumentos la persona más capacitada para evaluar el estado de este?

En el caso del OAN se han podido señalar disputas de experticias entre mecánicos, arquitectos y astrónomos. Tal es el caso de la reparación de los problemas de inclinación que presentaba el círculo meridiano del OAN, en 1885. Como no se pudo enviar el instrumento

9 «Documentos relativos a los trabajos de este establecimiento remitidos por el señor ministro de Justicia a la Honorable Cámara de Diputados y mandados a publicar el 17 del corriente» (1886), Santiago, Imprenta Nacional, p.15.

10 «Documentos relativos a los trabajos de este establecimiento remitidos por el señor ministro de Justicia a la Honorable Cámara de Diputados y mandados a publicar el 17 del corriente» (1886), Santiago, Imprenta Nacional, p.19.

11 «Documentos relativos a los trabajos de este establecimiento remitidos por el señor ministro de Justicia a la Honorable Cámara de Diputados y mandados a publicar el 17 del corriente» (1886), Santiago, Imprenta Nacional, p.19. 
a Alemania para que lo repararan, se le pidió al mecánico del OAN (Luis Grosch) que lo arreglara: esto produjo una disputa entre el técnico y el segundo astrónomo que lo usaba para su trabajo, que era quien había notado los errores (Wilhelm Wickmann). Según Grosch, el instrumento no poseía ningún problema de inclinación y permitía obtener datos de buena calidad. Wickmann, por el contrario, insistió en que el mecánico estaba equivocado, desacreditándolo, pues «no era costumbre en otros países preguntar cuestiones astronómicas a un zapatero, sastre o mecánico, que lo mismo me importaba lo que dijera el portero (Archivo Nacional Histórico de Chile, 1885)» ${ }^{12}$. Para el astrónomo, el mecánico no comprendía la disciplina y la práctica de observación; mientras que, para el mecánico, el astrónomo era quien no estaba usando bien el instrumento ni realizando correctamente las observaciones. Esta discusión y deslegitimación mutua escaló a tal nivel dentro del observatorio que, finalmente, el mecánico cerró con llave la sala donde estaba el instrumento, para impedir por cuatro meses que el astrónomo realizara observaciones. Disputas de este tipo afectaban la práctica observacional, generando frustraciones dentro de la institución:

Yo esperé y trabajé privadamente, pues por fortuna habia traido conmigo toda mi biblioteca [...] Por fin y después de 17 meses obtuve el permiso de hacer arreglar el instrumento. El mecánico está fuera de sí de rabia; no me importa, no le haga caso. Por el momento estoi ocupado en el arreglo de los microscopios y creo poder en poco tiempo poder acomodarlos todos, a fin de tener al menos un instrumento servible ${ }^{13}$. (Archivo Nacional Histórico de Chile, 1885).

En otros casos, como en controversias públicas, estas disputas de saberes se resolvieron consultando a una persona externa que pudiera dirimirlas, indicando quién tenía la razón. Tal es el caso de la disputa sobre el estado del Gran Círculo Meridiano de seis pulgadas del OAN, el cual probablemente había llegado a la institución en 1882 desde Lima tras el conflicto bélico con Perú y Bolivia

12 Carta de Wickmann a Marcuse, 25 de diciembre de 1885

13 Carta de Wickmann a Marcuse, 25 de diciembre de 1885 
(1879-1883). Esta acusación formó parte de un debate público abierto en el Parlamento, que acusaba de mala gestión al director del Observatorio (José Ignacio Vergara), quien al mismo tiempo era ministro del Interior. En esta acusación los trabajadores del OAN se encontraban divididos en cuanto a las percepciones sobre el estado real de los instrumentos científicos, acusándose mutuamente de dañar los instrumentos o tratarlos con negligencia.

Sobre el Gran Círculo Meridiano, el mecánico del OAN (Grosch) culpaba en 1886 al primer astrónomo (Adolfo Marcuse) de haber realizado un mal trabajo construyendo los soportes: «la construcción fue mal dirigida, quedando las pilastras muy abiertas, y, a mi juicio, inapropiada para su destino, que [era] examinar por medio de ellos el instrumento con toda escrupulosidad ${ }^{14}$. Marcuse se defendía indicando que el instrumento se encontraba en mal estado antes de su llegada y que el mal mantenimiento del mecánico había producido dichos problemas, evidenciando su postura con una carta que el segundo astrónomo (Wickmann) le había enviado un año antes, en 1885:

El tercer instrumento, el Circulo Meridiano, tambien lo encontré en un estado inservible. Sus nivelaciones no servian: en el curso de 10 minutos encontré como inclinacion del eje $+6 ", 4 ",-7 ",+5$ ", etc. ¿Qué podia hacer yo? Por fortuna me guardé de desarmar el nivel para averiguar el motivo, en lo que, segun vi despues, habia hecho muy bien y esperé seis semanas hasta que el mecánico volvió de su viaje. Resultó que un tornillo estaba gastado, y le habian metido cañoncitos de plumas para ocultar la cosa. Esto probablemente habia sido la obra de uno de los muchachos, pero por detrás me echaron la culpa a mí. Puedo asegurarle que he obtenido esperiencia [...] Desde luego se manifiesta grandes diferencias en la inclinacion. En otro tiempo se habian enmohecido los pivotes y habian sido limpiados por nuestro famoso mecánico. Naturalmente que perdieron su forma cilíndrica ${ }^{15}$. (Archivo Nacional Histórico de Chile, 1885).

14 «Documentos relativos a los trabajos de este establecimiento remitidos por el señor Ministro de Justicia a la Honorable Cámara de Diputados y mandados a publicar el 17 del corriente» (1886), Santiago, Imprenta Nacional, p.17.

15 Carta de Wickmann a Marcuse, 25 de diciembre de 1885 
Dado que claramente los trabajadores del OAN se encontraban enfrentados en sus peritajes sobre el instrumento en cuestión, el ministro de Instrucción Pública pidió un informe al arquitecto Eloy Cortínez, quien no estaba contratado por el OAN y que solo había hecho algunos arreglos en el OAN por encargo del Ministerio de Justicia. Cortínez explicó que él, durante 1886, había realizado diversos arreglos a los soportes de los instrumentos bajo la supervisión del primer astrónomo (incluido los arreglos a los soportes del Círculo Meridiano), pero este no solo no le había facilitado los planos para realizar los trabajos, sino que además ignoró sus recomendaciones y le dio instrucciones erráticas que "cambiaban todos los días» ${ }^{16}$.

\section{Conclusiones}

En el presente capítulo hemos podido observar cómo la adaptabilidad de los instrumentos creados para la observación astronómica en el hemisferio norte dependió del uso dado a estos en el hemisferio sur, lo que trajo dificultades de diverso tipo: transporte, creación de tecnologías asociadas, adaptaciones al clima, mantenimiento y reparación. De esta manera, no es posible considerar los instrumentos astronómicos como neutrales, que pueden ser usados de igual manera en contextos locales, porque los diversos testimonios de quienes trabajaron con ellos dan cuenta de que no habían sido creados para la observación astronómica en el hemisferio sur. Este proceso de apropiación fue necesario y activo en la medida en que el uso no solo se adaptaba al instrumento, sino que el propio uso y su contexto modificaban el instrumento mismo, lo que traía una carga adicional de trabajo al OAN, pues debía resolver una serie añadida de problemas, desde la adaptación de ángulos hasta la reparación. Su uso, por lo tanto, al igual que el trineo motorizado planteado por Pacey (2000), requirió del doble de trabajo, pues, por ejemplo, se tuvieron que arreglar los mecanismos giratorios. De igual manera, los fabricantes, localizados en su mayoría en Alemania, podían efectuar

16 «Documentos relativos a los trabajos de este establecimiento remitidos por el señor Ministro de Justicia a la Honorable Cámara de Diputados y mandados a publicar el 17 del corriente» (1886), Santiago, Imprenta Nacional, p.19. 
reparaciones en caso de que estos se dañaran, pero la distancia entre Chile y Alemania aumentaba el costo y dificultaba su pronta reparación, inutilizando el instrumento incluso por varios años.

De igual manera, se configuraron experticias locales en torno a los instrumentos, que aparentemente no se condecían con la legitimación de estos expertos en observatorios europeos, como fue el caso de la disputa entre astrónomos y mecánicos. Los distintos actores que trabajaban en el observatorio se disputaban la autoridad para evaluar y juzgar la calidad de los instrumentos y observaciones que estos permitían. Esto produjo inevitables disputas entre los mecánicos y los astrónomos, que incluso algunas veces tuvieron que ser resueltas por terceros externos. Ambos aspectos (la apropiación y la configuración de experticias) produjeron y reprodujeron tensiones en la práctica científica, no permitiendo muchas veces el trabajo de los astrónomos, generando frustraciones entre los diversos trabajadores de la institución.

\section{FUENTES PRIMARIAS}

Anónimo. (1886). Documentos relativos a los trabajos de este establecimiento remitidos por el señor Ministro de Justicia a la Honorable Cámara de Diputados y mandados a publicar el 17 del corriente. Santiago: Imprenta Nacional.

Vol. 40, 13 de agosto de 1853, Fondo Ministerio de Justicia e Instrucción Pública, Archivo Nacional de Chile.

Vol. 186 (74), sin fecha, Fondo Ministerio de Justicia e Instrucción Pública, Archivo Nacional de Chile.

Vol. 84, 20 de mayo 20 de 1857, Fondo Ministerio de Justicia e Instrucción Pública, Archivo Nacional de Chile.

Vol. 554, 25 de diciembre de 1885, Documento N. ${ }^{\circ}$ 9, Carta de Wickmann a Marcuse, Fondo Ministerio de Justicia e Instrucción Pública, Archivo Nacional de Chile.

Vol. 554, 18 de agosto de 1886, Documento N. ${ }^{\circ}$ 2, Contra-informe de Wilhem Wickmann, Fondo Ministerio de Justicia e Instrucción Pública, Archivo Nacional de Chile.

Vol. 554, 20 de septiembre de 1885, Documento N. 9 "Carta de Wickmann a Marcuse”, Fondo Ministerio de Justicia e Instrucción Pública, Archivo Nacional de Chile. 


\section{BiBLIOGRAFÍA}

Bourguet, M. N., Licoppe, C y Sibum, O. (2003). Instruments, Travel, and Science: Itineraries of Precision from the Seventeenth to the Twentieth Century. London: Routledge.

Chinnici, I. (2017). Merz Telescopes. A global heritage worth preserving. Cham: Springer.

Dunn, R. (2009). The Telescope. A short History. London: Conway.

Edgerton, D. (2008). The shock of the old. Technology and global history since 1900. London: Profile Books.

Fehrenbach, C. (1984). Twentietn-century instrumentation. En O. Gingerich (Ed.), The general history of Astronomy, Vol. 4. Cambridge: Cambridge University Press, 166-189.

Henke, C. R. (1999). «The Mechanics of Workplace Order: Toward a Sociology of Repair». Berkeley Journal of Sociology, 44, 55-81.

Hollenback, K. L. y Schiffer, M.B. (2010). »Technology and material life». En D. Hicks y M.C. Beaudry. The Oxford Handbook of Material Culture Studies. Oxford: Oxford University Press, 313-332.

Keenan, P. C., Pinto, S. y Alvarez, H. (1985). The Chilean National Astronomical Observatory (1852-1965). Santiago: Universidad de Chile.

King, H. C. (1955). History of Telescope. New York: Dover Publications. Pacey, A. (2000). The Culture of Technology. Massachusetts: The MIT Press. Schrimpf, A. (2014). "An International Campaign of The 19th Century to Determine the Solar Parallax - The US Naval Expedition to The Southern Hemisphere 1849-1852». The European Physical Journal, 39(2), 1-20.

Williams, T. R. (1997). «Telescopes since 1820». En J. Lankford (Ed.). History of Astronomy. An Encyclopedia. New York-London: Taylor \& Francis, 519-527.

Wise, M. N. (1988). "Mediating machines». Science in Context 2(1), 77113. 



\title{
Ciencias y letras. Discursos De TRANSICIÓN SOBRE LA COMPRENSIÓN CIENTÍFICA EN TORNO A LOS MAPUCHE $\left(\right.$ I $900-$ I9IO) ${ }^{\mathrm{I}}$
}

\author{
Martín Lara Ortega ${ }^{2}$ \\ Universidad Autónoma de Chile
}

Resumen. El presente artículo tiene por objetivo analizar la concepción sobre los mapuche de Tomás Guevara y Nicolás Palacios. La hipótesis de la investigación sostiene que ambos autores construyen discursos de transición sobre el conocimiento mapuche, situándose como un engranaje entre los viejos textos coloniales y las investigaciones monográficas de las ciencias contemporáneas. Para la validación de la hipótesis se trabajará en base a dos nudos analíticos: el paradigma positivista y la noción de decadencia, mediante el trabajo de campo como ejercicio positivista y el racismo como noción de decadencia. Finalmente se sostendrá que estos autores junto con ser precursores del racismo, también lo serán de las primeras investigaciones indigenistas en Chile.

Palabras Clave: Decadencia, mapuche, positivismo, raza.

1 Una idea preliminar de este texto fue presentada en el seminario Tendencias y perspectivas de la Cultura Científica en Chile entre los siglos XIX y XXI desarrollado en la Universidad Autónoma de Chile en agosto del año 2018. En las XIX Jornadas de Historia regional de Chile, organizado por la Universidad de Los Lagos en noviembre del mismo año, se discutieron ideas que dieron forma final a este artículo.

2 Estudiante de Doctorado en Historia de la Universidad Autónoma de Chile y de Doctorado en América Latina y Unión Europea en el Contexto Internacional de la Universidad de Alcalá. Correo electrónico: martinlara@uc.cl 
Aвstract. The objective of this article is to analyze the perception of the Mapuche of Tomás Guevara and Nicolás Palacios. The hypothesis of this research maintains that both authors construct transitional discourses on what they know about the Mapuche, situating themselves between the old colonial texts and the monographic research of contemporary sciences. For the validation of the hypothesis we will work on the basis of two analyses, the positivism paradigm and the notion of decadence through positivist fieldwork and racism. Finally, it will be argued that these authors, along with being precursors of racism, will also be the first indigenous research in Chile.

KEYwORds: Mapuche, race, positivism, decadence.

\section{Presentación}

En vísperas de la celebración del Centenario de la Independencia de Chile, la cuestión mapuche fue prácticamente inexistente en los discursos de la elite política y de la prensa santiaguina, donde, muy de vez en vez, apareció algún tipo de noticia sobre dicha comunidad indígena. Caso contrario sucedió en algunas publicaciones de las ciencias sociales, que crecientemente empezaron a tomar a los mapuche como caso de estudio en sus investigaciones y que, bajo diversas premisas, fueron elaborando una serie de categorías que serán consideradas como verdades. A partir de lo anterior, el presente artículo que se sitúa teóricamente desde los aportes de la historia cultural de la ciencia (Hartley y Potts, 2014) (Harrison y Roberts, 2019) tiene por objetivo analizar el conocimiento generado desde las ciencias sobre los mapuche para evidenciar, mediante casos de estudio, de qué forma se construyó una serie de relatos que conformarán «discursos de transición» sobre la episteme mapuche. Las fuentes que se utilizarán son investigaciones publicadas por Tomás Guevara y Nicolás Palacios durante la primera década de 1900, ya que a estos dos autores, provenientes desde tradiciones disciplinares como la antropología y la medicina, los consideramos de referencia histórica por el alto impacto de sus publicaciones en la sociedad de la época. La metodología de trabajo se sostendrá en el estudio de casos mediante la correlación 
heurística y sincrónica de dichas fuentes publicadas, entendiendo que en ellas se generan nudos analíticos de convergencia que permiten dilucidar no solo un espíritu de época, sino también de un discurso fundante de las ciencias sociales (Bengoa, 2014).

\section{I900-I9IO. UNA ETAPA DE TRANSICIÓN EN EL DISCURSO SOBRE LOS MAPUCHE}

Nuestra hipótesis de trabajo considera que la década de 1900 es una etapa de "discursos de transición» del conocimiento científico sobre los mapuche, debido que en este arco de tiempo se da un desplazamiento protagónico de los textos coloniales en torno a los mapuche, para dar espacio a las primeras investigaciones referidas a dicho pueblo indígena por parte de las incipientes ciencias que en Chile se desarrollaron a fines del siglo XIX y principios del siglo XX.

Si bien durante gran parte del siglo XIX se dio un impulso por parte del Estado a las investigaciones históricas sobre el pasado de Chile, muchas de ellas siguieron recurriendo a las tradicionales crónicas indianas de los siglos XVI y XVII e investigaciones propiamente históricas como las desarrolladas en el siglo XVIII. El ejemplo más notable al respecto lo da Claudio Gay en su Historia física y politica de Chile (1844), quien, al referirse al universo mapuche, toma gran parte de esa información de las lecturas de autores coloniales como Alonso Góngora Marmolejo, Diego de Rosales y Juan Ignacio Molina. Si bien en el transcurso del siglo XIX se dan algunas excepciones como Aborígenes de Chile (1882) de José Toribio Medina, este tiende a ser una excepción a la regla.

Esta dinámica de repetición de la información colonial se debe, a nuestro entender, a la consideración de las obras coloniales como canon establecido del conocimiento de los mapuche, que para la sociedad del siglo XIX sigue siendo un pueblo bárbaro, deleznable y lejano culturalmente. De esta forma, la concepción de la Historia Natural que tuvo predilección por los elementos de la naturaleza por sobre los humanos, y de los artefactos humanos por sobre las sociedades que los generaban, lentamente empieza a ser remplazada por las nuevas ciencias que buscan comprender el mundo a partir de los elementos y tópicos no observados por la vieja Historia Natural (Wilson, 2018). 
De este modo, las nuevas ciencias contemporáneas como la historia, antropología, medicina y arqueología rápidamente se constituyeron no solo como un medio de transmisión de conocimiento sobre el hombre, la cultura y sus distintas manifestaciones, sino que también algunas de ellas, como la antropología y arqueología, tendrán una especial predilección por lo exótico y lejano culturalmente respecto a la cultura occidental (Gänger, 2014), mientras que otras, como la historia, lo tendrán por desentrañar la constitución social de los estados en formación (Salomon, 2018). En base a lo anterior, se puede considerar que las ciencias recién mencionadas se caracterizaron por generar decididamente un relato consistente para autorreconocerse como la salvaguarda del desarrollo de la civilización occidental y como una verdadera alternativa a las ciencias naturales. Más aún, a nivel global, fenómenos como la consolidación de los nacionalismos en distintas partes del globo, la profesionalización de las nuevas ciencias sociales, o la creciente red de comunicaciones que hizo más fácil el contacto entre científicos, dieron cabida a un inicio de siglo mucho más dinámico y supuestamente esperanzador de su labor y contribución a la construcción de la nación (Pavez, 2015). Puntualmente para el caso chileno, estas ciencias tendrán un espacio privilegiado, pues ellas fundamentalmente podrían consolidar y dar solución a los principales problemas que para la década se estaban haciendo notar: la definición jurídica del territorio nacional; el surgimiento de los problemas sociales $^{3}$; la explosión demográfica ${ }^{4}$; y el creciente debate en torno a

3 Los cambios no son cambios sin cierta tragedia. En estas palabras, Donoso (1963) resume la cuestión: «Disturbios sangrientos, severamente reprimidos por las autoridades, como fueron la huelga del personal de la Compañía Sudamericana de Vapores, en Valparaíso, en mayo de 1903, y la que se produjo en Santiago dos años más tarde, octubre de 1905. En febrero de 1906, se planteó otra en el puerto de Antofagasta; pero la más grave de todas fue la que estalló en el puerto de Iquique, en diciembre de 1907, donde se concentraron más de quince mil trabajadores procedentes de la pampa salitrera, que tomó un carácter subversivo. La fuerza pública disolvió la concentración de los obreros albergados en la escuela Santa María de esa ciudad, acto en que resultaron centenares de muertos y heridos» (pp. 97-98).

4 En 1907 la población total ascendía a 3.200.000 personas, de las que un 56,8\% residía en zonas agrícolas. Este aumento se debió no solo al crecimiento vegetativo, sino que también a la inclusión de los nuevos habitantes que aportaron las 
la supremacía entre el legislativo y ejecutivo, mediante modificaciones e interpretaciones de la Constitución de 1833.

Sobre todo lo anterior, se puede entender de qué forma aparecen los mapuche en el escenario de las ciencias. Dicho pueblo era considerado el eslabón entre la modernidad y el viejo tiempo colonial; una mezcla entre un exotismo social dentro del territorio y barbarie cultural en supuesta decadencia. En definitiva, los mapuche se convirtieron en un dilema por develar para las nuevas ciencias.

En este periodo de estudio, las ciencias transitan su devenir con la hipótesis de que el desarrollo humano se encuentra en una constante encrucijada: mientras algunos grupos sociales demuestran en su dinámica cultural un decidido progreso en sus formas de vida, en otros se da el caso contrario, manifestándose una clara evidencia de la decadencia de estas. Al respecto, la confluencia de la biología y filosofía, a través del evolucionismo darwinista y del historicismo hegeliano en que se vincularon raza y cultura, es uno de los símbolos rastreables en la mayoría de los argumentos científicos del Cono sur y de Chile en particular (Barceló, 2003).

Evidentemente, en nuestro país, se daba esta dicotomía cultural, al reconocer de forma generalizada que las comunidades indígenas no conformaban parte de la nación chilena (Harambour y Barrena, 2019). La sociedad chilena y en particular su grupo dirigente, caracterizada por su marcada identidad urbana, liberal y católica, asentada en el valle central y con una clara conciencia de sí misma, sobre todo, gracias a los resultados de una economía pujante y dinámica, se posicionaba en una situación opuesta a las comunidades mapuche que, en general, eran altamente rurales, aún en algunos casos politeísta y deprimida económicamente. Esta diferencia económica y social — que se daba bajo un mismo territorio— obligó a la intelligentsia nacional a dar una respuesta del porqué de esa diferencia, buscando identificar la génesis de aquel pueblo, sus características y sus potencialidades, si es que las había.

provincias salitreras del norte: Tacna, Arica, Antofagasta; la fronteriza Araucanía y la provincia austral de Magallanes. Para más detalles ver Andrés Estefane (2004). 
Con todo, las ciencias cumplieron un rol nada despreciable en dicho marco referencial. Este desarrollo científico se produjo en una frágil ambivalencia entre el positivismo, que se viene arrastrando desde mediados del XIX, y la noción de decadencia como precepto ideológico, afincado con fuerza en Chile desde principios del siglo XX. Es decir, la transición de las letras científicas se dará entre estas dos miradas que conforman un complejo e intrincado marco analítico para nuestro objeto de estudio.

Este cuadro mayor, que girará en torno a la idea de positivismo (como enfoque de las investigaciones) y decadencia (como postulado del estado social), se analizará en este texto mediante dos nudos analíticos: el estudio mapuche en su territorio y su raza como componente de la sociedad chilena. Ambos ejes creemos que son los que permitieron generar un cuadro reactivo hacia el estudio de los mapuche.

\section{LOS MAPUCHE EN SU TERRITORIO: EL POSITIVISMO Y SU PRÁCTICA}

El positivismo, como teoría científica del siglo XIX y principios del siglo XX, tuvo entre sus características fundamentales consignar la realidad mediante marcos analíticos medibles y empíricamente comprobables, es decir, la viabilidad de un postulado se sustentaba en la comprobación de la hipótesis de trabajo. Este principio reconocido obsecuentemente por los cientistas sociales, no impidió que se reprodujeran prejuicios sociales, étnicos y raciales dentro de la comunidad científica convertidos en verdades incuestionables, como lo demuestran trabajos como los de Stephen Gould, La falsa medida del hombre (1997), o más recientemente el trabajo conjunto de Philip Kohl, Irina Podgorny y Stefanie Gänger, Nature and Antiquities (2014).

Ya para la década de estudio, el territorio ancestral mapuche —salvo pequeños espacios rurales aislados de la cordillera de los Andes y zonas costeras- estaba totalmente dominado por el Estado: ferrocarriles, ciudades y asentamientos de migrantes europeos conformaban gran parte del paisaje de la llamada «frontera». A pesar 
de esto, es de suponer que los indígenas seguían conformando un porcentaje considerable de la población, sobre todo en el ámbito rural, superando con creces, según autores como Tomás Guevara, los cien mil habitantes (Guevara, 1910) (Comisión Central del Censo, 1908). En este marco, para la ciencia constituía un verdadero campo abierto para nuevas investigaciones ${ }^{5}$. Así, las posibilidades de adentrarse en territorio mapuche resultaban mucho más fáciles que en la época de Claudio Gay, Ignacio Domeyko o Gustave Verniory. Ahora, fácilmente se podía acceder a ellos, en su propio hábitat, para reconocerlos mediante su descripción, clasificación y tipificarlos según sus características culturales.

Según todo lo anterior, podemos decir que el estudio de campo, exigencia básica en la metodología para investigaciones etnológicas, puede ser considerado como un catalizador del cambio de imagen del mapuche. La convivencia con ellos y el análisis de sus formas de vida y pensamiento, permitieron un acercamiento cualitativo entre dos mundos que hasta hacía muy poco tiempo se consideraban diametralmente antagónicos; ahora, al mapuche se le consideró desde la cautela que el método científico promovía para sus objetos de estudio.

Uno de los cientistas sociales que durante esta década se acercaron al mapuche y lo consideraron como objeto de estudio fue Tomás Guevara (1866-1938). Formado como profesor de Castellano en el Instituto Pedagógico de la Universidad de Chile, realizó una carrera profesional que se centró en la enseñanza de su especialidad y el trabajo directivo de centros educacionales. Comisionado por el gobierno como profesor en el Liceo de Angol y más tarde como director del Liceo de Temuco, pudo realizar trabajo de campo en algunas comunidades mapuche, como la de Cholchol y, sobre todo, recurrir a sus propios estudiantes para el desarrollo de sus ideas. Sus investigaciones se vieron plasmadas en tres obras: Costumbres judiciales i enseñanza de los araucanos (1904); Psicolojía del pueblo

Lo que tenemos claro, gracias a investigaciones como las de Cristián Báez y Peter Mason (2006) y Jorge Pavez (2002), es un posible motivo del interés de los científicos sociales por los grupos primitivos. Existía una premura para estudiarlos porque se preveía su pronta desaparición o extinción. El hecho de que les reconocieran como ancestros era el otro argumento principal para su estudio. 
araucano (1908) y Los araucanos en la revolución de independencia (1910). En las tres obras de Guevara se denotan nudos analíticos que se tienden a repetir insistentemente sobre los mapuche: afirmaciones en torno a la inferioridad de su capacidad moral; noción de decadencia de su cultura en detrimento de una superior; y falta de flexibilidad para apropiarse y adaptarse a la sociedad occidental.

Con respecto a la primera investigación, que para el autor es de naturaleza histórica y sociológica (Guevara, 1904), se recurre a la lectura de las viejas crónicas coloniales para ser contrastada con el trabajo de campo desarrollado por él y que se logra mediante entrevistas con informantes mapuche que dan testimonio del pasado de sus comunidades. No es casualidad que, en su mirada positivista, ya de entrada y a lo largo de los ocho capítulos, considere al mapuche como «raza» y que entre líneas la denote como en vísperas de extinción. Es decir, el prejuicio de Guevara será una constante, no solo en este texto, sino en toda su obra posterior.

La obra, tal como reza su título, recoge y analiza las principales manifestaciones de justicia y educación que se dan en las comunidades. Sin embargo, en la lectura de la obra, el ejercicio que realiza Guevara es exponer los actos sociales moralmente prohibidos de su época y cómo paralelamente los mapuche, bajo su costumbre, solucionaban dichas diatribas. Las formas de violencia doméstica son ampliamente recogidas en la obra, como cuando describe la violencia física ejercida de hijo a padre al decir que "por una tendencia comun a los jóvenes de las asociaciones bárbaras, resistia en ocasiones, a su padre i lo golpeaba sin miramiento, desman que hasta hoi es frecuente»(Guevara, 1904, p. 28). Otras formas de violencia que son tratadas en la obra son el incesto, violaciones sexuales, robos y alcoholismo. Veamos un ejemplo de su análisis sobre la prostitución:

La prostitucion, forma de comercio sexual de que no han, estado exentas las aglomeraciones bárbaras, tuvo por esto en las costumbres araucanas la estension que se calculará. Hasta el presente existe, aunque no en el número ni con la libertad de ántes, una clase de mujeres designadas ñua o mangeve, que recorren las reducciones o asisten a las fiestas para, ejercer el vil oficio. (Guevara, 1904, p. 23) 
Lo que hace el autor en esta cita es constatar que la prostitución es una práctica habitual en el universo mapuche, existiendo, de hecho, un concepto para quienes se dedican a tal práctica; y, si bien reconoce que esta ha ido disminuyendo solapadamente por influjo moderno, su naturaleza sigue siendo inmoral. Ahora bien, la inmoralidad es un trasfondo mucho más complejo del universo mapuche, pues sería la causa de la inexistencia de juicios morales, sobre todo por la tesis central de su obra, que dice en relación con la inexistencia de justicia:

La idea abstracta de justicia no puede tener cabida en el horizonte moral restrinjido del hombre inculto. No concibe lo que es crimen, ni distingue la diferencia entre lo que es discusión de intereses i delito, entre lo civil y lo criminal. La lengua solo designa jenéricamente con la palabra huerin lo que es falta o malo. (Guevara, 1904, p. 40)

Esta ausencia de justicia para Guevara, a su vez, responde a un tema de fondo: la limitación de su inteligencia, pues para él: «Su actividad cerebral es restrinjida; no posee la facultad de reflexionar demasiado, porque se fatiga i distrae, i por lo tanto, de producir concepciones complejas» (Guevara, 1904, p. 85).

En su segunda obra, Psicolojía del pueblo araucano (1908), sus postulados son más audaces, pues lo que hace es reafirmar ideas del texto anterior con contundentes pruebas empíricas extraídas del trabajo de campo. Fundamentalmente, lo que hace es poner en escena las serias limitaciones que tanto hombres como mujeres mapuche tienen con respecto a determinados estímulos de orden mental. Claramente, su práctica positivista está más cargada de prejuicios culturales que de verdaderos resultados científicos.

Su premisa sobre los mapuche descansa en que estos, en tanto grupo cultural inferior, propio de razas primitivas, no poseen las mismas potencialidades que grupos más evolucionados:

Constituye una ley conocida que los rasgos psíquicos de las razas inferiores y semi civilizados, difieren por completo de los que caracterizan a las superiores: mientras que en estas se han fijado definitivamente esos caracteres mentales, en las 
otras se hallan en un estado de incompleto desarrollo. De aquí la deficiencia de las funciones intelectuales de los pueblos indígenas. (Guevara, 1908, p. 365)

Esta idea de base, es decir, sus preconcepciones, es la que permite corroborar y afianzar sus postulados en base a la experiencia en terreno. Ya adelantamos que su trabajo de etnógrafo lo alternó con sus labores docentes como profesor en Temuco. En su trabajo de campo en la Araucanía, llega a conclusiones como la siguiente:

Algunos experimentos hechos con mapuches adultos y trabajos más sistemados, emprendidos en los colegios con jóvenes indígenas adelantados, para sacar alguna luz en el problema de la asociación de las ideas dan invariablemente resultados escasos o negativos. (Guevara, 1908, pp. 367-368)

Este tipo de ejercicios también los puso en práctica con niños y escolares, sobre todo, con los que estaban bajo su cuidado en calidad de director del Liceo de Temuco. Es necesario recordar que, en el discurso positivista, un planteamiento era solamente válido en la medida en que era probado y constatado mediante pruebas de campo. Para el caso de esta obra, lo que sobran son pruebas en terreno, lo que lleva a Guevara a decir con total seguridad ideas como esta:

Los estudiantes indíjenas tampoco pueden mantener fija su atención por un espacio de tiempo algo prolongado. Las operaciones aritméticas, los episodios históricos i las lecciones de ciencia que se entienden demasiado, exceden a la cantidad de enerjía necesaria de que disponen. (...)

Los ensayos practicados en los colegios del sur acerca de la intensidad de la facultad retentiva, permiten comprobar que en las recitaciones de poesías y otros ejercicios los niños araucanos aparecen como inferiores a los de origen español o de otra nacionalidad. (Guevara, 1908, pp. 366-369)

Claramente, los niños araucanos, a pesar de estar insertos en el ámbito escolar, no podían lograr los mismos resultados que sus congéneres chilenos. Sus aptitudes, destrezas y habilidades están muy por debajo de lo que se espera en un niño con rangos de normalidad. 
Claramente, el factor racial se convierte en la clave para entender estas ostensibles diferencias. Guevara llegó a estas conclusiones tras un largo trabajo de campo y de gabinete: entrevistas con estudiantes, apoderados y profesores de los establecimientos educacionales secundarios de Temuco; lecturas de autores chileno-germanos como Rodolfo Lenz y Francisco Fonck, y extranjeros como Henry Schoolcraft, Karl Lamprecht, Francisco Cosentini, entre otros. De la misma forma, Guevara fue un investigador que colaboró en la "cientifización» sobre el mapuche, generando un supuesto conocimiento verosímil.

En su investigación Los araucanos en la revolución de la independencia (1910), se nota una clara matización de sus afirmaciones anteriores, tal vez porque tuvo que insertar a los mapuche en un cuadro mayor, como es el proceso de Independencia; o tal vez por la influencia que tuvieron los hermanos Miguel Luis y Gregorio Víctor Amunátegui, Benjamín Vicuña Mackenna y Diego Barros Arana a través de la metodología utilizada en sus libros. Con todo, sin desmerecer las ideas anteriores, sostenemos a modo de hipótesis que esto se debió a la magra cantidad de fuentes primarias que hicieran directa referencia sobre los mapuche durante el conflicto.

El aporte de Guevara en el discurso de transición descansa en la puesta en escena del trabajo de campo sobre los mapuche, considerando la observación y medición de respuestas por parte de sus objetos de estudio ante determinados estímulos. Si bien sabemos que su procedimiento cargó con ideas preconcebidas, no podemos defender que su pensamiento responde a un espíritu de época, sobre todo, al considerar que autores como el citado Francisco Fonck cuestionó duramente su idea de vincular la concepción de raza con psicología, que se evidencia con una respuesta que el mismo Guevara da a Fonck en El Ferrocarril:

Ha ganado adeptos la opinión de que no es racional asignar a las razas caracteres psico-sociales a propósito para diferenciarlas. La civilización, producto complejo del proceso histórico, es la causa aceptable de la diferenciación de razas y naciones; ella es la que forma un conjunto de condiciones morales, intelectuales, políticas y económicas que siempre se sobreponen al elemento biológico. Dentro de este principio, todas las razas pueden llegar a ser superiores. (Guevara, 1906) 
Esta cita, del todo clarificadora sobre una mirada alternativa al vínculo raza-psicología, nos lleva a pensar que, en el planteamiento de Guevara, al menos hasta la publicación de Psicología del pueblo araucano (1908), claramente existió una idea racista hacia los mapuche. Con el correr de los años y gracias a los contactos con autores como Rodolfo Lenz y la lectura de Ferdinand de Saussure y Franz Boas $^{6}$, fue cambiando el enfoque de sus investigaciones, pues de una orientación racial-psicológica pasó a una visión racial-lingüística de la cultura mapuche que se demuestra en sus obras Folklore araucano (1911) y La etnología araucana en la obra de Ercilla (1918). Sin embargo, las circunstancias que rodearon la difusión de los libros publicados antes de 1910 permitieron que quedaran registrados en la memoria colectiva de muchos chilenos a pesar de la fuerza y desgaste de los años.

\section{Mapuche mirados desde el gabinete: RAZA Y DECADENCIA}

La noción de decadencia fue una idea que se dio fuertemente a fines del siglo XIX y principios del XX. Fue, si se quiere, una contrarrespuesta paralela a la noción de progreso que se estaba dando gracias a los avances científicos y tecnológicos. Para autores como Arthur Herman (1998), la idea de decadencia responde al pesimismo que en la cultura occidental se manifestó mediante tres ejes de acción como son el racial, el histórico y el cultural. Para el Chile de cambio de siglo XIX y XX, caracterizado por los avatares sociales propios

6 En su cambio de percepción puede ser fundamental el vínculo establecido con Rodolfo Lenz, miembro del célebre contingente de profesores alemanes contratados por el Instituto Pedagógico de la Universidad de Chile. Sus trabajos en el campo de la lingüística tempranamente fueron conocidos. Solo o en conjunto con su colega Friedrich Hanssen, publicó diversos ensayos e investigaciones referidas a la gramática comparada y el folklore. En Estudios Araucanos (1895-1897), defendió que la observación del mapuche a partir de la naturaleza lingüística y filológica permitiría reconocer matrices culturales cuya naturaleza residía en el Volkstum (raza y cultura). Además, posibles lecturas de los trabajos de campo de Boas no pueden descartarse en la obra de Lenz, particularmente haciendo referencia a The social organization and the secret societies of the Kwakiutl Indians (1895). 
de lo que la historiografía nacional denomina como Cuestión Social (1880-1920), las ciencias contemporáneas serán activas receptoras de estas inquietudes, llevando a cabo trabajos que recogen dichas problemáticas. En el discurso de época, el cuestionamiento racial de determinadas sociedades se convirtió en un tema preferente de distintas disciplinas, siendo la medicina una de ellas.

Nicolás Palacios, médico de profesión, publicó en el año 1904 un libro titulado Raza chilena. Libro escrito por un chileno y para los chilenos. En este texto, lo que hace el médico oriundo de la ciudad de Santa Cruz es levantar una tesis que no pasó desapercibida: Chile está constituido por una raza predominante, la "raza chilena», cuyo resultado es el mestizaje virtuoso entre españoles y mapuche. A pesar de una relativa vaguedad en sus argumentos, el peso de sus ideas caló hondo en la sociedad chilena, de ahí que en 1918 viera la luz una segunda edición, texto con el cual trabajamos.

El complejo camino que sigue Palacios para levantar su teoría descansa en una serie de factores que le son propios a su época, pero también a su persona. Entre los primeros se pueden considerar: los últimos destellos de la idea de «nación y territorio", que se constituyó en la sociedad chilena como un imaginario dominante hacia el Centenario; justificar la naturaleza étnica de la mayoría de los chilenos en relación con otros grupos raciales foráneos; y el amplio rechazo a la inmigración mediterránea a Chile, que en algunos casos se consideraba perniciosa. En cuanto a los factores personales: su animadversión a las ideas anarquistas y de izquierda que, según su parecer, eran contrarias para la política chilena; la creciente distancia entre la elite y el grueso de la sociedad desde una perspectiva económica y notoria diferenciación étnica; y, vinculado con lo anterior, la concepción de sí mismo como un sujeto fenotípicamente mestizo que posiblemente le llevó a cuestionar su propia persona. Al considerar estos factores en su conjunto podemos comprender el pensamiento racial de Palacios y de qué forma aparecen los mapuche en la composición de su obra.

Al igual que Guevara, Nicolás Palacios construye gran parte su texto en base a la utilización de las fuentes coloniales para ir 
levantando su visión sobre el pueblo mapuche, citando a autores como Pedro Mariño de Lobera, Felipe Gómez de Vidaurre, y Vicente Carvallo Goyeneche, complementándolas con las últimas recopilaciones bibliográficas y monografías historiográficas. En nuestra lectura, hemos podido observar que, a diferencia de Guevara, Palacios hace un trabajo de mayor profundidad hermenéutica de dichos documentos, en tanto que los va utilizando, da una mirada explicativa e interpretativa a la luz del presente. Este ejercicio no es casual, pues se sabe que Palacios leyó a Guevara y sus ideas y textos pueden ser considerados directamente como una mirada alternativa a la tesis del profesor de Temuco. Esta contrapropuesta de Palacios responde, como ya adelantamos, a la necesidad de justificar el origen étnico de la sociedad chilena, cuyo indesmentible aporte mapuche facilitaría las ventajas de la raza chilena en relación con la de otras latitudes. Ahora bien, la distinción de la obra de Palacios es que utiliza al pueblo mapuche solo como una herramienta, pues su foco de atención no es dicho pueblo indígena, sino la sociedad mestiza.

En base a lo anterior, la concepción que Palacios tiene de los mapuche no difiere en gran medida de otros autores contemporáneos, pero su ejercicio consiste en justificar determinadas características y actos supuestamente negativos de la sociedad mapuche-parecida en las fuentes coloniales- como causa de justa defensa de depravaciones y abusos cometidos por los españoles ${ }^{7}$. En otras palabras, lo que hace Palacios es convertir los postulados de su obra en una corriente teórica alternativa a la de Guevara y, para ello, parte de una mirada interpretativa distinta a las fuentes coloniales, al invertir las ideas negativas en positivas, cuestionando e interpelando a Guevara por su intencionalidad de denostar a los mapuche.

Parte su investigación reconociendo el origen de la sociedad chilena al decir que:

Un ejemplo de ello lo da al cuestionar las ideas que ha ido publicando Tomás Guevara en los Anales de la Universidad de Chile, cuando dice que: «Desde unos cuatro años se está publicando en dichos Anales una Historia de la Civilización de la Araucanía, en la cual se trata a nuestros antepasados indígenas como indios salvajes, crueles, depravados, sin moralidad alguna, sin dotes guerreras, e interpretando como cobardía de su parte algunos ardides de combate» (Palacios, 1918, p. 62). 
La raza chilena, como todos saben, es una raza mestiza del conquistador español y del araucano, y vino al mundo en gran número desde los primeros años de la conquista, merced a la extensa poligamia que adoptó en nuestro país el conquistador europeo. (Palacios, 1904, p. 34)

Más aún, al avanzar en el texto, llama la atención a los lectores y sus potenciales detractores con una sentencia que resulta insoslayable:

El roto chileno es, pues, Araucano-Gótico. Hacer la demostración antropométrica y etnográfica de este acerto, no es de una carta; pero si se formara polémica sobre este tema, como sobre cualquiera de las afirmaciones que pueda hacer más adelante, estoy listo a probarlo. Sólo exigiré en el contendor una preparación científica suficiente, pues estas materias no pueden tratarse con declamaciones ni con el mero auxilio de la literatura. (Palacios, 1904, p. 36)

Es decir, de entrada, Palacios reconoce que el grueso de la población chilena es de origen mestizo y el aporte mapuche es crucial para su comprensión. Esta afirmación la sustenta en la «preparación científica» de su investigación, la misma que demanda de aquella persona que quiera rebatir sus ideas. Claramente está aludiendo de forma soterrada a Tomás Guevara.

En el transcurrir de su obra, aporta ideas notables al estado del arte sobre el conocimiento de los mapuche, como, por ejemplo, cuando hace referencia a la ubicación territorial ancestral, al decir que «el Araucano de pura raza existió sólo entre los ríos Aconcagua y Toltén. Al norte y al sur de esos límites los chilenos eran sólo mestizos del chileno» (Palacios, 1904, p. 104). Lo mismo hace al constatar la gran capacidad combativa del mapuche (p. 65), que no es más que un recurso para legitimar de forma histórica el triunfo de los chilenos en el campo militar durante la reciente Guerra del Pacífico (1879-1883) y, por cierto, su ferviente nacionalismo, que 
quedó demostrado en sus impresiones sobre la guerra y el fenómeno de la inmigración a Chile ${ }^{8}$.

Como ya adelantamos, en el texto de Palacios los mapuche no son los protagonistas de la obra, sino los chilenos como sujetos mestizos. En una lectura del libro, el ejercicio obliga a leer entre líneas las argumentaciones del autor, pues en su reconocimiento de las virtudes raciales del chileno, se pueden desprender, por consiguiente, el aporte de la raza mapuche. El concepto de «raza» utilizado por Palacios no se inscribe del todo en patrones estandarizados a un nivel morfológico, pues él reconoce que la «raza chilena» está constituida por un conjunto de hombres y mujeres distintos físicamente, no destacando en ellos determinadas características aplicables a otras razas. Así, por ejemplo, dice en su obra que:

Toda la gama que va del roto rubio de ojos azules y dolicocéfalo, con $80 \%$ de sangre gótica, hasta el moreno rojizo de bigotes escasos, negros i cerdosos, de cabello tieso como quisca, y braquicéfalo con $80 \%$ de sangre araucana, todos sentimos y pensamos de idéntica manera en las cuestiones cardinales, sobre las que se apoyan y giran todas las demás referentes a la familia o a la patria, a los deberes morales o cívicos: es uno mismo nuestro criterio moral y social. (Palacios, 1904, p. 37)

Esta definición del «roto chileno», que por sus venas corre en distintos grados sangre mapuche y goda, a pesar de sus diferencias físicas, sigue siendo un grupo racial único, cuyo denominador común no se da en una variante física, sino moral. Ahí radicaría la concepción racial de Palacios. En otras palabras, el aporte mapuche,

8 El doctor Palacios tuvo una ferviente vocación nacionalista y en textos como Decadencia del espíritu de la nacionalidad, escrito a propósito del reciente suceso de Santa María de Iquique y leído en el Ateneo de Santiago, escribe sobre los inmigrantes: «En Chile, como hemos notado, el exotismo ha invadido las esferas oficiales y adquirido una preponderancia por todo extremo peligrosa. La prensa del poderoso comerciante extranjero y el periodista inmigrante con su tenaz campaña de burlas, de censuras, de reproches y hasta de injurias a todo lo genuinamente chileno, renovada día a día, sin perder oportunidad, sin descanso, durante años y años, produciendo primer el rechazo, luego el silencio y más tarde la duda en los mismos chilenos, ha traído por fin el desaliento a su alma cuando ha visto traducirse en hechos innumerables de flagrante injusticia lo que empezó como simple doctrina de desprestigio» (Palacios, 1907, p. 113). 
si bien se notaría sobre todo en algunas características físicas, se demostraría por la fuerza moral de sus atributos raciales, en donde la hidalguía, valentía y coherencia, es lo que mueve a los chilenos.

Por ejemplo, una de las características que Palacios reconoce en la raza chilena es que existe una tendencia a llorar, diciendo que «los chilenos tenemos a quien salir en esto del llanto. Ya recordé que los Araucanos eran llorones y lo son todavía» (Palacios, 1904, p. 226). Pero ese llanto que puede ser considerado una muestra de debilidad en algunas razas germánicas, rápidamente Palacios (1904) lo transforma en una virtud, al considerar que llorar es «una manera de manifestar la ternura patriótica es menos común de lo que puede parecer a los chilenos, que la poseen de herencia» (p. 227).

En otro ámbito, la concepción del deseo sexual desenfadado que atribuye Guevara a los mapuche no se da de la misma forma en la opinión de Palacios. Para él, la sociedad mapuche - y, por consiguiente, los chilenos- son sumamente cuidadosos y recelosos en este ámbito. Al respecto, cuando se refiere a la relación que las mujeres tienen con el sexo dice que:

Las indias que se entregaban al vencedor como esposas o concubinas no podían sentir mortificada su conciencia por ese acto, puesto que esa era la costumbre consagrada de su raza; pero fuera de esas relaciones, para ellas regulares, la virgen indígena presentaba a los piratas de amor una resistencia sólo vencible por la fuerza muscular. (Palacios, 1904, pp. 231-232)

Lo que Palacios hace en este extracto es cuestionar fuertemente la acusación social generalizada en contra de los mapuche, al referirse a ellos como una sociedad inmoral y promiscua, situación que no la toma necesariamente desde una perspectiva religiosa, sino desde la visión de que esta práctica resulta negativa en términos de higiene, propia de razas inferiores y decadentes. Más aún, reafirma esta posición al citar disciplinas diciendo que:

Los estudios de sicología étnica tienen hoy comprobado que en las razas de sicología patriarcal o varonil la organización de la familia descansa en el celo sexual o egoísmo de reproducción del hombre, y que el pudor, el recato, virtudes 
fundamentales del grupo familiar en estas razas, deben su existencia a ese mismo celo varonil. (Palacios, 1904, p. 299)

En definitiva, Nicolás Palacios lo que hace en sus investigaciones es discutir sobre la naturaleza racial de la sociedad chilena en perspectiva histórica. Sus argumentos descansan en la idea de que el mestizaje representó uno de los puntos culminantes de una lucha racial, muy en la línea del historiador francés Agustin Thierry, cuando hace referencia en su Consideraciones sobre la historia de Francia (1840) a la lucha de los francos en contra de los galos. En este sentido, la sociedad chilena aparece como el resultado de fuerzas históricas que comulgaron para que el producto de las vinculaciones étnicas diera una particular nueva especie, única en su tipo. Si bien se parece fenotípicamente a la de otras latitudes de América, experimenta un particular desarrollo debido a circunstancias determinantes como la geografía y la guerra, pero que bajo el contexto de una decadencia moral de la elite que se ha encargado de condenar y despojar al roto chileno de su hábitat, sus recursos naturales, lo que sucede es que el progreso racial chileno se encuentra en una encrucijada.

En su concienzuda tarea de darle una clasificación a la nación chilena, Palacios reconoció que esta no era en ningún caso homogénea, la categorizó con un rarísimo escalafón de los chilenos. Gotas más o menos de sangre podían desequilibrar totalmente la balanza hacia la salvación o perdición genética de una persona. Cada uno, de acuerdo con su naturaleza, ocupaba un lugar en el escenario de la realidad social, política, laboral y finalmente económica del país9. Lo interesante de estas diferencias no residía precisamente en ello,

Tal vez, ese es un punto que no ha sido destacado mucho en las ideas de Palacios. Para él gran parte de las cuestiones que analizó descansaban en supuestos del momento. Es decir, muchas de las descripciones que hizo en sus textos fueron el resultado de sus observaciones como médico en sus propios pacientes y del entorno urbano-rural en el cual se desenvolvió. El tema económico para Palacios no pasaba inadvertido, siendo a veces recurrente. Tal vez, la situación económica tan disímil en la época (mucho más marcada que en la nuestra) lo llevó a considerar que estaba íntimamente ligado el triunfo económico de las personas con la naturaleza genofenotípica de ellos. Respuestas al tema pueden ser muchas: sustentos de ideas materialistas y/o capitalismo liberal. Dudamos que el enfoque religioso haya influido en un hombre progresista y de ciencia como él. Aunque no lo descartamos del todo. 
sino en sus similitudes o las similitudes de las diferencias, pues eran ellas las que permitían situarlas en un nivel superior frente a otras razas de la región.

Con todo, el esfuerzo por dilucidar una raza chilena no responde solo al tema de distinguir una raza y una nación, sino también a entender de qué forma el grueso de la sociedad agrupado como raza estaba siendo desplazado por una serie de amenazas que se daban al interior del país como eran la fuerte inmigración mediterránea, la mirada despectiva de la elite hacia el bajo pueblo y la falta de solución a problemas de orden social que hacia el Centenario se siguieron manteniendo.

\section{Conclusiones}

Ambos autores fueron sujetos que desde distintas ciencias como la antropología y la medicina tuvieron concepciones disímiles en torno a la sociedad y cultura mapuche. Sin embargo, a pesar de las diferencias, existen puntos de conexión marcados por el patriotismo y la postura reflexiva sobre la sociedad chilena del momento. No se puede caer en clichés de que fueron hombres de su tiempo para justificar sus postulados, pero tampoco se puede negar que los procesos y acontecimientos históricos les afectaron notablemente en su visión del mundo. Al primero, profesor de Castellano, el recorrer la Araucanía le permitió acercarse a la sociedad mapuche, siempre desde una mirada positivista los consideró como un objeto de estudio. Claramente en su texto se puede observar una mirada negativa y condenable hacia ese pueblo indígena. Tal vez, en ellos lo que buscaba era una justificación al comportamiento reprochable de la sociedad chilena. Los mapuche se convirtieron en el chivo expiatorio de su racismo. Al segundo, médico de profesión, las vicisitudes de su oficio lo llevaron a trabajar en el mundo rural. Durante la Guerra del Pacífico realizó una estadía en el norte como médico de campaña. Esta experiencia, unida a diversas lecturas, le hizo plantearse el lugar histórico que le correspondía a la sociedad chilena, sopesando sus virtudes y falencias, sus fortalezas y debilidades. Sin duda, su 
aguda lectura del tiempo presente, propio de un diletante, le sirvió para construir un discurso inédito para el momento, salpicado de agudeza, imaginación y frustración. Ambos autores, uno desde una mirada exacerbadamente positivista y el otro con un fuerte pragmatismo del progreso de la sociedad que se canaliza mediante su idea de «raza chilena», lo que hacen en sus respectivos textos es una crítica a la sociedad chilena de la primera década del 1900. En el caso de Guevara se da una fuerte tendencia en criticar a los mapuche, apuntando a la falta de educación, modales y costumbres. Para Palacios, la crítica se moviliza hacia la elite capitalina que, según él, ha dejado de lado al grueso de la sociedad chilena, despojándola de sus tierras, oportunidades económicas y una educación digna.

Claramente en Guevara y Palacios encontramos no solo un discurso de transición entre los textos coloniales y los propiamente científicos, sino también un discurso formalmente racista y que para el caso chileno, al igual que en otros países (Sánchez-Guillermo, 2007), se dio de modo conjugado con ideas-concepto tales como: nación, territorio, política, democracia, desarrollo y modernidad. Estos conceptos, en general, se pueden considerar desde la centralidad de las interrelaciones sociales, en un sentido de dominación de un grupo por sobre otros (Sapriza, 2001).

Viviana Gallardo (2005) propone que los discursos no desaparecen por completo en una generación, sino que se alternan, conviven y superponen. En nuestro caso, consideramos que la mutación discursiva también se debe sumar a las concepciones de los autores como Guevara y Palacios, puesto que los documentos que ya revisamos revelan en su constitución modificaciones sustanciales del cómo fue comprendido el mapuche.

En base a todo ello, nuestra lectura sobre los textos es que se pueden considerar, sin habérselo propuesto jamás, como los precursores del indigenismo en Chile. Esto lo decimos por dos ideas básicas. En primer lugar, porque el indigenismo de principio de siglo promueve el mestizaje como forma de solucionar el problema indio. En segundo lugar, tengamos en cuenta que, de un modo u otro, se justificaba en una superioridad racial al mestizo. Y, de facto, se 
aceptaba al indio, pese a que en estado puro se le negase. Nada más que parte de las contrariedades de ideas y argumentos sin mayor fundamento científico que la opinión personal de dichos autores, que lograron sobreponerse a la objetividad de la evidencia empírica (Hall, 2017). En este sentido, Henri Favre (1999) plantea para el caso latinoamericano:

El destino que los indigenistas le asignan [al indio] es el de una fusión con la población criolla, con objeto de engendrar una raza mestiza que sea la raza auténticamente nacional. El mestizaje biológico ofrece la solución definitiva al problema indio, al mismo tiempo que el de la cuestión nacional en todos sus aspectos. La miscibilidad no solo abatirá en la realidad cotidiana las barreras que aíslan a los diversos componentes de la población, sino que además resolverá las contradicciones políticas y sociales que desgarran al país y amenazan su existencia. Gracias a ello, el pueblo al fin 'nacionalizado' podrá avanzar con seguridad por la vía del progreso. (pp. 39-40)

Entre otras posibles respuestas de la época que permitieron acercarse el estudio sobre los indígenas, se cuenta el materialismo histórico: una ideología destinada a la salvación del campesinado y del obrero. Con ellos se identificó a los mapuche, aunque no con el mismo realce con el que se trató a la población urbana. Por otra parte, la Iglesia católica promovió su doctrina social a través de las misiones salesianas en la Patagonia, y los capuchinos en Araucanía. Ambas impulsaron los derechos de los indígenas y un conocimiento real de los mismos y requerirían, por su parte, un completo estudio que abordaremos en otra oportunidad.

\section{Bibliografía}

Báez, C. y Mason, P. (2006). Zoológicos humanos: fotografías de fueguinos y mapuche en el Jardín d'Acclimatation de París, siglo XIX. Santiago, Chile: Pehuén.

Barceló, R. (2003) «El indio según los intelectuales: racismo, discriminación e identidad en los siglos XIX y XX». América Indígena, LIX (3), 40-52.

Bengoa, J. (2014). «La trayectoria de la antropología en Chile». Revista Antropologías del sur, 1, 15-42. 
Boas, F. (1895). The social organization and the secret societies of the Kwakiutl Indians. Washington, D.C., Estados Unidos: Annual Report Smithsonian Institution, United States National Museum.

Comisión Central del Censo. (1908). Censo de la República de Chile levantado el 28 de noviembre de 1907. Memoria presentada al Supremo Gobierno por la Comisión Central del Censo». Santiago, Chile: Sociedad Imprenta y Litografía Universo.

Donoso, R. (1963). Breve historia de Chile. Buenos Aires, Argentina: EUDEBA.

Estefane, A. (2004). Un alto en el camino para saber cuántos somos... Los censos de población y la construcción de lealtades nacionales. Chile, siglo XIX. Historia, 37 (I), 33-59.

Favre, H. (1999). El indigenismo. Ciudad de México, México: Fondo de Cultura Económica.

Gallardo, V. (2005). «Héroes indómitos, bárbaros y ciudadanos chilenos: El discurso sobre el indio en la construcción de la identidad nacional». Revista de Historia Indigena, 5, 119-134.

Gänger, S. (2014). Relics of the Past The Collecting and Study of Pre-Columbian Antiquities in Peru and Chile, 1837-1911. Oxford, Inglaterra: Studies in the History of Archaeology, Oxford University Press.

Gould, S. (1997). La falsa medida del hombre. Barcelona, España: Crítica. Guevara, T. (1904). Costumbres judiciales i enseñanza de los araucanos. Santiago, Chile: Imprenta Cervantes.

Guevara, T. (1906). Carta respuesta a Francisco Fonck. El Ferrocarril, marzo.

Guevara, T. (1908). Psicología del pueblo araucano. Santiago, Chile: Imprenta Cervantes.

Guevara, T. (1910). Los araucanos en la revolución de independencia. Santiago, Chile: Anales de la Universidad de Chile.

Guevara, T. (1911). Folklore Araucano. Santiago, Chile: Imprenta Cervantes.

Guevara, T. (1918). La etnología araucana en el poema de Ercilla. Santiago, Chile: Imprenta Barcelona.

Guevara, T. (1898). Historia de la civilización de Araucanía. Santiago, Chile: Imprenta Cervantes.

Hall, S. (2017). The fateful triangle: race, ethnicity, nation. Cambridge, Estados Unidos: Harvard University Press.

Harambour, A. y Barrena, J. (2019). «Barbarie o justicia en la Patagonia occidental: las violencias coloniales en el ocaso del pueblo kawésqar, finales del siglo XIX e inicios del siglo XX». Historia Crítica, 71,25-48.

Harrison P. y Roberts, J. (2019). Science without God?: rethinking the history of scientific naturalism. Oxford, Inglaterra: Oxford University Press. 
Hartley, J. y Potts, J. (2014). Cultural Science. A Natural History of Stories, Demes, Knowledge and Innovation. Londres y Nueva Delhi, Inglaterra e India: Bloomsbury.

Herman, A. (1998). La idea de decadencia en la historia Occidental. Santiago, Chile: Editorial Andrés Bello.

Kohl, P.; Podgorny, I. y Gänger, S. (2014). Nature and Antiquities. Tucson, Estados Unidos: Arizona Press.

Lenz, R. Estudios araucanos. Santiago, Chile: Imprenta Cervantes.

Palacios, N. (2001) [1907]. «Decadencia del espíritu de nacionalidad». En C. Gazmuri (Ed.), El Chile del Centenario, los ensayistas de la crisis. Santiago, Chile: Instituto de Historia-Pontificia Universidad Católica de Chile.

Palacios, N. (1918) [1904]. Raza chilena: libro escrito por un chileno y para los chilenos. Santiago, Chile: Ediciones Colchagua.

Pavez, J. (2002). "Mapuche ñi nútrame chilkatun i. Escribir la historia mapuche: Estudio poslaminar de Trokinche müfu ñi piel. Historias de familia siglo XIX». Revista de Historia Indígena, 7, 7-53.

Pavez, J. (2015). Laboratorios etnográficos. Los Archivos de la Antropología en Chile (1880-1980). Santiago, Chile: Ediciones Universidad Alberto Hurtado.

Salomon, C. (2018). The Routledge history of Latin American culture. New York, Estados Unidos: Routledge.

Sanchez-Guillermo, E. (2007). Nacionalismo y racismo en el México decimonónico. Nuevos enfoques, nuevos resultados. Nuevo Mundo Mundos Nuevos. doi: 10.4000/nuevomundo.3528

Sapriza, G. (2001). «Historia y género». En A. Araujo y E. Behares (Comp.). Género y sexualidad en Uruguay. Montevideo, Uruguay: Editorial Trileu.

Wilson, R. (2018). Natural history: heritage, place and politics. New York, Estados Unidos: Routledge an imprint of the Taylor \& Francis Group. 



\section{TECNOLOGÍAS DE LA ENERGÍA SOLAR EN LA INDUSTRIA DE LOS NITRATOS (I872-2OI2). EXPLORACIONES EN LOS ARCHIVOS DE UNA HISTORIA FRAGMENTADA ${ }^{\mathrm{I}}$}

Nelson Arellano-Escudero

Resumen. Desde el siglo XIX al XXI ha habido continuidad y cambio en el proceso industrial para la producción de la minería no metálica en Chile y el mundo. En este estado de situación la industria incorporó en 1872 hasta 1908 el uso de la energía solar térmica para procesos de desalación de agua y, en 1948 hasta el tiempo actual, para la obtención de subproductos del salitre. Esta cultura de ciencia y tecnología en Chile muestra una circulación global de las ideas, del capital y de los servicios ecosistémicos.

Esta historia de la tecnología combina elementos de la historia económica y ambiental para analizar la gobernanza de la evolución de la tecnología en sus procesos de selección entre continuidad e innovación. Se atiende a los valores sociales que articularon el olvido y el silencio de las tecnologías de la energía solar en la industria de los nitratos como un asunto de circulación interoceánica de objetos y conocimientos

1 Este artículo fue posible gracias a los proyectos de investigación Fondecyt postdoctoral N 3160197 de Energía Solar e Industria del Salitre, HAR201675871-R (2017-2020). Mathematics and Engineering (UPC, Barcelona) y Fondecyt inciación 11180158 de Fronteras solares de Chile. Presentaciones parciales fueron realizadas en las Jornadas de Historia de Chile de Valdivia (2017) y Jornadas de Historia Regional (2018). El autor agradece sinceramente los valiosos comentarios de los/las pares evaluadores/as que han permitido mejorar aspectos sustanciales de este capítulo. Los errores y omisiones son, desde luego, responsabilidad del autor. 
científicos. Así es posible apreciar la proyección de la Ciencia y la Tecnología desde la región del desierto de Atacama al mundo.

PALABRAS ClAVE: evolución de la tecnología, minería no metálica, tecnologías de la energía solar.

Abstract. Since XIX to XXI century has been a continuity throw the industrial process for the non-metal miners in Chile and the world. In this situation, the industry got thermal solar energy, since 1872, for some of their desalting works. Later, since 1948 thermal solar energy contributed to the fraccionary cristalization for obtention of nitrates by-products. This last activity is working on hitherto. This science and technology culture in Chile show a global circulation of ideas, capital and ecosistemic services.

This History of technology uses conceptual elements from Economic History and Environmental History to analyze the governance of the evolution of technology in their selection process between continuity and innovation. We examine the social values able to articulate the solar techniques' silence and oblivion inside nitrates industry as a topic for interoceanic circulation of objects and scientific knowledge. In this way we can observe the science and technology launched from the Atacama desert region to the world.

Keywords: Solar Energy Technologies, Evolution of Technology, Non-Metal Mining.

\section{INTRODUCCIÓN}

A fines de la segunda década del siglo XXI el momento parece auspicioso para las energías renovables en Chile y la energía solar entre ellas (Espinoza, 2017; EMOL, 2017; Ministerio de Energía, 2016). Sin embargo, este escenario optimista tiene un alto contraste con respecto al desconocimiento de las trayectorias y desempeños de los pioneros y la continuidad de los esfuerzos de varias generaciones de ingenieros, técnicos, entusiastas e inversionistas, entre otros.

Lo anterior ha quedado en evidencia gracias al estudio de las memorias sueltas de las tecnologías de la energía solar en Atacama y 
su circulación mundial en los periodos 1872-1907 (Arellano, 2015), 1907-1981 (Arellano, 2016, 2017 y 2018a y b) y algunos datos de la primera década del siglo XXI. Este conjunto de información ha permitido configurar la relevancia de actores sociales en su despliegue transfronterizo (González, Artaza y Calderón, 2016; González y Ovando, 2017; Headrick, 1989), así como comprobar la existencia de una intermitencia técnica a lo largo del siglo XX cuya invisibilidad le circunscribe a la dimensión del silencio y el olvido en la memoria social (Augé, 1998; Burke, 1996; Stern, 2006).

Gracias a esta historia de la tecnología (Smith \& Marx, 1994; Misa, 1988), que combina elementos conceptuales con la Historia Económica (Llorca-Jaña y Barría, 2017; Stern, 2011, 2004) e Historia Ambiental (Thomas, 2017) ha sido posible establecer relaciones de grupos empresariales como Casa Gibbs, Baburizza y Guggenheim Bros., con la investigación, experimentaciones y construcción de proyectos industriales que utilizaron energía solar como suministro principal. En los casos de la destilación solar y las pozas de evaporación solar nos encontramos en el plano de la inversión privada en investigación y desarrollo que en ocasiones fue acompañada por el trabajo académico de las universidades Técnica Federico Santa María, Católica del Norte y de Chile, aunque se debe enfatizar que la academia tuvo su ruta y agenda propia.

Podemos tener una aproximación a la historia de las tecnologías de la energía solar gracias a la documentación preservada en los archivos: Nacional de Chile, Massachussets Institute of Technology, en Cambridge, Smithsonian Institute, Universidad Santa María, en Valparaíso y la colección privada de la familia Freed. Todo ello complementado con los testimonios de ingenieros y descendientes, como Sebastián Freed bisnieto de Stanley, que han conservado el patrimonio de testimonios de una parte significativa de la historia de la tecnología en Chile y del mundo.

El análisis de los acontecimientos y las estructuras ofrece una lectura del devenir como proceso de ensamblaje de memorias sueltas capaces de constituir una memoria emblemática de los usos de las tecnologías de la energía solar. Bajo este prisma es que se analiza 
la gobernanza de la evolución de la tecnología en sus procesos de selección entre continuidad e innovación y los valores sociales que articularon el olvido y el silencio tanto en procesos de descarte artefactual como de éxito en la gestión productiva.

\section{LA EXPLORACIÓN DE LA ENERGía SOLAR Y SU VIABILIDAD ECONÓMICA}

Las memorias sueltas de los proyectos de inversión representan un desafío relevante para la investigación historiográfica de los acontecimientos del desierto de Atacama entre 1872 y 1918 . Sin embargo, es su materialidad la que condensa la reunión de las estructuras políticas, económicas, ambientales y la imaginación tecnológica.

Justamente este ha sido el recorrido heurístico que se ha seguido una vez hallados los testimonios de Josiah Harding y Charles Wilson que desde 1883 revelaron una anomalía de la gestión de operaciones que a esa fecha acumulaba once años de funcionamiento. Una industria de producción de agua tratada para su desalación, a partir de las aguas continentales subterráneas del acuífero de Sierra Gorda perforado con los entonces llamados pozos artesianos. Esta industria se diseñó en base al bombeo del agua gracias a molinos de viento, podemos suponer que multipala, y la cosecha de energía solar mediante cajas de madera que pintadas con su fondo negro y con una cubierta de vidrio generaban un efecto invernadero que evaporaba el agua dejando las sales en el fondo y condensaba el vapor en el vidrio que se mantenía a baja temperatura en su exterior gracias al viento helado que recorre el desierto con mayor radiación solar en el mundo o, como lo muestra Patricio Guzmán en Nostalgia de la luz, la mancha marrón del planeta azul.

De la industria y su administración existen escasos antecedentes. Solo tenemos el testimonio de un investigador quien en 2011 —en una comunicación personal- indicó haber visto un plano de la industria desaladora de Las Salinas en una carpeta de los archivos de la Compañía de Salitres.

Este dato, por ahora pendiente de hallazgo, no pareciera ser aleatorio. En el Fondo del Salitre, en el Archivo Nacional, fueron 
encontrados los oficios que el ingeniero británico natural de Nueva Zelanda Josiah Harding enviara a John Hicks para solicitar materiales, pero más información reportó el propio Hicks que, informando a Valparaíso, daba cuenta del empecinamiento de Harding para obtener las herramientas necesarias para la construcción del ferrocarril de Antofagasta a Bolivia, cuyo destino final era el mineral de Huanchaca, aunque esto ocurrió una década más tarde, lo que nos muestra los tiempos de concreción de los proyectos de ingeniería, tal como ocurriera con el ferrocarril trasandino que unió Valparaíso con Buenos Aires, entre otros muchos que tardaron décadas en concretarse.

No obstante, es posible establecer que todos estos eran negocios relacionados, vinculando la extracción de sales y minerales con las inversiones de los procesos productivos en sus operaciones y capital: Opex y Capex, la participación de Casa Gibbs tiende a aparecer difusa y como una entidad financiera y comercial a propósito de suministros y circulación financiera (Couyoumdjian, 2000).

La situación de propiedad en relación a la industria de Las Salinas no ha logrado ser esclarecida, cosa que es diferente en el caso de la industria de desalación solar de Sierra Gorda, en la que el portugués Juan Oliveira es mencionado como su dueño.

Sin embargo, para el caso de Oficina Domeyko la suerte ha sido otra. En los London Metropolitan Archives donde fue trasladado el fondo documental de Anthony Gibbs \& Sons se halló una documentación que vincula directamente a Casa Gibbs con el lugar donde fue construida la tercera y más conocida industria desaladora del desierto de Atacama en tanto fue, hasta donde se sabe, la única que fue fotografiada y divulgada gráficamente tanto en 1907 como en 1908.

Esta situación es justamente la que nos facilita una reflexión crítica en torno a las teorías de los enclaves y la de los enlaces en tanto en ambos casos el problema es la concepción de un mundo gobernado desde un cierto punto en trayectorias lineales en impulsos asimétricos unidireccionales dificulta la comprensión de las interacciones aparentemente periféricas que a la postre terminaron por afectar las decisiones metropolitanas. 
Justamente esta es la problematización sobre la que trabaja Julia Thomas para intentar elucidar modelos teóricos en torno a la ecoeconomía, es decir, una apreciación donde la historiografía sea capaz de construir una narrativa que reúna la historia ambiental y la económica para abordar los desafíos de la sustentabilidad, mal acotados en la visión antropocéntrica del Antropoceno.

Es desde una de las cuatro categorías que propone Thomas que resulta explícita la vinculación de Escalas Intersectadas en las que los efectos de las decisiones y las acciones tienen repercusiones mutuas, incluso cuando ello ocurra de manera asimétrica.

En esa clave es que parece factible comprender que la familia Gibbs, de Londres, y la familia Guggeinheim, de Nueva York, fueron modelando el paisaje del desierto de Atacama por la puesta en marcha de las operaciones de extracción de las minerías metálica y no metálica siendo, además, protectores de las primeras experiencias de cosecha de radiación solar directa en procesos industriales.

\section{Experiencias pioneras. Los vínculos de Casa Gibbs y GuggenHeim Brothers CON EL DESIERTO DE ATACAMA}

\section{Desaladoras solares}

El desierto de Atacama fue y es un pivote mundial de la producción de un producto vital para las industrias de la agricultura (San Martín, 2017a y 2017b) y de los armamentos (Glaser-Schmidt, 1995): las sales de nitrato.

Gracias a los archivos podemos conjeturar que Guggenheim Brothers parece haber sido la continuación en el tiempo de la administración de varias de las propiedades de Anthony Gibbs and Sons Limited ${ }^{2}$. La Historia de la Empresa Compañía de Salitres y

2 La descripción de historia administrativa en el catálogo de colecciones del Metropolitan London Archives, dice: «The business of Antony Gibbs and Son was founded in London in 1808. In 1813 it became Antony Gibbs and Sons, and in 1948 Antony Gibbs and Sons Ltd. It was converted into a public company in 1972 and in September 1973 its name was changed to Antony Gibbs Holdings 
Ferrocarril de Antofagasta devino en la Compañía Anglo Chilena y su gemela, la Anglo Lautaro o Lautaro Nitrate Company, que terminaron fusionadas, debido a las operaciones de las pozas de evaporación solar para obtención de Magnesio y Potasio, en la Compañía Salitrera Anglo Lautaro, que derivara en la Sociedad Química de Chile (Soquimich) que en su tránsito hacia la estatización llegó a ser propiedad de la Corporación de Fomento (CORFO) en un 99,97\% para luego ser privatizada y llegar a convertirse en SQM. Cientocincuenta años de historia aún en movimiento.

La presencia de los negocios de casa Gibbs comenzaba en Londres y se expandían por los 5 continentes, tocando El Callao, Antofagasta y Valparaíso. Hemos comprobado que esta trasnacional, nacida a inicios del siglo XIX, adquirió en 1908 la Oficina Domeyko, vendida por la Compañía Salitrera El Boquete, propiedad de Ottorino y Nicolás Zanelli (Calle, 2013) ${ }^{3}$. El proceso de compra/venta consideró un detenido

Ltd. The company is now owned by the Hongkong and Shanghai Banking Corporation. The firm was based at 13 Sherborne Lane, Lombard Street (from ca. 1809), 20 Great Winchester Street (1814-15), 28 Great Winchester Street (1815-26), 47 Lime Street (1826-50) and 15 Bishopsgate, later numbered 22 Bishopsgate (from 1850). In 1881 Antony Gibbs and Sons absorbed two associated business houses, which had previously been separate firms: a company in Bristol originating in an eighteenth century partnership and trading from 1801 as Munckley, Gibbs and Richards, from 1802 as Gibbs, Richards and Gibbs, from 1808 as George Gibbs and Son, from 1818 as Gibbs, Son and Bright and from 1839 as Gibbs, Bright and Co; and a company in Liverpool founded in 1805 as Gibbs, Thompson and Co and from 1824 as Gibbs, Bright and Co, with two branch houses in Gloucester (1834-42) and Australia as Bright Brothers and Co (1853-81), with an office in Dunedin, New Zealand from 1864. Under the management of Antony Gibbs and Sons from 1881 these houses were re-organised; the Bristol and Liverpool houses traded as Antony Gibbs, Sons and Co, and the Australian house as Gibbs, Bright and Co. The company traded overseas under a variety of other names, as follows: CADIZ, SPAIN: Antony Gibbs and Son, 1808; Antony Gibbs, Son and Branscombe, 1808-13; and Antony Gibbs Son and Co, 1814-27; GIBRALTAR: Gibbs, Casson and Co, 1818-33; PERU AND CHILE (LATER ALSO BOLIVIA AND BRAZIL): Gibbs, Crawley, Moens and Co, 1822-4; Gibbs, Crawley and Co, 1824-47; William Gibbs and Co, 1847-79; Gibbs and Co, 1880-1948; Gibbs and Cia S.A.C. from 1948 and Gibbs, Williamson Ltd, from 1933; NEW YORK: Antony Gibbs and Co, 1913-20; and Antony Gibbs and Co Inc, from 1920.» ANTONY GIBBS AND SONS LIMITED

REFERENCE CODE: CLC/B/012. 
estudio acerca del suministro de agua. La correspondencia interna de Gibbs and Sons revela que desde abril de 1908 se estudiaron todos los factores relativos a legalidad, productividad y costo/beneficio de la operación. Para el 8 de octubre se había conseguido un crédito con el Banco de Chile para la adquisición de «El Boquete Nitrate Grounds» ${ }^{4}$

La relevancia de esta operación es que podría ser el motivo por el cual «El Boquete» generó las únicas fotografías conocidas de su industria de desalación de aguas subterráneas con energía solar, publicadas en 1907 y 1908 en Antofagasta, Londres, Oklahoma y Nueva York. La fotografía más conocida fue atribuida por alrededor de setenta años a la industria de Las Salinas, también en el desierto de Atacama, pero a unos 100 kilómetros al norte y treinta y cinco años antes, pues se conoce que desde 1872 a 1884 operó en buenas condiciones y no se sabe cuándo cesó sus operaciones. Tampoco sabemos, aunque parece bastante probable, que casa Gibbs también pudo haber estado implicada en su existencia a juzgar por los archivos que indican el involucramiento de casa Gibbs en la construcción del Ferrocarril de Antofagasta a Bolivia. Esta especulación se funda en el traslado de algunos de los archivos desde el Guildhall Library de Londres al Archivo Nacional de Chile donde se constituyeron en el Fondo Salitre, con documentación de las empresas donde Casa Gibbs tenía intereses y su proyección en la Corporación de Salitres de Chile (COSACH) y, luego, la Corporación de Ventas de Salitre y Yodo de Chile (COVENSA). Con ello, si la vinculación de Casa Gibbs es todavía algo difusa, la entrada a la escena salitrera de la familia Guggenheim es bastante clara y definida, especialmente conocida por su relevancia en el cambio tecnológico que se llevó adelante entre la década de 1920 y 1950 , entre las cuales -apostamos aquí- estuvo la investigación y desarrollo en ciencia y tecnología de la energía solar.

4 Private 766, London, 10/04/1908; Private 768, London, 8/05/1908; Private 769, London, 21/05/1908; Private 770, 4/06/1908; Private 771, 19/06/1908; Private 772, 03/07/1908; Private 775, 14/08/1908; Private 776, 28/08/1908; Private 778, 21/09/1908, Private 779, 8/10/1908. Gibbs \& Cía. S.A.C., Nov 1907-oct 1908. Private letter book, London to Valparaiso: CLC/B/012/MS11471/078, London Metropolitan Archives. 


\section{Potasio y Magnesio}

En un movimiento aparentemente paralelo, en el desierto de Atacama se construyó una industria productora de salitre potásico y magnesio, como subproductos del Nitrato chileno en la oficina de Coya Sur, ubicada en la zona de la oficina María Elena; estas instalaciones, aunque pioneras, fueron las terceras de su tipo en el mundo después de las de Bonneville situada en Wendover, Utah —a solo 100 kilómetros de Salt Lake City_ y las de Palestina, en el Mar Muerto.

El proceso de construcción comenzó en 1948, 15 kilómetros al norte de la oficina María Elena, con las primeras cuatro pozas de evaporación solar, con una dimensión de 40.000 metros cuadrados cada una. Para 1952 se completaron las otras seis de las mismas dimensiones y la producción alcanzó el pleno régimen.

Pero todo el proceso comenzó en las décadas de 1910 y 1920. No obstante, pese a la considerable atención que se le ha prestado, la dimensión de la influencia de la familia Guggenheim, aunque no ha sido subvalorada, parece ser que pudiera ser ponderada en una escala diferente, al menos en lo que respecta no solo a las tecnologías de la energía solar sino al estudio científico necesario para sus aplicaciones si miramos la vinculación de los Guggenheim con el Smithsonian Institute, que ya llevaba largo tiempo de vinculación con Chile que consta ya iniciado en $1848^{5}$.

Para 1917, Charles G. Abbot ya había instalado en cerro Montesuma de Calama sus instrumentos para medir la constante solar. Abbot llegó a ser el segundo director del Observatorio de Astrofísica del Smithsonian Institute y podemos verle aquí como el sujeto en cuyo cuerpo se encarnan las superposiciones de las historias de la ciencia y de la tecnología, de las relaciones del norte y sur hemisféricos y, preliminarmente, el colonialismo en su forma de extractivismo

«The first recorded participation by Smithsonian in planning for a foreing expedition was 1848 when Secretary Henry noted that $\$ 5.000$ had been appropiated by Congress to provide equipment for astronomical observations by Lt. J. M. Gilliss in Chile.» Craig, W. O. (2004). Around the World with the Smithsonian. Llumina Press. 
de la información local para propósitos metropolitanos y administración asimétrica. Abbot se formó en el MIT y cuando estudiaba el fenómeno de la constante solar en el Smitsonian Institute planificó instalar un observatorio astrofísico en el hemisferio sur, impulsando la iniciativa de que esas instalaciones se montaran en Australia. Sin embargo, la aprobación de los fondos apuntó a Sudamérica "where the United States was building a strong mining base. The Guggenheims operated a huge copper mine at Chuquicamata,and were happy to host a U.S. goverment presence» (DeVorkin, 1998, p.10). La clave, parece estar en la figura de John A. Roebling que "(...) was sympathetic to Abbot's mission and its hope of practical application, not only for weather forecasting but for the use of solar energy» (DeVorkin, 1998, p.11). Esta apreciación se corrobora porque, al menos,

The Institution is indebted to Mr. John A. Roebling for a further contribution of $\$ 28,288.19$ toward continuing researches in astrophysics by aiding the solar observing stations in Chile and the United States, and providing for publication of scientific papers, and for making meteorological investigations elsewhere ${ }^{6}$.

Energía solar aplicada. Esta parece haber sido una meta bien constituida en el primer cuarto del siglo XX, cuando operaba la «John A. Roebling solar research fund». No es un movimiento aislado en Estados Unidos de América, pues en 1901 Aubrey Eneas

6 Annual report of the board of regents of the smithsonian institution showing the operations, expenditures, and condition of the institution for the year ending june 301923 apr 1926. (publication 2758) Washington government printing office. 1925 letter from the acting secretary of the Smithsonian Institution submitting the annual report of the board of regents of the institution for the year ending june 30, 1923. Smithsonian Institution, Washington, June 21, 1923. To the Congress of the United States: In accordance with section 5593 of the Revised Statutes of the United States, I have the honor, in behalf of the Board of Regents, to submit to Congress the annual report of the operations, expenditures, and condition of the Smithsonian Institution for the year ending June 30, 1923. "I have the honor to be, very respectfully, your obedient servant, C. G. Abbot, Acting Secretary». Recuperado de internet el 07 de octubre de 2017: https://archive.org/stream/annualreportofbo1923smit/annualreportofbo1923smit_djvu.txt 
había fundado la Solar Motor Company en Boston y patentado su invento en México y Chile.

La novedad, en cierta medida, es el cambio de manos y sus diferentes perspectivas en la administración de los procesos de selección tecnológica entre la continuidad y la innovación. Mientras que en el siglo XX las cadenas de mando para las decisiones pasaban por Santiago, Valparaíso, Antofagasta, Tocopilla, María Elena, Coya Sur y Nueva York, puntualmente en la Avenida Broadway N 120 , en el siglo XIX el mismo recorrido terminaba en Londres, aunque - este puede ser relevante- la documentación siempre siguió llegando a Londres.

El ingeniero a cargo de todo el proceso de estudios, diseño y construcción llegó a trabajar en María Elena en 1922 y falleció en 1951. Era Edgar Stanley Freed, a quien el tiempo y los vientos del desierto fueron alejando del sitial en la memoria que había alcanzado. Pero su familia conservó sus documentos y gracias a ello y los archivos de las empresas gemelas compañía de Salitres Anglo Chilena y la Lautaro Nitrate Company podemos acceder a los eventos que comenzaron en la década de 1920 con llegada de Stanley a Chile, venido desde New York luego de haberse graduado en el MIT enviado por los propietarios de la industria: la familia Guggenheim ${ }^{7}$ Dos décadas más tarde, Robert Guggenheim escribió a este ingeniero consultándole por su estado de salud pues tenían conocimiento de la fragilidad del funcionamiento de su corazón ${ }^{8}$. De hecho, esa sería su causa de muerte a finales de 1951.

El contacto de los Guggenheim es una clave relevante en la historia de la tecnología en Chile. También fueron los responsables de la llegada de Elias Anton Capellen Smith (1873-1949) encargado del rediseño de los procedimientos de producción del cobre en

Propietarios de la American Smelting and Refining Co., Dan era el encargado de negocios de Meyer Guggenheim Son's en los mercados de minas de Cobre, Oro y Diamantes. Murry y Sol tomaron cargos en la estrategia de negocios futuros hacia 1923 asistidos por E. A. Cappelen Smith and John K. McGowan; Ver en: Glaser-Schmidt, E. (1995, pp. 176-177).

8 Carta September 9, 1949. Robert Guggenheim 2800 Albemarle Street, Washington 8 D.C. 
Chuquicamata ${ }^{9}$ (Chile Exploration Company, CHILEX) y, luego, del salitre chileno (Anglo Chilean Nitrate Corporation) ${ }^{10}$, además, como señalan Bergquist y Lindmark: "director and chief metallurgist at Guggenheim Brothers, and the British consulting company Selection Trust». (Bergquist \& Lindmark, 2016, pp. 197-225).

El Peirce-Smith converter es una de sus contribuciones más conocidas: una invención que mejoraba el rendimiento en la producción de cobre. En la producción de salitre su aporte también es reconocido por ser el encargado del sistema Manufacture of Sodium Nitrate, conocido popularmente como Sistema Guggenheim ${ }^{11}$.

Todo este movimiento en orden a la investigación y desarrollo requiere una explicación acerca de la gobernanza de la selección entre continuidad e innovación tecnológica, aproximarnos a los valores sociales en ingeniería y comprender el lugar de los inversionistas en el proceso como conjunto.

9 Southwick, L. M. (2008). William Peirce and EA Cappelen Smith and their amazing copper converting machine. JOM Journal of the Minerals, Metals and Materials Society, 60(10), 24-34.

10 Patente: Manufacture of sodium nitrate. Número de publicación: US1516550 A. Tipo de publicación: Concesión. Fecha de publicación: 25 Nov 1924. Fecha de presentación: 19 Ene 1922. Inventores: Cappelen Smith Elias Anthon. Cesionario original: Guggenheim Brothers. Estos aportes eran reconocidos en Chile lo suficiente como para que entre marzo de 1924 (Año 5, N 12, p. 555) y noviembre de 1929 (Año 11, No 8, p. 383) se aludiera a su trabajo al menos en 6 oportunidades en la revista Caliche, del Instituto Científico e Industrial del Salitre.

11 Cappelen Smith aparece mencionado «entre muchos otros innovadores» junto a: George Smith, Pedro Gamboni y James Thomas Humberstone (González, 2013, p. 232). 
GOBERNANZA: CONTINUIDAD, INNOVACIÓN, INGENIERÍA Y FINANCIAMIENTO.

Lejos de una pretensión difusionista, en la que una invención es producto de un destello genial que luego es simplemente replicado, la propuesta del modelo teórico de la evolución de la tecnología de George Basalla (2011) ofrece un amplio espectro de posibilidades, en los que se incluyen las creaciones paralelas o el errático comportamiento social que, como lo planteara Kubler (1988), produce descarte de artefactos o una duración intermitente de estos. El despliegue lúdico, las fantasías tecnológicas, la curiosidad, entre otros, son importantes impulsores de la invención y el descubrimiento. Este mundo, muy irracional, forma una parte considerable de las fuerzas no lineales de la historia de la tecnología que inciden en un tipo de evolución que no necesariamente implica progreso en tanto Basalla nos recuerda que la rueda fue inventada tres veces, en tres continentes diferentes (incluido América), pero en una sola ocasión de esas, fue complementada con un eje y caminos.

Esa evolución no lineal ha producido tal amplitud de objetos que se genera un problema de síntesis que es bien resuelto por la propuesta de Líneas Técnicas (Gille, 1999), cuya conceptualización posibilita agrupar conjuntos de artefactos no por su morfología sino por el encadenamiento que unos con otros pueden generar, lo que permite encarar desafíos mayores en escala, velocidad o continuidad. Estas líneas técnicas son las que permiten generar grandes sistemas tecnológicos (Hughes, 1987 y 1993) que pueden llegar a constituir complejos tecnoinstitucionales (Unruh, 2000 y 2001; Unruh and Carrillo-Hermosilla, 2006)

Es justamente esa tecnoinstitucionalidad la que debe ser interrogada en torno a su Gobernanza (Delanty y Mota, 2017; Ibarra, O’Ryan, and Silva, 2018), es decir, cuáles son los actores sociales que inciden en la toma de decisiones en relación con las posibilidades de selección en cuanto a la innovación o la tradición, también llamada continuidad. Esta es una pregunta densa pues apela a la interacción asimétrica de actores humanos y no humanos, lo que puede ser entendido como Actor-red (Latour, 1987) o construcción social de la 
realidad (Berger y Luckmann, 1968) o como una producción cultural (De Certeau, 2010; Geertz, 2003).

Entender este proceso en su complejidad histórica requiere describir y comprender la movilidad del conocimiento, sus intermediarios y su mediación (Sanhueza, 2017a). Como señala Sanhueza, es provechoso detenerse en las prácticas y bases de racionalidad en torno a objetos situados y contextualizados y las redes nacionales y transnacionales que les permitieron fluir. Esto refuerza la idea de la capacidad reinterpretativa o reinvenitiva y releva la importancia de los actores locales en los procesos internacionales, transcontinentales y/o globales como queda en claro en el caso de la ingeniería (Arellano, 2014).

Esto coincide con la idea de las Tecnologías Criollas (Edgerton, 2004, 2007, 2010) que subvierten la apuesta lineal unidireccional cuyo reduccionismo sitúa a las metrópolis y los imperios como agentes de creación y cambio y a sus periferias como sitios de recepción y mera aplicación acrítica de los instrumentos (Medina, Da Costa Marques, Holmes, 2014).

Siguiendo a Basalla (2011): «Las tres grandes invenciones que sir Francis Bacon identificó como fuente de los grandes cambios en la Europa del Renacimiento -la imprenta, la pólvora y la brújula magnética- fueron productos de la civilización china, no de la europea» (208). Por ello debemos preguntarnos por qué los inventores obtuvieron resultados diferentes a los de otros usuarios. Traído este fenómeno a las tecnologías de la energía solar, la búsqueda de una explicación nos conduce a la indagación de los valores sociales en la ingeniería.

La apuesta por un estudio de los valores sociales en la evolución de la tecnología y, específicamente, las termosolares y fotovoltaicas encuentra en las ingenierías el campo de estudio apropiado. Es allí desde donde se ha venido indagando de manera diversa (Greve, 1938; Ibáñez, 1983 y 2005; Parada, 2011, Sanhueza, 2017b; Vergara, 2017). Esta lectura, por supuesto, busca conocer la interacción con los estamentos políticos, económicos, sociales que contribuyeron a modelar aquellas racionalidades que se tradujeron en proyectos a 
nivel conceptual, básico o de detalles tanto como la investigación, desarrollo e innovación.

Asumimos aquí que este proceso, visto en el tiempo contemporáneo de la gran aceleración de la economía (Hibbard et al, 2007), ha venido ligado a la emergencia de la configuración de un valor social descrito como la retórica de la solución tecnológica (Johnston, 2018a, 2018b) cuya ambición mayor ha sido la constitución de una sociedad tecnocrática en la que las decisiones sean tomadas por los regímenes de la ingeniería, prescindiendo o relegando a las clases políticas, económicas e incluso militares.

Esta sobrevalorización de la solución tecnológica como estereotipo de la relación sociedad/naturaleza (Descola y Pallson, 2001) se ha visto beneficiada y al mismo tiempo ha propiciado la reificación de otro valor social enunciado como la persistencia de algunos mitos del binomio civilización y energía (Basalla, 1979 y 1982; Goudsblom, 2012; Issawi, 1991; Ray, 1983; Smil, 2017), a saber: i) se espera que el suministro de energía no tenga fallas, ii) que su abundancia sea infinita, como la cornucopia, y iii) que la energía cumpla con los cambios utópicos de la sociedad. Aquí se aumentan los efectos del descarte y duración intermitente de las tecnologías de la energía solar, a veces incluso tomando forma de un futuro anterior (Koselleck, 2004), arruinación (Wenzel, Lachenal, Manton, \& Tousignant, 2016), acumulaciones de fluctuaciones coexistentes (Delanda, 2011) u olvidos, en ocasiones, traumáticos (Davoine, 2013).

Los resultados del proceso parecen estar vinculados a las sutilezas de la autonomía relativa de la ciencia y la tecnología (Kleiche-Dray, 2017), o tecnociencia, que constituye aquella zona ambigua de las relaciones sociales, culturales, políticas, económicas y de medio ambiente en las que el conocimiento catalogado como científico-tecnológico adquiere una significación capaz de sostener el interrogante acerca de si no es la tecnología la que conduce a la Historia (Smith \& Marx, 1994).

En esas amalgamas de ciencia y tecnología (Marx, 1994) —donde la ciencia es ciega si no cuenta con los instrumentos mediadores de la comprensión humana con los elementos físico-químicos y la 
biología, pero la tecnología es inepta si no se conduce por preguntas significativas que le provoquen hacia un propósito- es que los Estudios Sociales de la Ciencia y la Tecnología (CTS) y la Historia de la Tecnología tienen oportunidades de desarrollo colaborativo, junto con el fértil campo de los Estudios Sociales de la Innovación (CTI).

Sin embargo, lo anterior tiene unos pasos previos que aún no han sido efectivos. La interacción de historia de la Tecnología y CTS, considerando sus riquezas, requiere un tratamiento meticuloso y pormenorizado para enfrentar esquemas de CTS que proponen la idea de Tecnociencia (Vessuri et Kreimer, 2017), lo que conceptualmente pudiera reensamblar la dicotomía ciencia/tecnología, pero que finalmente no ha llegado a pronunciarse acerca de la materia de fondo que es esta segmentación. Lo mismo ocurre con el problema de la concepción lineal de historia que predomina en la visión de los estudios CTS latinoamericanos (Kreimer, 2010) o de aproximaciones genéricas (Gibert, Gómez y Cancino, 2017). Este estado del arte debe ser entendido como un llamado a estrechar colaboraciones y fomentar el debate interdisciplinario.

Por ello, se propone un estudio transnacional e intercontinental acerca de la circulación de los objetos técnicos de la energía solar y de los sistemas sociotécnicos que los integraron, descartaron y/o recuperaron, en conjunto con la movilidad de las personas y colectivos de personas que lo hicieron posible.

Con todo, el problema historiográfico de la evolución de la tecnología encuentra un caso relevante en el uso industrial de la energía solar en Atacama y Chile, además también valorable para las visiones interdisciplinarias del problema de la sustentabilidad, lo que está siendo acogido por los expertos en la materia a juzgar por el uso de los resultados de investigación de historia de las tecnologías de energía solar entre sus referencias (Agostini, Nasirov \& Silva, 2016; Haas, Palma-Behnke et al., 2018; Núñez \& de Gortari, 2013; Torchia-Núñez, Cervantes-de-Gortari \& Porta-Gándara, 2014). 


\section{Los Archivos de la MEMoria del SAlitre: EL OLVIDO Y LA ENERGÍA SOLAR}

Esta investigación ofrece la oportunidad de continuar en el proceso de comprensión de la interacción de la sociedad nacional, las tecnologías y el problema de la sustentabilidad. Estamos conociendo el futuro anterior de las aplicaciones de la energía solar, considerando la circulación de los objetos, las ideas y los actores sociales y actores no humanos que constituyeron la red de relaciones que facilitó o impidió la incorporación de las tecnologías de la energía solar en proyectos de inversión privados.

Los archivos encontrados en Special Collections, Massachussets Institute of Technology (MIT) (Boston), Fundazione Luigi Michelletti (Brescia)y el Imperial College Archives (Londres) han permitido establecer las conexiones entre investigadores chilenos y la comunidad internacional tecnocientífica de las tecnologías de la energía solar. Esta información podría complementarse con archivos de energía solar disponibles en la Arizona State University (Machovec, 2013), University of Florida, y el archivo Tannheim, en Friburgo, de la International Solar Energy Society (ISES). Así mismo, archivos privados como el de Batelle Institute, de ASTRIUM o Foote Mineral Company, además de colecciones privadas de ingenieros, especialistas y técnicos son puntos de interés para la restitución de las memorias sueltas.

Otra fuente de memoria podría encontrarse en bancos de imágenes como el Centro Nacional del Patrimonio Fotográfico, Archivo Fotográfico de la Biblioteca Nacional, Archivo Fotográfico de la Dirección de Arquitectura del Ministerio de Obras Públicas de Chile y el Catálogo de Fotografía Patrimonial del Museo Histórico Nacional. Se pueden abordar aquí los llamados «actos de visualización» (Reinert, 2017, p. 154).

Un tercer componente de las fuentes se encuentra en la historia oral (Prins, 2003) en tanto descendientes y allegados a los y las protagonistas han brindado importantes informaciones que en su fragmentación corroboran la trayectoria general de las tecnologías de la energía solar. 
Como se ve, la reunión de datos e informaciones es una tarea de gran volumen y que representa un desafío historiográfico con mucho campo por abordar. Esta situación debiera ser parte de las discusiones acerca de cuál es y cómo se concibe la cultura científica en Chile.

\section{CONCLUSIONES: LA INGENIERÍA Y LOS NEGOCIOS TRANSFRONTERIZOS}

Una narrativa para las tecnologías de la energía solar debe reconocer un hecho sustancial: una gran parte de la memoria documental del quehacer científico y tecnológico se encuentra en el hemisferio norte. La mayor parte, además, en el mundo anglosajón. Se reúnen aquí las historias de un ingeniero que nació en Estocolmo, vivió en Brooklyn, trabajó en el desierto de Atacama y murió en el de Tarapacá con la de ingeniero de Pennsylvania, que estudió en Boston y desde Nueva York viajó a María Elena para trabajar allí apasionadamente hasta el día de su muerte. Hombres enamorados del desierto.

Pero entre estos nombres el de M.E. Martínez aún no figura: ingeniero en las oficinas Iris y La Granja su contribución a la experimentación con evaporación solar apenas conocida gracias a un informe puntual de 1933, sobreviviente en la correspondencia interna de la Compañía de Salitres Anglo Chilena y que fuera almacenado durante décadas en Londres hasta llegar al Archivo Nacional de Chile.

Es posible afirmar que fueron ingenieros extranjeros quienes valoraron el recurso abundante de la radiación solar, pero no se cuenta con suficiente información acerca de los aportes de los actores sociales locales, incluso cuando las trayectorias en el tiempo de las formas del olvido dejan a la vista el problema del reconocimiento a los méritos de investigación e invenciones de Carlos Espinosa Arancibia, Orlayer Alcayaga y Julio Hirschmann Recht, entre otros y otras, quienes durante toda la segunda mitad del siglo XX pugnaron por el aprovechamiento de un recurso abundante y gratuito.

Uno de los aspectos que se debe discutir en el caso de las tecnologías de la energía solar es cuál es su posición en la historia. En 
general, resulta difícil clasificarle como historia desde abajo o historia desde arriba o en alguna posición, cuando su circunstancia habitual es el movimiento y su participación multiescalar y transfronteriza. Desde aquí que el problema de la memoria sea un elemento crucial (Portelli, 2010). Por ahora los archivos de las empresas de Gibbs y Guggenheim y sus largas trayectorias documentales constituyen un eje en relación al cual parece posible componer el mosaico de las tecnologías de la energía solar en la industria de los nitratos.

Lo que podemos establecer, por el momento, es que el desierto de Atacama ha sido un laboratorio global desde el siglo XIX para las tecnologías de la energía solar. Allí fue construida la primera industria solar de desalación de agua del mundo en 1872 y otras dos en 1883 y 1907. En 1918, el Smithsonian Institute tuvo allí un observatorio astrofísico para conocer la radiación solar directa. Estas experiencias se desarrollaron en propiedades de Casa Gibbs o con el apoyo de las inversiones Guggenheim.

Los archivos nacionales e internacionales permiten tener una apreciación acerca de estos procesos de articulación multiescalar y proyección global del territorio local del desierto de Atacama. Las escalas intersectadas, en el decir de Julia Thomas, favorecen el estudio eco-económico en una lectura historiográfica de la intermitencia de las tecnologías termosolares.

La visita e informes de investigadores e ingenieros en la cosecha de energía solar al territorio del desierto de Atacama, en las décadas de 1870 hasta 1918, y la activación de los distintos nodos del actor-red implicados en la exploración de alternativas de desarrollo para la matriz energética local, sugiere la posibilidad de producir una narrativa de historia tecnoambiental transfronteriza que deja de manifiesto a los factores culturales y económicos que incidieron en el devenir de la evolución de la tecnología. Queda pendiente, por supuesto, una larga indagación más profunda e intensa acerca de los valores sociales que silenciaron hasta el olvido los aportes y éxitos de la energía solar.

Finalmente, con la discusión de los enfoques del desarrollo local en una historia regional se espera contribuir al análisis del 
binomio Energía y Civilización como aproximación al problema de la sustentabilidad considerando las identidades e integraciones desde el sur global en el actual norte grande de Chile que fuese el litoral boliviano hasta los tres cuartos del siglo XIX. Las realidades múltiples permanecen en acción.

\section{BIBLIOGRAFÍA}

Agostini, C. A., Nasirov, S., \& Silva, C. (2016). «Solar PV planning toward sustainable development in Chile: challenges and recommendations». The Journal of Environment \& Development, 25, 1, 25-46.

Alvarado, M. y Mason, P. (2001). «La desfiguración del otro: sobre la historia de una técnica de producción del retrato 'etnográfico'». Aisthesis, 34, 242-257.

Arellano, Nelson (2014). "Los ingenieros británicos en la Sudamérica del siglo XIX». Quipu Revista Latinoamericana de Historia de las Ciencias y la Tecnología, 16, 1, 39-62.

Arellano, Nelson (2015). La ingeniería y el descarte artefactual de la desalación solar de agua: las industrias de Las Salinas, Sierra Gorda y Oficina Domeyko (1872-1907), tesis para optar al grado de doctor, Universidad Politécnica de Cataluña.

Arellano, Nelson. (2016). «El debate de la energía solar para la desalación de agua en 1884: rastros de un discurso desatendido». Quaderns d'història de l'enginyeria, 15, 449-467.

Arellano, Nelson. (2017). «El desierto de Atacama como laboratorio: experimentos y tecnologías de la energía solar (1872-1981)». Aldea Mundo, 22, 044, 81-89.

Arellano, Nelson. (2018a). «La energía solar industrial en el desierto de Atacama entre 1933 y 1952: Investigación, desarrollo y sustentabilidad». Estudios Atacameños, aceptado para publicar.

Arellano, Nelson. (2018b). «MIT, Universidad de Barcelona, CORFO y Batelle Institute: búsquedas paralelas del poder solar en la década de 1970». Quaderns d'història de l'enginyeria, 2018. Aceptado para publicación.

Arellano, Nelson y Roca-Rosell, Antoni. (2018). Solar energy technologies: unity and disunity of loose European memories, Pannel accepted for European Society for the History of Science Biennial Conference 2018 in conjunction with the British Society for the History of Science. London, 14-17 September, Theme: Unity and Disunity. Augé, M. (1998). Las formas del olvido, Barcelona, Gedisa.

Barthes, Roland. (2009). La Cámara Lúcida, Barcelona, Editorial Paidós. 
Basalla, G. (1979). «Energy and civilization». EPRI Journal, 4, 6, 20-25. Basalla, George. (1982). "Some persistent energy myths». Energy and transport: Historical perspectives on policy issues, 15, 27-38.

Basalla, George (2011). La evolución de la tecnología, Barcelona, Editorial Crítica, segunda edición.

Battelle Institute (1976). Estudio de factibilidad de Centrales de Potencia en el norte de Chile. Battelle Centre de recherche de Géneve, Suiza. Biblioteca CORFO, Santiago de Chile.

Berger, P. L. \& Luckmann, T. (1968). La construcción social de la realidad. Buenos Aires: Amorrortu.

Blanco, Gustavo. (2016). La Vida Social De La Energía: Trayectorias Territoriales De La Energía En Tres Regiones Del Sur-Austral De Chile, Disciplina Fondecyt No 1160857: Ciencias Sociales, Sociología, Cambio Social y Desarrollo. Concurso Nacional Regular 2016.

Bouvier, Yves y Pehlivanian, Sophie. (2013). Introduction, Annales historiques de l'électricité, 1, 11, 8-10. DOI 10.3917/ahe.011.0007

Bouvier, Yves et Laborie, Léonard (dir.). (2016). L’Europe en transitions. Énergie, mobilité, communication. XVIIIe-XXIe siècles, Paris, Nouveau monde éditions, 332.

Burke, P. (1996). Hablar y callar: funciones sociales del lenguaje a través de la historia, Barcelona, Gedisa.

Burke, P. (2001). New perspectives on historical writing. Penn, Penn State Press.

Burke, Peter (ed.). (2003). Formas de hacer historia, Madrid, Alianza Ensayo. Calle, M. (2013). «La inmigración europea en la Provincia de Tarapacá. Su inserción en la estructura productiva 1860-1940». En González, S. (2013). La sociedad del salitre. Protagonistas, migraciones, cultura urbana y espacios públicos. Santiago de Chile, RIL editores,119-161.

Conant, James. (1957). Harvard case histories in experimental science, Cambridge, Harvard University Press.

Couyoumdjian, J. R. (2000). «El alto comercio de Valparaíso y las grandes casas extranjeras, 1880-1930: una aproximación». Historia (Santiago), 33, 63-99

Davoine, Françoise. (2013). Clínica de lo extremo, Entrevista con Dori Laub. Le Coq-Héron, Érès, Paris, 214, 143-158.

De Certeau, Michel. (2010). La invención de lo cotidiano, México, Universidad Iberoamericana.

De Landa, M. (2011). Mil años de historia no lineal. Barcelona: Gedisa. Versión original De Landa, M. (1997). A thousand years of nonlinear history. New York, Swerve Editions.

Delanty, G., \& Mota, A. (2017). «Governing the Anthropocene: Agency, governance, knowledge». European Journal of Social Theory, 20, 1, 9-38. 
Descola, Phillip y Pallson, Gísli. (2001). Naturaleza y sociedad. Perspectivas antropológicas, México, Siglo XXI.

DeVorkin, D. H. (1998). «Charles Greeley Abbot May 31, 1872-December 17, 1973». Biographical Memoirs, 73, 3.

Edgerton, D. (2004). «De la innovación al uso: diez tesis eclécticas sobre la historiografía de las técnicas". Quaderns d'Història de l'Enginyeria, VI, 1-23.

Edgerton, D. (2007). Innovación y tradición: historia de la tecnología moderna, Barcelona, Editorial Crítica.

Edgerton, D. (2010). «Innovation, Technology, or History. What is the Historiography of Technology About?» Technology and Culture, $51,3,680-697$.

Flyvbjerg, Bent. (2004). «Cinco malentendidos acerca de la investigación mediante los estudios de caso, Reis». Revista Española de Investigaciones Sociológicas, 106, 33-62.

Geertz, Clifford. (2003). La Interpretación de las culturas, Barcelona, Gedisa.

Gibert, Jorge, Gómez, Andrés y Cancino, Ronald (2017). Ciencia, tecnología y sociedad en América Latina: la mirada de las nuevas generaciones, Santiago de Chile, RIL editores.

Gille, B. (1999). Introducción a la historia de las técnicas, Barcelona, Editorial Crítica.

Ginzburg, Carlo. (1981). El queso y los gusanos: el cosmos de un molinero del siglo XVI, Barcelona, Muchnik

Glaser-Schmidt, E. (1995). "The Guggenheims and the Coming of the Great Depression in Chile, 1923-1934-2. Business and Economic History, 176-185.

González, S. (2013). «Heterotopía y utopía en la pampa salitrera. Desde los mitos de la ocupación del desierto y del descubrimiento del salitre a la urbanización de la pampa, 1870-1920». En González, S. La sociedad del salitre. Protagonistas, migraciones, cultura urbana y espacios públicos. Santiago de Chile, RIL Editores.

González, S., Artaza, P. y Calderón, R. (2016). «El fin del ciclo de expansión del salitre en Chile: la inflexión de 1919 como crisis estructural». Revista de Historia Industrial, 25, 65, 83-110.

González Miranda, S., \& Ovando Santana, C. (2017). «Sama y Camarones: Las fronteras que no fueron entre Perú y Chile». Revista de geografía Norte Grande, 66, 61-82.

Goudsblom, J. (2012). «Energy and Civilization». International Review of Sociology, 22, 3, 405-411.

Greve,Ernesto. (1938). Historia de la Ingeniería en Chile, Santiago de Chile, Imprenta Universitaria. 
Haas, J., Palma-Behnke, R., Valencia, F., Araya, P., Díaz-Ferrána, G., Telsnigc, T., Eltropc, L., Díaza, M., Püschela, S., Grandeld, M., Román, R., Jiménez-Estévez, G. (2018). «Sunset or sunrise? Understanding the barriers and options for the massive deployment of solar technologies in Chile». Energy Policy, 112, 399-414.

Headrick, D. (1989). Los instrumentos del Imperio. Tecnología e imperialismo europeo en el siglo XIX. Alianza Editorial. Madrid.

Hernando, M., \& Blanco, G. (2016). «Territorio y energías renovables no convencionales: aprendizajes para la construcción de política pública a partir del caso de Rukatayo Alto, Región de Los Ríos, Chile». Gestión y política pública, 25, 1, 165-202.

Hibbard, K. A., Crutzen, P., Lambin, E. F., Liverman, D., Mantua, N. J., McNeill, J. R., Messerli, B. and Steffen, W. (2007). The Great Acceleration. En R. Costanza, L. J. Graumlich, and W. Steffen (eds.). Sustainability or Collapse? An Integrated History and Future of People on Earth. Dahlem Workshop Report 96. Cambridge, MA, MIT Press, 341-378.

Hughes, Thomas. (1987). The Evolution of Large technological Systems. En Bijker, Hughes And Pinch The Social Construction of Technological Systems, Mass., MIT Press, 51-82.

Hughes, Thomas. (1993). Networks of power: electrification in Western society, 1880-1930. Baltimore, John Hopkins University Press.

Ibáñez, Adolfo. (1983). «Los ingenieros, el estado y la política en Chile: del Ministerio de Fomento a la Corporación de Fomento: 1927-1939». Historia, 188, 45-102.

Ibáñez, Adolfo. (2005). «Los ingenieros norteamericanos en la década de 1920 y su intento de construir un mundo feliz». Boletín de la Academia Chilena de la Historia, 71, 114, 87-107.

Ibarra, C., O’Ryan, R. and Silva, B. (2018). «Applying knowledge governance to understand the role of science in environmental regulation: the case of arsenic in Chile». Environmental Science \& Policy, 86, 115-124.

Issawi, C. (1991). "Technology, energy, and civilization: Some historical observations». International Journal of Middle East Studies, 23, 3, 281-289.

Johnston, Sean. (2018a). «The Technological Fix as Social Cure-All: Origins and Implications». IEEE Technology and Society Magazine, 37, 1, 47-54.

Johnston, Sean. (2018b). «Alvin Weinberg and the promotion of the technological fix». Technology and Culture. In press.

Kleiche Dray, M. (2017). Les ancrages nationaux de la science mondiale, XVIIIe-XXIe siècles. Paris, Éditions des archives contemporaines, en coédition avec IRD Éditions. 
Koselleck, R. (2004). Futures past: on the semantics of historical time. NY: Columbia University Press. Spanish version: Koselleck, Reinhart. (1993). Futuro pasado. Para una semántica de los tiempos históricos, Buenos Aires, Editorial Paidós.

Kreimer, P. (2010). Ciencia y Periferia. Nacimiento, muerte y resurrección de la biología molecular en la Argentina. Aspectos sociales, políticos $y$ cognitivos. Buenos Aires. EUDEBA.

Kubler, George. (1988). La Configuración del tiempo: Observaciones sobre la historia de las cosas, Madrid, Nerea.

Latour, B. (1987). Science in action: How to follow scientists and engineers through society. Harvard University Press.

Llorca-Jaña, M., \& Barría, D. (Eds.). (2017). Empresas y empresarios en la historia de Chile: 1810-1930. Santiago de Chile, Editorial Universitaria.

Machovec, George. (2013). Solar Energy Index: The Arizona State University Solar Energy Collection, New York, Pergamon.

Marcus, G. (2001). «Etnografía en/del sistema mundo. El surgimiento de la etnografía multilocal». Alteridades, 11, 22, 111-127.

Marx, Leo. (1994). «The idea of 'Technology' and Postmodern Pessimism». En Smith, Merritt and Marx, Leo. (1994). Does Technology drive History? The Dilemma of Technological Determinism, Cambridge, MIT Press, 11-28.

Matute Aguirre, A. (1999). «Heurística e Historia». México: UNAM, Centro de Investigaciones Interdisciplinarias en Ciencias y Humanidades, Videoteca de Ciencias y Humanidades, 29.

Medina, Eden, Da Costa Marques, Ivan, Holmes, Cristina. (2014). Beyond Imported Magic: Essays on Science, Technology, and Society in Latin America, Cambridge, MIT Press.

Misa, T. J. (1988). «How machines make history, and how historians (and others) help them to do so». Science, Technology, \& Human Values, 13, 3/4, 308-331.

Ministerio de Energía. (2016). Informe de Seguimiento 2016. Web. Recuperado de internet el 22 de mayo de $2017<\mathrm{http}: / /$ www.energia2050. cl/wp-content/uploads/2017/04/Informe-Seguimiento-2016.pdf>

NREL. (2018). Concentrating Solar Power Projects in Chile. Web. Recuperado de internet el 10 de abril de 2018 <https://www.nrel.gov/csp/ solarpaces/by_country_detail.cfm/country=CL $>$

NUMIES. (2014). Núcleo Milenio de Investigación en Energía y Sociedad (Numies. Web. Recuperado de internet el 16 de abril de $2015<\mathrm{http}: / /$ www.iniciativamilenio.cl/numies/>

Núñez, J. C. T., \& de Gortari, J. C. (2013). «Discusión sobre el modelado de la destilación solar: experimentos y teoría». Tecnología en Marcha, 26, 4, 100-108. 
Parada, Jaime. (2011). «La Profesión de Ingeniero y los Anales del Instituto de Ingenieros de Chile». 1840-1927, ix-lxxvii. En Sagredo, Rafael (Ed.) (2011) Anales del Instituto de Ingenieros de Chile. Ingeniería $y$ sociedad 1889-1929, Santiago de Chile, Centro de Investigaciones Diego Barros Arana de la Dirección de Bibliotecas, Archivos y Museos. Pehlivanian, S. (2014). Histoire de l'énergie solaire en France: science, technologies et patrimoine d'une filière d'avenir, Doctoral dissertation, Grenoble.

Podgorny, Irina (2017). «Hacia una historia burocrática de las ciencias». En Sanhueza, Carlos (ed.). La movilidad del conocimiento científico en América Latina, 19-54.

Portelli, A. (2010). Death of Luigi Trastulli and Other Stories, The: Form and Meaning in Oral History. Boston, Suny Press.

Prins, Gwyn. (2003). Historia Oral, 144-176. En Burke (2003) op. cit.

Ramírez, R. (2010). Estudio, análisis y discusión de las tecnologías utilizadas en el diseño y construcción de edificios sustentables en Chile, Tesis para optar al grado de ingeniero civil por la Universidad de Chile.

Ray, D. L. (1983). «Energy and civilization». Nuclear and Chemical Waste Management, 4, 1, 3-7.

Reinert, Kathrin. (2017). «Saber e imaginación: fotografías científicas de los legados Uhle y Lehmann-Nitsche». En Sanhueza, Carlos (ed.). La movilidad del conocimiento científico en América Latina, 149-168.

Román Latorre, Roberto y Palma Behnke, Rodrigo (Eds.). (2017). La Fuerza del sol, Santiago de Chile, Ayllu Solar - SERC Chile.

Rubio, G. (2013). «Memoria, ciudadanía y lo público en la elaboración del pasado reciente en la experiencia chilena». Memoria y Sociedad, 17, 35, 164-183.

Sanhueza, Carlos. (ed.), (2017a). La movilidad del conocimiento científico en América Latina. Objetos, prácticas, instituciones. Siglos XVIII$X X$, Santiago de Chile, Universitaria.

Sanhueza, Carlos. (2017b). Cien años Escuela de Ingeniería y Ciencias 1917-2017, Santiago, Universidad de Chile.

San Martín, W. (2017a). «Nitrogen, science, and environmental change: the politics of the Green Revolution in Chile and the global nitrogen challenge». Journal of Political Ecology, 24(1), 777-796.

San Martín, W. (2017b). Dissertation: Nitrogen Revolutions: Agricultural Expertise, Technology, and Policy in Cold War Chile. History Department. University of California Davis.

Smil, V. (2017). Energy and Civilization: A History. Cambridge, MIT Press. Smith, Merritt and Marx, Leo. (1994). Does Technology drive History? The Dilemma of Technological Determinism. Cambridge, MIT Press. Stern, S. J. (2006). Battling for hearts and minds: Memory Struggles in Pinochet's Chile, 1973-1988. Duke University Press. 
Stern, D. I. (2004). «Economic growth and energy». Encyclopedia of Energy, 2, 147, 35-51.

Stern, D. I. (2011). "The role of energy in economic growth». Annals of the New York Academy of Sciences, 1219, 1, 26-51.

Stoichita, V. I. (2006). Simulacros: el efecto Pigmalión: de Ovidio a Hitchcock, Siruela, Madrid, trad. por Anna Maria Coderch del original: The Pygmalion Effect: From Ovid to Hitchcock. Towards a historical anthropology of Simulacra, University of Chicago Press, Illinois.

Thomas, Julia. (2017). Historia económica en el Antropoceno: cuatro modelos. Desacatos, 54, 28-39.

Thompson, P. (2017). The voice of the past: Oral history. Oxford University Press.

Unruh, Gregory (2000). «Understanding Lock-in Carbon». Energy Policy, 28, 817-830.

Unruh, Gregory (2002). «Escaping carbon lock-in». Energy Policy, 30, 4, 317-325.

Unruh, Gregory and Carrillo-Hermosilla, Javier. (2006). «Globalizing Carbon Lock-in». Energy Policy, 34, 10, 1185-1197.

Vera, L. C. (2013). «Políticas públicas y gobernabilidad en las zonas extremas de Chile 2010-2012». Estudios de Seguridad y Defensa, 1, 17-43.

Vergara, Mario. (2017). Ochenta años formando ingenieros mecánicos. Un camino de búsqueda, Realización personal y profesional. 19372017 Chile. Valparaíso, Universidad Técnica Federico Santa María.

Vessuri, Hebe et Kreimer, Pablo. (2017). «Les sciences en Amérique latine. Tensions du passé et défis du présent». En Kleiche Dray, M. Les ancrages nationaux de la science mondiale, 99-134. Impreso.

Villalobos, Sergio. (1983). Historia de la energía en Chile, Santiago, Museo Histórico Nacional de Chile.

Wenzel, P., Lachenal, G., Manton, J., \& Tousignant, N. (2016). Traces of the future: an archaeology of medical science in Africa. Chicago, University of Chicago Press. 


\title{
LA CULTURA DE LA MEDICIÓN CIENTÍfiCA DOCUMENTADA EN CHILE. LA HERENCIA DE KIEV Y YALE
}

\author{
Alejandro Vega Muñoz \\ Universidad Autónoma de Chile \\ Fundación Escuela de Asuntos Internacionales
}

Resumen. Este capítulo revisa los orígenes de la cultura de medición de la ciencia, en base a la documentación científica en el movimiento ruso por la Nanka (наука) у la competencia académica entre las universidades de Kiev y Yale, por definir mejores formas de medir los resultados científicos publicados entre y pos ambas guerras mundiales. Y como esos condicionamientos teóricos generados en el origen de esta vertiente de la llamada Ciencia de la Ciencia, permiten hoy bajo la cienciometría, dar una revisión longitudinal y evolutiva de los resultados científicos documentados de corriente principal producidos en Chile, logrando una visión tanto sistémica como temática y disciplinar respecto de las investigaciones tratadas en esos documentos. Aportando así, información relevante y que además contribuye a comprender los cimientos de la discusión hoy abierta en Chile. Tanto, en torno a la instalación institucional del nuevo Ministerio de Ciencia, Tecnología, Conocimiento e Innovación; como por las nuevas exigencias de investigación impuestas a las Universidades chilenas.

Palabras clave: ciencia de la ciencia, Chile, cultura científica, economía de la ciencia.

Aвstract. This chapter reviews the origins of the science measurement culture, based on the scientific documentation in the 
Russian movement by the Nauka (наука) and the academic competition between the universities of Kiev and Yale, to define better ways to measure the scientific results published between and post both World Wars. And as those theoretical conditions generated in the origin of this Science of Science aspect, allow today under the scientometrics, to give a longitudinal and evolutionary review of the documented mainstream scientific results produced in Chile, achieving a vision both systemic and thematic and disciplinary with respect to the researchers in those documents. Contributing this, relevant information and that also contribute to understand the foundations of the discussion opened today in Chile. So much, around the institutional installation of the new Ministry of Science, Technology, Knowledge and Innovation; as for the new research requirements imposed on Chilean universities.

KEYwORDS: Science of science, Scientific culture, Economics of science, Chile.

\section{INTRODUCCIÓN}

La medición de la ciencia documentada tiene su expresión contemporánea en la bibliometría y la cienciometría, siendo la primera recurrentemente asociada como una de las subdisciplinas clasificadas por UNESCO (1988) dentro de la disciplina científica de Lingüística Aplicada con la posición codificada (570113). Las 207 tesis doctorales que el TESEO del Ministerio de Educación Cultura y Deporte de España (2018) tiene registradas a contar del año académico 1985-1986, hasta el último año académico finalizado (2017-2018), dan cuenta fehaciente de esto.

Además de este reconocimiento académico como subdisciplina científico-tecnológica, que la posiciona más allá de un mero método. Escorsa y Maspons (2001) dan cuenta de que tanto la bibliometría como la cienciometría constituyen un insumo creciente para los estudios en el ámbito del conocimiento.

Por una parte, la bibliometría se dedica al estudio organizacional sectorizado de la ciencia y la tecnología, en función de las fuentes 
bibliográficas y registros patentométricos ${ }^{1}$, para identificar en materia de conocimiento a: los actores de producción, las relaciones dentro del conocimiento y tendencias. Aplicando métodos de estudio bajo enfoques cuantitativos y análisis, principalmente, estadísticos descriptivos de producción y uso de documentos como referencias bibliográficas citadas en nuevos documentos, uso de libros y otros soportes de información dentro y entre los sistemas de bibliotecas, y unidades físicas publicadas, o unidades bibliográficas, o de sus sustitutos. (Spinak, 1998; Vega y Romero, 2006).

En cambio, la cienciometría, dando cobertura a un espectro conceptual más amplio, puede considerarse un instrumento de la subdisciplina de Sociología de la Ciencia, que se ocupa de evaluar cuantitativamente la actividad científica documentada bajo la óptica científico disciplinar de la economía sectorial o aplicada, en particular la subdisciplina dedicada al estudio de la economía del sector investigación y desarrollo (I+D). Así, sobre la base de indicadores bibliométricos, las ciencias económicas son aplicadas con el objeto de valorar el desarrollo de la ciencia y de las políticas científicas en relación con aspectos económicos y sociales locales y globales (Escorsa y Maspons 2001, Santa-Soriano et al, 2018; Spinak 1998). Así, para Spinak (1998), la cienciometría incluye entre sus intereses: «el crecimiento cuantitativo de la ciencia, el desarrollo de las disciplinas y subdisciplinas científicas, la relación entre ciencia y tecnología, la obsolescencia de los paradigmas científicos, la estructura de comunicación entre los científicos, la productividad y creatividad de los investigadores, las relaciones entre el desarrollo científico y el crecimiento económico» (p. 142).

Pero tal desarrollo métrico sofisticado no se genera para estudiar la ciencia "en pequeño», como el trabajo de un laboratorio dentro de la universidad o la discusión dentro de su claustro de catedráticos, sino que a las grandes estructuras de la ciencia que realzan a nivel mundial, lo que a continuación detallaremos como la ciencia «en grande».

1 Registros con información métrica de patentes de propiedad industrial que pueden servir de insumos para estudios cienciométricos y en especial estudios sobre innovación. (Cavaller, 2008; Griliches, 1990). 


\section{LA Big SCIENCE Y SU GRAN INFLUENCIA}

Según Echeverría y González (2009), se entiende por Big Science, gran ciencia o macrociencia a una corriente científica surgida en la Guerra Fría, la que se caracterizaba por una profunda simbiosis entre ciencia y tecnología (tecnociencia), el establecimiento de una política científica gubernamental basada en grandes programas de investigación con objetivos políticos, estratégicos, militares y sociales, y que a la vez era financiada por los propios gobiernos. Por tanto, estos programas serían los catalizadores del sincretismo conocido como tecnociencia, resultante de la relación bidireccional entre el constructo social de producción de conocimientos denominado ciencia y el desarrollo de ingenios llamado tecnología. (Gómez-Yepes, 2017).

Pero los avances tecnocientíficos, en nuestros días incluso desbordan a la Big Science de la post Segunda Guerra Mundial (19391945). Se agrega a la vinculación entre ciencia basal y desarrollo tecnológico $(\mathrm{I}+\mathrm{D})$ : una visión cada día más praxeológica ${ }^{2}$, una inversión del sector privado, y un tercer componente dado por la innovación $(\mathrm{I}+\mathrm{D}+\mathrm{i})$. Esta innovación se lleva a efecto en una estructura de red, constituida por unos pocos nodos: incipientes, escasos, concentrados, costosos, frágiles, tanto humanos, como no humanos; pero que a su vez brindan un impacto de gran cobertura social (Acuña, 2008; Alcántara-Santuario, 2000; Alcíbar, 2009; Casanueva y Caro, 2013; Covarrubias-Villa, et al., 2009; Coca y Valero-Matas, 2010; Echeverría y González, 2009; Gómez-González et al., 2014; Lizcano, 1996).

Como marco de acción, la tecnociencia se organiza bajo una estructura de poder y objetivos organizacionales claros, siendo dependiente de la disponibilidad de recursos humanos calificados (capital humano avanzado) e infraestructura tecnológica que le brinde coeficientes altamente productivos (eficiencia técnico económica), con el objeto de asegurar beneficios económicos y financieros

2 Visión que se enfoca en un discurso de perfección de la racionalidad humana y el saber-hacer o la praxis, el que también ha derivado en una corriente económica que tiene entre sus principales autores al austriaco Ludwig von Mises (Boff, 2018; Castela, 2016). 
conducidos por una eficiente gestión administrativa y control efectivo de los resultados científicos planeados (Alcíbar, 2009; Balmaceda et al., 2012). Al respecto, cierta corriente de autores señala que existe un gobierno de lo político con la concurrencia de la experticia técnica, pero quedando bajo los criterios políticos la decisión de dar mayor o menor realce a uno y otro (Calleja, 2010).

El punto de origen de los apegos (tecnofilia) y desapegos (tecnofobia) por la actividad tecnocientífica es que, aunque la decisión respecto de sus prioridades y la naturaleza de los problemas en estudio, hoy en día son más propias del debate político y económico, que del debate científico- tecnológico (dado el apoyo financiero bajo condiciones de riesgo e incertidumbre que la ciencia y tecnología requiere), en términos reales y concretos está en manos de los científicos decidir qué resultados son los más apropiados para ser utilizados en forma pública (dado los tecnicismos implícitos en tal decisión); en el otro extremo algunos actores sociales que se consideran excluidos de la tecnociencia hacen hincapié en las consecuencias indeseables de las tecnologías y abogan por un sistema tecnocientífico más democrático, que permita a los no científicos poder «tener voz y voto» en el desarrollo del mismo, para hacerlo más amigable con los límites humanos y naturales relativos a su accionar, alcanzar mayor apertura a los intereses y preocupaciones sociales, y por sobre todo para resguardar los aspectos éticos de su accionar ${ }^{3}$; a la vez de destacar la necesidad que la ciencia se desarrolle en ambientes democráticos, para que pueda alcanzar su amplitud metodológica y dar despliegue con libertad a su racionalidad. (Alcíbar, 2009; Coca, 2008; Feenberg, 2005; Guijarro, 2003; Parselis, 2016). En una revisión a los clásicos de la filosofía de las ciencias y la sociología del conocimiento científico, Guijarro (2003) nos representa esta realidad atribuyendo -en tiempos del origen la Big Science- a la ciencia, la búsqueda del conocimiento verdadero y calificándola en un rol antagónico como sustento de un complejo económico, militar e industrial (Casper, 2015).

Del punto vista histórico el movimiento «Ciencia para el Pueblo», que apelaba en contra de la participación de científicos en la Guerra de Vietnam, marcan un ejemplo señero de este enfoque no científico. (De Greiff y Nieto, 2005). 
Ahora sin duda, al estar la nueva economía basada en el conocimiento generado internamente en las organizaciones y el adquirido por estas desde su entorno (conocimiento social), así como en la aplicación práctica de la tecnociencia $(\mathrm{I}+\mathrm{D}+\mathrm{i})$. Los aspectos éticos se tornan altamente relevantes generando por tanto puntos de discusión. (Saiz-Álvarez, 2013).

Según Larrión-Cartujo (2008, 2011), uno de estos puntos de desacuerdo en la actualidad es la tercera revolución verde o biotecnologías modernas y su aplicación a la nueva ingeniería genética, donde las intervenciones no son azarosas, pues tienen fundamento científico, predicción de eficacia y la posibilidad de afectar la transformación de mecanismos vitales, especialmente en el genoma; ejerciendo un poder disciplinario sobre la naturaleza y los seres humanos (Lolas-Stepke, 2010, Paredes-Oviedo, 2016). El punto central es el disenso si la genética ha alcanzado una plausible mejora o más bien se trata de una degradación genética de los animales, las plantas y los productos industriales (Larrión-Cartujo, 2008).

A la luz de Le Breton (1994) y Trilles-Calvo (2017), al punto anterior, se puede sumar la actuación de la medicina moderna o «medicina del deseo», con su enfoque mecanicista de la atención al cuerpo enfermo, por sobre la realidad humana; ejemplificados en la fusión del hombre y la máquina con fines de aplazar el alcance del estado absorbente denominado muerte, la corrección del cuerpo en búsqueda de la perfección de lo corpóreo, la fecundación asistida, el aborto terapéutico, la eutanasia como fin del dolor y la donación de órganos de cuerpos inertes como mecanismo de reemplazo y «reacondicionamiento» de otros cuerpos vivos. Según Lolas-Stepke (2010) en esto existe el riesgo de dejarse influir por los deseos o necesidades de individuos que afecten a toda la masa genética de la especie, a merced del poder biogenómico. Ante lo cual, agrega Martin (2008, 2012) la ciencia y la ética están desarrollando, desde lo endógeno y por exigencia social, cambios profundos que permitan unificar creencias acerca de la supervivencia de la vida, ante los deterioros ambientales y las carencias sociales. 
Un segundo punto de disenso es el que se produce en la industria farmacéutica, entre el costo y el acceso de los medicamentos de extrema urgencia para los países en vías de desarrollo, cuya batalla se libra en torno al acuerdo de aspectos de los derechos de propiedad intelectual relacionados con el comercio (ADPIC) de la organización mundial de comercio (OMC) y sus efectos sobre las patentes de medicamentos y la posibilidad efectiva de hacer uso de las licencias obligatorias $^{4}$ (Love, 2006; Velásquez, 2006). A este respecto, casos como el del medicamento Cipro de Bayer con los gobiernos de Estados Unidos de América y Canadá, contrastan con la falta de acceso a medicamentos contra el Sida en Brasil o Sudáfrica (Love, 2006).

Un tercer punto de desavenencias y el último tratado en este capítulo, es el del desarrollo nuclear, el cual se encuentra con mayor fuerza en la discusión, después el episodio de Fukushima, tras el maremoto de 2011 en Japón (Greenpeace España, 2012). Pero, por otra parte, a pesar de los riesgos, dado el aumento del consumo eléctrico mundial y la carbonización de la matriz energética, la opción nuclear traería una disminución de las emisiones de dióxido de carbono, siendo esta su principal ventaja sobre los combustibles fósiles (Rotwell, 2008).

Para la superación de estas desavenencias entre el apego y desapego por la tecnociencia, según señalan Coca y Valero-Matas (2010) y Valero-Matas y Coca (2013), el cruce de ambos aspectos requiere que la tecnociencia alcance un estado de búsqueda de la verdad intercultural, pues dada la imposibilidad de alcanzar una forma de razonar la complejidad del mundo como un todo, es necesario alcanzar la búsqueda de la verdad en múltiples contextos culturales o como el autor denomina mediante una policontextura tecnocientífica. Incluso, resguardando la incorporación de grupos sociales «irrelevantes» que sin duda también se ven «afectados» por el desarrollo de la ciencia y la tecnología (Escobar, 2005; DomínguezMoreno, 2018). También se logra redefinir el sistema tecnológico mediante la apropiación social de dichas tecnologías, la que adopta

4 Medida que permite a un gobierno a obligar al titular de una patente a autorizar una producción local, negociando luego una compensación económica. 
características propias en función de los usos y costumbres de cada contexto social, permitiendo crear y recrear con celeridad: esquemas cognitivos, sistemas de valores, prácticas, costumbres, comportamientos, estilos de vida y cosmovisiones (Lezama-Escalante, 2006).

Según Quintanilla (2005), la cuestión filosófica más importante en relación con el progreso tecnocientífico no es su benevolencia o malevolencia, sino los mecanismos y razones que explican el por qué ha evolucionado la tecnología y el sentido que esto tiene. Al respecto, Escobar (2005) abunda ilustrando la valencia neutral de la tecnociencia, señalando que esta no puede ser calificada ni de benévola ni de malévola, pues solo es un instrumento al servicio del ser humano, y como instrumento no puede ser calificado por el énfasis con que sea empleado por sus usuarios. Es más, toda esta asociación entre innovación y progreso presente en las ideas de Schumpeter puede verse reforzada en la metáfora de «la flecha del progreso» o regeneración de la especie humana de Benjamin (Ayllón, 2009; Steimberg, 2001; Fernández, 2007; Quintero-González, 2016; Sánchez, 1993). Esto conduce, nuevamente a la cuestión de porqué y cómo medir la ciencia y su progreso.

\section{Kiev y Yale, entre el Nauka Ruso y la posguerra}

En el desarrollo del rol métrico en torno a la ciencia, existen precursores. A un lado de la vereda, se identifica a la otrora Unión Soviética y el movimiento denominado "Naukovodemia», cuyos orígenes se demarcan con una publicación de Boricharski en 1926 y una siguiente de Ossowaki en 1935, y que como movimiento de medición de la ciencia alcanza su definición cuantitativa con la obra publicada en 1966 en Kiev (Ucrania): «Nauka» por G.M. Dobrov. (González-Uceda, 1997). Tomás-Castera (2013), además de reconocer la importancia de la «Naukovodemia», en el origen de la cultura de la medición de la ciencia, también atribuye a la vertiente rusa el «nacimiento y trayectoria de Scientometrics, fundada en Hungría en $1978 »($ p. 25). 
Dobrov lideraba desde el año 1965 un grupo de nanocientíficos en el Departamento de Métodos Mecánicos de Información Histórica y Científica, que dentro del Instituto de Historia de la Academia de Ciencias de Ucrania se dedicaba a los estudios cienciométricos. El que desde 1991 fue conocido como el Centro de Capacidad Científica y Técnica e Historia de la Ciencia G.M. Dobrov NAS de Ucrania, formando parte del Departamento de Informática y actualmente como Instituto de Potencial Científico y Tecnológico y de Estudios de Historia de la Ciencia. AHEM. Dobrov de la Academia Nacional de Ciencias de Ucrania (2018, 2018b). Siendo reconocidas entre sus obras principales (Valderrama-Zurián, Gisbert-Tío, TerradaFerrandis, 1996), las siguientes:

- Dobrov, G.M. (1966). Nauka o nauka. Kiev: Naukova Dumka.

- Dobrov, G.M. (1970). Wissenschaftswissemschaft. Berlin: VEB Deutsche Verlag der Wissenschaften.

- Dobrov, G.M., Randolph, R.H. y Rauch, W.D. (1979). New options for team research via international computer networks, Scientometrics, 1, 387-404.

- Dobrov, G.M. y Dziekovskaya, I.V. (1982). Methods and results of studying the flow of information in the field of thin-film superconductivity, Scientometrics, 4, 27-44.

- Dobrov, G.M. y Tonkal, D.E. (1985). Comparative analysis and estimation of competence of research units, Scientometrics, 7, 309-325.

- Dobrov, G.M. y Skofenko, A. (1989). Fuzzy expertise and its application to research and development management, Scientometrics, 15, 21-31.

Desde la vereda opuesta, D.J.S. Price de la Universidad de Yale, inspirado en los trabajos iniciados por Bernal respecto de la función social de la ciencia en 1939 y los posteriores sobre la historia de la ciencia. Lograba publicar en 1963 Little Science, Big Science, obra que da cuenta de la visión cuantitativa del estudio de la sociología de 
la ciencia (González-Uceda, 1997). De la misma forma, ValderramaZurián, Gisbert-Tío, Terrada-Ferrandis (1996), destacan entre sus obras:

- Price, D.J.S. (1951). Quantitative measures of the development of science. Archives Internationales d'Histoire des Sciences, 14, 85-93.

- Price, D.J.S. (1961). Science since Babylon. New Haven: Yale University Press.

- Price, D.J.S. (1963). Little Science, Big Science. Nueva York: Columbia University Press.

- Price, D.J.S. (1965). Networks of scientific papers. Science, 149, 510-515.

- Price, D.J.S. y Beaver, D.B. (1966). Collaboration in a invisible college. American Psychologist, 21, 1011-1018.

- Price, D.J.S. (1970). Smiles at the unobtrusive. Nature, 226, 985.

- Price, D.J.S. (1971). Some remarks on elitism information and the invisible college phenomenon in Science. Journal of the American Society for Information Science, 22, 74-75.

Es de sus quince artículos publicados, en doce revistas de corriente principal indexadas en WoS, distribuidos entre $1975^{5}$ y 1986 , pero con un tercio concentrado en 1981, la publicación General Theory of Bibliometric and Other Cumulative Advantage Processes (1976) en Journal of The American Society for Information Science la de mayor impacto, a hoy referida por 742 trabajos en WoS $(2018)^{6}$.

Es interesante ver cómo se producen cambios temporales en revista especializada Scientometrics, pues como se explicará más adelante desde su origen como la primera revista focalizada, hasta hoy conserva una preeminencia relevante en este ámbito de discusión. Dado esto, mediante el vector de búsqueda ( $\mathrm{SO}=(\mathrm{SCIENTOMETRICS}))$ AND TIPOS DE DOCUMENTOS: (Article), Índices=SCI-EXPANDED,

Año de mayor antigüedad disponible en Web of Science, al momento de realizar este estudio.

6 Obtenidas, para el vector de búsqueda en WoS: ((AU=((PRICE DD) OR (PRICE DJD))) AND (OG= (YALE UNIVERSITY))). 
SSCI Periodo de tiempo=1978-2017, se obtienen los países y organizaciones que lideran las contribuciones en los artículos publicados en esta fuente, en cuatro décadas móviles.

TABla I CONTRibuciones POR PAÍS A los ARTículos PUblicados EN LA REVISTA SCIENTOMETRICS ENTRE I978 y 2017.

\begin{tabular}{|c|c|c|c|c|c|}
\hline País ${ }^{7}$ & $\begin{array}{l}1978- \\
1987\end{array}$ & $\begin{array}{c}1988- \\
1997\end{array}$ & $\begin{array}{l}1998- \\
2007\end{array}$ & $\begin{array}{l}2008- \\
2017\end{array}$ & $\begin{array}{l}1978- \\
2017\end{array}$ \\
\hline US & 117 & 89 & 115 & 365 & 686 \\
\hline $\mathrm{CN}$ & 3 & 10 & 59 & 459 & 531 \\
\hline ES & 2 & 32 & 82 & 291 & 407 \\
\hline $\mathrm{HU}$ & 22 & 49 & 55 & 82 & 208 \\
\hline NL & 19 & 72 & 96 & 148 & 335 \\
\hline $\mathrm{DE}$ & 9 & 74 & 70 & 169 & 313 \\
\hline $\mathrm{BE}$ & 4 & 25 & 106 & 146 & 281 \\
\hline IN & 7 & 49 & 88 & 84 & 228 \\
\hline FR & 2 & 58 & 88 & 76 & 194 \\
\hline UK & 11 & 56 & 78 & 188 & 333 \\
\hline $\begin{array}{l}\text { Total } \\
10 \text { países }\end{array}$ & 286 & 673 & 1007 & 2649 & 4615 \\
\hline
\end{tabular}

Fuente: elaboración propia, con datos disponibles en Web of Science (2018).

TABla 2 CONTRIBUCIONES POR ORGANIZACIÓN SELECCIONADAS A LOS ARTÍCUlos PUblicAdos EN LA REVISTA SCIENTOMETRICS ENTRE I 978 Y 2017.

\begin{tabular}{|l|r|r|r|r|r|}
\hline Organización & \multicolumn{1}{|c|}{$\begin{array}{c}1978- \\
1987\end{array}$} & \multicolumn{1}{c|}{$\begin{array}{c}1988- \\
1997\end{array}$} & $\begin{array}{c}1998- \\
2007\end{array}$ & \multicolumn{1}{c|}{$\begin{array}{c}2008- \\
2017\end{array}$} & $\begin{array}{c}1978- \\
2017\end{array}$ \\
\hline MTA & 20 & 45 & 53 & 69 & 187 \\
\hline CSIC & 2 & 21 & 33 & 101 & 157 \\
\hline KUL & 0 & 1 & 54 & 102 & 157 \\
\hline
\end{tabular}

7 Utilizando la codificación estandarizada de ISO 3166-1 (2013) de dos letras por país. 


\begin{tabular}{|l|r|r|r|r|r|}
\hline CSIR-IN & 6 & 36 & 60 & 42 & 144 \\
\hline UL & 7 & 31 & 43 & 51 & 132 \\
\hline NAS UKR & 8 & 2 & 1 & 6 & 17 \\
\hline YALE U & 4 & 0 & 0 & 0 & 4 \\
\hline & 286 & 673 & 1007 & 2649 & 4615 \\
\hline
\end{tabular}

Fuente: elaboración propia, con datos disponibles en Web of Science (2018).

Al ser las instituciones con mayores contribuciones a la revista Scientometrics: la Academia de Ciencias de Hungría (Magyar Tudományos Akadémia, MTA), el Consejo Superior de Investigaciones Científicas (CSIC), la Universidad Católica de Lovaina (Katholieke Universiteit Leuven, KUL), el Consejo de Investigación Científica e Industrial (Council of Scientific Industrial Research, CSIR - India), y la Universidad de Leiden (Universiteit Leuven, UL).

Si bien la presencia de la Academia de Ciencias de Ucrania (NAS UKR) y la Universidad de Yale (Yale U) se ve disminuida en el tiempo la presencia de los trabajos de Dobrov y en especial los de Price son importantes en los dos primeros tramos temporales revisados.

Tabla 3 Contribuciones de los autores Price y Dobrov en artícuLOS PUbliCADOS EN LA REVISTA SCIENTOMETRICS ENTRE I978 Y I 997.

\begin{tabular}{|c|c|c|c|c|c|}
\hline Autor & Año & Artículo & Afiliación & $\begin{array}{c}\text { Citas di- } \\
\text { rectas en } \\
\text { Artículos } \\
\text { WoS hasta } \\
2017 \\
\text { (A) }\end{array}$ & $\begin{array}{c}\text { Citas de 2 } \\
\text { orden en Artí- } \\
\text { culos WoS } \\
\text { (B = citas de } \\
\text { A) }\end{array}$ \\
\hline Price & 80 & $\begin{array}{l}\text { United-States sci- } \\
\text { ence in an interna- } \\
\text { tional perspective } \\
\text { - Comments }\end{array}$ & Univ. Yale & 4 & $46 / 45^{8}$ \\
\hline
\end{tabular}

8 Descontadas las autocitas. 


\begin{tabular}{|c|c|c|c|c|c|}
\hline Price & 81 & $\begin{array}{l}\text { The analysis of sci- } \\
\text { entometric matrices } \\
\text { for policy implica- } \\
\text { tions }\end{array}$ & Univ. Yale & 26 & $627 / 614$ \\
\hline Price & 81 & $\begin{array}{l}\text { The analysis of } \\
\text { square matrices of } \\
\text { scientometric trans- } \\
\text { actions }\end{array}$ & Univ. Yale & 40 & $1336 / 1284$ \\
\hline Price & 81 & $\begin{array}{l}\text { The distribution } \\
\text { of citations from } \\
\text { nation to nation } \\
\text { on a field by field } \\
\text { basis - A computer } \\
\text { calculation of the } \\
\text { parameters }\end{array}$ & Univ. Yale & 11 & $224 / 222$ \\
\hline Dobrov & 79 & $\begin{array}{l}\text { New options for } \\
\text { team research via } \\
\text { international com- } \\
\text { puter-networks }\end{array}$ & $\begin{array}{l}\text { IIASA, Aus- } \\
\text { tria }\end{array}$ & 2 & $13 / 13$ \\
\hline Dobrov & 82 & $\begin{array}{l}\text { Methods and re- } \\
\text { sults of studying } \\
\text { the flow of infor- } \\
\text { mation in the field } \\
\text { of thin-film super- } \\
\text { conductivity }\end{array}$ & NAS UKR & 3 & $22 / 21$ \\
\hline Dobrov & 85 & $\begin{array}{l}\text { Comparative-anal- } \\
\text { ysis and estimation } \\
\text { of competence of } \\
\text { research units }\end{array}$ & NAS UKR & 3 & $5 / 5$ \\
\hline Dobrov & 89 & $\begin{array}{l}\text { Fuzzy expertise and } \\
\text { its application to } \\
\text { research and devel- } \\
\text { opment manage- } \\
\text { ment }\end{array}$ & NAS UKR & 2 & $2 / 2$ \\
\hline
\end{tabular}

Fuente: elaboración propia, con datos disponibles en Web of Science (2018).

Si bien los trabajos de Dobrov se observan de un menor impacto, de sus veintiuna publicaciones en WoS $(2018)^{9}$, dos tercios de estos se ubican entre 1978 y 1979, para contribuir con eso a fundamentar

9 Obtenidas, para el vector de búsqueda en WoS: (AU=((DOBROV G) OR (DOBROV GM))). 
gran parte del trabajo de otros investigadores posteriores, así como a distribuir su producción con otros veintitrés coautores, en once revistas.

Es de esta forma, como estos aportes seminales cimientan un amplio espectro de leyes bibliométricas (López-López, 1996: 26-37; Price, 1976; Sancho, 1990: 852-853), que dan cuenta de las métricas actuales con que se evalúa la actividad científica contemporánea, destacándose dentro estas:

- Ley de crecimiento exponencial, hace referencia al crecimiento exponencial puro de la información científica o explosión de la información, logrando masa crítica, hasta incluso llegar a un límite de saturación.

- Ley de envejecimiento u obsolescencia de la literatura científica, a medida que el número de publicaciones se duplica, el número de citas que reciben esas publicaciones se divide por dos. Utilizándose como tecnicismo segregador el semiperiodo (mediana) o vida media (half-life) y definir según esto entre literatura contemporánea y obsolescente.

- Ley de dispersión de la literatura científica o Ley de Bradford, respecto a la gran concentración de artículos en un núcleo pequeño de revistas de discusión especializada.

- Ley cuadrática inversa de la productividad de los autores o Ley de Lotka y la radicación cuadrática de Price, ambas orientadas a identificar a los autores más prolíficos dentro de un área de estudio.

- Así como los conceptos de «colegios invisibles», para las citas recurrentes y comunes empleadas por un grupo de autores en un campo específico de la ciencia y denominando a quienes los referencian como «frente de investigación». En complemento a lo anterior se establece el índice de Price, obtenido como el número de referencias de no más de cinco años del total de referencias. Ideas también reforzadas y detalladas por Sancho (1990). 
En adición a estas leyes, también se asientan una serie de supuestos respecto a: la disposición de los investigadores por documentar sus avances, el uso estricto de base de datos especializadas, el impacto mediado por las citas, el prestigio de las revistas como fuente de influencia científica y social, y las referencias como fuente de respaldo al valor de lo publicado (Sancho, 1990). Así como el establecimiento de niveles de profundización en el estudio cienciométrico, dados por la producción científica, el impacto o productividad de esa producción científica, y el relacionamiento o redes en que se produce dicha actividad científica (Escorsa y Maspons, 2001; Sancho, 1990, Vega y Salinas, 2017).

$\mathrm{Al}$ realizar un breve estudio bibliométrico sobre bibliometría y cienciometría, en función de artículos de corriente principal publicados entre el año 1975 y 2017, aplicando un vector de búsqueda de filtro temático sobre los conceptos «scientometr" ${ }^{10} \mathrm{y}$ "bibliometr" " (TS=(scientometr* OR bibliometr $\left.\left.{ }^{*}\right)\right)$, restringido a los artículos indexados en el Science Citation Index Expanded (SCI-EXPANDED) y el Social Sciences Citation Index (SSCI) de WoS. Se logra extraer 7348 artículos, en los que se observa en primer lugar que, el número de artículos producidos anualmente que se relacionan con ambos conceptos no supera los ochocientos por año, así como un comportamiento de acuerdo con la ley de Price de crecimiento exponencial, tendencia a la que la serie temporal de datos expuesta en el gráfico 1 , se ajusta por sobre el noventa y siete por ciento $(97,35 \%)$.

10 El símbolo asterisco (*)reemplaza a cualquier carácter posible después de los caracteres que le preceden, pudiendo buscar de esta forma por la raíz o fracción inicial de una palabra y todas sus posibles derivaciones. 
Gráfico i Evolución del número de artículos en Web of Science PARA EL FILTRO TEMÁTICO SELECCIONADO, ENTRE I975 Y 2017

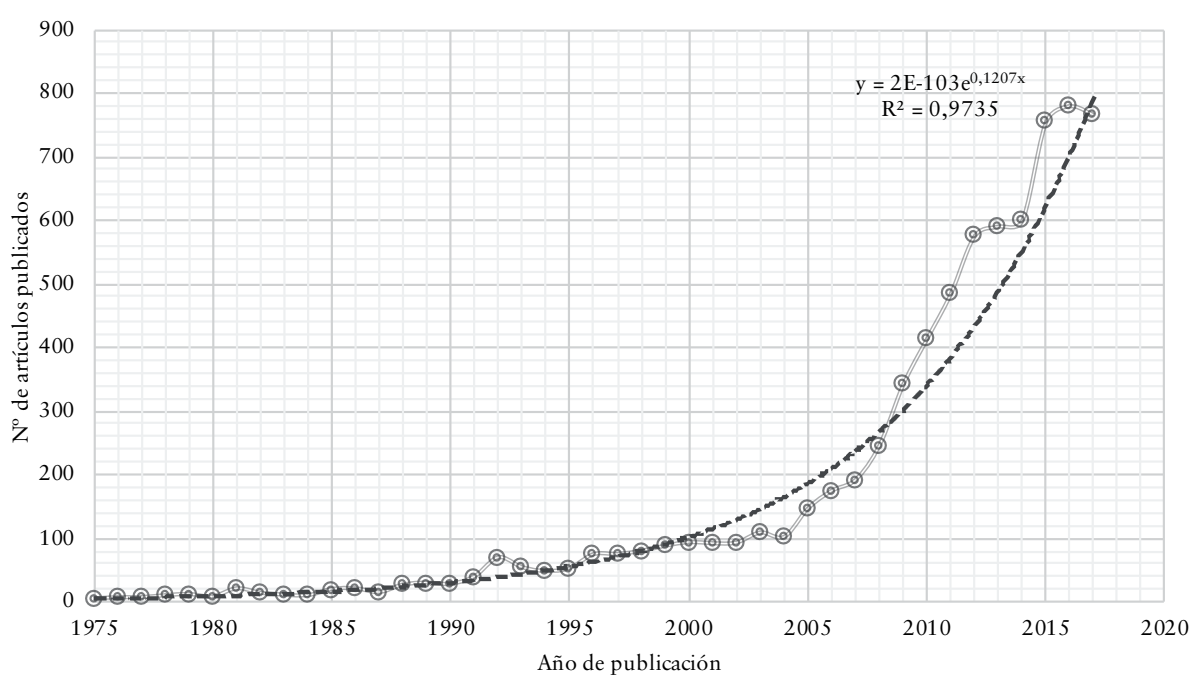

Fuente: elaboración propia, con datos disponibles en Web of Science (2018).

Sin lugar a dudas, la mayor particularidad asociada a las publicaciones de esta disciplina es su altísimo grado de concentración en la revista indexada WoS Scientometrics, la cual considerando solo las 500 revistas con más producción científica entre 1975 y 2017 (equivalentes a 5.672 artículos), constituye por sí sola el núcleo de revistas de Bradford en este campo de investigación, representando el $0,2 \%$ de esas quinientas revistas, pero dando cobertura a 1.789 artículos, concentrando así el $24 \%$ de esos 5 artículos.

En términos de los diez principales países y organizaciones, se destacan las contribuciones como país de Estados Unidos y España. Mientras a nivel de Organizaciones figura el Consejo Superior de Investigaciones Científicas (CSIC) de España, en el primer lugar, pero solo con 3,4\% de los 7.348 artículos, destacando también para el caso de España la Universidad de Granada y la Universidad de Valencia. 
La cultura de la medición científica documentada en Chile...

Tabla 4 Número Artículos WoS de corriente Principal por país y ORGANIZACIÓN PARA EL FILTRO TEMÁTICO SELECCIONADO, ENTRE I975 Y 2017.

\begin{tabular}{|l|r|r|}
\hline País & \multicolumn{1}{|c|}{$\begin{array}{c}\# \\
\text { Artículos }\end{array}$} & $\begin{array}{c}\% \text { de } \\
7348\end{array}$ \\
\hline US & 1392 & $19 \%$ \\
\hline ES & 922 & $13 \%$ \\
\hline CN & 707 & $10 \%$ \\
\hline UK & 612 & $8 \%$ \\
\hline DE & 541 & $7 \%$ \\
\hline NL & 452 & $6 \%$ \\
\hline BR & 357 & $5 \%$ \\
\hline IT & 345 & $5 \%$ \\
\hline CA & 289 & $4 \%$ \\
\hline FR & 250 & $3 \%$ \\
\hline
\end{tabular}

\begin{tabular}{|l|r|c|}
\hline Organización & \multicolumn{1}{|c|}{$\begin{array}{c}\# \\
\text { Artículos }\end{array}$} & $\begin{array}{c}\% \text { de } \\
7348\end{array}$ \\
\hline $\begin{array}{l}\text { Consejo Superior de Investi- } \\
\text { gaciones Científicas (CSIC) }\end{array}$ & 249 & $3,39 \%$ \\
\hline Universidad de Leiden & 215 & $2,93 \%$ \\
\hline Universidad de Granada & 172 & $2,34 \%$ \\
\hline Academia Húngara de Ciencias & 141 & $1,92 \%$ \\
\hline $\begin{array}{l}\text { Universidad Católica } \\
\text { de Lovaina }\end{array}$ & 121 & $1,65 \%$ \\
\hline Sociedad Max Planck & 115 & $1,58 \%$ \\
\hline $\begin{array}{l}\text { Consejo de Investigación } \\
\text { Científica e Industrial (CSIR), } \\
\text { India }\end{array}$ & 112 & $1,52 \%$ \\
\hline $\begin{array}{l}\text { Consejo Nacional de Investi- } \\
\text { gación (CNR), Italia }\end{array}$ & 112 & $1,52 \%$ \\
\hline $\begin{array}{l}\text { Sistema Universitario } \\
\text { de Indiana }\end{array}$ & $1,55 \%$ \\
\hline Universidad de Valencia & & $14 \%$ \\
\hline
\end{tabular}

Fuente: elaboración propia, con datos disponibles en Web of Science (2018).

\section{LA CiEnCIA DOCUMENTAdA EN ChILE}

En el caso de Chile, como es de esperar el conocimiento, la ciencia documentada reflejada en artículos de corriente principal WoS ha ido creciendo a ritmo exponencial, lo que se aprecia en el gráfico 2. Por sobremanera, en lo relativo a la ciencia más que en la ciencia social. 
Gráfico 2 Evolución del número de artículos en Web of Science CON CONTRIBUCIONES CHILENAS, ENTRE I975 Y 2017.

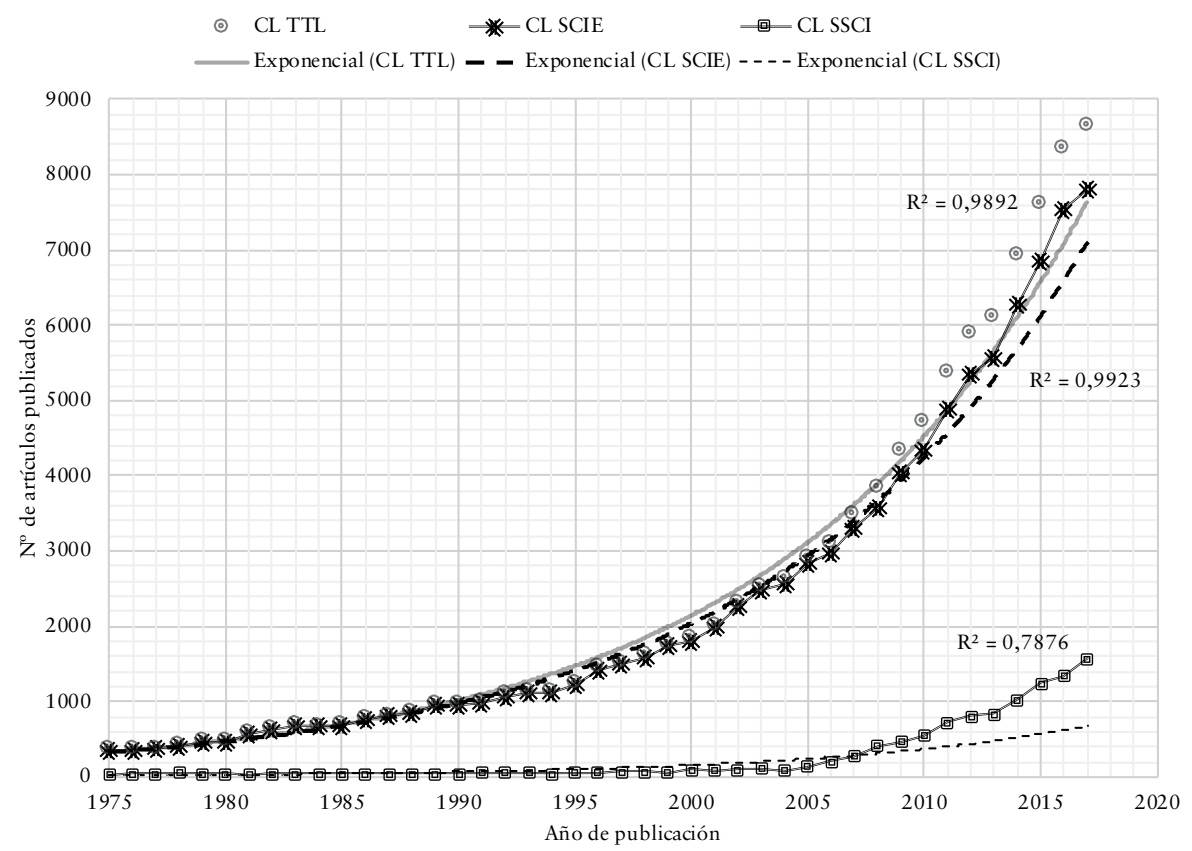

Fuente: elaboración propia, con datos disponibles en Web of Science (2018).

Así, como se observa en la tabla 5, existe un importante desbalance entre la ciencia asociada al índice Science Citation Index Expanded (SCI-EXPANDED) y la ciencia social indexada Social Sciences Citation Index (SSCI). 
Tabla 5 Número de artículos indeXados en WoS CON CONTRibucioNES DE CHILE ENTRE I975 Y 20I7, POR ÍNDICE DE IMPACTO.

\begin{tabular}{|l|l|r|r|}
\hline$(\mathrm{CU}=(\mathrm{CHILE}))$ & Índice & \multicolumn{1}{|l|}{ Artículos } & \multicolumn{1}{l|}{$\%$} \\
\hline Ciencia & SCI-EXPANDED & 98.171 & $90 \%$ \\
\hline Ciencia Social & SSCI & 11.325 & $10 \%$ \\
\hline Ciencia $\cup$ Ciencia Social & SCI-EXPANDED OR SSCI & 105.099 & \\
\hline Ciencia + Ciencia Social & SCI-EXPANDED + SSCI & 109496 & $100 \%$ \\
\hline
\end{tabular}

Fuente: elaboración propia, con datos disponibles en Web of Science (2018).

Aunque al observar como la unión de ambos índices genera un número menor de artículos (105.099) inferior a su simple suma (109.496), dando cuenta de un traslape en la indexación de revistas, el $90 \%$ que representa la «ciencia» sobre la suma alzada de los artículos recuperados de cada índice, da cuenta de una alta concentración que evidencia la idea desbalance entre ambas vertientes de la producción de conocimiento.

Ciertamente, al considerar las cinco disciplinas principales de las ciencias sociales: Antropología, Ciencia Política, Economía, Historia y Sociología (Wallerstein, 2011) y las exigencias locales impuestas por sus grupos de estudio (Conicyt, 2018), estás no consideran a exclusivamente la producción científica en WoS, salvo en lo relativo a la Economía. Eso da cuenta de la valoración brindada por cada disciplina y los esfuerzos que los investigadores realizarán por obtener logros en este sentido, siendo las diez áreas más estudiadas por los investigadores chilenos, en ciencias y ciencias sociales, las que se observan en la tabla 6 . 
Tabla 6 Número de artículos indexados en WoS CON CONTRibucioNES DE CHILE ENTRE 1975 Y 20I7, POR ÍNDICE DE IMPACTO PARA LAS DIEZ PRINCIPALES CATEGORÍAS WOS.

\begin{tabular}{|l|l|}
\hline Categorías WoS & SCIE \\
\hline Astronomy Astrophysics & 13.164 \\
\hline Medicine General Internal & 7.373 \\
\hline Biochemistry Molecular Biology & 4.333 \\
\hline Ecology & 3.645 \\
\hline Marine Freshwater Biology & 3.377 \\
\hline Chemistry Multidisciplinary & 3.183 \\
\hline Mathematics Applied & 2.806 \\
\hline Environmental Sciences & 2.779 \\
\hline Physics Particles Fields & 2.759 \\
\hline Chemistry Physical & 2.714 \\
\hline
\end{tabular}

\begin{tabular}{|l|l|}
\hline Categorías WoS & SSCI \\
\hline Economics & 1.762 \\
\hline Anthropology & 663 \\
\hline Medicine General Internal & 656 \\
\hline Psychology Multidisciplinary & 647 \\
\hline $\begin{array}{l}\text { Public Environmental } \\
\text { Occupational Health }\end{array}$ & 598 \\
\hline Education Educational Research & 499 \\
\hline Environmental Studies & 485 \\
\hline Linguistics & 456 \\
\hline Psychiatry & 452 \\
\hline Management & 451 \\
\hline
\end{tabular}

Fuente: elaboración propia, con datos disponibles en Web of Science (2018).

Incluso entendiendo que las revistas donde se publica un artículo WoS con contribución de autores chilenos, pueden estar asociado a más de una categoría. Es notoria el liderazgo de la categoría WoS de Astronomía y Astrofísica entre las ciencias, que prácticamente duplica a la segunda categoría de mayor importancia, en este caso la Medicina General Interna. Y aunque a una escala diez veces inferior ocurre lo mismo con la categoría WoS de Economía entre las Ciencias Sociales, la cual más que duplica la categoría siguiente de Antropología.

En ello tiene cierta influencia, que los grupos de estudio que definen gran parte de los fondos de investigación competitivos, han restringido a la producción en WoS los requisitos para los investigadores que postulan a estos, en las áreas de: Agronomía; Astronomía, Cosmología y Partículas; Biología 1, 2 y 3; Ciencias de la Tierra, Ciencias Económicas y Administrativas, Física Teórica y 
Experimental, Ingeniería 1, 2 y 3; Medicina G1 y G2+G3; Química, y Salud y Producción Animal (Fondecyt, 2018).

Esta diferencia entre ciencia y ciencia social, así como las áreas que se enfatizan entre la medición científica documentada también genera una posición diversa entre las universidades chilenas, así como un desbalance en algunas de estas el que se ve reflejado, en la posición que estás logran como actores locales que contribuyen desde Chile al desarrollo de la ciencia mundial.

Tabla 7 NÚmero de artículos indeXados en WoS CON CONTRIbucioNES DE CHILE ENTRE I975 Y 20I7, POR ÍNDICE DE IMPACTO Y ORGANIZACIÓN LOCAL PRODUCTORA DE CONOCIMIENTO.

\begin{tabular}{|l|l|}
\hline Organización & SCIE \\
\hline Universidad de Chile & 30.757 \\
\hline $\begin{array}{l}\text { Pontificia Univ. Católica } \\
\text { de Chile }\end{array}$ & 20.718 \\
\hline Univ. de Concepción & 11.433 \\
\hline $\begin{array}{l}\text { Universidad Austral } \\
\text { de Chile }\end{array}$ & 5.750 \\
\hline $\begin{array}{l}\text { Universidad de Santiago } \\
\text { de Chile }\end{array}$ & 5.265 \\
\hline $\begin{array}{l}\text { Univ. Técnica } \\
\text { Federico Santa María }\end{array}$ & 4.051 \\
\hline $\begin{array}{l}\text { Pontificia Univ. } \\
\text { Católica de Valparaíso }\end{array}$ & 3.395 \\
\hline Universidad de La Frontera & 3.058 \\
\hline Universidad Andrés Bello & 3.024 \\
\hline $\begin{array}{l}\text { Universidad Católica } \\
\text { del Norte }\end{array}$ & 2.815 \\
\hline
\end{tabular}

\begin{tabular}{|l|l|}
\hline Organización & SSCI \\
\hline Universidad de Chile & 3.080 \\
\hline $\begin{array}{l}\text { Pontificia Univ. } \\
\text { Católica de Chile }\end{array}$ & 2.836 \\
\hline Universidad Diego Portales & 672 \\
\hline $\begin{array}{l}\text { Universidad } \\
\text { de Concepción }\end{array}$ & 622 \\
\hline $\begin{array}{l}\text { Universidad Católica } \\
\text { del Norte }\end{array}$ & 440 \\
\hline $\begin{array}{l}\text { Universidad de Santiago } \\
\text { de Chile }\end{array}$ & 417 \\
\hline Universidad Adolfo Ibáñez & 405 \\
\hline $\begin{array}{l}\text { Pontificia Univ. Católica } \\
\text { de Valparaíso }\end{array}$ & 358 \\
\hline Universidad de Tarapacá & 337 \\
\hline Universidad del Desarrollo & 316 \\
\hline
\end{tabular}

Fuente: elaboración propia, con datos disponibles en Web of Science (2018). 
Más que una mera cuestión local, al observar los principales países con que se constituyen en redes de contribución internacional los científicos chilenos, también existen diferencias entre ciencia y ciencia social. Como se refleja en la tabla 8.

Tabla 8 Número de artículos indeXados en WoS

CON CONTRIBUCIONES DE CHILE ENTRE I 975 Y 20I7, POR ÍNDICE DE IMPACTO Y PAÍS COPRODUCTOR DE CONOCIMIENTO.

\begin{tabular}{|l|r|l|l|r|}
\hline País & Artículos SCIE & & País & Artículos SSCI \\
\hline CL & 98.171 & CL & 11.325 \\
\hline US & 20.461 & US & 2.294 \\
\hline SP & 10.991 & SP & 1.397 \\
\hline UK & 10.100 & UK & 859 \\
\hline DE & 9.094 & AR & 412 \\
\hline FR & 8.666 & DE & 384 \\
\hline BR & 5.692 & CA & 349 \\
\hline IT & 5.152 & BR & 335 \\
\hline AR & 4.812 & AU & 323 \\
\hline CA & 4.698 & FR & 288 \\
\hline AU & 3.956 & CO & 281 \\
\hline
\end{tabular}

Fuente: Elaboración propia, con datos disponibles en Web of Science (2018).

Como se observa la contribución conjunta de Chile en artículos de WoS en Ciencias y Ciencias Sociales, se desarrolla mayoritariamente con Estados Unidos, España y el Reino Unido. Pero en el caso de las Ciencias Sociales se ve acrecentada la colaboración con Argentina, se incorpora Colombia y se mantiene una colaboración importante con Brasil. Aunque en suma la contribución europea es la más relevante para este país. 


\section{Conclusiones}

La bibliometría y la cienciometría se han logrado ir posicionando, en las últimas décadas, como una forma de medir la ciencia, especialmente la ciencia documentada. Pero además logrando un crecimiento que permite catalogarla como un área de estudio que posee masa crítica de investigadores en el contexto mundial.

En esto es de destacar las ideas originales del movimiento Nauka y los avances logrados en Kiev (Ucrania) por Dobrov y su equipo. Aunque en el tiempo, son las ideas de Price, generadas en la Universidad de Yale las que han logrado mayor connotación, especialmente por el artículo de Price en 1976 y sus centenares de citas en WoS.

El que la revista Scientometrics, que ha logrado ser el núcleo de la discusión sobre la subdisciplina científica de bibliometría y de los estudios cienciométricos, desde sus orígenes a nuestros tiempos, sea húngara también da cuenta de la influencia rusa sobre esta temática.

Si bien el conocimiento mundial sobre bibliometría y cienciometría se produce principalmente en Estados Unidos, a nivel de instituciones son España y otros países europeos las que logran mayor producción y preponderancia, en especial el Consejo Superior de Investigaciones Científicas (CSIC) y la Universidad de Leiden.

En el contexto de Chile, se ha aquilatado la herencia de los trabajos desarrollados en la NAS UKR en Kiev y la Universidad de Yale. Pero principalmente en las ciencias, que producen el $90 \%$ de la ciencia documentada en WoS con presencia de autores chilenos y que es liderada por la Astronomía/Astrofísica. Cuestión que es fuertemente influenciada por los requisitos de acceso a fondos públicos de investigación competitivos.

Del lado de las ciencias sociales, estas son lideradas por la economía, que es seguida a la distancia por la Antropología, pues, la economía en Chile también es evaluada para acceder a fondos públicos con criterios de producción académica exclusivamente de producción en WoS. En cambio, las otras ciencias sociales no se ven influenciadas por esto.

Del punto de vista de la cooperación internacional, son las ciencias sociales las más cercanas a la interacción latinoamericana, y la cultura de estos países, también podría estar influenciando los menores niveles de producción científica en WoS. 


\section{Bibliografía}

Academia Nacional de Ciencias de Ucrania. (2018). Historia del Centro de Investigación del Potencial Científico-Técnico e Historia de la Ciencia que lleva su nombre. G.M. Dobrova (TsDPIN) de la Academia Nacional de Ciencias de Ucrania. Disponible en: <http://www1.nas. gov.ua/institutes/steps/about/Pages/history.aspx>

Academia Nacional de Ciencias de Ucrania (2018b). Inicio. Disponible en: $<$ https://stepscenter.org.ua/>

Acuña, M. E. (2008). «Reflexiones sobre las prácticas de producción de conocimientos: ciencia y tecnología». Cinta de Moebio, 31, 14-22.

Alcántara-Santuario, A. (2000). "Ciencia, conocimiento y sociedad en la investigación científica universitaria». Perfiles Educativos, 87.

Alcíbar, M. (2009). «Comunicación pública de la tecnociencia: más allá de la difusión del conocimiento». Zer, 14(27), 165-188.

Ayllón, M. (2009). MATE, Reyes, La herencia del olvido, Madrid: Errata Naturae, 2008. Constelaciones. Revista de Teoría Crítica, (1), 212215.

Balmaceda, M., Yornet, C., Cerviño, N., y Sánchez, M. (2012). «Formación en comunicación pública de la ciencia y la tecnología: algunos ejes para el debate». Fundamentos en Humanidades, XIII (26), 73-86.

Boff, E. (2018). «Tensions between Theory and History in Von Mises's Critique of Socialism». Revista de Economia Contemporânea, 22(2), e182221. DOI: https://dx.doi.org/10.1590/198055272221.

Calleja, L.M. (2010). «Politización y tecnocracia». Revista Antiguos Alumnos del IEEM, 49, 89-92.

Casanueva, C. y Caro, F.J. (2013). «La Academia Española de Comunicación: productividad científica frente a actividad social». Comunicar, 41, 61-70. DOI: https://doi.org/10.3916/C41-2013-06.

Casper, S.T. (2015). "Of Means and Ends: Mind and Brain Science in the Twentieth Century». Science in Context, 28, 1-7. DOI: http://dx.doi. org/10.1017/S0269889714000295.

Castela, C. (2016). "Cuando las praxeologías viajan de una institución a otra: una aproximación epistemológica del 'boundary crossing'"». Educación matemática, 28(2), 9-29.

Cavaller, V. (2008). Fonaments d'anàlisi estratègica de la informació. Quaderns d'intel-ligència competitiva, vigilància estratègica, científica $i$ tecnològica, 1(1), 55-64.

Coca, J. R. (2008). «Hacia una tecnociencia policontextural». Ludus Vitalis, XVI (30), 207-210. 
Coca, J.R., y Valero-Matas, J. A. (2010). «Tecnociencia e interculturalidad: Nuevos retos para una nueva sociedad». Sociología y tecnociencia. Revista digital de sociología del sistema tecnocientífico, 1, 25-38.

Covarrubias-Villa, F., Cruz Navarro, M., y Arceo Ortega, M. (2009). «La Formación de Científicos en Teorías Paradigmáticas». Tiempo de Educar, 10 (19), 115-147.

De Greiff, A., \& Nieto, M. (2005). «Anotaciones para una agenda de investigación sobre las relaciones tecnocientificas sur-norte». Revista de Estudios Sociales, (22), 59-69.

Domínguez-Moreno, M. (2018). «La Cibercultura como Herramienta para Edificar Mundos Contemporáneos, Reales y Virtuales». Revista Scientific, 3(10), 317-329. DOI: https://doi.org/10.29394/Scientific. issn.2542-2987.2018.3.10.18.317-329.

Echeverría, J., y González, M. I. (2009). «La teoría del actor-red y la tesis de la tecnociencia». ARBOR Ciencia, Pensamiento y Cultura, CLXXXV, (738), 705-720.

Escobar, A. (2005). «Bienvenidos a Cyberia. Notas para una antropología de la ciber cultura». Revista de Estudios Sociales, (22), 15-35.

Escorsa, P., y Maspons, R. (2001). De la vigilancia tecnológica a la inteligencia competitiva. Madrid: Pearson Educación.

Feenberg, A. (2005). «Teoría crítica de la tecnología». Revista CTS, 2(5), 109-123.

Fernández, A. (2007). «Los ruinosos pilares del progreso». Estudios Humanísticos. Historia, (6), 317-339.

Fondecyt. (2018). Grupos de Estudio. Web. Disponible en: <http://www. conicyt.cl/fondecyt/grupos-de-estudios/>

Guijarro, V. (2003). «Las relaciones ciencia-tecnología después de Merton». Barataria, 6, 25-46.

Gómez-González, F., Durlan, C., Cáceres-Gómez, S., \& Aleixandre Mendizábal, G. (2014). «El reto de la Evaluación del Impacto Social de la Tecnología en España». Política y Sociedad, 51(2), 447-480. DOI: http://dx.doi.org/10.5209/rev_POSO.2014.v51.n2.42390.

Gómez-Yepes, V. (2017). «Ciencia y tecnología: cambios, transformaciones y retos». Revista Ciencias Estratégicas, 25(37), 9-12. DOI: http:// dx.doi.org/10.18566/rces.v25n37.a1.

González-Uceda, L. (1997). «Teoría de la ciencia, documentación y bibliometría». Revista General de Documentación e Información, 7(2), 201-215.

Greenpeace España. (2012). Las lecciones de Fukushima. Madrid: Greenpeace.

Griliches, Z. (1990). «Patent statistics as economic indicators: a survey». Journal of Economic Literature, 28(4), 1661-1707. Web. Disponible en <https://www.jstor.org/stable/2727442> 
Larrión-Cartujo, J. (2008). «Las encrucijadas de la tecnociencia. El conflicto sobre las similitudes y las diferencias entre la selección, el cruzamiento y la manipulación genética». Nómadas. Revista Crítica de Ciencias Sociales y Jurídicas, 18(2).

Larrión-Cartujo, J. (2011). «Luces y sombras de la tercera revolución verde. Demandas sociales, opciones agrícolas y desacuerdos narrativos». Bitácora-e. Revista Electrónica Latinoamericana de Estudios Sociales, Históricos y Culturales de la Ciencia y la Tecnología, (1), 3-23.

Le Breton, D. (1994). «Lo imaginario del cuerpo en la tecnociencia». REIS, 68, 197-210.

Lezama-Escalante, C. (2006). «Descifrando los códigos culturales en la tecnología contemporánea». Desacatos, (21), 200-204.

Lizcano, E. (1996). «La construcción retórica de la imagen pública de la tecnociencia: impactos, invasiones y otras metáforas». Política y Sociedad, 23, 137-146.

Lolas-Stepke, F. (2010). «Biotecnologías y ética: con especial referencia a la ingeniería genética». Atenea, 502, 13-24.

López-López, P. (1996). Introducción a la bibliometría. Valencia: Editorial Promolibro.

Love, J. (2006). «Los países ricos obstaculizan el acceso a los medicamentos». En L. M. Diplomatique (Ed.), Medicamentos: ¿derecho o mercancía? salud y comercio, laboratorios, patentes farmacéuticas $y$ multinacionales... Santiago de Chile: Editorial Aún creemos en los sueños, 27-35.

Martin, V.R. (2008). «Ética de la ciencia». Revista Electrónica de Humanidades, Educación y Comunicación Social, 5, 11-18.

Martin, V.R. (2012). «Universidad socialmente responsable: Universidad éticamente inteligente. Megatendencias sobre la vida, lo humano y el futuro». Opción, 28 (68), 233-240.

Ministerio de Educación Cultura y Deporte de España. (2018). Consulta de la Base de datos de Tesis Doctorales (TESEO). Web. Disponible en <https://www.educacion.gob.es/teseo/irBusquedaAvanzada.do>

Paredes-Oviedo. (2016). «Las antropotécnicas desde Peter Sloterdijk: la ingeniería genética y la información como técnicas para la mejora del hombre contemporáneo». Revista de Investigaciones, 16(27), 148-157. DOI: http://dx.doi.org/10.22383/ri.v16i1.66.

Parselis, M. (2016). «El valor de las tecnologías entrañables». Revista iberoamericana de ciencia tecnología y sociedad, 11(32), 71-83. Web. Disponible en <http://ref.scielo.org/ygnj2c>

Price, D. (1976). «A general theory of bibliometric and other cumulative advantage processes». Journal of the American Society for Information Science, 27(5-6), 292-306. 
Quintanilla, M.Á. (2005). Tecnología: Un enfoque filosófico y otros ensayos de la filosofía de la tecnología. México: Fondo de Cultura Económica. Quintero-González, B.M. (2016). «El concepto de progreso en La rebelión de las ratas, de Fernando Soto Aparicio». Kénosis. Revista de Ciencias Sociales y Humanas, 4(7), 108-132.

Rothwell, G. (2008). «¿Energía nuclear en Chile? Los costos y beneficios de la opción de construir una central nuclear en 2020». Estudios Públicos, 112, 5-30.

Saiz-Álvarez, J. M. (2013). «Ética, capital intelectual y gestión del conocimiento». Revista EAN, 73, 44-59.

Sánchez, D. (1993). «Sobre las aporías internas de la idea de progreso». Endóxa: Series Filosóficas, (2), 5-59.

Sancho, R. (1990). «Indicadores bibliométricos usados en la evaluación de la ciencia y la tecnología». Revista española de documentación científica, 13(3-4), 842-863.

Santa-Soriano, A., Lorenzo-Álvarez, C. y Torres-Valdés, R.M. (2018). «Bibliometric analysis to identify an emerging research area: Public Relations Intelligence-a challenge to strengthen technological observatories in the network society». Scientometrics, 115, 15911614. DOI: https://doi.org/10.1007/s11192-018-2651-8.

Spinak, E. (1998). «Indicadores cienciométricos». Ciência da Informação, 27(2), 141-148.

Steimberg, O. (2001). «Moda y estilo a partir de una frase de Walter Benjamin». deSignis, (1), 29-39.

Tomás-Castera, V.J. (2013). Estudio bibliométrico de la producción científica y de consumo de las revistas sobre nutrición indizadas en la Red SciELO. Tesis Doctoral del Departamento de Enfermería Comunitaria, Medicina Preventiva y Salud Pública e Historia de la Ciencia, Alicante: Universidad de Alicante. Web. Disponible en <http://hdl. handle.net/10045/33457>

Trilles-Calvo, K. (2017). «El nuevo cuerpo-objeto: de la víscera a la @». Bajo Palabra, 0(16. Web. Disponible en <https://revistas.uam.es/ bajopalabra/article/view/9014>

UNESCO. (1988). Proposed International Standard Nomenclature for Fields of Science and Technology. UNESCO/NS/ROU/257 rev.1, París: UNESCO. Web. Disponible en <http://unesdoc.unesco.org/ images/0008/000829/082946eb.pdf>

Valderrama-Zurián, J.C., Gisbert-Tío, A. y Terrada-Ferrandis, M.L. (1996). Bibliografía española e internacional de estudios bibliométricos, Cuadernos de Documentación e Informática Biomédica, Vol. 11. Valencia: Universitat de València. 
Valero Matas, J., y Coca, J. (2013). «Epistemología y hermenéutica de la ciencia: una visión desde la obra de Kuhn». Arbor, 189(761), a039. DOI: http://dx.doi.org/10.3989/arbor.2013.761n3007.

Vega, A. y Romero, L. (2006). «Innovación Tecnológica Forestal, Desarrollos y Desafíos Científico- Tecnológicos en Chile». Journal of Technology Management \& Innovation, 1(4), 71-82. Web. Disponible en $<$ http://www.jotmi.org/index.php/GT/article/view/art23>

Vega, A. y Salinas, C.M. (2017). Análisis de la Producción Científica en Asuntos Públicos de Chile y Perú. Desafíos para una mejor Gestión Pública. Lex, 15(20), 463-478. DOI: http://dx.doi.org/10.21503/ lex.v15i20.1451.

Velásquez, G. (2006). «Medicamentos: ¿derecho o mercancía?». En L.M. Diplomatique (Ed.), Medicamentos: ¿derecho o mercancía? Salud y comercio, laboratorios, patentes farmacéuticas y multinacionales... Santiago de Chile: Editorial Aún creemos en los sueños. 15-25.

Wallerstein, I. (2011). Abrir las ciencias sociales, Comisión Gulbenkian para la reestructuración de las ciencias sociales. México: Siglo XXI Editores. 


\section{SOBRE LOS AUTORES}

Francisco Martínez Hoyos (Barcelona, 1972). Se doctoró con una tesis sobre JOC (Juventud Obrera Cristiana). Volvió a profundizar en la historia de los cristianos progresistas en otros estudios, como su biografía de Alfonso Carlos Comín (Rubeo, 2009) o la obra de síntesis La Iglesia rebelde (Punto de Vista, 2013). Por otra parte, se ha interesado profundamente en el pasado americano, con Francisco de Miranda (Arpegio, 2012), Hernán Cortés (Nowtilus, 2014), La revolución mexicana (Nowtilus, 2015), Kennedy (Sílex, 2017) o El indigenismo (Cátedra, 2018). Antiguo director de la revista académica Historia, Antropología y Fuentes Orales, colabora en medios como Historia y Vida, Diario16, El Ciervo o Claves de Razón Práctica, entre otros.

Daniela Serra. Es Licenciada (2009) y Magíster en Historia (2014) por la Pontificia Universidad Católica de Chile y Doctora (C) en Historia, Pontificia Universidad Católica de Chile. Profesora del Instituto de Historia y del Centro del Patrimonio Cultural de la Pontificia Universidad Católica de Chile. Su principal área de interés es la historia de museos y coleccionismo, especialmente la formación de colecciones de historia natural y la circulación de objetos naturales durante los siglos XVIII y XIX. Actualmente participa como tesista de doctorado del proyecto Ecos-Conicyt «Fragmentos de mundo en tránsito. Objetos y artefactos americanos en Europa, siglos XVII-XX» (ECOS-C16H04), entre el Instituto de Historia de la Pontificia Universidad Católica de Chile y el Centre AlexandreKoyré. Histoire des Sciences et des Techniques, de la École des Hautes Études en Sciences Sociales, París. 
Carolina Valenzuela Matus. Es Doctora en Estudios del Mundo Antiguo por la Universidad Autónoma de Madrid. Es investigadora académica de la Universidad Autónoma de Chile e investigadora responsable del proyecto Fondecyt Iniciación $\mathrm{n}^{\circ} 11170033$ Antigüedades y naturaleza. Circulación interoceánica de objetos en los primeros gabinetes de Historia Natural como estrategia de posicionamiento de la ciencia en Chile. Sus líneas de investigación son gabinetes y museos de Historia Natural, tradición clásica y antigüedades. Ha publicado dos libros sobre tradición clásica en Hispanoamérica y varios artículos en revistas especializadas. Es investigadora de referencia del Instituto Universitario La Corte en Europa y académica del claustro del doctorado en Historia de la Universidad Autónoma de Chile.

Lorena B. Valderrama. Es Doctora en Historia de la Ciencia y Comunicación Científica por la Universidad de Valencia. Es académica de la Universidad Alberto Hurtado y coinvestigadora del Fondecyt Regular 1170625 «Mirando las estrellas desde el Sur del Mundo: el Observatorio Astronómico Nacional de Chile (1852-1927)». Sus líneas de investigación son la historia y la divulgación de la ciencia y la tecnología durante los siglos XIX y XX. Es académica del claustro del Magíster en Ciencia, Tecnología y Sociedad de la Universidad Alberto Hurtado.

Carlos Sanhueza Cerda. Es Doktor der Philosophie en Historia Moderna por la Universität Hamburg, Alemania. Es profesor del Departamento de Ciencias Históricas de la Universidad de Chile. Su principal área de interés es la historia de la ciencia durante los siglos XIX y XX, especialmente relativo al estudio de la circulación de viajeros y saberes entre América Latina, Europa, y América del Norte. En el año 2018 realizó una estadía de investigación en el Instituto Max Planck para la Historia de la Ciencia (Berlín, Alemania) junto a Jürgen Renn. Actualmente está realizando una investigación referida a la observación astronómica en el siglo XIX con un financiamiento FONDECYT Regular. 
Martín Lara Ortega. Es estudiante del Programa de Doctorado en Historia de la Universidad Autónoma de Chile y del Doctorado en América Latina y Unión Europea en el Contexto Internacional de la Universidad de Alcalá. Su principal línea de investigación se ha centrado en la historia indígena de Chile, con particular énfasis en el universo mapuche, cuyos resultados de investigación lo han llevado a publicar artículos en revistas especializadas y difundir sus investigaciones en simposios, congresos y seminarios en distintos países de América Latina. Actualmente es profesor adjunto de las cátedras América Indígena y Chile Indígena en la Escuela de Educación en Historia y Geografía de la Universidad Católica Silva Henríquez.

Nelson Arellano Escudero. Es Doctor en Sostenibilidad, Tecnología y Humanismo por la Universidad Politécnica de Cataluña. Es investigador académico de la Universidad Academia de Humanismo Cristiano e investigador responsable del proyecto Fondecyt Iniciación $\mathrm{n}^{\circ} 11180158$ «Las fronteras solares de Chile: Desierto, Antártica, Polinesia y Espacio. Una historia de gobernanza y valores sociales de tecnologías solares en zonas extremas (1976-2011)». Sus líneas de investigación se encuentran en los campos de la sustentabilidad, la historia de la tecnología y los conflictos tecnoambientales. Ha publicado un libro acerca de los estudios sociales de las personas que viven en la calle y varios artículos en revistas especializadas. Es miembro de varias sociedades científicas en Europa y Chile y académico del claustro del Doctorado en Estudios Transdisciplinares Latinoamericanos en la Universidad Academia de Humanismo Cristiano.

Alejandro Vega-Muñoz. Es Doctor en Ciencias Empresariales por la Universidad Antonio de Nebrija (España). Académico de la Universidad Autónoma de Chile, Investigador Asociado del Programa Interdisciplinario de Investigaciones en Educación (PIIE) y de la Fundación Escuela de Asuntos Internacionales. Ha publicado una decena de capítulos de libros en Estados Unidos, México, Argentina, Bulgaria y Chile y varios artículos indexados. Sus intereses de investigación se centran en la relación del desarrollo económico con 
la gestión de I+D+i, la gestión y política de Educación Superior y la política de ciencia y tecnología. Actualmente participa como profesor del Doctorado en Políticas y Gestión Educativa de la Universidad de Playa Ancha de Ciencias de la Educación y de Educación de la Universidad Academia de Humanismo Cristiano. Además de dirigir tesis en los Doctorados de Derecho y Administración de Empresas de la Universidad de Lleida (España) y de Educación con mención en Gestión Educativa de la Universidad Privada de Tacna (Perú). ORCID: http://orcid.org/0000-0002-9427-2044 


\section{Agradecimientos}

Agradecemos el apoyo de la Universidad Autónoma de Chile a través del Centro de Comunicación de las Ciencias y a CONICYT a través de su programa FONDECYT Iniciación. Dentro de la institución, agradecemos el constante apoyo de la Vicerrectoría de Investigación y Postgrado y del Instituto de Estudios Sociales y Humanísticos (IDESH). Extendemos nuestros agradecimientos al comité editorial y a los pares evaluadores quienes han contribuido con sus observaciones a elevar la calidad de nuestra propuesta. 


Este libro se terminó de imprimir en Santiago de Chile, agosto de 2019

\section{Teléfono: 222238100 / ril@ rileditores.com}

Se utilizó tecnología de última generación que reduce el impacto medioambiental, pues ocupa estrictamente el papel necesario para su producción, y se aplicaron
altos estándares para la gestión y reciclaje de desechos altos estándares para la gestión y reciclaje de
en toda la cadena de producción. 
ste libro se propone valorar la contribución de Chile y América Latina como agentes activos en la construcción y difusión del conocimiento científico. Cada uno de los capítulos que componen esta obra quiere evidenciar este aporte reflexionando en torno al papel de Chile e Hispanoamérica en la cultura científica de los siglos XIX al XXI a partir de una amplia diversidad de temas que van desde las exploraciones cientificas, las historias naturales, las colecciones de gabinetes y museos, las reflexiones positivistas acerca de los pueblos originarios, pasando por la historia de los instrumentos hasta las tecnologías de energía solar y la cienciometría.

Los estudios que aquí presentamos cuestionan el concepto de una historia de la ciencia periférica en pos de la construcción de una historia global que supone amplias interconexiones entre los distintos rincones del planeta y donde se pone de relieve el conocimiento científico generado por los actores locales, especialmente desde Latinoamérica. Estas investigaciones caracterizan la cultura científica destacando algunos de sus principales debates y los desafíos de la ciencia para el futuro. Los autores esperamos, a través de este trabajo colectiva, seguir contribuyendo en la construcción de una historia de las ciencias desde América Latina. 